\title{
Changing Games and Evolving Contexts: Political Bargaining In European Energy Disputes
}

\author{
Fabio Franch \\ West Virginia University
}

Follow this and additional works at: https://researchrepository.wvu.edu/etd

\section{Recommended Citation}

Franch, Fabio, "Changing Games and Evolving Contexts: Political Bargaining In European Energy Disputes" (2010). Graduate Theses, Dissertations, and Problem Reports. 4591.

https://researchrepository.wvu.edu/etd/4591

This Dissertation is protected by copyright and/or related rights. It has been brought to you by the The Research Repository @ WVU with permission from the rights-holder(s). You are free to use this Dissertation in any way that is permitted by the copyright and related rights legislation that applies to your use. For other uses you must obtain permission from the rights-holder(s) directly, unless additional rights are indicated by a Creative Commons license in the record and/ or on the work itself. This Dissertation has been accepted for inclusion in WVU Graduate Theses, Dissertations, and Problem Reports collection by an authorized administrator of The Research Repository @ WVU.

For more information, please contact researchrepository@mail.wvu.edu. 


\title{
Changing Games and Evolving Contexts: Political Bargaining In European Energy Disputes
}

\author{
Fabio Franch \\ Dissertation submitted to the \\ Eberly College of Arts and Sciences \\ at West Virginia University \\ in partial fulfillment of the requirements \\ for the degree of \\ Doctor of Philosophy \\ in \\ Political Science
}

Robert D. Duval, Ph.D.

Scott R. Crichlow, Ph.D., Co-Chair

Joe D. Hagan, Ph.D., Co-Chair

Susan Hunter, Ph.D.

William N. Trumbull, Ph.D.
Department of Political Science
Morgantown, West Virginia
2010

Keywords: Energy Security, Political Bargaining Theory, Europe, Natural Gas. 


\title{
ABSTRACT \\ Changing Games and Evolving Contexts: Political Bargaining In European Energy Disputes
}

\author{
Fabio Franch
}

Energy has recently become a very important item on the political agenda of most Western countries; it is bound to be even more so in the future, due to the increasing scarcity of natural gas and oil. With Russia using the energy weapons to advance its economic and political goals, energy security has become a central topic in European politics. Important political bargaining models like game theory can offer valuable insights and contribute to the explanation of the outcome of important political confrontations like the ones between Russia and its former satellites. Game theory, however, fails to adequately account for an evolving context which can affect the preferences of the disputing actors, an issue which is likely to systematically produce inaccurate explanations and predictions. The relevance of the preferences of external actors will be demonstrated in this work by finding empirical evidence that the start of the dispute has damaged GDP and stock market performances of external players; in fact, this would give them a reason to become a relevant part of the game by exerting pressure on the two players so as to reach an agreement in the shortest time possible. The growing importance of external actors, I argue, needs to be modeled by game theory because, as it was especially the case for the Russia-Ukraine dispute in 2006, their role can be pivotal to in determining the duration and the outcome of the political bargaining. I select a Pooled Panel Nonlinear Auto Regressive Conditional Heteroskedasticity (PP-NARCH) model and Box-Tiao intervention models to support the validity of what I define a Fully-Fuzzy game. I rely more on the general message conveyed by the statistical models considered, thus freeing my analysis from the specificity of the model chosen for its better fit. My work, however, would be incomplete if simply finding empirical evidence of a negative effect of the gas disputes on the real growth of GDP and main stock markets of European countries. I summarize the most relevant statements, agreements, and partnerships which are likely to have exerted pressure on Russia and the other negotiating country. 


\section{Acknowledgements}

I wish to thank several people for having supported me throughout this long journey. First of all, my family, who understood my desire to keep studying away from home. My advisor, Professor Robert Duval, for his incredible support. No words can describe enough how valuable his presence and his words were for me.

Professor Hagan, for his invaluable help in guiding International Students.

Professor Trumbull, who accepted to be part of the committee under such a short notice, yet offering precious suggestions.

Professor Hunter and Professor Crichlow, for their insights and knowledge.

Dr Cumming, for his experience and his wonderful diplomatic skills.

Prof Pinto, for his ideas and his time.

Friends, who gave me suggestions, ideas, inspired me, or simply made me laugh. Many played an important role, all of them an unforgettable memory. Among these I would like to thank Aki Oguri for her patience and her beautiful smile and Don Enrico, an incredibly combative and far-sighted person. 


\section{Table of Contents}

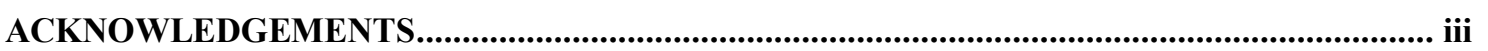

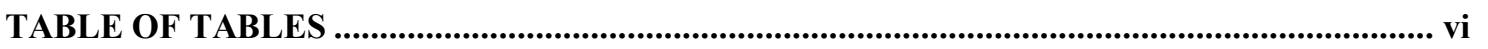

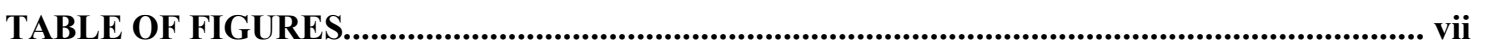

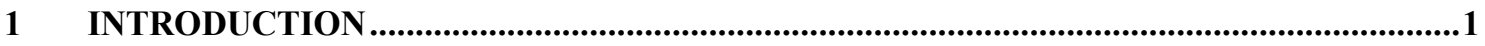

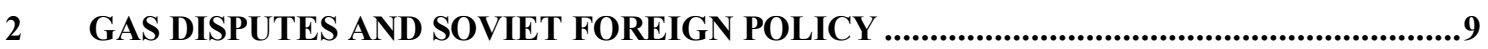

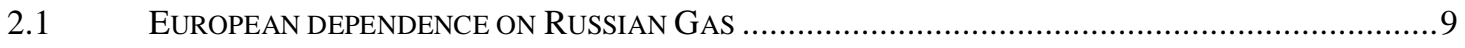

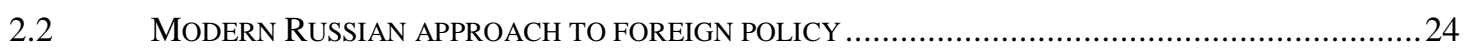

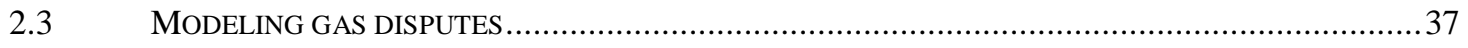

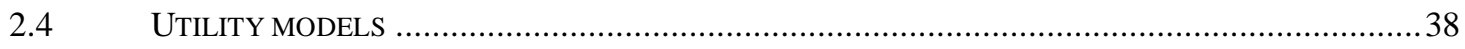

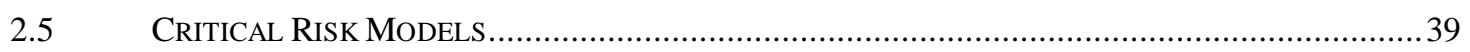

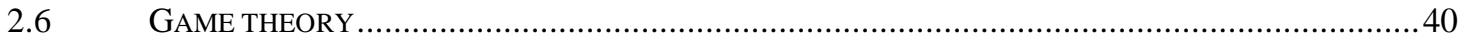

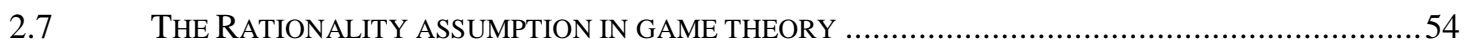

2.8 ADVANTAGES AND DISADVANTAGES OF RATIONAL CHOICE THEORY ......................................63

2.9 CAN TODAY'S GAME THEORY EXPLAIN THE OUTCOME OF A SIMPLIFIED DISPUTE? ...................66

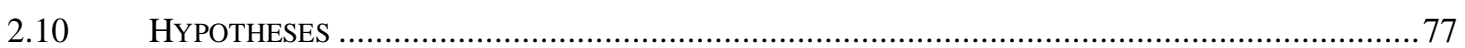

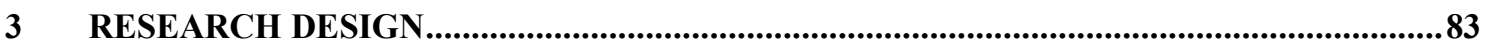

3.1 APPLICATIONS OF TIME SERIES MODELS IN THE LITERATURE ............................................ 86

3.2 Auto Regressive InTEgRATEd Moving AVERAge (ARIMA) ModELS............................94

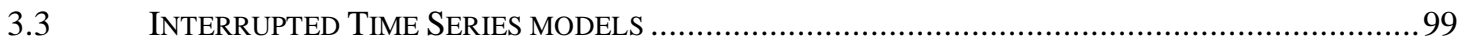

3.4 HETEROSKEDASTICITY MODELS (ARCH/GARCH) .................................................... 106

3.5 METHODOLOGY AND HYPOTHESIS TESTING ................................................................... 114

3.6 DATA AND VARIABLES: REAL GDP GROWTH AND STOCK MARKET MODEL ......................... 116

PRINCIPAL COMPONENT ANALYSIS (PCA) ................................................................ 129

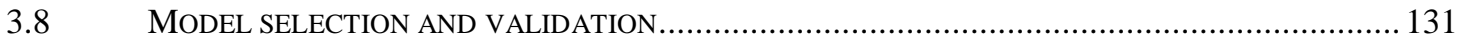

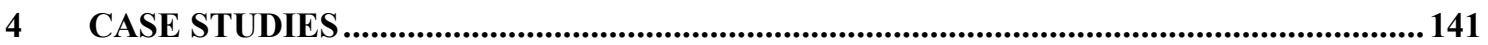

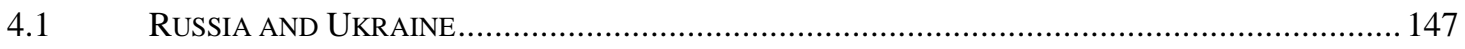

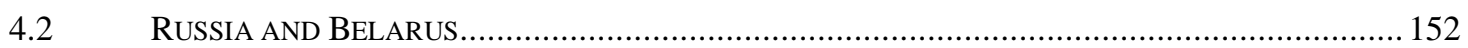

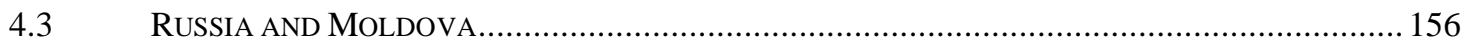

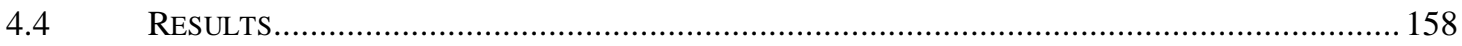

5 THEORETICAL ISSUES AND GAME THEORETIC APPROACHES ............................ 167

5.1 ALTERNATIVE GAME THEORETICAL MODELS FOR A CHANGING ENVIRONMENT .................... 167

5.2 A CRITIQUE OF BARGAINING THEORY: A DYNAMIC, EVOLVING CONTEXT ........................... 174 
5.3 CHANGING GAMES IN AN EVOLVING ENVIRONMENT......

C.4 CONNECTING THE DOTS: DISCUSSION OF RESULTS ........................................................ 202

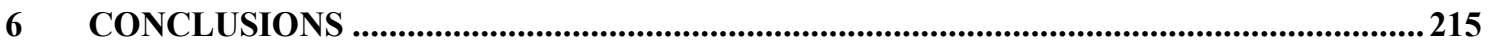

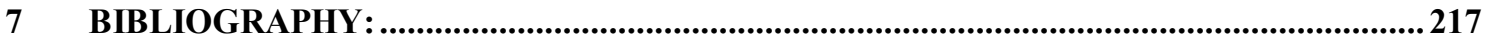




\section{Table of Tables}

Table 2.1 Energy dependence on Russian gas of European countries......................... 12

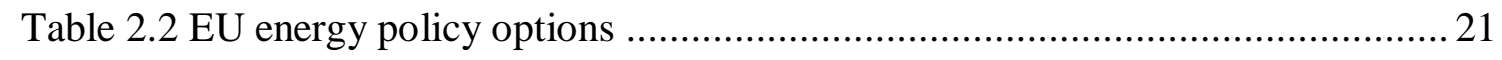

Table 2.3 Hypotheses for the Russia-Ukraine case studies....................................... 80

Table 2.4 Hypotheses for the Russia-Belarus case studies ..................................... 80

Table 2.5 Hypotheses for the Russia-Moldova case study...................................... 81

Table 3.1 Observable daily duration of impact of gas crises and observable daily effect of reaction functions (Stock Market model) ...................................................... 119

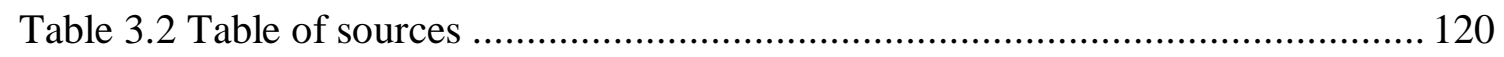

Table 3.3 Summary statistics of dependent, independent variables and control variables

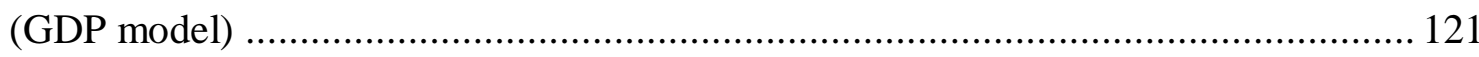

Table 3.4 Dates corresponding to the start of the disputes analyzed ......................... 123

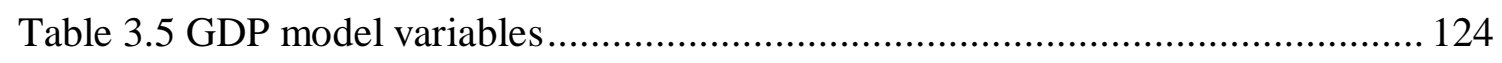

Table 3.6 Stock market model: summary statistics of dependent and independent

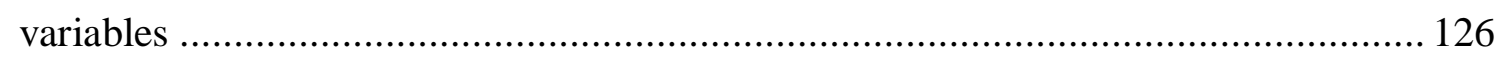

Table 3.7 Stock market model: summary statistics of dependent and independent

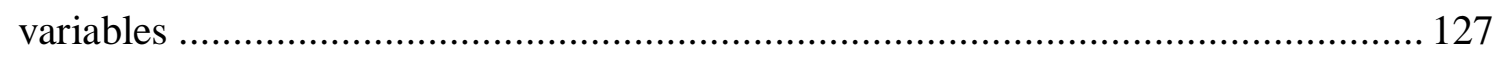

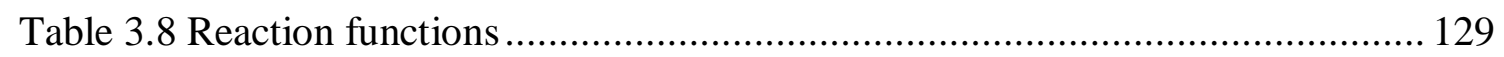

Table 3.9 Control variables processed by PCA and resulting factors (GDP model only) 131

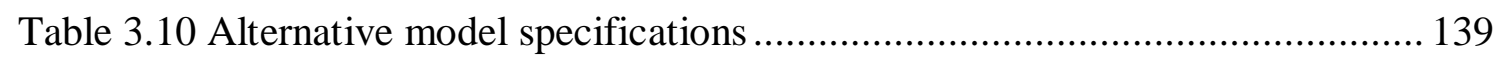

Table 4.1 Regression results of the PP-NARCH model (GDP model) ....................... 160

Table 4.2 Hypotheses supported by alternative model specifications ........................ 161

Table 4.3 Regression results of the stock market model......................................... 164

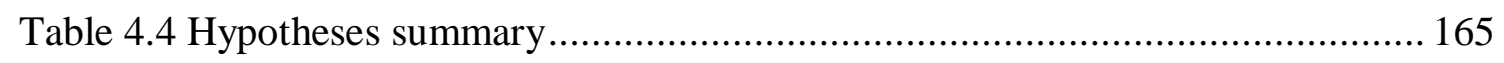




\section{Table of Figures}

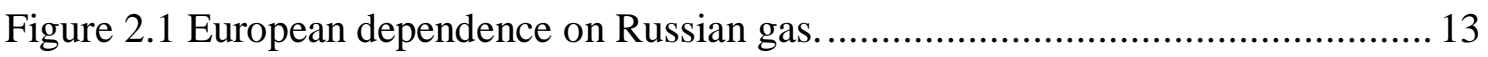

Figure 2.2 Russian oil and gas pipeline system................................................. 15

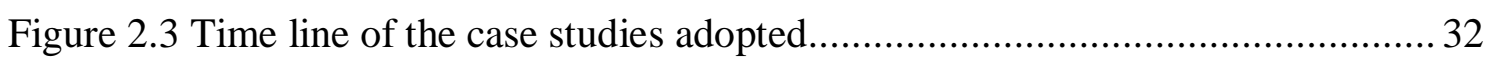

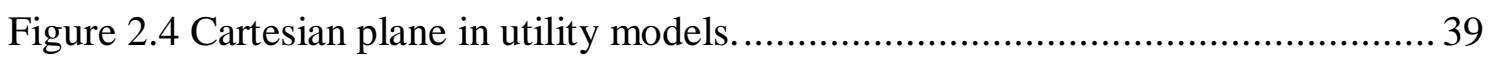

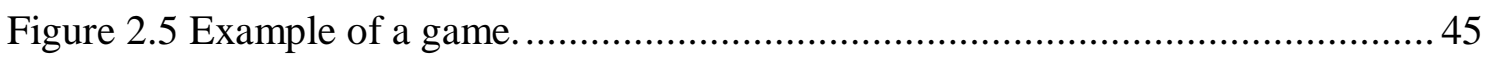

Figure 2.6 Distribution of payoffs in a prisoner's dilemma game.............................. 49

Figure 2.7 General distribution of payoffs in $2 \times 2$ games........................................ 50

Figure 2.8 Model representing the Russia-Ukraine dispute..................................... 68

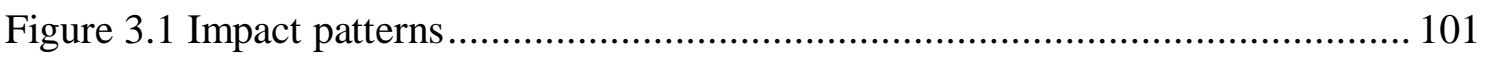

Figure 3.2 Gradual permanent impact patterns ................................................ 103

Figure 3.3 Gradual temporary impact patterns ...................................................... 105

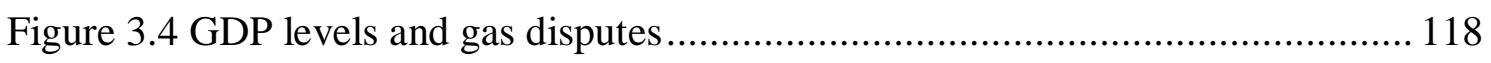

Figure 3.5 Raw series of the dependent variable (GDP model) ............................... 132

Figure 3.6 First differencing of the dependent variable (GDP model) ...................... 133

Figure 3.7 First differencing of the logged dependent variable (GDP model) ............. 134

Figure 3.8 Residuals of a pooled cross sectional GDP model with first order autoregressive and moving average disturbances ............................................ 135

Figure 3.9 First differencing of the logged dependent variable (stock market model,

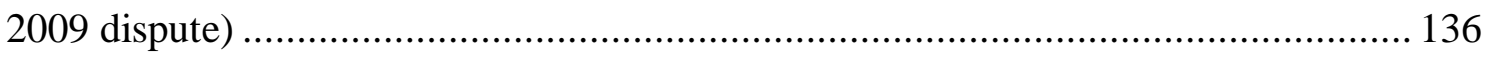

Figure 3.10 Residuals of a pooled cross sectional Stock Market model with first order

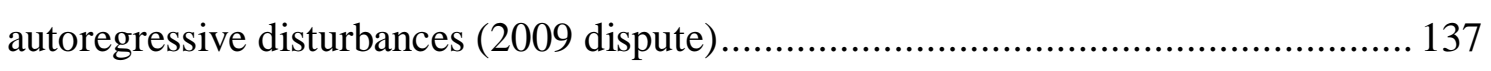

Figure 3.11 QQ Normal Scores of Standardized Residuals from the fitted PP-NARCH

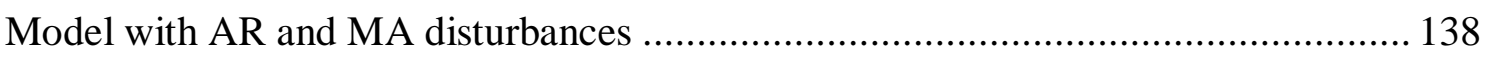

Figure 3.12 QQ Normal Scores of Standardized Residuals from the fitted PCSTS Model

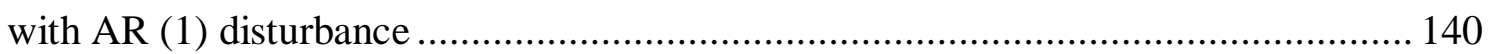

Figure 4.1 Countries affected by the 2009 gas crisis and gas pipeline system. ........... 149

Figure 5.1 Porter's Five Forces model........................................................... 183

Figure 5.2 A modified Porter's Five Forces model. ................................................. 185

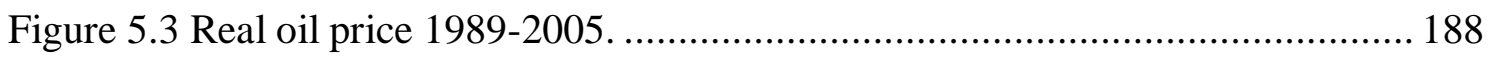

Figure 5.4 The proximate environment of a firm ................................................ 192

Figure 5.5 The proximate environment of a gas importer..................................... 193 
Figure 5.6 A Fully-Fuzzy game with three players

Introduction79497688 \h |201\}\}

\} 


\section{Introduction}

(...) it doesn't matter whether the forecast of the future is true or not. If a mathematician should predict a long and happy reign for me, a time of peace and prosperity for the Empire -- Eh, would that not be well? (Asimov, 1988)

Energy has recently become a very important item on the political agenda of most Western countries and it is bound to be even more so in the future due to the increasing scarcity of natural gas and oil. Energy resources and their allocation have been the central element of conflict between producer countries and the countries in the distribution systems in recent years. The intensity of these conflicts, however, has reached over the past 6 years a level that was unseen since the seventies. More specifically, political scientists have noted that the conflicts between Russia and some of its former satellites beginning in 2004, can be justified not only in economic terms, but also, and more importantly in political terms.

In the literature, political scientists attribute this new Russian approach towards Ukraine, Belarus and Moldova not only to the Russian desire to collect as many financial resources as possible from these countries, but also to use the financial leverage gained by increasingly expensive gas exports to gain economic and political control over these countries. In fact, Putin himself recognized the importance of gaining access to the old Soviet pipeline system in order to restore, at least in part, Soviet prestige. It is probably a secondary goal to secure a steady flow of gas and oil through its former satellites, when one compares it to that of establishing a tighter economic and political relationship with those areas that play an important to role in the Russian economy. 
The relevance of this topic, however, is not in the expansion of Russian political influence per se, as it was the case during the Cold War. The concern of the highest European spheres stems from the growing suspicion that Russia may also use the energy weapon to advance its political agenda in Eastern and Western Europe.

Political bargaining models can offer valuable insights and contribute to the explanation of the outcome of important political confrontations like the ones between Russia and its former satellites. However, the understanding of the evolution of these confrontations can depend on the quality of the formal models that one uses to disentangle all the threads that one identifies as relevant. If one of the important threads is not accounted for in the model, then our understanding will be inherently flawed and the adoption of the model, however accurate and refined, will systematically produce inaccurate explanations and predictions.

The main goal and contribution of the present work is that of showing that one of the most respected political bargaining models, game theory, has thus far been limited by its inability to deal with a changing environment. Several modifications to classical game structures have been proposed since its conception in the 1920s: evolutionary games (Danielson 1998; Binmore and Samuelson 1992; Nachbar 1992), infinitively repeated games (Myerson 1994; Shubik 1991), multi-agent games (Snyder and Diesing 1977; Dixit and Nalebuff 1991), two-level games (Putnam 1988), nested games (Tsebelis 1990; Scholz 1991), fuzzy games (Aristidou and Sarangi 2006; Kandel and Zhang 1998), neutrosophic games (Bhattacharya, Smarandache, Khoshnevisan 2006) supergames, and metagames (Snyder and Diesing 1977). Despite of their complexity, none of these enhancements is designed to account for an evolving environment where additional actors' preferences are gradually included in the political bargaining process. 
The relevance of the preferences of these actors will be demonstrated in this work by finding empirical evidence that the start of the dispute has damaged other external economies; in fact, this would give them a reason to be a relevant part of the game by exerting pressure on the two players so as to reach an agreement in the shortest time possible. The growing importance of external actors, I argue, needs to be modeled by game theory because, especially the case for the Russia-Ukraine dispute in 2006 , their role can be central in determining the duration and the outcome of the political bargaining.

I use a statistical model to find empirical evidence that politics and economics interact with each other so intensely that politically-induced gas crises (especially those from 2004 to 2009) are capable of influencing GDP and stock market indices. This supports my hypothesis that game theory should take into consideration the preferences of the actors within the proximate environment and sets the stage for my representation of dispute through what I term a Fully-Fuzzy game. It is important to note, however, that these preferences although relevant to explain the outcome of the bargaining process, may have nothing to do with the original causes that led to the start of a dispute. I believe that when studying these kind of crises, one needs to realize that are at least two phases that need to be modeled: one in which the preferences of the players that were behind the start of dispute are relevant, and one in which the preferences of all actors interested in the resolution matter. If one wants to understand why a specific outcome is the result of the bargaining process, I argue that one needs to broaden the reference context to comprise all the other actors that may have influenced through diplomatic acts or statements the preferences of the disputing actors. 
Thus, I hypothesize that the start of a dispute leads to a negative trend in the real GDP and in the stock markets of several important European oil importing countries that belong to the same environment of the two disputing countries. I use quarterly GDP data since I believe these are a good measure of the medium-to-long term effects of the disputes on external economies, without having to deal with the intricacies of daily stock market data, which reflects not only traders' expectations, but also speculations and stochastic behaviors that may be erroneously attributed to the variables. The kind of argument advanced in this work, however, requires also studying the statistical effects of these crises on a daily basis. For this reason, I provide a statistical analysis also of the main stock market index for each of 9 countries considered in this work.

Given that the data used is affected by heteroskedasticity, which is evident in correspondence of the negative downturn in the economies of the countries studied in this work, I select a Pooled Panel Nonlinear Auto Regressive Conditional Heteroskedasticity (PP-NARCH) model, which provides a better general fit of the data and more consistent estimation of several control variables added in the model. Nonetheless, I rely more on the general message conveyed by the several models considered, thus freeing my analysis from the specificity of the model chosen for its better fit. For the stock market model, however, I select a Pooled Cross Sectional Time Series model with constant variance (for simplicity identified as PCSTS to distinguish it from the GARCH model), given the higher speed with which it can process the data and the lack of a significant advantage of using a more complicated GARCH model.

My work, however, would be incomplete without an analysis of the political maneuvers that may have affected the bargaining process between Russia and the transit countries. In fact, just by finding empirical evidence of a negative effects of the gas dis- 
putes on the real growth of GDP and the main stock market of the European countries would not suffice to prove that their preferences should be gradually incorporated in the game theoretic model: it may (implausibly) be that all EU countries may prefer to remain neutral, without expressing any concern regarding the potential effects of prolonged gas supplies disruptions both in Europe in general and in the countries directly involved in the dispute. The analysis of the most relevant facts reveals not only that countries did react to the disputes, but that they also exerted pressure on Russia and the other negotiating country. This pressure took the form of public statements about the reliability of Russia as a gas supplier, the concern about the negative effects of gas disruptions on the EU, the establishment of new institutions designed to predict and anticipate possible disruptions that may damage the economies of the EU members, and, most importantly a renewed interest for alternative energy resources and the construction on new infrastructure designed to bypass Ukraine, Belarus and Moldova and to reduce European dependence on Russian energy. Some of the reactions selected as the most important are found to have a significant and positive effect on the stock markets of several EU countries.

This work starts with a chapter on the relevance of energy security in today's political agendas. This chapter quickly narrows down the energy security issue to the specific case of Europe and its dependence especially on Russian gas. As I specify in this chapter, oil, very important for Europe as well, is not much of concern for European leaders, given the large array of producers available. Gas, however, is a much more critical issue, given the centrality of Russia in terms of exports, and the use that Russia made of it to gain access to the distribution networks in Ukraine, Belarus and Moldova. The chapter continues with a review of the explanations of some important political 
scientists regarding the motivation behind the Russian use of the energy weapon and a description of the main disputes that occurred starting in 2004. I then introduce political bargaining theory, with its strengths and weaknesses. Here I also discuss the preeminence of game theory among the political bargaining theories, describing in what way the literature praises it and what are the most common critiques made to this theory. At this point I only briefly hint that game theory lacks the ability of accounting for an evolving context.

In Chapter 3, I provide a review of some articles published in important journals that offer a statistical analysis which shares, at least in part, some of the methodological choices adopted in this work. I continue with a description of the methodology chosen to support my argument, starting from Auto Regressive Integrated Moving Average (ARIMA) models, incorporated in the final specification identified, moving on with a description of intervention models and a review of Generalized Auto Regressive Conditional Heteroskedasticity $(\mathrm{GARCH})$ models and some of the most important generalizations. I discuss variables, model selection and model evaluation techniques adopted. Mainly due to my use of quarterly data, Principal Component Analysis is used in order to retain as much variance as possible from all control variables selected, while at the same time drastically reducing the collinearity which would inevitably affect the tests of significance.

The results of model chosen as the "most fit" are then analyzed in Chapter 4, not just from a methodological point of view, but also in the larger context of the nature of the cases studies examined in this work and the true meaning of the significance of the independent variables. 
Given the results, I offer my own critique, pointing out that game theory appears to be limited by its inability to work with a changing environment, where new actors emerge as relevant players. I test my argument against the most important modifications of the classic game, noting also that my critique goes in the same direction as that of Gintis, recently published in the Journal of Economic Behavior \& Organization, but it differs from that for being more general. It is at this point that I informally introduce the Fully-Fuzzy game. Thus, I make comparisons across the cases bridging the narratives describing the case studies with the quantitative results.

Chapter 5 summarizes the purpose of this work, its main contributions and what is left to future research. 
8 Changing Games and Evolving Contexts: Political Bargaining in European Energy Disputes

Page intentionally left blank 


\section{Gas Disputes and Soviet Foreign Policy}

\subsection{European dependence on Russian Gas}

Energy is a growing issue in today's world arena. Energy has been an element of the national security agenda and foreign policy of many states for more than a century, bringing not only wealth, technology, and sociological progress, but also aggressive foreign policies. Here national security is viewed as in Nye (1990), who maintains that national security has evolved over the past few years from a predominantly military issue to a more economic and ecological issue. Interdependence, which has made modern countries reliant on the political and economical performance of other countries, has changed the global situation from a set of highly self-sufficient areas to a set of highly interconnected individual states, whose survival is largely determined by the international situation. The destruction of the adversary is nowadays no longer a feasible solution, Nye says, in that it is assumed to lead to catastrophic consequences also for the aggressor, since all states are mutually dependent. The realist concept of 'national interest' is now ill-suited to represent the underlying force driving modern global affairs, since it now incorporates the stability and the prosperity of other mutually-dependent states as well (Keohane and Nye 2001).

Russia's control over European energy has been consolidating over the years, and it is now the supplier of over twenty-seven percent of natural gas consumed in the 
EU $^{1}$ (Howorth 2007, 247, Lebedev 2010), not to mention its investments in sixteen different European countries, including Italy, Britain, Germany and Holland (Lucas 2008, 165). The lack of a unified EU energy foreign policy and the growing European dependence especially on Russia's natural gas (given the fact that it cannot be transported in ways other than pipelines, unlike oil $)^{2}$ has the potential of being capable of undermining the political independence of the European countries. According to Lucas $(2008,163)$ and Nichol, Woehrel and Bernard (2006), Russia has clearly stated its intentions of using its energy reserves for political purposes. This can be found in the Russian energy strategy approved by the Government of the Russian Federation in 2003, where one can read that:

The new factor for the period up to 2020 will be the participation of Russia, as a large supplier of energy resources, in securing of the world energy safety. Forming of the common energy and energy and transport infrastructure in the regions of Europe and Asia, development of the international energy and transport systems, providing of the undiscriminatory transit of energy answer the strategic interests of Russia. In order to reach these aims, the state will foster the participation of Russian joint-stock companies in development and realization of the great international projects of transport of gas, oil and energy both in western and eastern lines (Ministry Of Energy of The Russian Federation 2003).

A similar intent has been claimed to be evident also in Putin's personal belief on the matter expressed in his dissertation ${ }^{3}$, in which he clearly declares that the management of the energy sector is so important that it has to be taken over by the Russian government (Lucas 2008, 163). A similar statement is found also in Yasmann's (2006) article, in which Putin is reported to envision Russia's future as that of an "energy su-

\footnotetext{
${ }^{1}$ Data refers to 2008 figures. It is also important to note that, as I will show below, Russia also depends on Europe, being the latter the major client of Russian energy; however, Russia has demonstrated over the past 4 years that it is willing to use the energy weapon to achieve it economic and political goals.

${ }^{2}$ The Liquefied Natural gas market (LNG) is still expanding and still represents a more expensive source of gas than traditionally-delivered gas.

${ }^{3}$ Lucas (2008) claims that it is possible that not even Putin was the true author of the dissertation. See http://www.cdi.org/russia/johnson/2006-78-3a.cfm for more information (as reported by Lucas 2008: see footnote).
} 
perpower" and of a leader in the energy market. Therefore, to Putin, energy is to be seen as the most powerful force in today's world and in the immediate future.

Over the past few years, Russia has shown that if the condition is favorable, that is if the opponent is particularly weaker, it has no hesitation in resorting to coercion to achieve its purposes (Youngs 2008). When Russia abruptly doubled the price of the natural gas supply to Ukraine in 2009 , and the latter refused to pay, at which point Russia halted the supply, Russia was clearly demonstrating to the world that the alignment between the Russian government and Gazprom ${ }^{4}$ had reached critical levels ${ }^{5}$ and that Europe had a new priority, if it wanted to assure that its citizens and its economy were not subject to the will of Russia (Lucas 2008, 168).

Some have argued that Russia does not actually have much power in terms of energy coercion, since Russia needs Europe as its main energy market (Lucas). In some respects, such a statement is correct, but the knowledge and awareness that Russia can halt supplies and endure the loss of natural gas revenues for several months gives credibility to the leverage that Russia has in terms of using energy coercion to advance other political ends. In other words, even though Russia will indeed be disadvantaged by the interruption of gas supplies to the Western countries, this will cause an immediate and

\footnotetext{
${ }^{4}$ Gazprom is the largest energy company in Russia. Its business is field exploration, and production, transportation, storage of energy sources like natural gas, oil, heat and electricity. Gazprom supplies the domestic market and is a key player in the supply of energy to several European countries. The strong connection between Gazprom and the Russian government is often emphasized by the fact that important political figures like Putin and Medvedev had previously played (or still do) a key role in Gazprom. The Russian government also owns a controlling share in Gazprom (Howorth 2007).

${ }^{5}$ Shaffer $(2009,121)$ maintains that the Russian government and its energy sector are so deeply linked to each other that the election of Dmitry Medvedev to the position of President of Russia should not surprise, given his past as the Gazprom chairman. See also Youngs (2009, 90-93).
} 
substantial disruption within the countries that depend on Russian gas, enabling Russia to possess bargaining leverage over the other contestant (Youngs 2008).

In Europe, there exist several countries that heavily depend on Russian gas, some of them even totaling up to $100 \%$ of their gas demand and with an average of over fifty percent dependence on foreign gas (Energy Information Administration 2008, Howorth 2007, Lucas 2008) and over twenty-seven percent on Russian gas (see Table 2.1).

Table 2.1

Energy dependence on Russian gas of European countries.

\begin{tabular}{|c|c|c|c|}
\hline Rank & Country & $\begin{array}{l}\text { Imports } \\
\text { (bcf/y) }\end{array}$ & $\begin{array}{l}\text { Percent of Domestic } \\
\text { NG Consumption }\end{array}$ \\
\hline 1 & Germany & 1,291 & $36 \%$ \\
\hline 2 & Italy & 824 & $27 \%$ \\
\hline 3 & Turkey & 630 & $65 \%$ \\
\hline 4 & France & 406 & $23 \%$ \\
\hline 5 & Hungary & 294 & $56 \%$ \\
\hline 6 & Czech Republic & 252 & $75 \%$ \\
\hline 7 & Austria & 246 & $72 \%$ \\
\hline 8 & Poland & 226 & $39 \%$ \\
\hline 9 & Slovakia & 226 & $99 \%$ \\
\hline 10 & Finland & 148 & $95 \%$ \\
\hline 11 & Romania & 140 & $22 \%$ \\
\hline 12 & Fmr Yugoslavia & 134 & $57 \%$ \\
\hline 13 & Bulgaria & 101 & $53 \%$ \\
\hline 14 & Greece & 85 & $85 \%$ \\
\hline 15 & Switzerland & 13 & $11 \%$ \\
\hline \multicolumn{4}{|c|}{ Sales to Baltic \& CIS States, 2005} \\
\hline & Ukraine & 2,113 & $69 \%$ \\
\hline & Belarus & 710 & $99 \%$ \\
\hline & Baltic States & 205 & $89 \%$ \\
\hline & Azerbaijan & 120 & $33 \%$ \\
\hline & Georgia & 46 & $88 \%$ \\
\hline 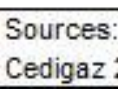 & $\begin{array}{l}\text { Domestic Consumpti } \\
2006 \text { and BP Statistic }\end{array}$ & $\begin{array}{l}\text { AA International } \\
\text { view } 2007 \text {. }\end{array}$ & gy Annual, 2005; Imports: \\
\hline
\end{tabular}

Up to one year may pass before Russia would start accruing the loss of revenues which stem from the sales of the gas (Howorth 2007). 
Figure 2.1

European dependence on Russian gas.

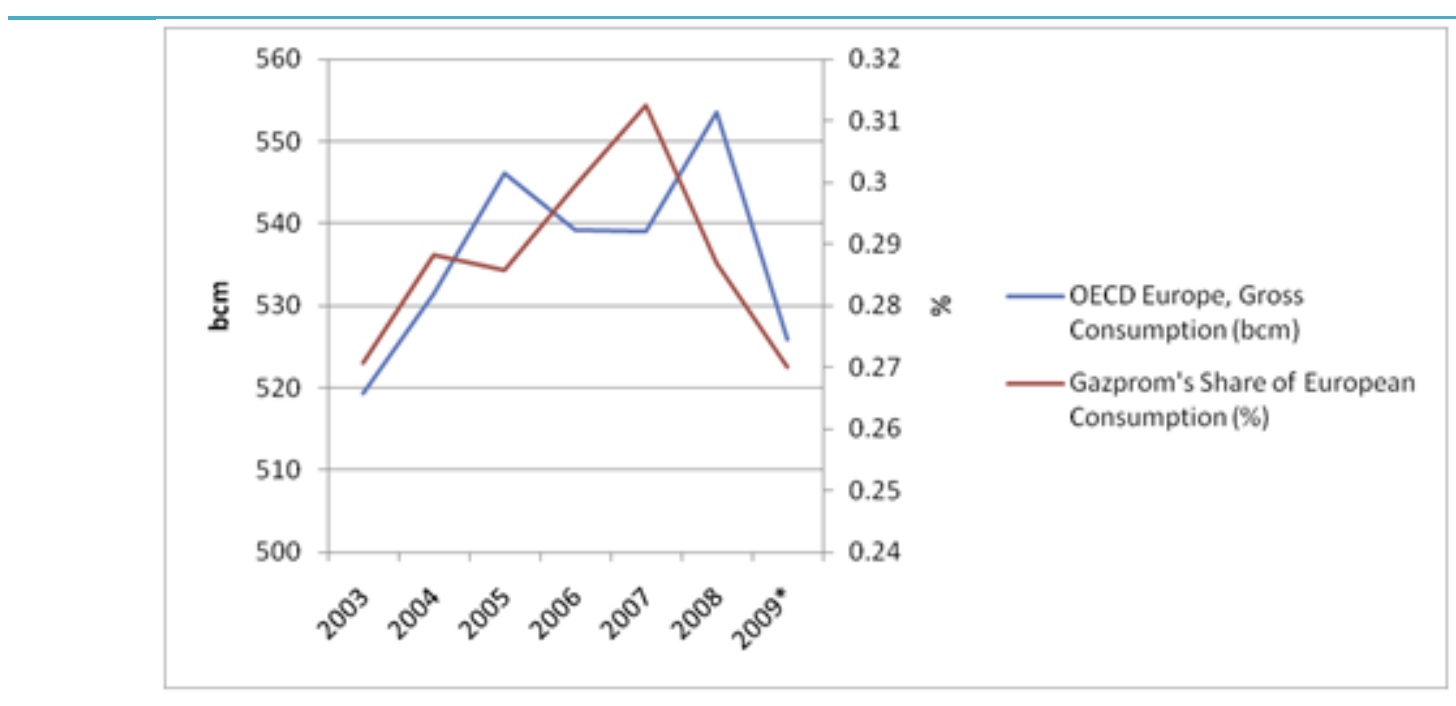

Source: IEA Data, Gazprom Data, EPRINC calculations. Estimate for 2009 (Energy Policy Research Foundation. 2009)

As said above, a sudden interruption of gas supplies would strike the economies of those countries that heavily depend on Russian gas, while their supplier would start feeling the blow some time later, depending on how well Russia is able to divert the gas to other consumers ${ }^{6}$. Up to one year may pass before Russia would start feeling the loss of revenues coming from the sales of the gas (Howorth 2007). This is a very large time in which Russia can exploit its leverage on its energy resources to extend its political influence $^{7}$ (without actually territorial expansions) ${ }^{8}$ and increase the energy dependence of target countries. Even though energy weapons do not immediately produce the destruction and the likely loss of lives as much as a conventional attack would, energy disruptions in the middle of the cold season might cause as much death and economic disaster

\footnotetext{
${ }^{6}$ Should Russia not be able to supply its excess gas to other countries, the sudden reduction in sale revenues is likely to strike the Russian economy and political sphere harder than otherwise.

${ }^{7}$ Influence is here meant as the ability to defend one's interest without waging war and is conceptually similar to Nye's (1990) concept of soft power.

${ }^{8}$ See Oliker et al. $(2009,135-136)$.
} 
as a military conflict, achieving the same results, that is the creation of instability, raising the likelihood of military conflict and paving the way for terroristic activities (United States Congress Senate Committee on Foreign Relations 2008) ${ }^{9}$.

Moreover, Russia is in control of the old Soviet infrastructure ${ }^{10}$ that channels oil and gas from its surrounding regions to the West and is also the major buyer of the energy resources produced in the ex-Soviet republics, which it then resells to Europe at a higher price (Lucas 2008).

\footnotetext{
${ }^{9}$ USCSCFR (2008) from now on.

${ }^{10}$ This control can be direct, with stakes in the companies managing and/or owning them, or indirect, by having a tight economic and political control over the government and/or the companies operating with them (see picture below).
} 


\section{Figure 2.2}

\section{Russian oil and gas pipeline system.}

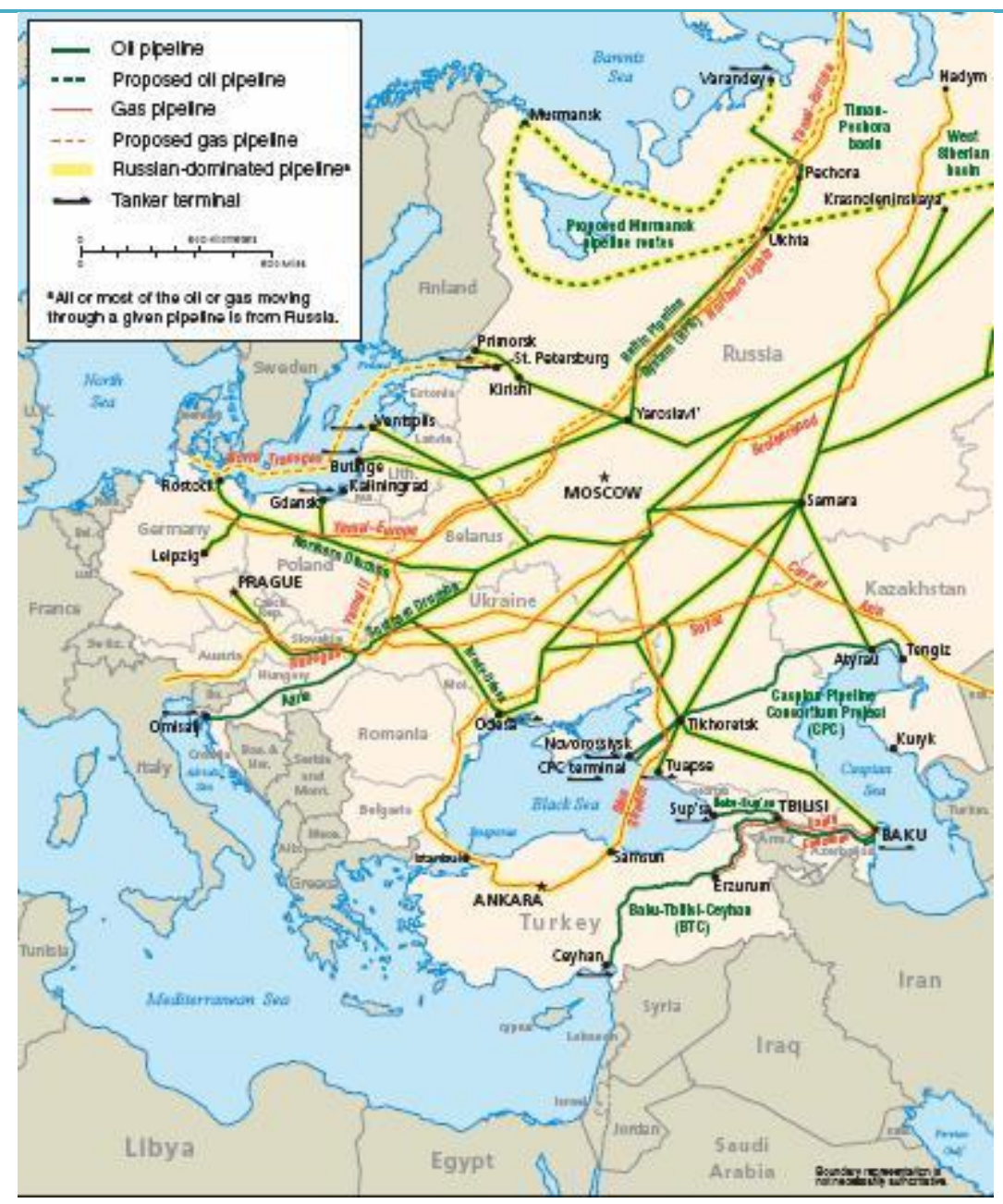

\section{Source: IEA ${ }^{11}$, CIA.}

A portion of the profit coming from those sales has been invested in Airbus, which lately it has become known that it may have extended those shares in the company, which happens to be an important provider of services and goods that are used to improve Europe's security (USCSCFR 2008).

The best option for Europe and the US is thus that of diversifying the supply of oil and gas, by dismantling the monopoly that Russia has, especially on some Eastern

\footnotetext{
${ }^{11}$ See http://www.eia.doe.gov/emeu/cabs/Russia/images/PrimaryOGPipestoEur06.gif.
} 
European countries. Better efficiency and new pipelines that introduce competition in the supply of energy products is currently seen by European leaders as the best tool to weaken Russia’s energy dominance over Europe.

Nonetheless, both the construction of new pipelines and an increased efficiency involve mutual understanding and a more consistent and unified strategy on the part of the European countries, which is lacking as of now. So far, many European countries have demonstrated little interest in finding a common energy security ${ }^{12}$ policy, to the point where they have closed private deals with Moscow or joined non-European partners in constructing new energy infrastructures, even though they are aware that the economy of those countries is heavily dependent on the continued flow of energy (Lucas 2008, Shaffer 2009, 133-134).

This has not been the case so far, in that Russia has close dealings with several countries like Greece, Bulgaria and Hungary for a direct supply of energy (Lucas 2008, Young 2009, 8687). An agreement was also concluded with Germany to construct the so-called "Nord Stream pipeline", and similarly, with Italy to construct the "South

\footnotetext{
${ }^{12}$ Pascual and Elkind $(2009,2)$ note that 'energy security' is a term that does not only refer to energy independence, but it involves also considerations about the relationships between energy suppliers and energy consumers, about the necessary transition to low-carbon energy economies, and about the management of the side effects of our using carbon fossil fuels. Energy security is based on three components: reliability, affordability and environmental friendliness (Shaffer 2009, 92). Reliability refers to continuous, uninterrupted supplies over time, affordability refers to the price levels that promote economic growth and environmental friendliness refers to policies that do not impact the current environmental situation. Sounders (2008) notes that "energy security" takes on a different meaning for Europeans and Americans. For Americans, energy security mainly refers to oil and its large availability on the global market, possibly at a very low price. For Europeans, energy security is an issue that does not really have much to do with oil; it is more about natural gas, and achieving an abundant and steady flow of natural gas from Russia. To the author, this conceptual difference is what characterizes the different diplomatic approach that Europe and the US have in dealing with Russia. In this work, I will mainly discuss reliability issues (Europe in general) and affordability (Ukraine and Belarus) issues.
} 
Stream pipeline"13 (Lucas 2008). The result of this is a lower interest on the part of these countries to unite their political and economic needs with the other European states, thus weakening every effort to improve Europe's energy dependence on Russian energy resources (Lebedev 2010).

Starting from 2006, Russia has demonstrated its resolve in using its dominance in the energy market to project influence not only in Europe, but also in Asia and along the Southern Russian territories (Douglas 2008, 317). Gazprom's decisions cannot be interpreted just from a business point of view. Given the fact that Gazprom is a state owned company ${ }^{14}$, and that both Putin and Medvedev served as the Chairman of Gazprom's Board of Directors, it is a priority for Russia to make sure that the company stays in good shape (Lucas 2008, 163-164). That is not only because that will grant a consistent flow of financial resources into the country, but it will also allow Russia to use those energy resources to accomplish what has been put forth by the Russian foreign policy agenda (Douglas 2008, 320-321). According to the United States Congress (2008) Gazprom has even preferred in some cases some financial losses in order to achieve political victories, reducing at least partly the flow of gas to six different countries.

It is argued that the increased dependence on Russian energy resources is the result of the lack of consistency and unity among European countries (Lucas 2008). As mentioned above, private agreements between some countries and Russia itself have weakened the European will to challenge dependence on Gazprom services. The Na-

\footnotetext{
13 The South Stream pipeline replaced the Blue Stream II project which would have connected existing Russian infrastructure with Bulgaria, Serbia, Hungary and Croatia.

${ }^{14}$ Fifty-one percent of the stakes of Gazprom are in fact owned by the Russian government (Lucas 2008).
} 
bucco pipeline ${ }^{15}$ is to be seen as a relevant energy source that is able to weaken Russia's dominant position in the European energy market. Such a new pipeline will be in direct competition with Russian gas and infrastructure, diversifying Europe's energy imports, allowing it to be in contact with Central Asian gas and reducing Russia's coercive power over Europe. As of now, in fact, Russia is the only one that has access to Turkmenistan's and Kazakhstan's gas which Russia is using to support its own economy and by exporting the gas it produces at a much higher price than that imported from these regions (Stern 2005, 71-72; Youngs 2008).

The European energy security issue is also characterized on the one hand by European states and their lack of a unified strategy, and on the other hand by a Russian government and its majority stakes in Gazprom. Government and energy companies have already become one entity under Putin, whose intentions are clearly those of expanding Russian economic and political influence. It is spread in terms of unity of intentions which has given the Russians the advantage that has resulted in European dependence on foreign gas. The Nabucco pipeline is a direct threat to Russian dominance, in that should Russia really lose the privileged access to the gas it is currently selling (Turkmenistan, for example), it would have to support its economy with its own gas, thus losing the revenues that it could have benefitted from by selling it.

\footnotetext{
${ }^{15}$ Nabucco is part of the EU's Southern Gas Corridor project and is a natural gas pipeline supported by several European countries to erode the Russian dominance in the natural gas market. Nabucco starts from Turkey and reaches Austria, crossing several countries like Romania, Hungary, Bulgary. This project was proposed by the EU as an alternative to the Russian exports of natural gas, seen as unreliable especially after the Ukraine-Russia dispute in 2006 and it aims at granting EU access to Middle Eastern and Caspian natural gas resources. Nabucco may be further expanded in the future by connecting Turkey to Greece and Italy or connecting Greece to Italy through Albanian territories (Trans Adriatic pipeline).
} 
According to the United States Congress $(2008,2009)$ in order to help Europe achieve its energy security goals, it is also important that the democratic transition of the new republics be aided in reaching maturity and stability. Russia has also demonstrated unwillingness to allow this pipeline to be constructed by offering the creation of the South Stream pipeline, which would nullify the construction of Nabucco from an economic point of view, since the markets that it would serve would be saturated or nearly saturated by the gas transported via the new Russian pipelines. Allowing the completion of the Nabucco pipeline would seriously impair Russia's monopoly over the gas market. Russia had primarily offered to become a partner in the works, but this was refused by the state members since it would have made their efforts meaningless. The main goal of constructing the Nabucco pipeline system is that of reducing Russian control of the energy market (Lucas 2008).

Clearly seeing that that is the goal of Nabucco pipeline, Russia has first offered to build a pipeline that will transport gas to Turkey therefore excluding the Central Asian gas supplies that would have been provided by the Nabucco pipeline (Lucas 2008;). After Turkey refused to allow this pipeline to be constructed, Russia has proposed the construction of another pipeline that will transport gas to Bulgaria and continue to Greece, thus ending up supplying the same markets Nabucco was designed for. Russia's statements that there is just not enough gas to justify the construction of the Nabucco pipeline is another attempt to weaken the investors' will to support the project (Lucas). The same strategy was adopted in the case of the Baku-Tbilisi-Ceyhan pipeline, where it was also added that the project was nothing more than just an American political idea. As it can be clearly seen, time is the key variable in this game. In fact, the party that is able to construct its own pipeline will also probably win such a game, pro- 
vided that the newly constructed supply channel will likely rule out the economic feasibility of a similar construction by a delayed party. Once again, however, a disparity in resolution will determine the results of this economic dispute. Nabucco, in fact, will be the result of the confidence of its main investors that it leads to high profit. In addition, there is a Russia-backed plan, with the government and Gazprom aligned to reach their goals, in which they are willing to support economic losses if that entails the achievement of long term economic and political influence.

For Russia, the construction of the proposed pipelines would entail a further strengthening of its dominant position, reducing the economic appeal of the Nabucco project (probably leading to its abandonment), and the European countries would be left to compete against each other in order to extract privileged access to Russian energy. This is a precarious situation in that it would place Russia in the position to use its economic leverage to extract political favors and extend its influence in the whole of Europe. Russia's interests in the Caspian Sea would be highly threatened after a two century long monopoly over it, which has been estimated to contain energy reserves whose value exceeds the $\$ 4$ trillion threshold (Belopolsky 2009). Moreover, as South Stream is constructed, this would provide Russia with another advantage, namely the possibility to expand its gas supply to other European countries, de facto gaining supreme dominance in the continent and making the construction of other pipelines like White Stream ${ }^{16}$ economically unthinkable ${ }^{17}$.

\footnotetext{
16 The White Stream pipeline would go from Turkmenistan through Azerbaijan to the Georgian port of Supsa and then through the Black Sea and through Crimea to the EU.

${ }^{17}$ Please note that Nord Stream, the underwater pipeline system under costruction to bypass transit countries is not included in this table, since it is a project that is supported by Russia and the EU, in that even though it increases Russia's role as energy supplier, it bypasses Ukraine and Belarus, thus increasing the
} 
Table 2.2

\section{EU energy policy options}

\begin{tabular}{|c|c|c|c|}
\hline Option & Primary goal & Supporters & Opponents \\
\hline Nabucco & EU direct access to Central Asian gas & EU & Russia \\
\hline South Stream & Undermine economic viability of Nabucco & Russia & EU \\
\hline White Stream & Bypass Russian transportation system & Ukraine & Russia \\
\hline
\end{tabular}

Russian influence will keep growing unless the main European leaders come together and devise a common plan on how to resolve the problem (Lucas 2008). The effort that is being put forth by the Committee is not even comparable with the unity of intents and resources that Russia has been contributing to expanding its economic dominance. The same Committee recommends that the US inform the European leaders of the strategic relevance of gas independence not only in the short term (avoiding shocks like the one caused by the Ukraine-Russia gas dispute), but also in the long term, justifying this statement in terms of guaranteeing the freedom of the European leaders from their economic and political dependence upon Russian influence.

Making sure that European countries benefit from steady and diversified sources for the energy they require is very important for a stable and thriving economy (Nefte Compass 2010). The volatility that the markets have recently experienced due to the instability of the major suppliers (Saudi Arabia, Iraq, Algeria and Iran) is damaging per se, because it reduces the profit expectations of opening and/or expanding businesses 
(making expansions or the opening of new businesses economically not feasible). Suchvolatility generally reduces investors' confidence (a consequent drop in investments) and lowers consumers' expectations of the future that lies ahead (lower consumption) (Howorth 2007, 248). Russia itself is in a troubled situation with a plunging and an overly oil-centric economy vulnerable to oil and gas price fluctuations, debilitating social and demographic problems, not to mention a diffused corruption at all levels. The last four months of 2008 were characterized by a record price for oil ( $\$ 150$ per barrel), followed by just a few months later in January 2009 by a quick and substantial fall in the oil price, down to just $\$ 40$ per barrel. Such volatility, even though it gives speculators some interesting opportunities, is very damaging to the global economy for the reasons reported above and that it brings about a general reduction in the confidence of investors and consumers.

The problem of European dependence on Russian oil is further aggravated by the expectation that global demand will grow, referring especially to China and India, whose oil demand has been estimated to more than double by $2030^{18}$. Europe will soon find itself competing with more and more other states for energy resources that are becoming scarcer, and their demand will keep growing at faster paces than Europe's ${ }^{19}$. For this reason, diversification of energy sources, efficiency, capacity, transparency and emergency stocks have become priorities in dealing with European energy security (Howorth 2007; Nefte Compass 2010). A higher demand for energy will increase its price; however, the most distressing shock for the world economy with high oil prices is not just that oil price spikes cause inflation, since businesses at least partly

\footnotetext{
${ }^{18}$ See also Lucas 2008, page 16.

${ }^{19}$ Shaffer $(2009,46)$ maintains that if Russia built a new pipeline system to China, that would improve its bargaining position with respect to both China and Europe as well.
} 
transfer the increased energy expenses on consumers, but they are also followed by a general recession or a slowdown of the economy. In fact, according to Bemanke, Gertler and Watson $(1997 ; 2004)$ a $10 \%$ oil price spike corresponds to a peak output decline of $0.7 \%$. However, if the influence of oil price spikes is combined with monetary policy (restrictive to lower inflation), then it becomes much more difficult to understand whether it is actually the increased oil price that caused a slowdown of the economy, or whether it was the restrictive monetary policy that it is mainly responsible for the decline. According to Carlstrom \& Fuerst (2005), this is exactly the case, for their Dynamic New Keynesian Models of monetary policy shows that it is the monetary policy that is associated with the decline of economic output, while the oil price spike is associated with an increase in the output. Such a statement is directly contrary to what has been found by Bemanke, Gertler and Watson $(1997,2004)$.

Moreover, according to the United States Congress (2009), economic instability or recession is associated with lower levels of security. The resource curse literature ${ }^{20}$ shows that economies mainly based on exports of energy are also vulnerable to the volatility of markets, given their dependence on the revenues from oil and gas, and the lack of diversification of the economic sectors. For the Committee cited above, the key to solving the issue of Russia's dominance is diversity of gas sources, gas consumers, and transportation routes, in other words, competition. For this reason the Senate Foreign Relations Committee has continually emphasized governmental help to advance the Nabucco project. To note, a milestone in its development is the July 2009 signing of the Inter-governmental Agreement, which was closed in August 2009 between the

\footnotetext{
${ }^{20}$ According to this literature, countries rich in energy resources like oil and gas are less likely to develop than countries which do not possess similar resources, due to greater exposition of energy price volatility and lack of economic differentiation.
} 
country members of the project and is necessary to create a legal framework for the transportation of gas between the European partners of the project and Turkey. Diversity could be achieved also with the creation of the pipeline connecting Turkey-GreeceItaly (Lucas 2008, $177^{21}$ ). The construction of these pipelines is one of many steps that Europe is to take to ensure its economic and political independence from Russia. Other initiatives, like separating ownership between gas transporters and gas producers, improving the gas network among European countries that allows them to more flexibly distribute the gas among them, and increase in the storage capabilities of gas are all strategies that the United Stated favors in order to help develop European energy independence. Also important is the establishment of diplomatic relations with European countries so as to create a commonly shared sense and perception of the necessity to come together with a united energy security policy $^{22}$.

\subsection{Modern Russian approach to foreign policy}

The dependence of Europe on imported gas has been growing over the past decades, and it is likely to do so in the near future. This is so because European production has been constantly declining, while at the same time its demand has been increasing (Youngs 2008). With an economy that is increasingly improving after the financial and economic crisis that started in 2008, the perspectives of European dependency on foreign energy resources are likely to worsen (World Gas Intelligence 2009). In 2006 over $40 \%$ of OECD Europe's gas consumption was of foreign origin and over $75 \%$ of this

\footnotetext{
${ }^{21}$ See United States Congress Senate Committee on Foreign Relations (2009) and Lucas 2008.

${ }^{22}$ See United States Congress Senate Committee on Foreign Relations (2008, 2009).
} 
gas was produced either in Russia or Algeria; projections claim that in 2030 well over $50 \%$ of the total gas demand will be satisfied with foreign gas (World Gas Intelligence). Moreover, energy security in Europe has been a growing concern given the cooperation agreements that several gas producers have reached, especially after the supply disruptions that occurred starting in 2006 (World Gas Intelligence 2009).

Russia seems to not be preoccupied with the consequences of its disputes with the transit countries, mainly Ukraine and Belarus. In fact, Bindi (2010) notes that current diplomatic relations with Europe are certainly not the most favorable and that therefore it is not expected that Russia would avoid using force, in whatever form it may be even the use of the gas weapon, for the continuation of its policy. The author notes that according to some European countries, the major source of Russian discontent is the American presence in countries that were once under Soviet influence, which spreads American influence throughout the European continent, while at the same time reducing the defense capability of the Russian government.

The last statement refers especially to the Russian disapproval of the missile shield, which, according to Bindi (World Gas Intelligence), would significantly reduce Russian capability to protect itself. According to some East-European countries, however, the intent of the Russian political sphere can be better approximated by its eagerness to exert political and economic influence over its neighboring countries ${ }^{23}$. Russia seems to have a positive opinion of Europe in general, while Americans are the true problem (Bindi; Shaffer). If Russia did not strongly oppose the enlargement of the Eu-

\footnotetext{
${ }^{23}$ See Bindi $(2010,216)$. Shaffer $(2009,116)$ simply summarizes Russia's behavior as that of a country that it is maximizing its own energy security.
} 
ropean Union, it is because Russia viewed it as an alternative to the expansion of NATO.

However, with the integration of several countries that used to be under the Soviet influence, two new paradigms emerged that dominated the discussion of Russian foreign policy. According to the first paradigm, which views the joining of ex-Soviet republics as a positive event, the lower transaction costs, given the lower distance between European countries and Russia, and a unification of trading procedures and norms all would benefit from the economic and therefore political situation within the European countries. The second paradigm views the entrance in the European Union of ex-Soviet republics as a direct threat to the Russian existence, in that following the expansion of the EU to Eastern Europe would put Russia at the border of the main trading routes and outside the political center of world policy making. More specifically, the enlargement would prevent Russia from having privileged access to the East-European markets, which would then be drawn into the European system, away from Russian sphere of influence ${ }^{24}$.

Even though some collaboration between Russia and the EU seemed likely in the early 1990s, when the EU and the Russian federation signed the Partnership and Cooperation Agreement (a document that recognized the need to work together to promote security, peace, democracy and economic cooperation), the relationship started deteriorating and the two paradigms developed, therefore substantially reflecting the deeper economic relationship between the two entities, and the greater ideological distance that mounted throughout the 1990s (Bindi; Shaffer).

\footnotetext{
${ }^{24}$ The assumption here is that the European Union is dominated by anti-Russian individuals (Bindi; Shaffer, 123).
} 
A cold war approach has prevailed since then, characterized by frustration stemming from seeing the expansion of the European Union and $\mathrm{NATO}^{25}$ in Eastern Europe. Additional motivations are the strong demands from the EU to support its own expansion (Olker et al. 2009, 105-106) ${ }^{26}$ and the European insistence on promoting values like democracy and human rights well beyond its territories (Oliker et al. 2009, 107). Since then, Russia has been ignoring the Baltic States, preferring a direct diplomatic relationship with each European country, rather than dealing with the European supra-national institutions, as if not recognizing the power of the European Union as a community ${ }^{27}$. Following this paradigm is the diffusion of a more negative perception of the European countries. Even though the US still ranks first among the 'less-liked countries', the European countries have now been gaining so many positions in the afore mentioned ranking, that some have reached the second slot following the US (Bindi 2010, 124). "Fear and disagreement" (Bindi) have characterized the Russian opinion of the West in general, but are now assumed to be working towards the destruction of Russian power (Bindi). There have been times at which the European Union and Russia seemed to be striving to reach some more cooperative agreements towards more coop-

\footnotetext{
${ }^{25}$ See Oliker et al $(2009,110)$ and Douglas 2008 (221).

${ }^{26}$ Nonetheless, Oliker et al $(2009,105-106)$ maintain that several figures of the Russian elites and many Russians as well, see themselves and their country as European. They specify that especially Western Europe has been perceived by Russia from three different points of view. First of all, it used to represent an 'enlightened' region where values like democracy, religious and race tolerance are widely spread. Such a conceptualization of Europe seems not apply anymore after Putin came to power, which coincided with Russia perceiving Europe as simply following the US policies (often viewed as damaging for Russia's security). Europe has also been perceived as a modernized and prosperous society, which seems to represent the end goal of Russian transformation. Finally, Europe it is seen as an opportunity for Russia to show its great-power status by interacting with European institutions and nations. Its identity, partly European, as recognized by some, is reinforced with its interaction with the EU.

${ }^{27}$ Bindi (2010).
} 
eration. An example of this is when the two parties met in Khanty-Mansiysk in 2008 and started discussing again strategic issues that were abandoned without a renewal of the Partnership and Cooperation Agreement which had expired at the end of $2007^{28}$. The situation quickly worsened due to Russian concern over European support of disputes against Russia and the construction of missile defense equipment on the Russian border at the expense of its own security (Bindi 2010, 126). Diplomatic relationships took an even worse turn with the breakout of war in Georgia in 2008 when the European countries found themselves disapproving of Russian conduct in the war which consisted of militarily and diplomatically supporting the secession of Abkhazia and South Ossetia. Meanwhile, others blamed Georgia for the start of the crisis (Bindi) ${ }^{29}$.

Such a difficult relationship with Europe does not benefit efforts by Russia to settle issues with countries via diplomatic means. This is especially true if those European countries are the reason for the Russian "great resentment of joining "the West" 30 and where Russian "soft power", not just "hard power", does not exert the same political pressure as in the Soviet era (Lucas 2008, 131). It is more likely that, as the war in Georgia showed, force may be preferred as a means to advance the Russian political agenda.

That being said, I would expect to see Russia using its energy weapons as often and as intensively as needed. Although some of the crises merely lasted few days, others in fact lasted some months before a satisfactory agreement was found, thus suggesting that in those cases, the accomplishment of the goals of one (or more) parties was not heavily affected by other pressures to quickly end the dispute.

\footnotetext{
${ }^{28}$ Trading issues, however, were still predominant in the talks (Bindi 2010, 124).

${ }^{29}$ See also Youngs $(2009,89)$.

${ }^{30}$ See page 123 .
} 
With the 1998 financial and economic crisis, diplomatic relations between Russia and Ukraine deteriorated, requiring that Gazprom compensate with energy revenues for the recession. The crisis reached a climax in November 1999, when oil and electricity exports to Ukraine were stopped; however, knowing that that would have not achieved much, given the Russian lack of control over the Ukrainian pipeline system, Russia decided that it was in its interest to bypass Ukraine and find an alternative way to supply gas to Europe ${ }^{31}$. It was at this time that the idea of building a pipeline to be used to bypass Ukraine became a serious enterprise. Ukraine perceived that the new pipeline, which was supposed to bypass up to $50 \%$ of the pipe system in the Ukrainian territory, was a serious threat to its centrality and gas delivery to Europe ${ }^{32}$. For this reason, a wave of agreements followed, and the situation, at least temporarily, stabilized.

In 2006, when Gazprom requested a higher price for the gas imported, Ukraine refused to comply with Gazprom's requests and with the January 1 gas disruption, Ukraine reacted by diverting some gas that was meant for the European market. The reduction of gas towards Europe triggered an immediate reaction of the European customers and the following day the two countries restored the gas flow and on January 4, 2006 an agreement was reached. Once again, the external environment changed, putting pressure on the disputing actors and ending the crisis sooner.

This was also evident on January 1, 2009, when the situation between Russia and Ukraine degenerated again, with a partial gas reduction first and a total stop just six days later, causing vast damages in a large number of European countries. Only nine-

\footnotetext{
${ }^{31}$ Stern $(2005,89)$ maintains that the new pipeline would have paid off itself very soon, given the large losses due to acts of siphoning of gas.

${ }^{32}$ Its centrality represented its main bargaining advantage in the negotiations with Russia.
} 
teen days later, Russia and Ukraine finally found common ground and resumed gas exports to Europe soon after (World Gas Intelligence 2009).

Of apparently different nature are the crises between Russia and Belarus, probably due to the minor centrality of the Belarusian network to Russian gas exports. Diplomatic relations between the two countries started degenerating after 1998, when Belarusian gas debts started reaching very high levels and the two parties failed to agree on the price of the gas deliveries (World Gas Intelligence 2009). In 2002, a temporary agreement was reached, but, due to disagreements over unpaid energy, in 2003 Gazprom stopped its supplies to Belarus as soon as the contract binding them to do so expired. Belarus and Russia did not reach any agreement in January of that year and on February 18, 2004 Gazprom cut off all gas supplies for 30 hours, including those that were meant to be delivered to the European market. The consequences of the cut were significant especially for the Kaliningrad region and Poland, the former being forced to switch to oil fuel and to hot water, the latter suffering a $35 \%$ gas diminution on February 18, and $50 \%$ by February 19, while Latvia was able to compensate using its own gas reserves, which were even sufficient to help neighboring Lithuania as well (World Gas Intelligence, 100). The particularity of this crisis revolves around the Belarusian confidence that it still holds bargaining leverage in terms of being an important route to the European market. Until other pipelines were constructed which bypassed Belarus, it would have been still in a position to avoid entering the Russian influence sphere (Kupchinsky 2006). Should the gas be cut off, Belarus could shift the burden of such a move back to Russia, by redirecting, as Ukraine did, the gas that was supposed to be reaching the European markets, at the expense, evidently, of increased European concern of energy security. It is probably for these reasons that an agreement was signed by the 
two countries not earlier than December 31, 2006 (Yafimava and Stern 2007). Despite the likely mitigating effects of direct or indirect pressures, Belarusian confidence in its relevance as a transit country and in its ability to shift the burden back to Russia prolonged the duration of the conflict.

No significant damage to the larger community resulted with the 2007 crisis since Belarus refused to pay a higher price and failed to repay its accumulated debt up to that point, Gazprom threatened to reduce gas supplies by $45 \%$ on August 1, 2007, even after it had to give up 50\% of the shares in Beltranshaz for 2.5 billion dollars (Maksymiuk 2007); In this instance, Belarus reluctantly paid its debt back to Russia just 1 week later, quickly ending the dispute and complying with Russian requests (Ria Novosti 2007).

The Moldovan situation, although in smaller scale if compared to Ukraine's and Belarus', shows a similar pattern, in which Russia fully exploited its strategic use of the gas weapon to achieve its goals thanks to a relatively stable diplomatic environment. Similarly to Ukraine and Belarus, energy-related debts accrued since 1991 to the point where Gazprom renewed its threats of cutting gas supplies, which, however, failed to be implemented in 2004 due to the recognized Moldovan role as a transit country and its ability to shift the burden of the 'cold war' approach back onto Russia (Stern 2005, 102). However, on January 1, 2006 Moldova was left with no gas supplies due to its refusal to accept a $100+\%$ increase in price, up from the $\$ 80$ per mcm paid just the year before. Sixteen days after the gas disruption, Russia resumed the gas supply, having settled with Moldova to pay a higher price (BBC News 2006). See Figure 2.3 for a summary of the main events of these crises just described and used in this work as case studies. 
Figure 2.3

Time line of the case studies adopted

\begin{tabular}{|c|c|c|c|c|c|}
\hline \multicolumn{6}{|l|}{ Ukraine } \\
\hline $1 / 1 / 2006$ & \multicolumn{2}{|c|}{$1 / 4 / 2006$} & \multicolumn{2}{|r|}{$1 / 1 / 2009$} & $1 / 20 / 2009$ \\
\hline 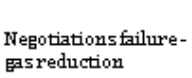 & \multicolumn{2}{|c|}{ Agreement reasched } & & $\begin{array}{l}\text { Nepotiations ffilure- } \\
\text { Eas reduction }\end{array}$ & Agreement reached \\
\hline \multicolumn{6}{|l|}{ Belarus } \\
\hline $1 / 1 / 2004$ & $2 / 18 / 2004$ & $08 / 23 / 2004$ & & March 2006 & $1 / 8 / 2007$ \\
\hline $\begin{array}{l}\text { Negotiations failure- } \\
\text { Easreduction }\end{array}$ & Gas stop & Agreement & & $\begin{array}{l}\text { Gaspriceraise } \\
\text { announcement }\end{array}$ & Threats of gas reduction \\
\hline \multicolumn{6}{|l|}{ Moldova } \\
\hline \multicolumn{3}{|c|}{2004} & $1 / 1 / 2006$ & \multicolumn{2}{|c|}{$1 / 17 / 2006$} \\
\hline \multicolumn{3}{|c|}{ Gas shortage threats } & $\begin{array}{l}\text { Negotiations failure- } \\
\text { Easreduction }\end{array}$ & \multicolumn{2}{|c|}{ Agreement reached } \\
\hline
\end{tabular}

These cases suggest that the negative externalities of these disputes seem to have an effect on the length of the gas disputes. The more external countries are affected by them, the shorter the duration of these crises, due to the acknowledged relevance of external actors' preferences in reaching an agreement.

Pirani, Stern, Yafimava $(2009,33)$ speculate as to why Russia gambled (and still does) over imposing higher prices at the expense of destroying its reputation as a reliable gas supplier. In the case of the Ukrainian crisis in 2009, Russia also knew that the financial and economical significance of an escalation of the dispute resulted in a loss of 
over a hundred million dollars per day ${ }^{33}$. Moreover, Russia was aware that a disruption of the gas supply, on which Ukraine is highly dependent, had the potential to destroy the Ukrainian economy. It was already very weak at the time and could not afford to pay the $\$ 400-450$ per mcm that Gazprom asked during the apex of tension between the two countries. In fact, Ukraine (and also Belarus and Moldova) had already had difficulty in paying back the debt that had accumulated starting from the 1990s, when the Soviet Union collapsed and Russia started charging higher prices to support its economy. Pirani, Stern and Yafimava (2009) seem to be surprised that Russia, obviously not ignoring the aforementioned issues, neglected them and preferred escalating the dispute the way it did, rather than accepting a lower price for the gas consumed by Ukraine, who already had a large debt given the price levels.

The authors continue by noting that the conclusion that can be drawn from the event is that for Russia, and more specifically for Prime Minister Putin, it was more important to consolidate the Russian bargaining position by demonstrating its resolve rather than being guided by purely economical and financial considerations. Such 'punishing' actions took priority over guaranteeing that Europe was constantly and consistently being supplied. Given the importance of the European market for Gazprom and the important economical and financial role of Gazprom for the Russian economy it is surprising that political motivations overrode purely economic motivations. The authors conclude by speculating that these political motivations may have reflected a Russian intention to destabilize the Ukrainian economic and political system, given the recent

\footnotetext{
${ }^{33}$ In this sum are included also claims for damages and the liabilities for not having been able to fulfill contractual obligations, which, however could have been cashed most likely only years later, in case of successful filing of a litigation in the Stockholm court (Pirani, Stern, Yafimava 2009).
} 
Ukrainian shift to more pro-Western and pro-Georgian policies demonstrated in recent years, especially in $2008^{34}$.

However, Pirani, Stern and Yamifava (2009) also warn that defining the priority of imposing higher prices to be an expression of the Russian will to extend its political goals would be rather simplistic and it would not accurately represent the true motivations behind the escalation. In fact, they suggest that for Russia, achieving a general rise in the price was first an economic goal, and then a political one, given the losses that domestic gas sales had represented for Gazprom at least until 2003 (Stern 2005, 43; Shaffer 2009, 42-43). In fact, Gazprom is subject to Russian law that requires it to sell at predetermined prices $^{35}$ (Stern 2005, 144). Moreover, even though control over the pipelines transporting gas to its main customer, Europe, should rather be seen as an economic goal itself ${ }^{36}$, by establishing control over down-stream activities, thus reaching its customers and assuring that interruptions would no longer occur as in the past.

Following this logic, risking damage to its reputation as a reliable gas supplier appears to be a reasonable consideration in order to gain control of the gas transportation system and obtain the certainty of no further disruptions due to disputes with the transit countries. Such reasoning makes sense when the gas dispute is placed within the wider context in which it occurred characterized by declining global economies in financial difficulty. Pirani, Stern, and Yafimava (2009) summarize the main motivations of the Russian actions by claiming that exasperation played a relevant role especially on

\footnotetext{
${ }^{34}$ See Pirani, Stern and Yamifava (2009), Oliker et al $(2009,95)$ and also Youngs $(2009,90)$.

35 The levels cannot be rationally justified given the inconsistencies and the lack of data collection relative to gas sales at the domestic level. See previous note.

${ }^{36}$ Higher gas prices entail first of all higher income for the Russian government, which taxes gas energy exports (Bindi 2010, 143).
} 
the Russian side. Seeing that Ukraine was able to threaten a diversion of the gas from the pipelines, frustration mounted among the top Russian political spheres and enabled them to take advantage of the situation by using its "gas weapon" to achieve more control of the network or extract some other benefits from the dispute ${ }^{37}$.

The authors also believe that Russia purposefully decided to involve Europe in the dispute intending to employ them as an additional source of pressure for Ukraine to accept Russian requests. Also, this would therefore restart discussions of a closer collaboration over the construction or refurbishment of existent or new transportation networks (Pirani, Stern, and Yafimava 2009, 35-36). Putin was reported to have claimed that:

The gas pipeline system is the creation of the Soviet Union. We intend to retain state control over the gas transport system and over Gazprom. We will not split Gazprom up. And the European Commission should not have any illusions. In the gas sector, they have to deal with the $\operatorname{state}^{38}$.

It is not surprising therefore that Russia incurred in the escalation of the dispute a reasonable risk that was promising in order to assure that the financial situation of the debtor country worsened, thus leaving it vulnerable to concessions over the transportation system management. In this sense, the gas crisis at the end of 2005 and beginning of 2006 reflected another major desire of the Russian leaders: the disengagement of the

\footnotetext{
${ }^{37}$ See Pirani, Stern and Yafimava (2009).

${ }^{38}$ Fredholm (2006). Oliker et al (2009, 87-88) describe Russia as prestige-seeker state, a trait which more clearly emerged in Putin's second term. Starting from 2004, Russia foreign policy has been consolidating around a few important goals, and that is the promotion of the Russian economy and the re-establishment of Russia as a 'modern great power'. Russian might should not only be based on its policies and its armies, but also on its economy, technology, culture, and authority. According to Shaffer $(2009,123)$ the oil and gas export policy are deeply entrenched with other major goals, namely making these energy markets as profitable as possible, reducing dependence on transit countries, maintaining (and possibly improving) its centrality as the key supplier of energy to Europe, and gaining control over foreign networks in order to increase its economic and political influence over those countries.
} 
transportation of its gas towards Europe from other states' systems to avoid the crises that have often undermined Russia's credibility as a gas supplier. Lucas $(2008,168)$ points out that it was Russia's prerogative to ask its customers a price it felt was reasonable. However, as said above, that does not mean that any price requested by Russia decides provides a viable and sustainable commercial and political relationship with the transit countries. Moreover, it was the European Union that asked Russia, as a term for entering into the WTO, that it charge higher prices for its gas thereby forcing the countries that depended on it to improve the efficiency of their industries (Lucas). Increasing the price of the gas would have pushed Gazprom to renovate and refurbish its pipeline systems since a higher price would have consequently meant that any gas waste represented a larger loss of profits.

The author also confirms Pirani, Stern and Yafimava's (2009) main conclusions; that the 2006 gas dispute, which damaged so many countries and in a significant fashion was an occurrence that someone from an economical perspective would have avoided at all costs, even though such a move carries some significant economic and political advantages. Lucas (2008) confirms that the 2006 action of doubling the price requested for gas supplies was overly ambitious, given the economical and financial situation in the Ukraine at the time. A political reason was the one behind the start and the continuation of dispute. The Orange revolution ${ }^{39}$, which inaugurated the rise to power of Victor Yushcenko, who is still popular for his pro-Western visions ${ }^{40}$, had apparently slowed

\footnotetext{
${ }^{39}$ Similar revolutions occurred also in Georgia and Kyrgyzstan. For Russian leaders, all these represent a security threat given the danger that Islamist governments could be installed especially in Georgia and Kyrgyzstan (Oliker et al 2009, 101).

${ }^{40}$ Yushcenko's election was particularly controversial, in that after strong allegations of voting irregularities against his main political rival, Viktor Yanukovych, a revolution, called the Orange revolution,
} 
down Russia's dream to regain control over the ex-Soviet territories, seeing that Ukraine was moving further away from the Russian influence to move closer to that of Europe (Shaffer 2009, 42). "Punishing" Ukraine for allowing a pro-Western regime ${ }^{41}$ to take power by doubling the gas price has been interpreted as an evidence of the Russian will to extend its control over at least the Ukrainian economy and its transportation system (Lucas 2008, 168; Bindi 2010, 134).

Several political scientists, as shown above, have tried to reconstruct Russian preferences, suggesting what the main drivers of Russian energy policy are. However, how do we exploit this knowledge and how can we model it to have a better understanding of the dynamics that define the outcome of these bargaining situations? Are there political bargaining models which can model these political crises? The answers to these questions will be discussed in the next section.

\subsection{Modeling gas disputes}

Political bargaining theory has evolved to the point where several different theories have been adopted and accepted in the academic world. Among these are 'proto models' like utility models and critical risk models. However, probably due to its dominance in the field of economics, game theory has become the primary political bar-

emerged and new elections were set in motion again to discover that the true winner was indeed Yushcenko (BBC News 2010).

${ }^{41}$ Shaffer $(2009,41-42)$ also maintains that similar observations apply for the case of the Georgia, which Russia has tried to destabilize with its support for South Ossetia for over a decade given its strategic position between Central Asia and the Caucasus. Russia, in fact, benefits from the Central Asian countries inability to export directly to other markets other than Russia by exporting their gas at two or even three times the original price. 
gaining theory. For sake of completeness, a brief review of utility models and critical risk models is offered in this chapter; however, a much larger portion of this work is dedicated to game theory, given its centrality to the main argument here.

\subsection{Utility models}

Snyder and Diesing (1977) present an interesting review of formal models of bargaining. The authors note that these models tend to represent in general the same concept of what bargaining is, but they focus on different aspects to explain the phenomenon being investigated ${ }^{42}$.

Utility models study the distribution of goods among the (usually two) bargaining players. Their interaction is usually represented in a Cartesian plane (see below), where offers that can be placed in the first quadrant represent a gain for both parties (X and $\mathrm{Y}$ ), offers in the second quadrant offer some benefits for player $\mathrm{Y}$, but lead to a worse status quo for player $\mathrm{X}$. The third quadrant is one where both players lose, while the fourth quadrant describes a situation in which the offer accepted benefits player X, but entail losses for player Y. The Cartesian plane can be further restricted by drawing limited areas within which the two parties can reach an agreement. These areas may or may not be centered on the origin (where there is no agreement) or have particular shape which potentially leads to more benefits/losses for one party rather than the other one.

\footnotetext{
${ }^{42}$ See page 33.
} 
Figure 2.4

Cartesian plane in utility models.

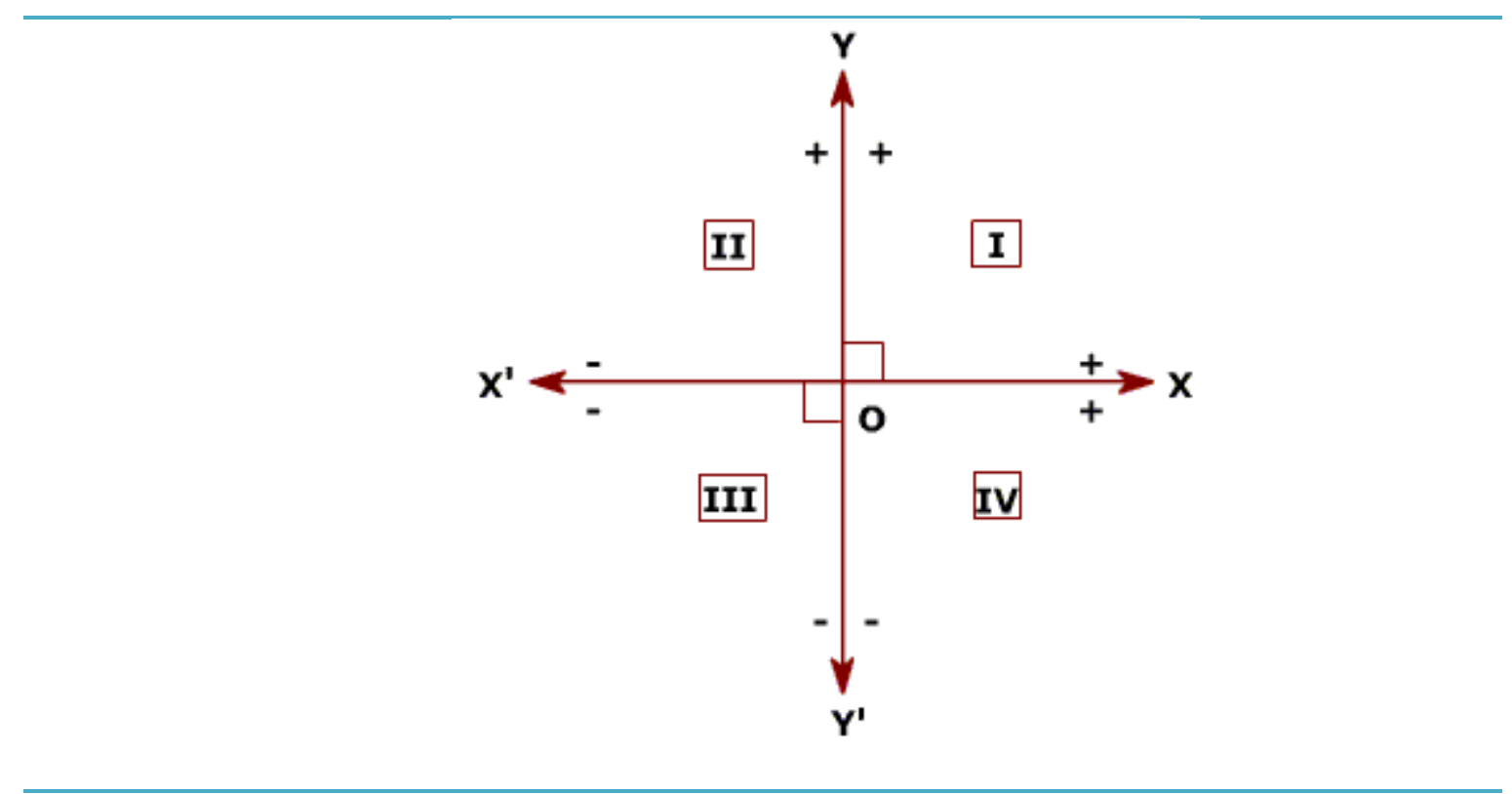

\section{Source: $\underline{\text { http: }}$ //content.tutorvista.com}

Utility models can be mixed with strategic models (game theoretical approaches) by identifying subareas where cooperation or defection occurs. Such models as the Prisoner's dilemma (described below) can be modeled also by utility models; CC (Cooperation of player A and Cooperation of player B) for example, will therefore be located in the subarea in the first quadrant, where both players improve their situation by finding an agreement in this area, while DD (Defection of player A and Defection of player B) will label the subarea that belongs to the third quadrant.

\subsection{Critical Risk Models}

This model was developed to study coercion and persuasion and differs especially from game theory for its use of cardinal utility values and exact likelihood statements (Snyder and Diesing 1977). It follows that each player makes probabilistic guesses of 
what the other player's strategy is, instead of deciding that the other player is going to take a specific course of action, given the individual's structure of pay-offs and the strategies available. Moreover, unlike other models, critical risk models do not assume that each player knows the other player's payoffs; nonetheless, a player can make rough estimates of these payoffs, which this theory further assumes to be vulnerable to bargaining tactics. The outcome of the bargaining depends on how high the maximum risk a player is willing to take before deciding to cooperate; if this limit is set much lower than the expected likelihood that the other player is going to cooperate, given its reputation or its credibility, then the former will cooperate. If the maximum risk is set higher than the credibility/commitment of the other player, then no cooperation will occur. Clearly, the assessment of the other player's credibility is based on the same individual's estimates, which could bias the estimation and make it unreal. However, players have at their disposal several sources of information like ideology, personality profiles, economy, intercepted communications (Snyder and Diesing 1977, 51) which they can use to better approximate their estimates to the true value.

\subsection{Game theory}

A majority of the literature covering the topic of bargaining derives from the field of economics, but given the nature of the problems dealt with in many political disputes, it is applicable to political science and energy disputes. Strategic interactions occur at any level in a society, and in order to study these social interactions one needs a theory: game theory is one of the more prominent. Brams (1975), Ordeshook (1986), Brams and Kilgour (1988), Dixit and Nalebuff (1991), Rumelt, Schendel and Teece 
(1994), Morrow (1994), McCarty and Meirowitz (2007), Dixit, Skeath, Reiley (2009) provide a deep analysis of the use of strategy and formal modeling in political science and the main issues that follow. Game theory started becoming popular in 1943 with the publication of Von Neumann and Morgenstern's Theory of Games and Economic Behavior, even though some works had already started as early as the 1920s (Morrow 1994, 2). After the Second World War, game theory quickly developed into a field in which its mathematics and its applications also prospered due to the flow of resources dedicated to social sciences. The theory evolved from simple two-person, zero sum games to n-person games with complex assumptions, and with one or more rationality assumptions relaxed ${ }^{43}$.

Game theory is the model that is without any doubt among the most commonly used in political science to analyze strategic interactions. As its name suggests, game theory views the behavior of the participants in ways analogous to a game in order to understand the most likely result of the interaction between the players. A game can be defined as a situation in which the behavior of the parties determines the "pay-offs" of their interaction (Bennet 1995; McCarty and Meirowitz 2007).

The behavior that is being studied can be defined by the number of the players involved, the rules used in the game, the "pay-offs" and their structure, the outcomes and the strategies involved to win the game. In each game, the players do not have complete control and their decisions rely on the other players' actions (Dixit and Nalebuff 1991; Dixit, Skeath and Reiley 2009; Myerson 1994).

\footnotetext{
${ }^{43}$ The assumption of complete information has been relaxed and has been dealt with by signaling games, in which communication play a pivotal role in reaching an agreement (Dixit, Skeath, and Reiley (2009, 317-318; Morrow 1994, 237).
} 
Games are usually characterized by the presence of at least two players, who interact with each other in two (or more) possible ways. Players can be single individuals, or larger groups that operate as a single entity: game theory assumes then that the preferences of the members belonging to the larger group can be properly aggregated, thus assuming first that it is possible to do so $^{44}$, and therefore that the internal preferences can be well-represented in such a manner (Shubik 1982, Rumelt, Schendel and Teece 1994; McCarty and Meirowitz 2007). Players have at their disposal specific resources, the opportunity to choose among a predefined set of actions, the possibility to communicate their actions and probable collaborations, and a set of preferences they can use to select the best strategy (Shubik 1982, 16). The players can in fact participate in some games in which the players take an action which is then followed by the other players' actions and thereby what others have done already, a sequential game. The decisions of the players occur in a social context, other times called the "structure". The structure defines the choices that the players have, how their choices are followed by the outcomes, and how the players judge the outcomes (Morrow 1994, 1). In all games, players are assumed to have well-defined goals while choosing within specific limits among the possible actions (Shubik 1982, 16).

A second type of game is one in which players make their move ignoring what the others have done, but being aware that the game is also played by other players who know in turn that they are not alone in the game. Playing a specific game does not mean

\footnotetext{
${ }^{44}$ In reality, it is often impossible to aggregate the preferences of the single members in one function. The evidence of such a statement is more evident when one tries to reconstruct the preferences of entire states or communities (Shubik 1982,18). The voters paradox illustrated the probable case in which three players, with specific sets of preferences may never reach an agreement as to what their preference as a group is (Shubik 1982, 109). A caveat to this problem has to do with reconstructing the preference of the leader of the country or the community being studied.
} 
that features of the other kind of game are automatically excluded. There are in fact games among two or more players that share features of both games (Dixit and Nalebuff 1991; Dixit, Skeath and Reiley 2009; McCarty and Meirowitz 2007). In soccer, for example, players alternate their moves, a sequential game, but they also have to make moves for example, preparing the line of defense or constructing a sequence of scoring moves without the intervention of the other players. This is accomplished often without knowing exactly how the other team is organizing itself or is adjusting to the new situation.

Dixit and Nalebuff, in particular, point out that in sequential games every action is followed by a reaction ${ }^{45}$, which implies that when a game has started, then a reaction should be expected and be accounted for before taking an action. Playing a static game or participating in a conflict or dispute involves taking actions that must account for the possible reaction that the counterpart may take and minimize its effects. Meanwhile, this is done considering what the other player might do so in return (Rumelt, Schendel and Teece 1994; Ordeshook 1986). Being firm on a decision may bring benefits on the one hand ${ }^{46}$. On the other hand it can also be the reason for the inability of finding an agreement even though a reasonable counteroffer was made ${ }^{47}$. Acting first is not the factor that always leads to a successful outcome for the initiator (Dixit and Nalebuff 1991, 10), and unpredictability, culture, pride, and different rationalities are important variables that significantly change each game's outcome (26).

\footnotetext{
${ }^{45}$ See 'To Lead or Not to Lead' (Dixit and Nalebuff 1991, 10-11).

${ }^{46}$ For example, by signaling the other player that offers not in the acceptance range will be firmly rejected.

${ }^{47}$ See De Gaulle's case (Dixit and Nalebuff 1991, 14-16).
} 
In order to better understand the nature of game theory, one imagines a typical game, similar to those found in the literature, where two players are involved and where one player (player B) has to decide between spending resources on defense or saving them and risking being attacked and defeated by the potential invader (player A).

In such a situation (game), the attacker (player A) has two options. If he does not attack, his payoff will be zero (nothing occurs); if he does attack, two scenarios are possible:

1. Player B is unprepared and the player A's attack is successful. A large positive payoff is attributed to player A, since he/she has obtained the sum desired, and a negative payoff is attributed to player $\mathrm{B}$, because of the substantial loss;

2. Player B has mounted a defense that can repel player A. A large negative payoff is attributed to player A, since he/she has lost the army for no gain, and a negative payoff is attributed to player B, but of smaller entity, because an expensive defense system was put in place which, however, has led to a victory over the invader.

If Player A does not attack, costs for Player B are assumed to be equal. A justification for this could rely on the fact that if Player A does not attack and Player B defends, Player B will have to face the costs for having employed a useless defense and justifying a useless expenditure to the public. If it does not defend, player B might have to pay the same amount of costs in terms of internal instability due to the absence of any defense with the possibility of an external threat. See Figure $2.5^{48}$.

\footnotetext{
${ }^{48}$ In game theory two types of representations can be used. The strategic form is the one used for this example, while the extensive form is the one in which each possible move is represented so as to entirely reproduce the whole game starting from the initial, triggering event and moving on to the very last deci-
} 
Figure 2.5

\section{Example of a game.}

\section{Player A}

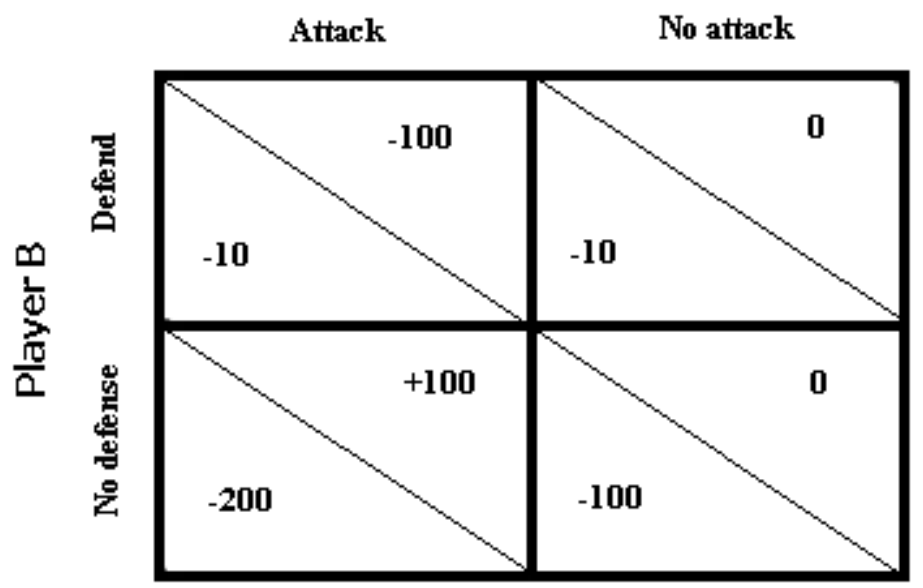

Considering the model illustrated in Figure 2.5, one can see that Player B has a dominant strategy, that is, it is always convenient for him/her to defend. In fact, in case Player A decides not to attack, Player B will still prefer to defend (payoff=-200). However, should Player A attack, Player B would minimize the negative pay-off by having in place defending troops. One can therefore expect that Player B will spend resources to defend, regardless of whether Player A will attack or not. Should Player A realize that Player B has a dominant strategy, he/she might choose not to attack, in order to avoid the consequences associated with an unsuccessful attack. Even if Player A is the first to move in this game, the outcome of the game does not change, given that one is assuming that the players profit from ideal information of pay-offs and the available options. In fact, in deciding what to do, Player A knows that Player B has a dominant strategy, which is defending and will minimize his losses by not attacking. Once again, 
the game reaches the same solution: Player A does not attack and Player B defends. The game is not likely to depart from this equilibrium for if Player A decides to attack, it will incur a lower pay-off because Player B will be already defending and it will successfully repel the attack. If Player B decides to leave the equilibrium by not defending, it will do so at the cost of a lower pay-off (due to having to justify lack of defense in a very unstable conjuncture) and at the expense of giving the other player the opportunity to attack at an unexpected moment, achieving a higher pay-off while inflicting a much lower pay-off to the defenseless Player B.

The game just described is a basic rendition, but it helps to understand the usefulness of such an approach in order to foresee the most likely outcome of the game. As said above, there are many different kinds of games, and they can be defined by the rules used in the game, the payoffs and their structure, the outcomes and the strategies involved to win the game. The game discussed most often in the literature is that of the Prisoner's dilemma, in which both players have a dominant strategy ${ }^{49}$, This, however, leads to a sub-optimal solution of the game since both players, not knowing the actions of the other party, will solely base their strategies on the maximization of their payoff (Dixit, Skeath, Reiley 2009, 398; Morrow 1994, 78).

A different outcome, however, can be reached in the case where the amount of the interactions amongst the players are known to be infinite, in which parties are aware that they will establish long-term relationships with the other players (Myerson 1991, 308). In an infinitely repeated game, there are an infinite number of rounds during which players make new decisions given the new information they have acquired in the bargaining process. Since in this kind of game the players know that their move is not

\footnotetext{
49 Thus differing from the one reported here, where only one player has a dominant strategy.
} 
going to be the only one (or the last one), they are aware of the consequences of their actions, and they know that the other players will react to the strategies. Thus, players of repeated games are relatively more extreme in behavior, that is more cooperative or less cooperative than they would otherwise be in a simple game (McCarty and Meirowitz 2007, 46; Myerson 1994, 309; McCarty and Meirowitz 2007, 251). In finitely repeated games (Morrow 1994, 100), players know that at the last round, the 10th, cooperation would achieve unfavorable results in terms of convincing the other party to cooperate, opting for defection. Similarly, the two players would choose not to cooperate once again, knowing that the other player is not willing to cooperate in the 10th round. Both players will not only defect in the 9th round, but also in all the previous rounds for the same reason: defection is the dominant strategy, given that during the following round generosity would not induce cooperation (McCarty and Meirowitz 2007).

A different result is obtained in infinitely-repeated games. As said above, the inability to determine when the game will finish will render the payoff, which can be obtained through cooperation, an interesting incentive for the players to cooperate. If players adopt the so-called "tit-for-tat" strategy, according to which a player starts out with a less aggressive move and then mirrors the other player's move in the following rounds (Myerson 1994, 325), what results is that both players end up cooperating in all rounds and therefore possibly maximizing their individual pay-offs. This solution represents an equilibrium in that if one player decides to become more aggressive and chooses not to cooperate, then the other player will retaliate by not cooperating as well, preventing the other player from gaining due to their refusal to cooperate. "Tit-for-tat" is therefore a strategy that punishes the non-cooperative player, because once this strategy is enacted, it is followed by lower payoffs which do not justify engaging in more aggressive prac- 
tices (Myerson 1994, 326). A different outcome for the Prisoner's dilemma can also be obtained by allowing the two players to communicate among themselves and, if they deem it necessary, signing contracts that bind them to specific courses of actions. In contract-signing games, players are shown to receive more than the Minmax value (Myerson 1994, 329), which is the value they would obtain by following a mixed strategy (Myerson 1994, 329).

Another classical symmetric game ${ }^{50}$ is chicken, traditionally represented by two teenagers that challenge each other in a test of manhood, in which both of them are driving at full speed towards each other. The winner is the one that does not swerve. Being the winner in this game is certainly the best outcome, but if at least one player does not swerve, both players die and victory is not achieved. Such an unstable game has been shown to have two equilibriums, characterized by one player choosing a different strategy from the other player's (Brams 1975, 39; Brams and Kilgour 1988, 40-42; Morrow 1994; Shubik 1982).

According to Snyder and Diesing (1977) there are two more games, out of the possible $782 \times 2$ games, that are particularly interesting given the presence of conflict between players $^{51}$. The authors define these four models as the archetypes among $2 \times 2$ games (42). Usually, these symmetric games are based upon an ordinal ranking between

\footnotetext{
${ }^{50}$ Mixed strategies are (pure) strategies to which are assigned specific probabilities. For example, a pure strategy is a strategy that is played with a $100 \%$ probability, while mixed strategies are played with a probability that is less than 100\% (Morrow 1994). Symmetric games are those whose have the same ordinal structure for all players. Asymmetric games like Called Bluff, Bully, Big Bully and Protector have payoff structure that differ from player to player (Diesing and Snyder 1977, 46; Dixit, Skeath, Reiley 2009, 214; Brams 1975, 17).

${ }^{51}$ In another game that the authors present, Deadlock, both players prefer defection rather than cooperation.
} 
preferences: for games like the Prisoner's dilemma, for example, preferences are ordered as follows (see Figure 2.6) (Ordeshook 1986, 13)

Figure 2.6

\section{Distribution of payoffs in a prisoner's dilemma game}

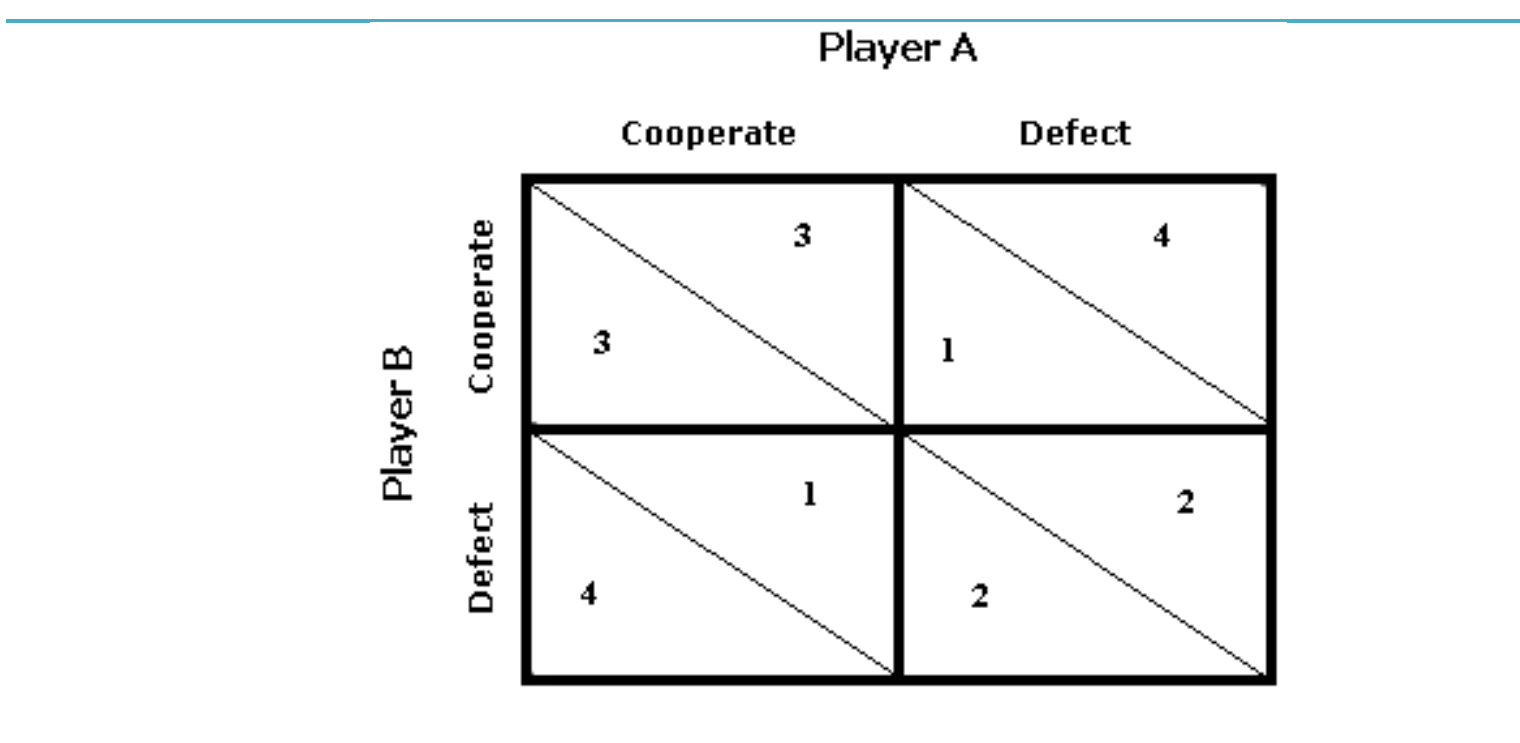

\section{Rapoport and Guyer 1966}

Following the general notation, the distribution of payoffs in a prisoner's dilemma is ordered in such a manner that:

$$
\mathbf{T}(4)>\mathbf{R}(3)>\mathbf{P}(2)>\mathbf{S}(1)
$$

where T, R, P, and S represent the two players' payoffs which are distributed as shown in Figure 2.7. 
Figure 2.7

\section{General distribution of payoffs in $2 \times 2$ games}

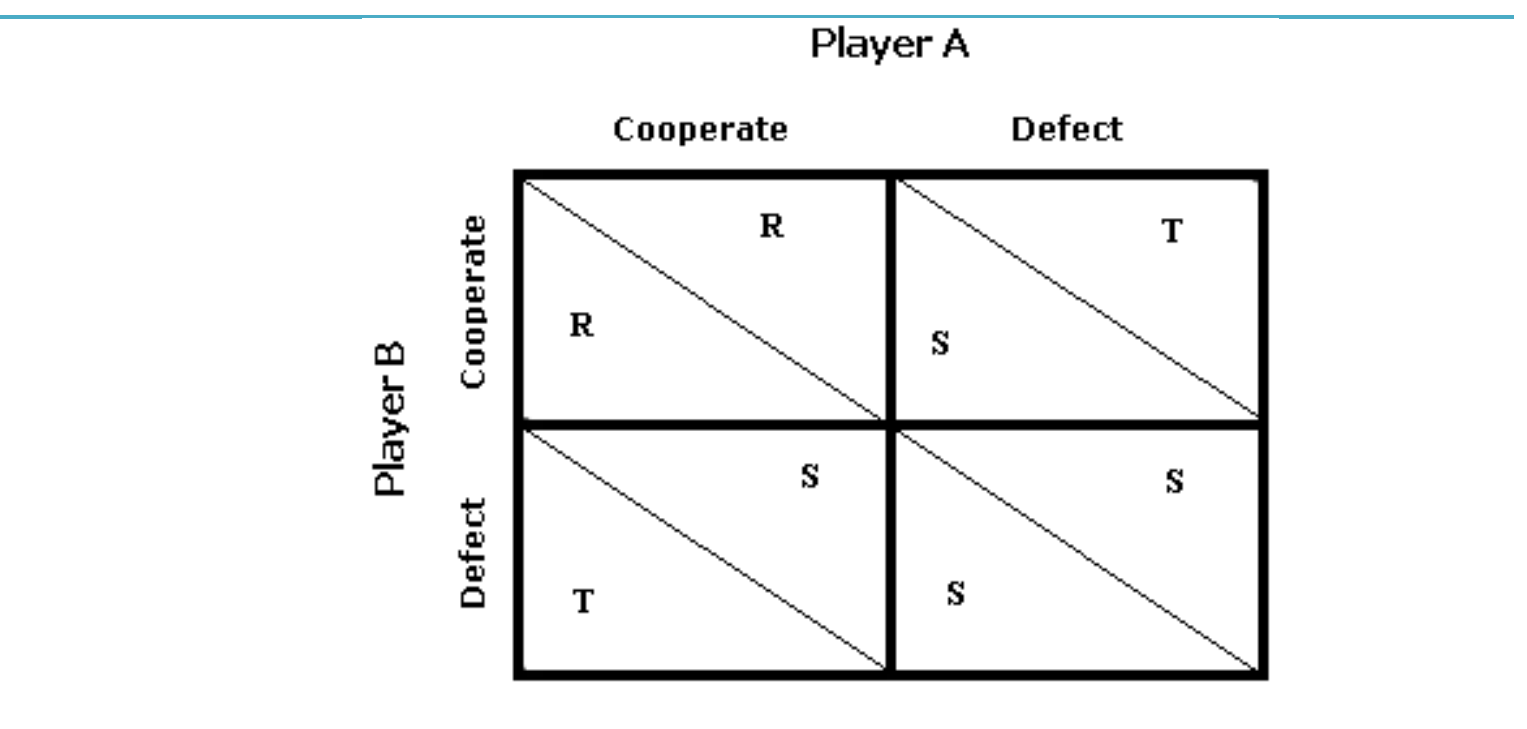

\section{Rapoport and Guyer 1966}

Chicken games, as explained above, have a direct clash of interests and are based on a preference ranking in which

\section{$\mathbf{T}>\mathbf{R}>\mathbf{S}>\mathbf{P}$}

Snyder and Diesing (1977), drawing on Rapoport and Guyer's (1966) work, identify two other important games, the Hero game and the Leader game. In these two games, the opposition of interests is less complete and for this reason they are defined by the authors as alliance games. Hero and Leader, in fact, may lead to cooperation even though one of the players uses coercion (p. 45), because for the other player it is still convenient in terms of high-payoffs (p. 3) to cooperate, even if that occurs in the face of defection. In these two games, players must struggle over how to cooperate; however, if both of them struggle, the situation returns to the point in which both defect. More specifically, Hero is based on the payoff structure

\section{$\mathbf{T}>\mathbf{S}>\mathbf{P}>\mathbf{R}$}

while Leader follows the payoff order 


\section{$\mathbf{T}>\mathbf{S}>\mathbf{R}>\mathbf{P}$.}

Other games employ mixed strategies ${ }^{52}$, characterized by the lack of the Nash equilibrium $^{53}$, that is a solution from which there are no players that want to depart by making a unilateral move. Assume, for example, that the pay-off for not defending and Player A is not attacking is zero. There would not be a dominant strategy in the game. Therefore the players' best strategy would be to estimate the other player's most probable action so as to then make the successive move to maximize his own pay-off (Morrow 1994, 81; Ordeshook 1986, 133).

Calculating the expected utility for each move is typically the approach employed to solve this kind of game. In fact, by attributing a probability to the event that one player chooses a strategy over another one, the second player is in the position to estimate what his/her strategy is. The key to playing these games are to prevent the other player from understanding what the strategy is that will be played and to choose the strategies that maximize the expected utility. However, the expected utility depends on the probability of one player choosing a certain strategy. If Player A is known to choose a specific strategy more frequently, the expected pay-off of that strategy is automatically reduced. The reason behind this reduction of value is that Player B, knowing this fact will choose in turn another strategy that will counter that player A's strategy, which maximizes his own pay-off. The reasoning of such a game is even more evident for zero-sum games in which the gains of one player are the losses of the others. In fact, if a player possesses a strategy that he or she should prefer because it is more likely to be beneficial, due to the efficiency of that strategy, that player should not opt for such a

\footnotetext{
${ }^{52}$ A review of the games described in the literature is needed in order to understand the value of the contribution of the present work.

${ }^{53}$ Like the one just seen above.
} 
predictable strategy and the other player, knowing the relative advantage of that strategy, will be prepared to counter it with a proper strategy ${ }^{54}$. Following this line of reasoning, it emerges that it is in both players' interests to be as unpredictable as possible, therefore to assure that all options are equally likely to be chosen. As a result, in fact, the other player will be forced to consider all of his un-dominated strategies, rendering him or her indifferent to them. Having more certainty, that is knowing what strategy has a better chance of producing a higher pay-off is actually a weakness for the same player. This will push the other player to counteract with a best reply that has the potential to not only cancel the benefits inherent in the better strategy, but has the potential to impose costs on the predicted player. However, the same line of reasoning on the other side as well, turns the game into a mutual adjustment game that is based on the randomization of moves. In fact, a player must conduct a mixed strategy in order to prevent the other player from anticipating his moves, making him unable to benefit from knowing the other player's strategy. By doing so he is making his actions unpredictable since the goals of mixed strategies are to avoid the other player have the advantage of knowing what is the most likely action that another player will take (Morrow 1994, 87). As shown in the section 2.9 , such a situation closely resembles that of a simplified gas dispute between Russia and Ukraine. In fact, although other similar crises have occurred in the past, Russia is showing its firm intentions of gaining more influence over Ukrainian economy and politics by increasing gas prices and leveraging the Ukrainian debt to consolidate its position. Ukraine, aware of being in a weaker bargaining position, it expects Russia to be consistent with its behavior and to continue with its hard line policy. By

\footnotetext{
${ }^{54}$ It is important here to remember that games are being played in which both players enjoy perfect information (Ordeshook 1986, 120)
} 
having more certainty about Russian strategy, Ukraine counters with a less expectable reaction, that of resisting even at the cost of bringing its own economy to disaster.

According to the Minimax Theorem, for every two-person and zero-sum game with limited strategy sets, there is always a mixed strategy for Player A that guarantees him a total payoff of at least a value $v$, and a total payoff that is at most $v$ for Player B (Shubik 1982; Morrow 1994; Dixit, Skeath, Reiley 2009; Ordeshook 1986, 149-153). According to this theorem the two mixed strategies reach an equilibrium which produces a payoff equal to $v$ and both strategies are at equilibrium as well. The consequence of this theorem is important, in that it states that an equilibrium can be found for every two-person, zero sum game. Moreover, even if there are multiple equilibriums, all of them produce a payoff that is equal for both players and it equals $v$, from which it follows that all players' strategies are in equilibrium with each other. This means that no matter what a player chooses to do, an equilibrium that leads to a payoff equal to $v$ can be found (Morrow 1994, 90).

It is crucial to quickly look at the assumptions of this theory in order to understand the real contribution of this work. Scholars have suggested many critiques that weaken the validity of the game-theoretic assumptions ${ }^{55}$. At the center of those critiques $^{56}$ is the belief that players do not always behave in a utility-maximizing fashion, and thus are never affected by temporary issues or changed environmental conditions (Rumelt, Schendel, Teece 1994, 55).

\footnotetext{
${ }^{55}$ See also Goeree and Holt (2001) for a study of strengths and weaknesses of applying game theory to phenomena that closely resemble political crises.

${ }^{56}$ See for example prospect theory, which claims that there are behaviors, or more general biases that consistently invalidate the predictions and explanations of utility-maximizing theories (Thaler 1980). To know more about prospect theory and other critiques to rational theory, see Simon (1947), Becker (1962), Kahneman and Tverski (1979), Posner (1998), Parisi and Smith (2005), Rumelt, Schendel, Teece (1994), Jervis (1976, 1989), Lebow (1984), Shubik 1982, Kahneman, Slovic, and Tversky (1987), List (2004) and Harrison and Rutström (2009.
} 
In the section that follows, I do not criticize the validity of the rationality assumption. I briefly review it with the intent of reporting how several other authors have dealt with the problem, and, more importantly, because it helps understanding the contribution of the present work under the assumption that rational choice is a reasonable representation of reality. In other words, I review the discussion about the rationality assumption to show that two rational actors like Russia and Ukraine need to account for an evolving environment, which can even have the ability to modify the structure of the pay-off of the political bargaining game that describes it.

\subsection{The Rationality assumption in game theory}

Game theory may prove to be a powerful tool in the hands of decision makers because it can provide insight into what is likely to happen in a wide range of events. Game theory assumes that all the players in the game behave in a rational fashion, that is, they understand what their preferences are and base their decisions on the maximization of their payoffs (Morrow 1994; Bennet 1995, Doron and Sened 2001). According to rational choice theory, choices are made in a rational and individual fashion, which means that it is the maximization of those pay-offs that determines the final result of the social interaction (Dixit, Skeath, Reiley 2009). The participants of a game are not necessarily single individuals; they can be organizations or even states, as long as their preferences are coherent and consistent (Doron and Sened 2001, 20). Rational choice theory further assumes that social agents possess some goals that they try to achieve by knowing what the other actors in the same environment are expected to do. In order for this 
assumption to hold true, three conditions must be met: completeness, transitivity and reflexivity (Doron and Sened 2001).

Completeness refers to the requirement that every player is able to order any pair of possible outcomes and select the pair that is relatively better. Such a condition is based on the assumption that players have enough information to understand that an outcome is to be preferred over another outcome. Also that the value of the outcomes, if complex, can at least be reduced to a meaningful measure that players can refer to in order to preference order the outcomes.

Transitivity assumes that a player that prefers outcome A over B, and prefers B over $\mathrm{C}$, must also prefer A over $\mathrm{C}$. The assumption here is that players are logical actors and are able to correctly identify the differences among all options and therefore transitively rank them in a logical manner. Such an assumption may seem reasonable for a very limited set of outcomes, which can be differentiated among them given wellunderstood and clear features. But when the outcomes are unclear or, in very complex situations which cannot be fully described, then such an assumption becomes untenable. In fact, a real world situation in which two actors are bargaining often results in outcomes that cannot fully be described or that the player does not fully understand and therefore are likely to not be ordered in a logical way as required by the rationality assumption.

Take for example the case in which a player has to decide whether he or she prefers low gas supply prices (A) over maximizing economic independence from foreign control (B), and also it prefers maximizing economic independence from foreign control (B) over the minimization of the chance of being occupied (C). Thaler (1980) describes the player's risk aversion and shows that they do not follow the rationality assumption, 
according to which participants should prefer outcomes whose expected utility is greater, even if improbable. In fact, he shows that what happens often in reality is that parties tend to prefer certain outcomes over probable outcomes, even though the expected utility of the probable outcome is higher. The same, however, does not apply in 'negative situations', where players have been found to prefer probable outcomes, instead of accepting a sure loss of lesser value (reflection effect). Risk aversion thus disappears when it comes to a situation in which the actors have to choose between two prospects that both entail a loss in property, value or any other good.

According to Thaler (1980) and Dixit, Skeath, Reiley (2009), there are situations in which participants have been found not to behave rationally, because the transitivity property does not hold. In fact, that may well be the case for the example cited above, where a player may prefer lower gas supply prices (A) over the maximization of economic independence from foreign control (B), and the maximization of economic independence from foreign control (B) over the minimization of the probability of being occupied $(\mathrm{C})$. The transitivity property would require that $\mathrm{A}$ be preferred over $\mathrm{C}$, but, as Thaler shows, that is not often the case, in that the player may prefer minimizing the chance of occupation over low prices. This particular circularity of preferences ${ }^{57}$, where $\mathrm{A}$ is preferred over $\mathrm{B}, \mathrm{B}$ is preferred over $\mathrm{C}$ and $\mathrm{C}$ over $\mathrm{A}$, which violates the rationality assumption, can then easily occur whenever the circumstances permit the understanding of all unclear scenarios and are therefore fully understood by the player. In fact, the player may be able to prefer low gas prices over an infinite period of time, given the actual value that it has at the expense of conceding the other player some access to its economic structures. The same player may also prefer to maximize economic indepen-

\footnotetext{
${ }^{57}$ Similarly as presented in the discussion about the Arrow's Paradox (Arrow 2008)
} 
dence because he or she believes that it is more valuable than reducing to its minimum the probability of being invaded by complying with the opponent's requests. However, the player may judge that the economic value of being guaranteed an infinite gas supply for a lower value may be of less value if compared to the minimization of the possibility of being occupied by not complying, since after all, an economic advantage, even if over the long term, cannot be preferred over the chance of losing both economic and political independence. Such a chain of preferences, even though realistic, is a direct violation of the transitivity assumption, upon which the rationality criterion is based upon. As shown above, such a violation is likely to occur when the outcomes being ordered are very complex situations, where not only numbers and quantifiable entities are compared to each other, but also perceptions, risk assessments, and influence of prejudices.

Reflexivity refers to the requirement that every possible outcome be weakly preferred to itself. This means that an outcome may be judged by a participant as equivalent as or of lesser value than the same outcome itself (Doron and Sened 2001, 22).

Rational choice has been widely misunderstood by scholars for its alleged attempt to explain human cognitive processesand its focus on players' preferences over outcomes where rational choice theory studies choices given their preferences (Morrow $1994,21)$. Other critics have claimed that rational choice is not useful due to the existence of well-documented behavior that go against the preditions of this theory. But as Morrow (1994) explains, this is just part of what one should expect from a utility function which encompasses different attitudes (for example risk aversion), even though they share at least one important characteristic: all parties try to maximize benefits from their interaction with the other players. In addition, Morrow argues, actors can make mistakes and make choices that lead to sub-optimal results because in many interac- 
tions, risk is a part of the game, information is limited, and actors may not be fully aware of the consequences of their actions (Brams 1975, 8-9; Morrow 1994, 21).

Rational choice theory has also been criticized because it is of rarely of practical use in real policy-making decisions (Walt 1999), and for the lack of consideration of more concrete elements, such as communication among players, that would render the game or the bargaining process more comprehensible (Geva and Mintz 1997). One critique is that interactions between actors in a given environment might be defined not only in terms of preferences over strategies, but also in communicative terms, stressing the importance of information, or lack thereof (Geva and Mintz). Incomplete information partially deletes all rational-choice projections toward a more favorable explanation of political affairs because the impossibility of having impeccable environmental information regarding other actors' behaviors minimizes the ability to analyze political games using this framework. Geva and Mintz discuss both strengths and weaknesses of rational choice theory and through the use of mathematic models show the appropriateness of a rational-choice approach as the main strength of the theory. Moreover, as with any quantitative approach, the result is precise in the explanation, transparent and reproducible. According to the authors, the main weaknesses are repetitiveness, loss of generalization (since the models are designed to more favorably coincide with the specific situation analyzed, and distance with the real world, due to the oversimplifications assumed by the model (Geva and Mintz 1997). As Morrow $(1994,1)$ points out, the only thing game theory does (and therefore the rationality assumption) is to predict what behavior should be expected given the assumptions of the theory and it does not tell much about whether game theory is an accurate description of the reality. 
Another benefit of using a rational choice approach is its flexibility (Geva and Alex Mintz 1997; Martin 1999). Flexibility is provided by the use of mathematical models such as game theory (Geva and Alex Mintz 1997), and the pliable possibility of building transversal bridges and trans-paradigmatic connections among different political models or schools (Martin 1999). It is used as well as to facilitate connections among macro-level and micro-level approaches (Geva and Alex Mintz 1997). Martin (1999) defends the ability of rational choice to analyze the micro foundations of political phenomena, but she criticizes its ability to explain details. This hinders the ability of the political scientist to generalize from each case and to understand the broader picture of the phenomenon.

Formal modeling helps to determine empirical regularities, and promotes reproducibility, transparency, originality, and empirical validity. Rational choice focuses on players as the main political actors, while simultaneously taking into account the environment where they act by defining a set of strategies and outcomes that well represent the environment in which the political bargaining takes place (Lake and Powell 1997). According to Lake and Powell, rational-choice has offered an original solution to the anarchy dilemma which is a milestone for neo-realists and neo-liberals who define anarchy as an absence of central authority (Keohane and Nye 1977; Axelrod and Keohane 1985). They observe that the presence of formal institutions, governments and territorial powers develops a formal authority at the domestic level whereas all of these features are absent in the international system where states have no formal constraints and operate in an environment in which commitments are not enforced. Rational-choice theorists solve this problem observing that strategic interactions take place everywhere; in the international arena and the domestic arena. At any level, actors use similar strate- 
gies which then nullify the traditional distinction between domestic formal institutions and international absence of them (Lake and Powell 1997).

In sum, game theory is based on the rational choice assumption following which players try to gain as much as they can from the situation they are involved in. The social events in which the players participate are called games. As already mentioned above, they are characterized by the existence of a set of rules, a range of possible outcomes, the probabilities and the pay-offs assigned to each outcome and the sequences of actions that lead to specific outcomes that can be defined as strategies. All games are played between at least two or more players (Dixit and Nalebuff 1991; Doron and Sened 2001) and reach a Nash equilibrium if no player has an incentive to change strategy, based on the actions and the strategies of the other players. In other words, the players of the game, being fully rational, will immediately or after a certain number of stages, reach a situation in which both will not change their strategy. To change strategy would entail gaining a lower pay-off which would violate the rationality assumption according to which social actors are utility-maximizing.

Political scientists mainly use two models to explain social bargaining situations: cooperative and non-cooperative game theory (Dixit; Nalebuff, 25). In cooperative games, all outcomes that are found inside a specific set of outcomes called core are situations that cannot be dominated by any other outcome (Shubik 1982, 145; Ordeshook 1986, 340). Players can reach binding agreements throughout the game during which they are able to communicate among themselves (Morrow 1994, 75). Following this, only the outcomes in the core will survive and all are likely to be stable solutions since by definition a better solution cannot be found for all players. A weakness of the cooperative model is that it is based on the assumption that the communication among play- 
ers is costless and that there are precise authorities that can enforce the agreements reached by the players (Doron and Sened 2001, 24). Arguably at the international level, there are no relevant enforcers for the agreements and therefore non-cooperative game theory may be a better choice to explain complex bargaining events. Non-cooperative bargaining theory focuses more on the strategic behavior of single players without making any assumptions of the existence of cores and in which a pay-off is connected to each specific choice of strategies for all the players of the game. Binding agreements cannot be made while communications among players may or may not be allowed because players define their own strategies ${ }^{58}$, even though traditionally communication is not allowed in non-cooperative games (Morrow 1994, 76). This theory also helps political scientists to predict the expected outcome of very complex bargaining processes and to analyze the strategic choices of the players.

In non-cooperative games each player chooses a specific strategy out of the available strategies with the intent of maximizing his or her pay-off. This pay-off is the result of the interaction of each player with the other players, the expectation of their strategies and the lack of knowledge of what the other players have agreed upon (Doron and Sened 2001, 25). It is worth noting that the main difference with cooperative games is that players in non-cooperative games develop decisions that are independent from the other players' and without the ability to define a core in which the players know that a possible agreement is present. For non-cooperative games the solution is found by looking for a Nash Equilibrium, which Donon and Sened $(2001,25)$ define as a situation in which no players can unilaterally gain more than what they currently hold by unilaterally changing their strategy, given the strategies that the other players have already

\footnotetext{
${ }^{58}$ See Morrow 1994, 75.
} 
chosen. Given the circumstances, it is in no players' interest to change the situation and for that reason the game stalls where it would be unfavorable for a single player to unilaterally adopt a different strategy resulting in a lower pay-off.

A Nash Equilibrium does not necessarily pertain to a positive situation. In fact, two players may find themselves locked in a situation in which both could gain higher pay-offs, for example in the well-known Prisoner's dilemma, in which both players have a dominant strategy resulting in a lower-than-optimal benefit. This particular game is often used in politics to describe domestic and international conflict and to illustrate why individuals may not achieve cooperation (Donon and Sened 2001, 26). In the simplified dispute I describe in section 2.9 to describe the relevance of an evolving environment, two are the possible Nash Equilibria: in both one player chooses a different strategy from the other player's (Morrow 1994; Shubik 1982).

As said above, in the present work I will not criticize the rationality assumption and I will not add to its limitations. Reviewing the basic tenets of the Rational Choice theory and its main weaknesses, however, contributes to a better understanding of the addition of the present work to the existing game theory literature. Other authors have already made efforts pointing out flaws and the limits of the rationality assumption. Here I want to argue that, in addition to the critiques made by others, game theory might be constrained also by its lack of consideration of an evolving environment. This was clearly the case in the 2006 Ukrainian crisis, which quickly ended especially thanks to the European customers' intervention and prompt reaction to the disruption of supplies (Nichol, Woehrel and Bernard 2006; Yhiah 2008). 


\subsection{Advantages and disadvantages of rational choice theory}

Despite their applicability for real world problems, non-cooperative bargaining processes have often been criticized for the leeway political scientists possess in defining the pay-offs linked to each strategy adopted by the players. Such flexibility is vital for the definition of this kind of game because the structure of the pay-offs can heavily affect the problem. Moreover, given the nature of the conceptual framework, some have also argued that the analysis of a political bargaining affair may result in an oversimplification of a problem which in reality is more complex than represented by the model. The arbitrariness of the political scientist in deciding the overall structure of the model is also relevant in identifying the bargaining problem as a prisoner's dilemma or as a game of chicken; the conclusions drawn by the selection of either model can significantly change.

Such an assumption can severely constrain the usefulness of these models, because not all participants are likely to follow the same mindset. One must ponder actors who make their decisions in order not to maximize utility (viewed here in terms of financial resources), but to maintain an internal status quo (religious or social). In this case, we are dealing with "non-monetized" utilities, which, however, cannot be reliably and consistently measured due to their particular nature.

Assuming that the other players' reasoning coincides with that of Western countries, mirror-imaging one's mindset is probably the major issue that decision makers have to confront. Mirror-imaging can also lead strategists to think that all actors perceive the game in the same way. One can consider, for example, all instances where one group perceives a situation as that of defeat; while the other party perceives it as a victo- 
ry (US troops that kill thousands of terrorists believe that they are the winner. As is the same for terrorists who perceive themselves as winners by killing few US marines, even if at the cost of thousands of men) (Dixit and Nalebuff 1991).

Another limitation of game theory is the simplicity of its models. Although game theory can be useful to better understand the dynamics underlying a particular game, it can be useless or even dangerous, to reduce a very complex situation to a Prisoners' dilemma or Chicken (Bennet 1995).

Negotiations, like the ones that occur in price disputes between Russia and Ukraine, are particular games that take place under specific rules, and in which 'time is money' (Bennet 1995, 45). In fact, as time passes the conditions under which the negotiation is taking place change so as to make on some occasions the game end. In a hypothetical case, Russia halts the supply of gas to Ukraine and decides not to accept counteroffers from Ukraine regarding the price of Russian gas being used that does not equal its first request Both actors lose something from their failure to reach an agreement. Russia, in fact, loses revenues from the lack of sales to Ukraine and is potentially contractually vulnerable to pay for the damages inflicted on the Ukrainian economy. On the other side, Ukraine also loses (much more than Russia at the beginning), because the unexpected cut of the supply cripples its economy, potentially harming its infrastructure and even its population. In fact, if the cut off of supplies occurs in winter, that may damage the pipelines due to a potential freeze, increase their costs for repair and maintenance. In addition, dire consequences may result such as the suffering and deaths of civilians who do not expect the sudden halt to gas flow. In this particular negotiation then, large costs are immediately translated by one of the parties involved, while the in- 
creasingly larger costs are placed upon the other party, where serious consequences will be dealt with at a later time ${ }^{59}$.

The disputed final price can change by simple ways, if one assumes that its reduction occurs at equal rates in the chosen time unit. For example, one can assume that with every passing day without an agreement that satisfies both parties, following which the gas supply is resumed, a large cost is inflicted upon Ukraine in terms of sudden interruption of energy in the country and the lack of other energy sources given the unexpected event. However, as time passes, Ukraine may find means to remedy the situation, shifting the burden to the other player which was done by redirecting the gas that was supposed to be delivered to Europe to its own needs.

One can think of such a relationship as a linear function in which time is on the $\mathrm{x}$-axis and the total costs of not accepting the other player's requests on the $\mathrm{y}$-axis. In this context, the initial cost is much greater for Ukraine (sudden interruption of gas flow), and much smaller (close to zero) for Russia, assuming that Russia has taken every proper step towards the interruption of the gas supply in order to minimize its impact on its own infrastructure and its economy. However, such an interruption will be more costly as time progresses in that the expensive pipeline system needs not only to be maintained and repaired, but it is also costly in terms of revenues lost by the coercive strategy that was adopted.

In game strategy, the number of players is vital to understanding the likely outcome of the interaction among the players because they significantly change the balance and the rules of the game. The importance of this statement can be understood

\footnotetext{
${ }^{59}$ Such a situation reflects the Ukrainian need of a strategy of developing alternative energy sources or a strategy of energy supply diversification.
} 
representing the interaction among the actors using a game tree, where one starts at the first node, at which a player finds him or herself at a specific situation in which they have to decide whether a determined strategy will be followed or not. According to the specific chosen strategy, the other player may decide to follow a specific course of action among potential strategies, to which the first player can reply with a set of possible actions and so on. Game trees are very useful because if one knows in advance the number of interactions among the players, one can reason and determine the optimal way to approach the bargaining ${ }^{60}$. There are some games that end after a finite number of steps and are complex due to the number of players and possible moves or strategies so that the solution of the game is not within reach of easy calculation. In complex games, players construct a smaller game tree consisting of fewer interactions with the intent of devising a strategy that leads to a relative improvement of the current situation. These games are usually approached by reconstructing the whole game tree and starting from the desired outcome to determine the possible pay-offs associated with and expected for every decision ${ }^{61}$.

\subsection{Can today's game theory explain the outcome of a simplified dis- pute?}

I have shown above that Russia has strong economic and political reasons to exploit to its maximum extent the potential of the gas weapon on those countries that used

\footnotetext{
${ }^{60}$ See Dixit and Nalebuff 1991, 42.

${ }^{61}$ This is what Dixit and Nalebuff refer to as "Think forward and reason back".
} 
to be under the Soviets' influence in order to increase its economic and political presence in the region.

In a simplified game, the two players Russia and Ukraine know that they cannot keep the gas interruption continuing for a long period ${ }^{62}$. On one side there is Russia, who is determined to achieve control over the energy transportation networks, and it is not limited by any strong diplomatic relations with other European countries. On the other side there is Ukraine, which after no more than 1 year would be completely destroyed, with an economy that produces little, no revenues coming from the transportation of gas, and a starving population that is potentially completely exposed to the frigid temperatures of the winter season.

One can view this bargaining context as consisting of several of a finite number of interactions, for the preferences of the leaders (or their representatives) involved in finding an agreement already have in mind the required conditions for agreement. Only offers that are within their acceptance range will be admitted, while other offers will be rejected. The leaders can reschedule other meetings for the purpose of finding additional information, evidence that can improve their bargaining position, or simply to seek domestic support for reaching an agreement that is not strictly within their bargaining range, due to possible side-payments or via issue-linkage. Meetings cannot be assumed to repeat for an infinite amount of times, due to the fact that the reputations of both countries are being damaged, and they require some time to be planned and organized, as well some negotiations in dealing with domestic forces. As seen above, time is li-

\footnotetext{
${ }^{62}$ Howorth (2007) notes that after 1 year the consequences of the gas supplies interruption would backfire also on the Russian economy.
} 
mited, because after about 1 year there will not be any benefits to be shared by both actors.

I believe that, especially if one looks at the 2006 Belarusian dispute, characterized by the firm belief of the smaller country that it had a bargaining advantage in terms of being able to shift the burden of supply reductions to Europe and therefore back to Russia, a Chicken game can describe rather well this type of bargaining situation. As seen previously, Belarus firmly believed in its position. Russia, however, was also strongly motivated by economic consideration to increase gas prices and gain access to the pipeline system. Assuming a symmetric game, that coming to no agreement in the long term will be the least preferable solution for both countries, the distribution of the preferred payoffs can be as described in Figure 2.8.

Figure 2.8

Model representing the Russia-Ukraine dispute.

\section{Player A}

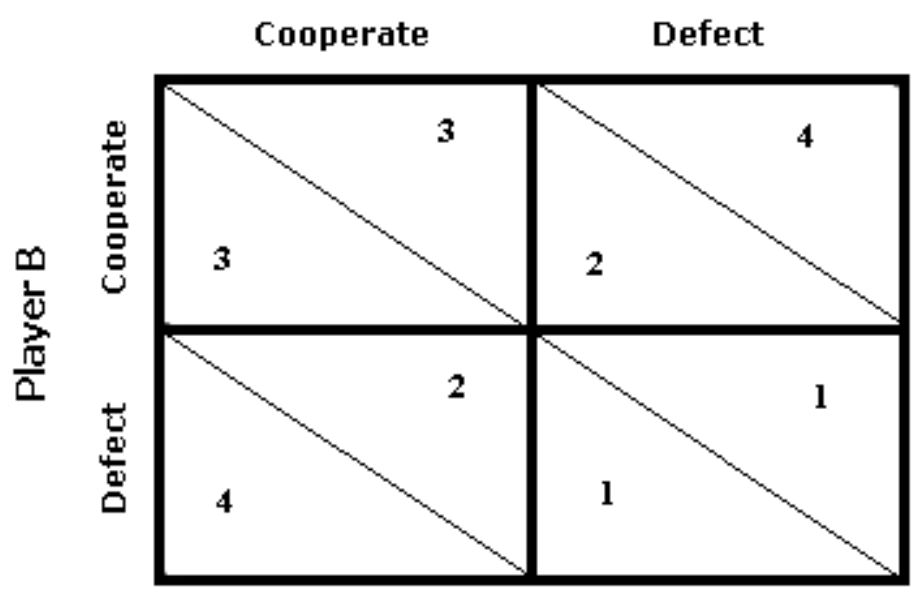


For Russia, the highest payoff is certainly that of defecting, that is not complying with Ukraine's request of keeping the same price and having Ukraine accepts all its demands. A similar situation would apply for Ukraine.

However, unlike a Prisoner's dilemma, the payoff for accepting the requests of the other player is slightly higher than the payoff that corresponds to the situation in which both players decide not to cooperate and reach an agreement. In fact, in this case Ukraine would witness a quick decay of its economy due to lack of supplies, while Russia would lose an important customer, thus losing its grip on both its economic and political structure. The situation in which both players find common ground for their requests represents a quasi-optimal solution in terms of payoff for both players. In fact, having at least some requests accepted by both players represent a better outcome than having to comply with the other's requests only, or suffering long term economic damages due to lack of agreements. This situation, however, is clearly worse than that of having one own's requests accepted by the other player without conceding anything.

This payoff structure matches that of a game of Chicken. In fact,

\section{$\mathbf{T}>\mathbf{R}>\mathbf{S}>\mathbf{P}$}

As said above, the game of Chicken has been shown to have two equilibriums, characterized by one player choosing a different strategy from the other player's (Morrow 1994; Shubik 1982). For games that are played only once, the players cannot choose which equilibrium they should approximately settle on. Bornstein, Budescu, Zamir $(1997,387)$ note that without coordination, mixed strategy chicken games tend to settle on an equilibrium which does not maximize the utility for all the players taken together. 
The authors point out that signaling, that is costless communication outside the game, and/or repetition are two items that allow not only a fairer outcome which is also more Pareto-efficient, but it allows the settlement on one specific Nash equilibrium point (387-388). In the case of Russia and Ukraine, this means that negotiations have to be repeated a specific amount of times in order for the two players to resolve the dispute (McCarty and Meirowitz 2007, 252). Alternatively, or in addition to repetition, players need to signal their resolve or their commitment to one option in order to stabilize a game on a particular outcome.

Other issues must be taken into account when trying to explain why a specific equilibrium was reached (Dixit and Nalebuff 1991, 33-34). First of all, one party may be advantaged because it can replace the service, product, or term of the agreement with a temporary version. Having an opportunity to do better regardless of what the other party does represents a strong bargaining advantage. For example, even though Ukraine can divert some gas that was directed to other countries to make up for its requirement to survive and its economic growth, Russia knows that it can suddenly cut the gas supply that will cause Ukraine to consequentially suffer from large costs. The gas diversion is only a temporary solution and in the long term will cost lost revenues (for the lack of revenues coming from transportation fees) and it costs the loss of customers who will look for a more diversified source for energy ${ }^{63}$. Russia, knowing this, will be more

\footnotetext{
${ }^{63}$ This is actually something that happened, since the recent gas disputes have shown that the political agenda of Russia and its surrounding countries can make the flow of gas to Europe unreliable (Shaffer 2009, 45).
} 
likely to support an agreement that closely reflects the imbalance in the costs that the two parties suffer from not resolving the dispute ${ }^{64}$.

Similar reasoning describes another advantage, using once again the RussiaUkraine dispute. The Russian gas supply disruption damages, in the short term, Ukraine more than its own economy. As said above, it has been assumed that the Russian economy will start being severely damaged by the loss of the revenues of gas sales to Ukraine and Europe after a period of about one year. During the first months, the losses are unlikely to hit the Russian economy too harshly, but expected to do damage by striking violently the Ukrainian economy, causing it to stop its significant production and endangering its population. The disruption of gas, in other words, is seen here as something that both parties know that, especially in the short term, will be more detrimental to one party than the other one. Following Dixit and Nalebuff $(1991,291)$, this will further improve the bargaining position of Russia, and the agreement reached is likely to reflect also this advantage in terms of deviation from an agreement that is moderate between the two requests.

A deviation from the agreement that is balanced between the two extremes represented by the two party preferences is more likely to occur when the party that is less fearful can play a game in which it threatens the other party to keep the dispute open until the demands are met (in this case the party is Russia, given the fact that its economy would significantly suffer from the gas cut only after a significant period). Every day that passes, a total breakdown of the negotiations becomes more and more likely, because of the increasing tensions among the players. If there is a party that can-

\footnotetext{
${ }^{64}$ On this regard, I have assumed that a symmetric game better represents the situation, since for both countries no agreement is the least preferable (ordinal) outcome in the long term.
} 
not afford to have the negotiations collapse and to lose the opportunity to find an agreement that would return the situation to normality, this will expose them to the use of brinkmanship. This is prolonging of the bargaining with the goal that each additional day will improve their position regarding the settlement of the dispute with the other party (Dixit and Nalebuff 1991, 294).

However, in disputes, as well as in militarized conflicts, perceptions do matter. Jervis (1976) notes that a state must often go to extremes because moderation and reconciliation can be taken for weakness. Even though the state may be willing to settle on a dispute that involves some concessions, it may not concede for the fear that the other side will not accept the settlement, but would rather attempt to gain additional benefits. Players, according to Jervis, have an incentive to mask their own willingness to enter the spiral that leads to the destruction of the benefits that the dispute is actually trying to divide between the parties involved. However, if on one side this approach may convince one party to concede, there is a chance that both players will find themselves moving towards mutual destruction. This is the total breakdown of negotiations and a catastrophe for both economies (Jervis 1976, 293). The solution that Jervis offers regarding this kind of situation entails the claim that one side must make an initiative that increases the other side's perception that a mutually beneficial solution can be found. This is accomplished by demonstrating its amicable intentions and a lack of interest in harming the other party. All of this lies in a context that justifies and supports the first state's intentions to respect the other state's legitimacy.

Thus, how the final prize will be divided highly depends on psychological factors, which one can employ to explain why people only apparently behave irrationally and risk the chance of ending up in a situation in which both players lose everything 
they can. In fact, states tend to develop a specific image of one other, and once they do so, ambiguous and even discrepant information will be attached to that image. This mechanism, however, does not apply to the state itself since each state knows that it is following its own preference which is not intended to harm the counterpart, even though they may be perceived to be doing so. However, states often assume that the other states are also fully aware of this. A negative image developed by a state has a strong effect on the stability of the relations between the parties, since they will start an escalation of preventive reactions which will magnify the dispute (Jervis 1976, Lebow 1984). As seen above, threats, like halting the gas flow perpetually, are more likely to work when the other side sees the high costs associated with standing firm. More specifically, this will be the case when the other is risk-averse, has a short-term predominant point of view, is relatively weak or vulnerable and it values the lives and property of its citizens (Jervis 1976). Also according to Jervis, states tend to be unable to deal with random events and to see the behavior of others as more centralized and coordinated than they actually are in an attempt to draw inferences from complex and unrelated events. On the other end, states exaggerate the centrality of their role in others' policies, especially if it is somehow connected to the favorability of that specific outcome. This in turn leads to the consequence of believing that deterrence actually works since a state will tend to select the explanation of why the adversary has not harmed him or her and to believe that random events are not as such, but were the product of the intentions of the other (Jervis 1976, 1989; Brams and Kilgour 1988, 128-129). Thus, Jervis recommends realizing that actors come to harm others more than they mean to because they do not see the degree to which their policies conflict with the other's interests. The problem is further complicated by the fact that the actor usually does not realize that the perceiver tends to con- 
clude that if the actor's behavior has harmed him, that it was purposeful. The actor also assumes that even if he or she has inadvertently damaged the other's interest, the other will realize that this was not the actor's goal, thus failing to comprehend that the other will perceive more hostility (Jervis 1976, 1989).

Thus, perceptions may ruin the game initiated by the party who believes they are in a favorable position, and to use it to reach an agreement that coincides with its own preferences. Such a move is called brinkmanship ${ }^{65}$, and it consists of a set of actions which take the opponent to the "brink" of disaster which forces him or her to exit the situation. The core of this approach relies on the creation of a risk that is substantial enough to change the opponent's mind and make him or her follow the desired line of thought (Dixit and Nalebuff 1991, Lebow 1984).

Brinkmanship is based on three pillars (Dixit and Nalebuff 1991). The first refers to the fact that the threat that creates the risk has to be credible. If one desires the opponent to change his/her mind, one will have to make a threat that is viable enough to represent a danger for the opponent, but that is not too strong to be appropriate for the specific situation. For example, threatening to start a nuclear war only because a state is alleged to have some unimportant documents is not a credible threat. The term brinkmanship is often referred to as one of the strategies employed by the US to solve the Cuban Missile Crisis (Dixit and Nalebuff 1991). In this conflict, the US created a risk of starting a nuclear war should the Russians have failed to comply with American requests. The threat they made was a credible one because the US created a threat that was strong enough to raise the concern of the Russians and was believable. Brinkman-

\footnotetext{
${ }^{65}$ Although brinkmanship and game of chicken are sometimes used as synonyms (Rapoport and Chammah 1966), brinkmanship refers to the move that brings the two players on the edge of disaster, while the game of chicken refers to game with a payoff structure as previously described.
} 
ship relies on a threat that does not imply a certainty of retaliation in the absence of compliance. It is rather based on defining a situation in which repeated violations lead to an increase of the risk of the occurrence of a substantially detrimental event (Dixit and Nalebuff 1991).

This condition does not suffice to make brinkmanship a useful strategy. The very fact that one of the two parties is in full control of the happening of the harmful event (it was up to the US to decide whether to start the war or not), that makes such a threat not credible, since that party might still decide that, despite the repeated violations, it is not worth going to war. It is therefore necessary to devise a way to convince the opponent that there is not going to be consideration of a second option. A common strategy used for this purpose is losing control of the possible actions that may follow noncompliance. In the case of the Cuban Missile Crisis, such a strategy relied on the procedures entrenched in the US naval fleet, which weaken the overall control that President Kennedy had over the operations. In other words, by pointing out that he did not have full control of what would happen due to internal procedures rooted in the Naval fleet that formed the blockade, Kennedy created what Dixit and Nalebuff (1991) defines as a credible "slippery slope", where the two (or more) players might find themselves after some undeterminant time, suddenly plunging "deep in the abyss" of the nuclear war. Repeated violations would have pushed the two parties further and further "down the slope", increasing the chances of war (Allison 1971).

Brinkmanship has been successfully employed to explain US behavior in the Cuban Missile Crisis, the Cold War, and is possibly the strategy that is being used to deal with Iran's nuclear program. The Bush administration created the impression of willingness and ability to push a highly dangerous situation to the limit (war) rather than 
concede and permit Iranians to continue to acquire the technology needed to develop a nuclear weapon (Young 2008). The US made this threat credible by moving many U.S. Navy units into the Persian Gulf and by placing pressure on Iranians about their presence in Iraq. Therefore the US showed themselves focused upon the efforts to stop the Iranian nuclear program and also willing to go to war if that was deemed necessary (Young). However, one has seen that for brinkmanship to produce any effect, it is necessary to let chance play a role or at least lack full control of the final decision of going to war. This element appears to be missing, for the US seems to want to rely more on the pressure it is exerting on Iranians to force them to yield ${ }^{66}$.

In conclusion, the deviation from the mean in the agreement reached in the stylized example of the gas between Russia and Ukraine depends also on the presence of other issues the two countries may be interested in resolving. In other words, the particular agreement of gas prices may be settled by taking into account the fact that one of the two countries may be willing to concede more in terms of gas price for the sake of improving the benefits stemming from arriving at a deal relative to another issue (Dixit and Nalebuff 1991, 295-296). Axelrod and Keohane (1985) talk about 'issue-linkage',

\footnotetext{
${ }^{66}$ As an example of working brinkmanship, one can look at the situation of December 2007 when the National Intelligence Estimate (NIE) on Iran's nuclear program, Iranian hardliners had found grounds to keep supporting their nuclear program and therefore becoming more willing to push the game even further. In the National Intelligence Estimate mentioned above, the U.S. appears to have considered an attack on Iran unlikely in the near future, leading Iran's hardliners to go their way, without concern of possible consequences. Such a situation highlights the main issue related to the use of brinkmanship that limits its usefulness. In fact, if all players do not yield, there is a possibility that the situation becomes uncontrollable, possibly causing a major disaster (in Iran's case, the start of a war and in all likelihood, a new burst of violence in the Middle East). Brinkmanship has been successfully employed in several occasions proving its value at resolving complex international crisis. However, it can be a volatile strategy that might turn out to be lethal for the brinkman itself; this can be especially true if the other party involved in the game is not a rational actor who bases his/her decisions on a different set of values than just utility.
} 
that is the practice of linking together several issues with the intent of improving the overall bargaining position possibly by conceding on one issue to obtain a more favorable payoff from another issue. In the Russia-Ukraine case, the resolution of the gas price dispute could have been resolved by offering to lower the cost of the gas sent to Ukraine for its own use but simultaneously allowing Russia to gain partial control of the pipeline system that transports the gas to Europe, which is exactly what occurred.

Issue-linkage, asymmetries, repetition, signals, perception, and brinkmanship moves are all elements that the literature describes as relevant in order to understand why a specific outcome was the result of the negotiation process. They all assume a constant environment, in which players and their involvement is constant throughout the entire game. However, a changing environment, in which other players (countries or large European institutions) gradually enter the game, played a key role in the 2006 Ukraine-Russia dispute. Current game theory does not deal with such a dynamic environment. However, this becomes a relevant issue only in the case there is empirical evidence that the context changed since the dispute started.

\subsection{Hypotheses}

As stated above, Europe heavily depends on Russia especially in terms of gas supplies which Russia has used to advance its political agenda. The relationship between the Russian government and the state-owned Gazprom makes the distinction between purely economic decisions (which could be assumed by such a large company) and politically-motivated decisions barely discernable. In fact, it is impossible in the Russian case to distinguish when it is politics, rather than economics, that is guiding the 
behavior of the energy giant. Such a statement is especially true for the gas disputes that occurred from 2004 on, where economic decisions to disrupt gas supplies and the political allegations behind these decisions cannot be easily distinguished and weighted.

Given the importance that Russia has as an energy supplier, it is important to understand not only why these crises started, but also especially how these disputes were solved. Game theory provides some useful insights to understand why some disputes were settled much earlier than other. Deviations from the expected outcome of the dispute can be attributed to the particular distribution of pay-offs, and elements like issue-linkage, asymmetries, repetition, signals, perception, and brinkmanship. As seen above, all these elements assume that the environment in which the game takes place is constant during the entire length of the game.

Nonetheless, I argue that the very onset of the dispute changes the nature of the problem, as it was clear in the case of the 2006 Ukraine-Russia dispute. Thus, from a two-actors clash of interests, the gas dispute needs to be treated as a larger problem, where not only the preferences of the two disputing actors need to be examined, but also the larger international arena need to be accounted for. If this is clear in situations where gas disruptions have caused visible damages (the gas disputes examined above all occurred in the coldest months of the year), the fact that the larger environmental context matters is not similarly evident. However, if one finds evidence that gas disputes have an effect on the economy of other countries, one has the evidence that supports our claim that external actors have a non-ideological reason to intervene in the gas dispute and make sure that it ends in the way that least damages the surrounding economies. For these reasons I hypothesize that gas supply crises have an impact on the real GDP growth and the stock market of other economies. Clearly, the longer the effect of these 
crises can be observed on these two economic measures, the more likely is that the political leadership of the surrounding countries will take steps towards helping the gas dispute resolve at a faster pace.

Finding evidence of this sort is important for measuring the impact of political bargaining crises on the oil and gas markets, which in turn I assume to be able to affect the preferences of the actors involved in the dispute because of the diplomatic actions that external actors, damaged by the effects of the crisis, can take to help the crisis resolve.

Thus, I hypothesize that:

1. Gas disputes negatively affect the real GDP and stock markets of energy importing countries like Spain, Sweden, the UK, France, Italy and Germany, Netherlands, Czech Republic, and Poland. These countries are not only net energy importers, which makes them vulnerable to the start of a new dispute, but are also important members of the Council of the European Union, which hold legislative initiative in the EU;

2. Negative effects in the economies of states in the proximate environment will give rise to new actors entering the dispute.

3. The statements and institutions whose significance is studied in the stock market model have a significant and positive relationship with the trends in the stock markets studied in this work. I represent these statements and institutions with what I call 'reaction functions'.

The hypotheses for each specific case study are formally summarized in Table 2.2, Table 2.3 and Table 2.4 . 
Table 2.3

\section{Hypotheses for the Russia-Ukraine case studies}

H1a: There is a significant and negative relationship between the GDP growth and the start of the 2006 dispute.

H1b: There is a significant and negative relationship between the GDP growth and the start of the 2009 dispute.

H2a: There is a significant and negative relationship between the stock market trend and the start of the dispute between Russia and Ukraine in 2006.

$\mathrm{H} 2 \mathrm{~b}$ : There is a significant and negative relationship between the stock market trend and the start of the dispute between Russia and Ukraine in 2009.

H3a: There is a significant and positive relationship between the stock market trend and the reaction function in the dispute between Russia and Ukraine in 2006.

H3b: There is a significant and positive relationship between the stock market trend and the reaction function in the dispute between Russia and Ukraine in 2009.

Since no relevant official reply to the start of the disputes between Russia and Belarus in 2006 has been found, only two hypotheses on the relationship between stock market and the reaction functions will be tested.

Table 2.4

\section{Hypotheses for the Russia-Belarus case studies}

H4a: There is a significant and negative relationship between the GDP growth and the start of the 2004 dispute.

H4b: There is a significant and negative relationship between the GDP growth and the start of the 2006 dispute.

H4c: There is a significant and negative relationship between the GDP growth and the start of the 2007 dispute.

H5a: There is a significant and negative relationship between the stock market trend and the start of the 
dispute between Russia and Belarus in 2004.

H5b: There is a significant and negative relationship between the stock market trend and the start of the dispute between Russia and Belarus in 2006.

H5c: There is a significant and negative relationship between the stock market trend and the start of the dispute between Russia and Belarus in 2007.

H6a: There is a significant and positive relationship between the stock market trend and the reaction function in the dispute between Russia and Belarus in 2004.

H6b: There is a significant and positive relationship between the stock market trend and the reaction function in the dispute between Russia and Belarus in 2006.

H6c: There is a significant and positive relationship between the stock market trend and the reaction function in the dispute between Russia and Belarus in 2007.

In Table 2.4 are presented the hypotheses that will be tested for the Russia and

Moldova 2006 dispute.

Table 2.5

\section{Hypotheses for the Russia-Moldova case study}

H7: There is a significant and negative relationship between the GDP growth and the start of the 2006 dispute.

H8: There is a significant and negative relationship between stock market trend and the start of the 2006 dispute.

H9: There is a significant and positive relationship between the stock market trend and the reaction function in the dispute between Russia and Moldova in 2006.

Brams (1975), Ordeshook (1986), Brams and Kilgour (1988), Dixit and Nalebuff (1991), Rumelt, Schendel and Teece (1994), Morrow (1994), McCarty and Meirowitz (2007), Dixit, Skeath, Reiley (2009) all describe game theory, and its 
numerous variations, within a constant framework, where the number of players is unchanged and their preferences are fixed.

If my analysis supports at least part of these hypotheses, I can conclude that taking into account external actors' preferences should occur not only when there is a substantial gas disruption, but also whenever a crisis starts. In fact, a damaging effect on other countries' economies will slowly push European leaders to put pressure on the countries involved in the crisis to find an agreement and restore the balance in the market. Moreover, change in the environment can occur where statements or other acts from relevant institutions have such a strong influence that they are able to adversely affect GDP growth or the local stock markets. 


\section{Research Design}

Testing these hypotheses formulated for examining these gas disputes will require the use of Time Series models. Time Series models are often affected by this presence of dependence of the observation at time $t$ to the previous time-lag(s). In other words, what one can see in time series is that the level of each observation of the dependent variable usually depends on the levels of the observation of the previous time unit(s), that is that the previous lags themselves define to a certain degree the level of the successive observations. For example, the value of the assets of company XYZ on a specific day depends to a large degree on the value it had the day before, since the investors usually rely on that value as a rough estimate of the current value in absence of new developments that may affect the estimate of that value. The current value can depend on more than just one observation: in fact, it is possible, but rather more usual in the social sciences, to discover that a phenomenon's observations depend on the observations at time $\mathrm{t}-1$ and time $\mathrm{t}-2$, or that there are seasonal influences of the process generating the data. Seasonal corrections may be needed for variations that occur annually, monthly or weekly: e.g. sales of ice creams reach higher levels during the summer time, while during the winter season they are at their lowest. All these processes can be modeled by a time series analysis ${ }^{67}$, so that the understanding of the data-generating process

\footnotetext{
${ }^{67}$ Time series are defined as a set of observations $\mathrm{x}_{\mathrm{t}}$ measured at a specified time $t$. Time series are continuous if their observations can be measured at any moment over a specified time frame. However, statistical time series models are usually discrete, that is they present observations that are measured at some (fixed or varying) intervals (Brockwell and Davis 1987, 1).
} 
improves, enabling the researcher to perform a successful description, control or prediction of the studied phenomenon (Chatfield 2001, 12-13).

Plotting of a time series is always the starting point of a scholar that wishes to study a phenomenon across time (Brockwell and Davis 1987, 14). The plots can reveal not only seasonal differences, but also trends (upwards or downwards), shocks, outliers, cyclical variations and other irregular fluctuations (Chatfield 1984; Chatfield 2001; Brockwell and Davis 1987). A proper graphical approach to the afore-mentioned issues is a good start to the understanding of the processes being studied when using classical methods.

Even though the detection of trends ${ }^{68}$ may be effective simply by looking at plots of the data, the definition in the literature changes widely (Chatfield 2001, 19). However, even though in a few cases a deterministic linear trend may be appropriate, local models, in which parameters vary according to time $t$ seem to be have been accepted by most researchers (Chatfield 2001, 18). Seasonal variation can depend on the local mean, and in that case is defined as 'multiplicative ${ }^{69}$. Seasonal effects, once properly identified, can be removed by using dummy variables for each period of the year affected by the seasonal effects and if they are assumed to be constant in time. Otherwise, seasonal differencing can be an effective way of removing this effect. Assuming the use of data collected on a monthly basis, the difference between the current observation (time $t$ ) and the observation at time $t-12$ represent a valid method to eliminate the seasonal effects rather than running statistics to estimate them (Chatfield 2001, 22; Brockwell and Davis 1984, 15).

\footnotetext{
${ }^{68}$ Defined by Chatfield $(2001,18)$ as "long-term change in the underlying mean level per unit time".

${ }^{69}$ Seasonal variation which does not depend on the local mean is called "additive" (Chatfield 2001, 21).
} 
It is important to note that an Ordinary Least Squares (OLS) regression model would likely not be appropriate in that the autocorrelation in the residuals that is typical of time series would heavily bias downwards the estimation of the standard errors, thus biasing the testing of the hypothesis that gas disputes do bring change in external economies in terms of GDP and the stock markets. For large sample sizes, however, the OLS estimates are found to be minimum variance if the assumption that the trend is "polynomial in time, trigonometric polynomial, has seasonal means or a linear combination of these" holds true. Generalized Least Squares (GLS) are in all other cases the unbiased and minimum variance estimators, but they require perfect knowledge of the covariance function of the stochastic component (Cryer and Chan 2008, 40).

Serial correlation ${ }^{70}$ or residual autocorrelation occurs whenever the order of observed errors is statistically significant in explaining the level of the observed variable. Pure serial correlation indicates that in a correctly specified model the error term is correlated with another error term in a different, usually contemporaneous, time lag. Firstorder autocorrelation indicates that an error term is a function of the (temporally) preceding error term (plus an error term). This autocorrelation can be positive or negative, in which cases the error has respectively a tendency to following the ongoing trend, or to behave by switching back and forth between a positive sign and a negative sign. Autocorrelation does not bias OLS the coefficients, which will be still centered on the true mean. Typical causes of autocorrelation are omitted variables (like inflation), poor functional forms, and lagged effects (Studenmund 2005).

Serial correlation is often the product of a misspecification of the model, in which a variable has been omitted, there is a measurement error, the functional form in

\footnotetext{
${ }^{70}$ See Studenmund (2005), Chapter 9.
} 
nonlinear or it is pure stochastic error. All these problems may be characterized by serial correlation that cannot be resolved in ways other than by adding the missing variable, finding the proper functional form, or a correct measurement. Serial correlation makes OLS no longer as the minimum variance estimator and it biases downward the estimate of the standard errors of the coefficients, leading to unreliable hypothesis testing in terms of increasing the chances of Type I errors, that is the probability of rejecting a true null hypothesis. Serial correlation can often be detected by plotting the residuals, or using a statistical test for autocorrelation such as the Durbin Watson d test, especially if its requirements are met. In Generalized Least Squares, the error terms are corrected for autocorrelation and thus the model is minimum variance and the beta coefficient of the independent variables converge to the values calculated by a standard OLS regression, but the estimated $\mathrm{R}^{2}$ and adjusted $\mathrm{R}^{2}$ are not directly comparable with the OLS equivalent since the dependent variable is transformed. Finally, Newey-West standard errors are specifically design to estimate the standard errors of the estimated parameters without causing bias in them taking into account first-order autocorrelation. First differencing can provide an easy solution to the problem of autocorrelation (Chatfield 1984, 21).

\subsection{Applications of time series models in the literature}

Time series analysis has been successfully applied also in political science. There are a number of similar studies, that are somewhat related to the present work. 
Schneider and Troeger (2006), noting that little is said in the literature about the effects of war on the economy ${ }^{71}$, while much more has been said about the causes of war, warn that a better understanding of what follows wars in terms of stock market oscillations may provide policy-makers a deeper understanding of what the consequences are of deciding that war is the only solution to a crisis. Schneider and Troeger (2006) note that there is some uncertainty about the reactions of the stock market to wars. In some cases, like the one after the Second World War, the economy of the US had largely expanded, probably as a result of the fact that the war had been waged on foreign territory. In other cases, where war is waged on national territories, the reaction of the stock market to the event is generally negative ${ }^{72}$. In other cases, the Dow Jones lost a $6.31 \%$ due to the invasion of Kuwait by Iraqi forces in 1990, but it gained more than twice as much when the coalition reacted to Saddam's aggressive expansion policy in the following months ${ }^{73}$. Schneider and Troeger (2006), aware of the complexity of the issue, conclude that the impact of wars on financial markets is largely dependent on the degree of gravity of the conflict and the degree to which economic actors are able to predict the events, whether they were inherently cooperative or war-prone. They place their study inside a larger context, that of classical mercantilism, which maintains that international markets react in a negative manner to destructive events like wars, since they damage existing economic relationships. Classic mercantilism does not contem-

\footnotetext{
${ }^{71}$ See also Braun and McGrattan (1993). The authors provide a refined econometric model to document the effect of war on the main macroeconomic factors both the First World War and the Second World War. Chappel and Eldridge (2000) offer a test for market efficiency (which assumes an expected return equal to zero, which implies a white noise process) based on a GARCH model using the data of the UK FT30 stock index during the Second World War, in the period 1939-1945.

${ }^{72}$ See Schneider and Troeger (2006, 624).

${ }^{73}$ See also Earle and Foster 2003.
} 
plate positive reactions to wars, as it has been demonstrated to be the case when wars are waged on foreign territories, and it does not even account for the expectations that economic actors may have regarding the outcome of a conflict. In fact, it makes perfectly sense that markets react positively when a hostile act is exerted if that act represents a clear signal that the war will soon be over or that that act will bring the end to the conflict. In order to test this hypothesis, Schneider and Troeger (2006) study how the Dow Jones, the British FTSE and the French CAC stock market indices reacted to the invasion of Kuwait, the Israeli conflict and the internal conflicts in ex-Yugoslavia. In order to do so, they use variants of the Generalized Auto Regressive Conditional Heteroskedasticity model $(\mathrm{GARCH})^{74}$ and they conclude that the stock markets considered all reacted negatively to most of the hostile events considered that characterized each conflict. However, they also note that international crises trigger different reactions in the stock markets that reflect the importance of the conflict to the local actors and that negative events influence the volatility much more strongly than positive events. More specifically, the authors seem to find evidence to conclude that economic actors change their trading patterns according to their perception of severity of the future of the current crisis and the belief that something of consequence is going to follow the specific event (Schneider and Troeger 2006, 642-643). The more a country has deep ties with the conflict, the more pronounced will be the reactions of that country's financial markets.

Frey and Kucher (2000) were interested in testing whether all main historical events in the 1933-1948 period are reflected in the Swiss bond market. More specifically, they use the Swiss market to test whether there are deviations from a random walk at

\footnotetext{
${ }^{74}$ See below for a description of this statistic technique and a review of some important modification to Bollerslev and Engle's model.
} 
the times that correspond specifically, for example, to when the Second World War broke out or when Poland was invaded, using the value of five countries that were involved in the events (Switzerland, Belgium, France, Germany and Austria). Not only did the values of the bonds issued by these governments reflect the importance of all of these events, but they also provide additional information of how the market and investors operate. In fact, when Germany invaded Poland, the Swiss bonds gained more value because at that point it was clear that it would have been easier for the Swiss government to fulfill its financial obligations than France, Germany, Belgium and Austria (Frey and Kucher 2000, 490). However, their model, which combines the use of an OLS model $^{75}$ to estimate a regression curve for the behavior of the bonds/markets and the Ftest, which was used to check for differences from the estimated equation was unable to find any statistical deviation from the random walk on the occasion of the defeat of Germany in 1945 . They suggest that this can be explained by the fact that traders had already predicted the occurrance of that event and had already adjusted their portfolio accordingly.

In a very interesting work, Leigh, Wolfers and Zitzewitz (2003) show that the probability of $\operatorname{war}^{76}$, in the specific case the war against Saddam, is strictly related to the price of oil and the performance of the S\&P 500. Moreover, they find that this probability is able to explain over 30 percent of the variance of the S\&P 500 and over 75 per-

\footnotetext{
75 The authors tested the same hypothesis also considering autoregressive processes up to the sixth order, finding no statistical difference in results. They controlled for inflation and real interest rates.

${ }^{76}$ In an attempt to bypass polls in order to reconstruct the probability that war, the authors use the now defunct website www.tradesports.com whose business was that of running double auction on well-defined futures. They recorded the performance of the future "Saddam Securities" under the assumption that financial market of this sort are able to measure and aggregate the information that individuals hold about a specific topic, in this case the probability that Saddam is still a President or not by a certain date (see also Surowiecki 2004), and are therefore a good tool to estimate the probability of staying in power.
} 
cent of spot oil prices (Leigh, Wolfers, Zitzewitz 2003, 2). More specifically, they conclude that a ten percent rise in the probability of war is able to influence the spot oil price by $\$ 1$, or 3-4 percent of its value, which suggests that when war breaks out, that it is able to push up the oil price by $\$ 10$ at least in the short term. Moreover, they discovered that the US stock market reacts to small variations of the probability of wars. They estimate that a rise of ten percent in the risk of war can cause a decline in the S\&P 500 that roughly equals 1.5 percent of its value, which in turn suggests that war is capable of affecting a fifteen percent loss of S\&P 500 value. The negative consequences of war on option prices are estimated by the authors to amount to between no effect and fifteen percent with a probability of seventy percent, between fifteen and thirty percent change in option prices with a probability of twenty percent and an effect of thirty percent or more with a probability that equals to ten percent. Rigobon and Sack (2005), criticizing the previous authors, reach, however, similar conclusions by implementing a generalized method-of-moments (GMM) estimation procedure ${ }^{77}$ to measure the sensitivity of financial market variables to war risk. They measure this by just assuming that in correspondence with the publication of some war-related news, the risk of war changes. The authors find that several of the financial variables they study are significantly affected by war risk as they measured it. More specifically, an increase war in the risk of is often followed by an increase in year-ahead oil futures contracts by $2.9 \%$, a decrease of equity prices by $4.8 \%$, while the corporate yield spread $\operatorname{rose}^{78}$. Even though the authors find that all yield spreads are widened, they note that the lower quality ones are

\footnotetext{
${ }^{77}$ In this case, the GMM method appears to be a good option for its ability to deal with the heteroskedasticity that occurs whenever news about the possible outcome of the war is published and the fact that there are other variables affecting the variance of the financial markets.

${ }^{78}$ See Rigobon and Sack 2005.
} 
those that showed a larger increase. An increased risk of war pushes down the ten-year yield and the two-year yield about the same amount, and it reduces the value of the dollar by $0.6 \%$. However, the authors find no evidence of any effect of war risk on the liquidity of Treasury notes, which the authors interpret as the fact that investors react to news about war not by changing their investments preferences, rather by changing their opinion of the future of the US economy.

Li and Sacko (2002) attempt to bridge the realist and liberalist theories (war disrupts trade) and the findings of Morrow (1999), according to whom trade and military conflicts should be two uncorrelated events. The authors do so by employing a pooled cross sectional time series analysis (PCSTS) to support their hypothesis that governments have the power to modify the cost-benefit analysis of trading companies, thus including realist and liberal claims, they also note that there are conditions under which some characteristics of the war like its duration, and its intensity should influence the trading relations between the two fighting countries. More specifically, Li and Sacko (2002) claim that even in the presence of restrictions on economic relationships with the opponent, what truly matters is the cost-benefit differentials upon which the trading companies base their decisions. Governments, however, can influence trading relationships by modifying this differential with specific policies. Expectations play an important role in trading relations, and if trading companies can foresee an increase in risk of their relationships with their trading partners, they will rationally reduce their trade even before the war breaks out. In the case their expectations do not meet the reality of the facts, the trading companies re-adjust their optimal decisions to the new situation: if a war starts, companies take into account not only the fact that it started, but also its severity, and its duration (Li, Sacko 2002). 
A similar study, justified by slightly different motivations, is that of Anderton and Cartier (2001). They are interested in studying whether war really disrupts trade, since other authors (Barbieri and Levy 1999) showed that the assumption that 'trade promotes peace' relies on the false claim that due to conflictual events trade exchanges are disrupted. The authors find that there is no significant relationship between wars and the interruption of trade among war-prone countries. They employ an interrupted time series model which shows that even though there is no long-term disruption in the trade among war-waging countries, there are usually some temporary reductions in the amount, which are sometimes even replaced by an increased volume of trade in the long term. A weakness of Barbieri and Levy's (1999) study is that their analysis is confined to merely seven cases (dyads), making it highly vulnerable to case-selection critiques. Thus Anderton and Cartier (2001) attempt to solve the issue by running a similar interrupted time series analysis but extending it to a total of twenty-seven dyads, half of which represent great powers conflicts (Anderton, Cartier 2001, 455). Even though there are interesting methodological and operationalization differences, the two authors come to different conclusions, claiming that the statistical model supports the general assumed idea that war does indeed disrupt trade. A similar conclusion is drawn by the same authors in a later book (Anderton and Cartier 2003, 306).

Caplan (2002) is interested in drawing generalizations about the consequences of war at the macroeconomic level. Criticizing what other authors claimed (Braun and McGrattan 1993) regarding the main effects of the two World Wars on the global economies, Caplan (2002) provides a pooled time series analysis to show that both the UK and the US were atypical cases, and that what happened to their economies during the two World Wars do not represent cases from which scholars can easily generalize to 
form new theories. More specifically, Caplan (2002) draws his own conclusions, noting that his pooled time series design demonstrates that all wars raise expenditures and taxation (both raw and as a percentage of GDP) ${ }^{79}$. Domestic wars are usually followed by a diminution in output, an increase in monetary supply (which leads to higher inflation), but it increases slightly if the war is waged in foreign lands. Domestic wars are also characterized by an increase in taxation as a percentage of the total output, but the same effect is not found for wars in foreign lands, which are found sometimes to even bring a tax reduction. In conclusion, the author also finds evidence that there are significant differences between the results obtained for advanced industrialized countries and the rest of the world. In particular, Caplan (2002)'s model shows that government expenditure as a percentage of the output does not suffer from the distinction between wars conducted domestically or abroad. In fact, in both instances government spending grows for advanced industrialized countries, but the same cannot be said for the rest of the world, for which the governmental tendency to spend more occurs only in the case of foreign wars.

Collier (1990) also studies the consequences of war, but he does so without distinguishing between domestic and foreign wars. Collier's main conclusions, that are based on simple OLS estimates, are that during civil wars annual GDP tends to decrease by $2.2 \%$ which is explained in terms of both output reduction and asset destruction. The collapse of GDP does not uniformly affect the structure of internal production, in that war hits first the transportation, manufacturing, construction, distribution and finance sectors, while the agricultural sector is shown to expand. Collier also draws interesting

\footnotetext{
${ }^{79}$ Results are proof of problems like autocorrelation and the lack of consideration for hyperinflation periods.
} 
conclusions about the duration of internal conflicts. If they are long enough, the financial market shrinks to such a low point that when the conflict is over, it quickly returns to its pre-conflicts levels. Capital comes back from abroad and fosters the economy and its reconstruction (Collier 1990, 191). However, if the civil war is short enough (one year or less) then the financial market is assumed not to have the time to reach that point, and it is assumed to keep losing strength even though the internal conflict is over. More specifically, the author quantifies this decline in the amount of $2.1 \%$ per year for the first five years of the post-conflict period (Collier, 192).

Neumayer (2004) studies the impact of war on tourism and he does so by using Arellano and Bond's Generalized Method of Moments (GMM) estimator, a dynamic panel estimator, which relies on the use of all prior dependent variables (Neumayer, 15). The author, not surprisingly, discovers that episodes of violence and/or political instability affect tourists' choice of holiday destinations, since they are assumed to play against the relaxed and pacific atmosphere that a vacation is supposed to offer. For this reason, the decision-makers of countries that highly depend on tourism as a source of income are inclined to care about maintaining low levels of instability and violence. The author shows that politically-motivated violence is able to reduce tourists' arrivals by up to 25 percent, and that being an autocratic regime is not enough to prevent tourism from becoming a major source of income for the country. No statistical significance is found that supports this claim, especially if they have the reputation of a stable and pacific autocracy (Neumayer 2004, 27).

\subsection{Auto Regressive Integrated Moving Average (ARIMA) models}


The vast majority of the works described above entail the use of at least some parts of the Auto Regressive Integrated Moving Average (ARIMA) models, also known as Box-Jenkins models ${ }^{80}$. These models are based on the observation that with timeseries data the dependent variable $\mathrm{Y}_{\mathrm{t}}$ can be explained not only by correctly specified independent variables, but also by the previous values (in temporal terms) of the dependent variable $\mathrm{Y}_{\mathrm{t}-1}$ and values of the independent variables that do not refer to time $t$.

An ARIMA model is based on some assumptions: first of all, the shocks must have a zero mean ${ }^{81}$; shocks have constant variance, are statistically independent from each other and are normally distributed (McDowall et al 1980, 15; Cryer and Chan $2008,16)$. At this point it is necessary to be aware of the difference between trend and drift. A time series is said to have a trend when it shows a steadily increasing or decreasing slope for the whole time frame under analysis. In a case where a time series is trended, ARIMA requires differentiation ${ }^{82}$. However, in the case of drift, which is random and not systematic variation in the data, then no differentiation is necessary in order for the ARIMA model to function properly. McCleary and Hay (1980) describe the event of flipping a coin as a random walk ${ }^{83}$. Some long runs of just heads or tails can happen, since the probability of such an event will never be zero, and it might take a

\footnotetext{
${ }^{80}$ Box and Jenkins should not be credited for the creation of all the elements of the ARIMA models. However, they should be credited for their comprehensive formulation of the ARIMA model (McDowall et al 1980, 14).

${ }^{81}$ Such requirement of stationarity, if strict, ensures with finite variance that the covariance function is only a function of the time lag (Cryer and Chan 2008, 16).

${ }^{82}$ Differentiation is performed by using the vector of differences between $Y_{t}$ and $Y_{t-1}$ as dependent variable.

${ }^{83}$ Chatfield $(2001,28)$ more generally describes a random walk as a process that generates observations based on the previous lag and a purely random process, in turn defined as "sequence of uncorrelated, identically distributed random variables with zero mean and constant variance". See also Cryer and Chan 2008, 12).
} 
while before the average of score between heads and tails becomes even. More generally speaking, it might take a very long series of coin flips to have a number of heads and tails that is (almost) even. Differencing the series removes trends and allows the observation of the random shocks (Chatfield 1984, 21), which represent the complex way all the variables of the model interact among themselves. Formally, an ARIMA model that requires one differencing is described as an ARIMA $(0,1,0)$ model, where the central term in the parenthesis indicates that the series had to be differenced once in order to model the random walk and to remove the trend. A time series that has been de-trended by differencing and has no other temporal variation is said to be 'white noise" ${ }^{84}$.

In order for an ARIMA model to work properly, it is also necessary that the time series has a constant variance. This requirement entails a single constant variance throughout the whole time series. A common solution for this kind of requirement is to log-transform the series. By doing so, it is rather likely that the log-transformation minimizes the difference in levels of variance.

Once a model is constant in both level and variance, the researcher has to decide which processes can better describe the time series. The same scholar can choose between first order autoregressive processes or second order autoregressive processes, which are respectively described as an ARIMA $(1,0,0)$ model and a ARIMA $(2,0,0)$ model, and are regressed on the preceding one (or two) observations ${ }^{85}$. Less common are second-order autoregressive processes, where the observation under analysis is a function of the two preceding observations.

\footnotetext{
${ }^{84}$ White noise is stationary by definition, when the mean of the observations are zero and when the variance is constant (Cryer and Chan 2008, 17).

${ }^{85}$ In social science, it is uncommon to study process that can be modeled with second-order or higherorder autoregressive processes (McDowall et al 1980; McCleary and Hay 1980).
} 
Moving average processes are characterized by the limited effect of previous errors on the present output. In other words, the present output is affected by some processes which, once entered the system, completely disappear from it once a certain amount of time (lags) has passed. The difference between autoregressive and moving average processes should be therefore clear. Autoregressive processes assume that some shocks enter the system and keeps affecting it for a long period of time, before its effect becomes so small as to be considered insignificant. Moving average processes assume that a shock enters the system and after a well-defined period of time its effect vanishes completely from the model (McCleary and Hay 1980). There exist also second-order processes $^{86}$, which can be more formally represented as ARIMA $(0,0,2)$. In that case, the effect of two or more time lags has to be considered when regressing the dependent variable on the independent variables. Finally, it is worth noting that a time series can be affected by seasonality that is a cyclical shock that occurs over specific ranges in time and affects the present observation in this cyclic pattern. Models that take into account seasonality effects are generally formally represented as ARIMA (p,d,q)(P,D,Q) models ${ }^{87}$, where $\mathrm{P}$ denotes the order of the seasonal autoregressive process, $\mathrm{D}$ the seasonal differentiation, and $\mathrm{Q}$ the order of the seasonal moving average process (McDowall 1980, 56).

In order to decide whether the underlying processes are autoregressive (of any order) and/or moving average (of any order), the researcher has to look to the AutoCor-

\footnotetext{
${ }^{86}$ Higher order moving average processes are possible, but are rarely found in social processes commonly studied (McDowall 1980).

${ }^{87}$ Brockwell and Davis (1984, 310-313) formally represent such a model as SARIMA (p,d,q) x (P,D,Q) .
} 
relation Function $(\mathrm{ACF})^{88}$ and the partial autocorrelation function $(\mathrm{PACF})$ of the data series. Autoregressive processes have decaying ACF graphs and spiking PACF graphs, while moving average processes have spiking ACFs and decaying PACFs (McDowall et al 1980; McCleary and Hay 1980). Should both of these graphs be decaying, that would mean that the underlying processes are a mix of moving average and autoregressive processes. Once the model has been correctly identified, and the parameters estimated, it must be diagnosed both in terms of checking if the processes identified make the residual variance white noise, and in terms of whether the model can explain a large amount of variance in the model (by using the Residual Mean Squared Error statistic). Moreover, the model to be selected has to be chosen among those that show a plot of the residuals that is stationary around a certain level. Quantile-Quantile plots are often used to test the normality of the models selected. A model respects the assumption of normality of the residuals if the points plotted seem to be following the line closely. As additional supporting evidence, it is possible to use the Shapiro-Wilk normality test applied to the residuals (Cryer and Chan 2008, 178). The independence of the noise terms can be verified with the $\chi^{2}$, or Ljung-Box G test, or the sample autocorrelation function of the residuals; autocorrelations values that exceed the significant threshold are to be interpreted as statistically different from zero and will possibly require a change in the model specification (Cryer and Chan, 180). The Ljung-Box Q test considers the magnitude of the residual autocorrelations as a group, not just one by one. The idea behind the statistic is that of measuring whether the autocorrelations are too high as a group even though none of them exceeds the significance level of $\pm 2 / \sqrt{n}$ (Cryer and Chan 2008, 183). Finally, a

\footnotetext{
${ }^{88}$ Every process has its own ACF, which characterizes it. A stationary stochastic process is fully described by its mean, variance and ACF (McDowall 1980, 24).
} 
model can be diagnosed by 'overfitting', that is by fitting a more general model that it is similar to the one that has been chosen as the best-performing. Such model would be confirmed to be so if the estimates of the overfitted parameters are not significantly different from zero and if the estimates of the parameters of the overfitted model do not significantly change from the original estimates (Cryer and Chan, 185).

\subsection{Interrupted Time Series models}

Interrupted Time Series analysis has been well described by Campbell (1963) and Campbell and Stanley (1966) for the purpose of measuring the impact of shock or an intervention on a social process (McDowall et al 1980,10). The time series that describes such phenomenon is usually represented by a set of 'Os' and an $\mathrm{X}$ in correspondence with occurring of a particular shock or intervention which breaks the time series in two periods ${ }^{89}$. The latter, unlike the former, is characterized by the presence of the phenomenon and its effects on the social process being studied. An ARIMA model can be developed to study the significance of a variable similar to the one described above. By using zeros instead of Os and a 1 instead of the $\mathrm{X}$, one can study the impact and the statistical significance of this independent variable.

These models have been widely applied to behavioral data (Hartmann et al 1980; Eden 1982; Wagner, Rubin, Callahan 1988; Sheldon et al 2004), medical applications (Tryon, W 1982; Fowler et al 2007; Grijalva et al 2007) and also to social science (Rundquist and David 1976; Bonham, Fujii and Mak 1992; Glick and Rose. 2002). In the political science field, interrupted time series analysis has been implemented to as-

\footnotetext{
${ }^{89} O$ s and an $\mathrm{X}$ are used in the original description by Campbell and Stanley (1966).
} 
sess the effect of war on trade (Anderton and Carter 2001), the impact of reforms on taxation and expenditures (Morgan and Pelissero 1980), to test the impact of change of social order on the level of crime and deviance (Pridemore, Chamlin and Cochran 2007), or to measure the impact of anti-terrorist policies on the frequency of terrorist acts (Brophy-Baermann, Conybeare 1994), just to name a few of the most significant applications.

As said above, Interrupted Time Series analysis divides the time series into two parts: one that is unaffected by the shock or intervention, and another one which is indeed affected by it (McDowall et al 1980, 12). It follows that the analysis will be a test of significance between the two parts, the pre-intervention series level and the postintervention model. This can be more formally represented as (McDowall et al).

$$
Y_{t}=b_{\text {pre }}+b_{\text {post }}+e_{t}
$$

and also as

$$
Y_{t}=N_{t}+I_{t}
$$

By modeling the serial dependence as a time series process using ARIMA models, one can control for the autocorrelation that is typical for time series and properly study the significance of the difference between the two levels.

The intervention function $I_{t}$ can be represented as a variable consisting of zeros before the intervention and $1 \mathrm{~s}$ during or after that. The intervention function can take on different shapes, as shown in Figure 3.1. 
Figure 3.1

Impact patterns

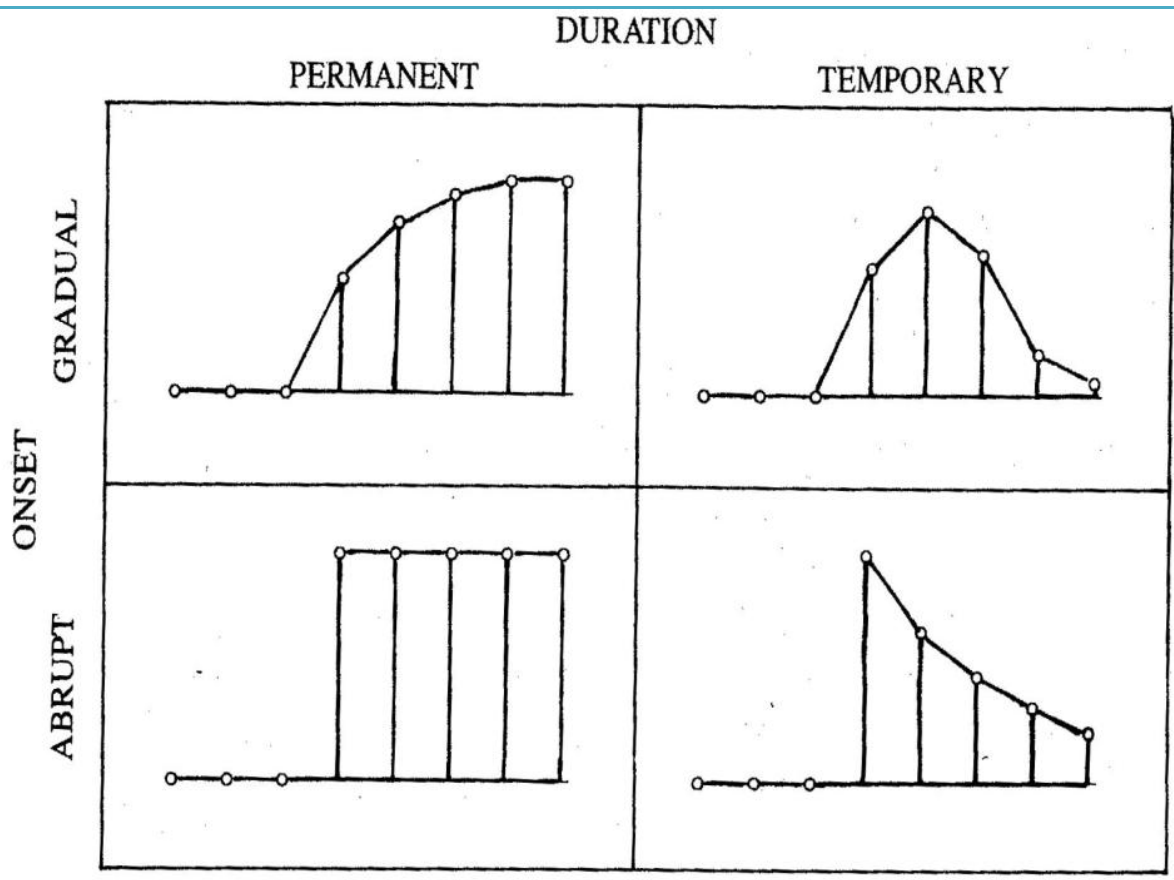

\section{Source: McDowall et al (1980)}

The intervention functions described above are characterized by an abrupt onset of the intervention and assumed to be lasting permanently (McDowall et al 1980). However, a similar function can be used also to represent an intervention whose effect is only temporary by assuming that its effect manifests itself only for a certain amount of time and then suddenly disappears.

When an intervention is assumed to be 'abrupt' and of permanent duration, the intervention component can be represented as:

$$
f\left(I_{t}\right)=\omega I_{t}
$$

Where $\omega$ is a parameter to be estimated and $I_{t}$ is a dummy variable of zeros before the shock or intervention is introduced, and 1s after the shock. Since the estimation 
model is linear, the noise component can be removed from the time series and the level of the time series, which does not consider the random behavior of the observations, is

$$
y_{t}=\omega I_{t}
$$

Pre-intervention, the level will be equal to 0 , while after the shock has been introduced in the time series (assuming it is permanent and constant) its level will equal the value of the estimated parameter (McDowall 1980, 67).

A gradual permanent impact entails the use of a lagged value of the series in the intervention component, that is

$$
y_{t}=\delta y_{t-1}+\omega I_{t}
$$

where $0<\delta<1$ is required in order to maintain stationarity (McDowall et al $1980,75)$

McDowall et al. point out that for low values of the parameter $\vartheta$ the change in the intervention component is rather rapid, with the abrupt jump from zero to $\omega$ if $\delta$ equals zero. On other hand, the more $\vartheta$ approaches 1 , the more balanced the increased per lag unit. In the particular case that $\vartheta$ equals 1 , the increased per time lag is constant and equals $\omega$. 
Figure 3.2

\section{Gradual permanent impact patterns}

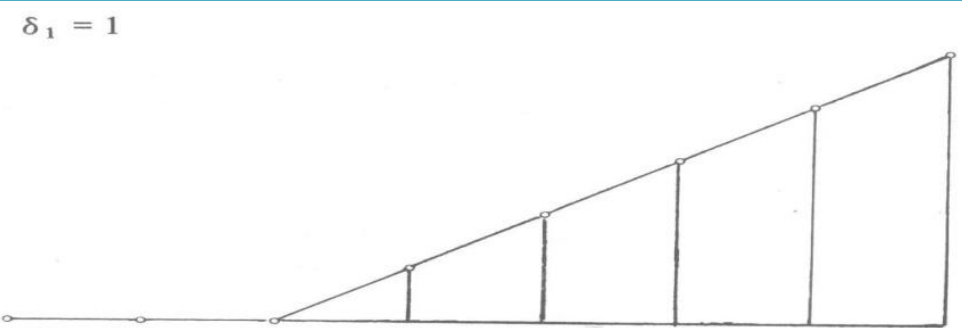

$\delta_{1}=.75$

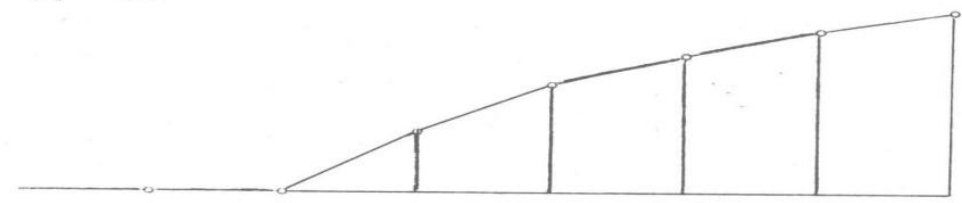

$\delta_{1}=.5$

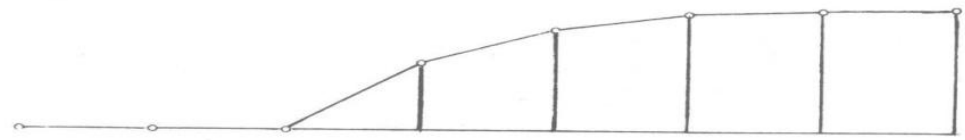

$\delta_{1}=.25$

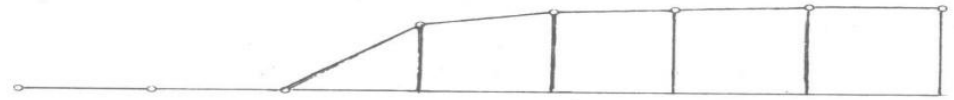

$\delta_{1}=0$

\section{Source: McDowall et al (1980)}

This model assumes that the intervention affects the time series permanently. For shocks on the stock markets following gas disputes, other temporary patterns are more likely to be more useful.

A pulse function $P_{t}$ is characterized by zeros before the intervention, 1 at the moment of its occurring and zeros thereafter (McDowall et al 1980, 80). The weakness of this model, which makes it unable to represent certain real world phenomena, is the assumption that the effect of the intervention is evident in just one moment in time and that it does not carry over other time lags. Thinking of gas disputes, one cannot expect a 
model to work properly, if it assumes that its effects are evident in just one time lag (day) or few days and then it disappears. As it is the case for many other social science processes, a shock is more likely to be modeled as if it was reabsorbed slowly, as depicted in the Figure represented by abrupt and temporary impacts.

The intervention component for this kind of impact is

$$
y_{t}=\delta y_{t-1}+\omega P_{t}
$$

where $\mathrm{P}_{t}$ equals to zero before the intervention and $\mathrm{P}_{t}$ is equal to 1 at the moment of the intervention onwards. It follows that the expected level of the time series follows a similar behavior, in which

$$
y_{i+n}=\delta^{n} \omega
$$

It is clear from the above formulation that as time passes, the level of the time series $y_{t}$ converges back to zero, since $\delta$ is constrained to be a value between zero and one. For low values of $\delta$ the post-intervention levels quickly assumes values close to their pre-intervention levels. On the contrary, for values close to 1 many more time lags will be needed to converge to the pre-intervention levels (McDowall 1980, 81). As noted above, the case of $\delta$ that is equal to one reduces the pulse function to a step func$\operatorname{tion}^{90}$.

\footnotetext{
${ }^{90}$ See picture below.
} 
Figure 3.3

\section{Gradual temporary impact patterns}
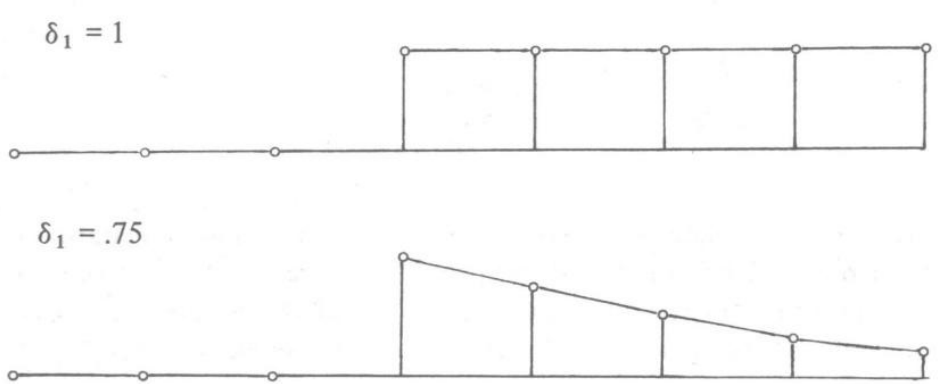

$\delta_{1}=.5$

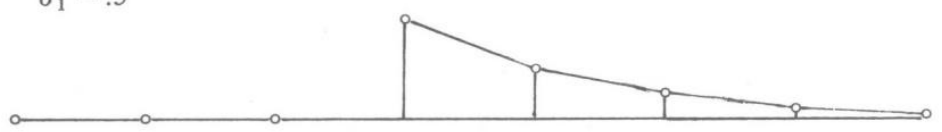

$$
\delta_{1}=.25
$$

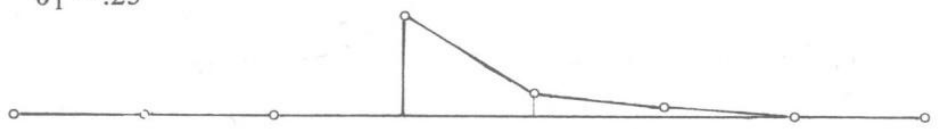

$$
\delta_{1}=0
$$

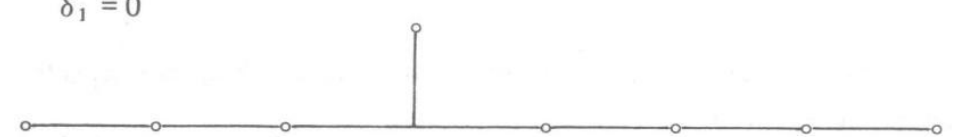

\section{Source: McDowall et al (1980)}

Theory should guide the researcher's choice of the proper impact model. In the absence of such theory, McDowall et al. $(1980,84)$ suggest to first use an abrupt, temporary intervention model. If $\delta$ is estimated to be too close to 1 given its $95 \%$ confidence interval, then this model should be rejected and a gradual, permanent impact model should be assessed. If the estimates of $\delta$ are in this case too close to zero, making it not statistically different from zero, then the abrupt, permanent model is the right one for the specific case to be studied (McDowall et al. 1980).

Britt, Kleck, Bordua $(1996,362)$ suggest that the researcher's understanding of the underlying process, rather than statistical tests guide the construction of the intervention model. The authors discuss another important issue, the robustness of the re- 
sults. Can they be generalized? If so, is it still the case if the time series under study is shortened or is made longer by inserting additional data? Only if that is the case then the results found are valid and robust. Britt, Kleck, Bordua (1996) are concerned that today's researchers are tempted by avoiding dealing with these issues, even though they may be so relevant to undermine the results obtained, risking the production of results that will lead to unsuccessful policy making.

\subsection{Heteroskedasticity models (ARCH/GARCH)}

$\mathrm{ARCH}$ (and GARCH) models do not attempt to treat heteroskedasticity (or assume it to be nonexistent), as it happens in the case of ARIMA and OLS models. They model heteroskedasticity, and as a result of it the overall performance of the model improves, enabling the researcher to improve predictions about the variance at future lags (Engle 2001). A first prototype of Auto Regressive Conditional Heteroskedasticity (ARCH) and Generalized ARCH models used a standard deviation that was calculated using a limited amount of the most recent observations, which means that the standard deviation at a specific time $t$ depensd on a weighted average of the squared residuals from the past observations. Such a model immediately fails to attract the researchers' attention because of its treating all past observations equally: common sense would indicate that the most recent observations are also the ones that on average best are able to determine the level of the current standard deviation. Engle's (1982) ARCH model prescribes that these weights be calculated so as to maximize the forecasting performance of the time series. 
The GARCH model revised by Bollerslev (1986) is based on a weighted average of the past squared residuals that asymptotically tend to zero as one moves farther in time from the present time lag $t$. However, researchers commonly assume that an adaptive behavior, based on the prediction of the variance of the next period with a weighted average of the long run average variance, the variance predicted for this period and the value attributed to it at the present period is the best approach (Christoffersen 2003, 23; Engle 2001, 160). In other words, unlike other models of the conditional variance ${ }^{91}$, the GARCH model more realistically assumes that variance will eventually revert to the average value sooner or later.

The most recent financial models take into account the conditional variance of $Y_{t}$ given the values that it assumes in previous time lags from its conditional mean $E\left(Y_{t} \mid Y_{t-1}, Y_{t-2}, \ldots,\right)$. If a typical ARIMA model can be fitted in the distribution, the conditional variance is assumed to be equal to the noise variance. The ARIMA or OLS models all assume that the variance is constant (or it is made constant by logging the dependent variable), but this is not a good approximation for financial data. In fact, daily returns of stock are usually found to have a larger conditional variance when the series is characterized by higher volatility of the prices than in calmer period (Cryer and Chan 2008, 277). That is because the conditional variance can be seen itself as a random process, and is commonly referred to as the conditional variance process.

There exist some models that are able to unite the properties of an ARIMA model with that of a model of conditional heteroskedasticity and the McLeod-Li test can be utilized to check the existence of $\mathrm{ARCH}$ processes in the data.

\footnotetext{
${ }^{91}$ See for example the RiskMetrics model (Christoffersen 2003).
} 
Cryer and Chan $(2008,283)$ suggest plotting the results of this test for a certain number of lags and plot the p-values resulting from this test. A long series of significant McLeod-Li tests supports the need to take into account ARCH processes which could be visible with the inspection of the ACF of the squared distribution. The inspection ${ }^{92}$ of the distribution of the dependent variable can reveal, for example, that there exist volatility clusters, that is segments of the distribution that are affected by larger or smaller variance $^{93}$. This can be done with a QQ normal plot, which can reveal that the distribution may deviate from the normal distribution because of a larger or smaller tail and the distribution is skewed to either sides of it. The Jarque-Bera test can be implemented in order to verify the normality of the distribution (Christoffersen 2003, 284) and if all these tests support the hypothesis that the distribution possesses a heavy tail (or a light tail), then the GARCH model provides a framework useful for dealing with such $\operatorname{processes}^{94}$.

A similar task is performed by the $\mathrm{ARCH}$ model ${ }^{95}$, a regression model in which the conditional variance is the dependent variable and the past lags of the squared distribution are the independent variables. In more formal terms, an ARCH (1) model generates a series $r_{t}$ as follows:

$$
r_{t}=\sigma_{t \mid t-1} \varepsilon_{t}
$$

\footnotetext{
92 Cryer and Chan (2008) strongly recommend the use of both statistical tests and visual inspection. The reading of their work in many instances reminds the reader that the observation of the results of these tests can reveal much more than just running the tests. By visually inspecting the data, in fact, many other problems can be seen, along with explanations for why deviations from the optimal situation occur.

${ }^{93}$ Christoffersen $(2003,27)$ reports that it is now a well-established phenomenon that the days that follow the weekend are also the days that have a higher variance than average.

${ }^{94}$ Financial data are mostly found to be of similar nature.

95 See Engle (1982).
} 


$$
\sigma_{t \mid t-1}^{2}=\omega+\alpha r_{t-1}^{2}
$$

where $\omega$ and $\alpha$ are parameters to be estimated ${ }^{96}$ and assumed in an ARCH model to be nonnegative ${ }^{97}, \varepsilon_{t}$ is a vector of random variables called also 'innovations' that are independent of $r_{t-j}, j=1,2, \ldots$ and are independent and identically distributed with zero mean and variance equal to 1 .

An ARCH (1) can be specified if it is warranted by an autoregressive process of first order, and $\alpha$ must be a positive value less than 1 in order to grant stationarity to the model. It is important to note that even if the innovation has a normal distribution, the distribution of an $\mathrm{ARCH}$ (1) model with the $\alpha$ value comprised between 0 and 1 (stationary) has fat tails, that is its kurtosis is strictly positive (Christoffersen 2003, 287).

ARCH models are usually implemented to predict to predict the future conditional variances at any time lag $h$, which can be computed with the following formula:

$$
\sigma_{t+h \mid t}=\omega+\alpha \sigma_{t+h-1 \mid t}^{2}
$$

ARCH models have been generalized by Engle (1982) to

$$
\sigma_{t \mid t-1}=\omega+\alpha_{1} r^{2}{ }_{t-1}+\alpha_{2} r^{2}{ }_{t-2}+\ldots+\alpha r^{2}{ }_{t-q},
$$

where $q$ simply refers to a more generic $q \mathrm{ARCH}$ order.

\footnotetext{
${ }^{96}$ The parameters are in general estimated through a Standard Maximum Likelihood estimation or a Quasi-Maximum Likelihood Estimation (Christoffersen 2003, 28).

${ }^{97}$ Since also the squared values of the distribution must be nonnegative.
} 
Combining the findings of Bollerslev (1986) and Taylor (1986), who introduce into the model also $p$ lags of the conditional variance, one can synthesize all these models into a GARCH $(\mathrm{p}, \mathrm{q}) \operatorname{model}^{98}$, where $\mathrm{p}$, as indicated above indicated the autoregressive lags and $\mathrm{q}$ the $\mathrm{ARCH}$ (moving average) $\operatorname{order}^{99}$. Moreover, an $\operatorname{ARIMA}(\mathrm{p}, \mathrm{q})$ model can be used to identify the $p$ and $\max (p, q)^{100}$. The requirement for nonnegative parameters $\omega$ and $\alpha$, sometimes adopted, does not necessarily apply for GARCH models, in that it can be shown that a nonnegative variance can be achieved even with negative parameters (Cryer and Chan, 290). This has the additional property of enabling the modeling of several other patterns, without violating the requirement of a nonnegative conditional variance.

The estimates of the GARCH parameters are usually compared with those of rival models, since the analysis of the EACF may not clearly reveal which is the right combination of $\mathrm{p}$ and $\mathrm{q}$ to be selected. The comparison is made by selecting the model whose AIC value is the lowest as in ARIMA models.

Before a GARCH model is approved, some diagnostics need to be run in order to test whether any assumptions are violated with the specific sample being analyzed. In case one or more assumptions are not met, a new model needs to be re-specified until all assumptions are met. Tests need to be run in order to verify:

\footnotetext{
${ }^{98}$ For applications of GARCH models in political science see Schneider and Troeger (2006) and Brunner (2009).

${ }^{99}$ See Cryer and Chan (2008), page 289 and Engle (2001), page 160.

${ }^{100}$ Cryer and Chan (294) suggest to first fit a $\operatorname{GARCH}(\mathrm{p}, \mathrm{q})$ model and then to estimate q by looking at the significance of the estimated ARCH coefficient. Since mixed autoregressive and moving average processes are usually hard to define, Cryer and Chan $(2008,116-117,294)$ suggest the use of the Extended Autocorrelation Function (EACF) of the squared observations. The best combination of $p$ e $q$ value will correspond to the upper-left vertex of the triangle of zeros, where $p$ is the row and $q$ is the column.
} 
1. the normality of the residuals: the model assumes that the residuals do follow a normal distribution and can be visualized, as said above, by inspecting the QQ normal scores plot (deviations from the straight line indicate lack of normality and provide information about the distributional properties of the innovations. From a numerical point of view, the normality test can be conducted with the Shapiro-Wilk test or the Jarque-Bera test. Estimates of these tests that exceed the significance level of 5 percent lead to the failure of rejection of the null hypothesis that the innovations are normal.

2. the assumption according to which the standardized residuals should be at least roughly independently and identically distributed must be tested next. Cryer and Chan $(2008,303)$ suggest to observe the sample ACF and to use the 'generalized Portmanteau test', a test that does not suffer from the inability to identify uncorrelated but serially dependent innovations ${ }^{101}$.

3. the nonnegativity of the conditional variance can be tested by verifying whether the GARCH parameters are all nonnegative. However, as said above, these constraints can be relaxed and nonnegativity of the conditional variance can be found to hold even if some parameters are found to be negative ${ }^{102}$.

GARCH models are commonly used to forecast financial data, which are often affected by heteroskedasticity, and it does so by iteratively calculating the estimated variance at each future lag and use the newly generated information to build further forecasts,

\footnotetext{
${ }^{101}$ Cryer and Chan (2008), page 303-304.

${ }^{102}$ For more information, see Cryer and Chan (2008), page 308-310.
} 
In conclusion, GARCH models can be further generalized ${ }^{103}$ by applying them to the residuals of the ARIMA model; in this case the ARIMA parameters will be identified according to the time series $Y_{t}$, while the GARCH parameters can be estimated according to the squared residuals from the fitted ARIMA model (Cryer and Chan 2008). Engle (2001) briefly describes other GARCH extensions, which take into account also the directions of the observations of the time series. These models are found to be especially useful for broad-based equity indices and bond market indices, where market declines predict an increased variance that similar to market increases. Among the models that perform such asymmetrical analysis of the conditional variance are EGARCH models ${ }^{104}$, whose variance can be represented as

$$
\ln \sigma^{2}{ }_{t+1}=\omega+\alpha\left(\phi R_{t}+\gamma\left[\left|R_{t}\right|-E\left|R_{t}\right|\right]\right)+\alpha \ln \sigma_{t}^{2}
$$

where $\alpha \theta<0$ indicates that the usual leverage effect is being displayed. The EGARCH model is able to ensure the positivity of the variance due to the use of the logarithmic specification, but is unable to calculate analytically the future expected variance beyond the first time lag.

There exist also TARCH models ${ }^{105}$ and TGARCH model ${ }^{106}$, which account for the fact that a negative return leads to an increased variance that is higher than one

\footnotetext{
${ }^{103}$ GARCH models that consider moving average processes and autoregressive processes of order greater than one (GARCH (p,q)) are defined as 'Long Memory in Variance' (Christoffersen 2003, 26).

${ }^{104}$ See Nelson (1991).

${ }^{105}$ See Rabemananjara and Zakoian (1993) and Glosten, Jaganathan and Runkle (1993).

${ }^{106}$ See Sabiruzzaman et al (2009) for a comparison of the two statistical tools.
} 
would have in the case of a positive return of the same size ${ }^{107}$. This happens to be the case because a negative return on a stock is generally viewed as a deterioration of equity value of the company and the consequent increase risk associated with that company ${ }^{108}$. The GARCH model can be modified so as to allow it to take into account this property of the markets according to which negative turns of the market affect the returns more heavily than positive ones. Nonlinear GARCH models (NGARCH), are therefore represented as follows

$$
\sigma_{t+1}=\omega+\alpha\left(R_{t}-\theta \sigma_{t}\right)^{2}+\beta \sigma_{t}^{2}=\omega+\alpha \sigma_{t}^{2}\left(z_{t}-\theta\right)^{2}+\beta \sigma_{t}^{2}
$$

where it is evident that a negative piece of news $(\theta>0)$ has a greater effect than $z_{t}$, a positive piece of news $\left(z_{t}>0\right)$ (Christoffersen 2003, 27).

Another model defines a variable $I_{t}$ that captures with a value of 1 the negative return, and with zeros otherwise. The variance of this model, called the GJR-GARCH model is represented as follows

$$
\sigma_{t+1}=\omega+\alpha R^{2}+\alpha \theta I_{t} R_{t}^{2}+\beta \sigma_{t}^{2}
$$

where $\alpha \theta>0$ captures the presence of the leverage effect.

Nonlinear Asymmetric GARCH (NAGARCH) models are the results of a generalization of Higgins and Bera (1992) NARCH models, which were created with the specific intent of generalizing the basic $\mathrm{ARCH}$ model to a model with a nonlinear con-

\footnotetext{
${ }^{107}$ Christoffersen (2003) defines this property as the 'leverage effect'. See Chapter 1.

${ }^{108}$ See Christoffersen 2003, 26.
} 
ditional variance (Engle and $\mathrm{Ng}$ 1993). According to Higgins and Bera, it is important to identify the correct conditional variance functional form in order to improve the accuracy of the forecasts of the model and to correctly identify the presence of ARCH processes. NAGARCH and NGARCH models are respectively defined by

$$
\begin{gathered}
\sigma_{t}^{2}=\omega+\alpha\left(\varepsilon_{t-1} \alpha_{t-1}{ }^{-1}+\gamma^{2}\right)+\beta{\sigma_{t-1}}^{2}, \\
\sigma^{\delta}{ }_{t}=\omega+\sum_{i=1}^{q} \alpha\left|\varepsilon_{t-1}\right|^{\delta}+\sum_{i=1}^{q} \beta_{i} \sigma^{\delta}{ }_{t-1} .
\end{gathered}
$$

The models have the additional property of modeling differences in variance in correspondence with negative shocks. In fact, NAGARCH attributes a different (larger) future variance whenever a negative return enters the series, a feature which is rather common especially in stock market data.

Several other generalizations and modifications of Engle (1982), Bollerslev (1986) and Taylor (1986) models have made their appearance in the statistic and economic literature. The revision of all these models goes beyond the scope of the present work; the reader interested in such a review may refer to Bollerslev's (2008) work.

\subsection{Methodology and hypothesis testing}

Given the particular nature of the hypotheses to be tested (see Chapter Model Selection and Validation), I selected a particular type of GARCH model for testing the hypotheses that measure the impact of the gas disputes on the GDP growth of the 9 countries selected (pooled panel design) and for all case studies considered. However, in the attempt to allow a more efficient estimation of the model, a simpler Box-Tiao intervention model is used to test both the hypotheses that disputes have an impact on the 
stock markets under investigation and that statements and other official acts had an effect on the stock markets for all case studies analyzed. In this case, given the desire to have a better look at the micro level of the dependent variable (the stock market), the analysis will not be performed using a pooled panel design; it will simply omit the other reaction functions and the other variables that measure the impact of the contemporaneous gas disputes on the GDP growth or stock markets of the other 8 countries studied in this work. 


\subsection{Data and Variables: real GDP growth and stock market mod- el}

Youngs $(2009,79-80)$ notes that even though Russia is often cited simply as just one of the largest energy supplier in the world, its importance for the European countries largely varies according to the country at which one is looking. As shown in earlier sections of this work, the dependence of European countries varies significantly, since some of them only slightly depend on Russian gas, while others depend entirely on Russia's energy. Youngs split European countries mainly in three groups; countries with low dependence on Russia, like Spain, Sweden, the UK, the Netherlands, Portugal, Belgium, and Ireland; countries with moderate dependence on Russia's energy like France, Italy and Germany, and countries with high to total dependence on Russian energy like Austria, Czech Republic, Greece, Hungary, Poland, Romania, Slovenia, Finland, Latvia, Lithuania and Slovakia ${ }^{109}$. In this work I am taking into account the fact that analyzing just countries with high dependence on Russian energy I might be biasing the results of the statistical analysis proposed below. For this reason I selected a total of 9 countries, 3 for each of the dependence level as described in Youngs (2009). The time frame spans from January 1, 2003 to December 31, 2009 for the GDP model, and it spans 200 days for the stock market model ${ }^{110}$. Such time span has been chosen given Youngs' notation that in the last 6 years Russia has clearly been using the gas weapon to achieve prede-

\footnotetext{
${ }^{109}$ Germany, Italy, Turkey and France are the biggest energy importers (Youngs 2009).

${ }^{110}$ An exception is made here for the 2004 Belarusian crisis. In this case, the time frame considered is 317 days, 100 days prior to the start of the dispute and 100 days after the onset of the reaction to the crises, which occurred later than the other disputes.
} 
fined political and economic goals. In doing so, I hope to capture a phenomenon that is rather constant over the years analyzed, thus reducing the probability of making incorrect inferences. The 2010 Belarusian dispute ${ }^{111}$, which has also shown that the 'early warning' system described below needs further refinement, has not been considered in this work due to data collection issues. In fact, many data on 2010 have yet to be published, including not only real GDP growth data, but also the stock market data used in the second model proposed in this work.

The time series models used in this work are based on the use of an independent variable for each crisis that measures the statistical significance of the effect of the gas dispute on the trends assumed by GDP and the stock market. I assume that such a phenomenon can be better reproduced by using a function that spikes on the quarter the dispute starts (when the two parties openly declare that no agreement was reached - see Figure 3.4) and declines as time passes, since it is reasonable to assume that once the crisis has been solved its effects will slowly be reabsorbed. However, as suggested by McLeary and Hay (1980), a practical analysis of the statistical model has been performed in order to test the fit of the assumption that the gas dispute can be better represented by a spiking and decaying function or a simpler step function ${ }^{112}$. In Figure 3.4 the reader can visualize GDP levels and disputes ${ }^{113}$. A similar procedure has been adopted to hypothesize the duration of the gas dispute effects and reaction function effects on the stock market.

\footnotetext{
${ }^{111}$ See http://www.nytimes.com/2010/06/22/world/europe/22belarus.html?_r=1\&fta=y .

${ }^{112}$ See below.

${ }^{113}$ Please note that in correspondence to the third dispute, two disputes occurred at the same time: the Moldovan crisis and the 2006 Ukrainian crisis.
} 


\section{Figure 3.4}

\section{GDP levels and gas disputes ${ }^{114}$}

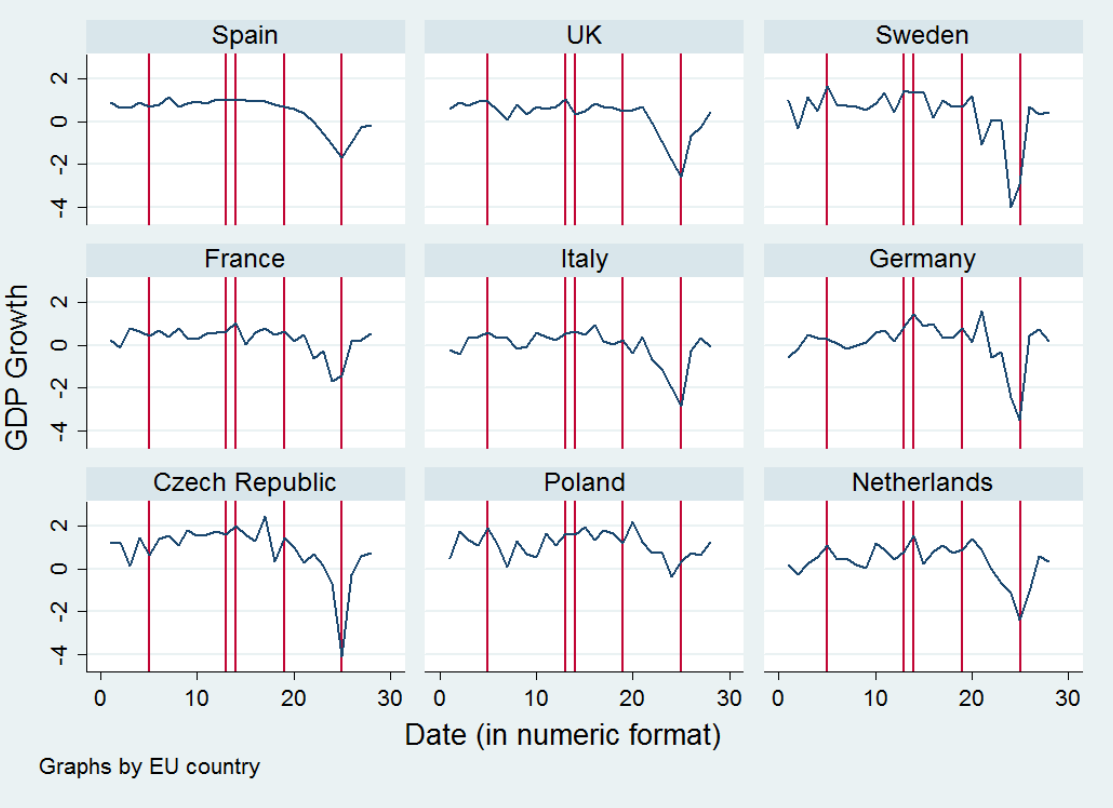

The duration of the effect of gas disputes on external economies has been estimated by observing the dependent variable and building hypotheses regarding the duration of the impact. The results of this analysis for both models are summarized in Table 3.1 .

${ }^{114}$ The disputes presented in the figure are ordered chronologically: Belarus (2004), Moldova (2006) and Ukraine (2006), Belarus (2006), Belarus (2007), Ukraine (2009). 
Table 3.1

\section{Observable daily duration of impact of gas crises and observable daily effect of}

\section{reaction functions (Stock Market model)}

\begin{tabular}{|c|c|c|c|}
\hline Crisis & $\begin{array}{l}\text { Dispute (GDP } \\
\text { Market) - days }\end{array}$ & $\begin{array}{c}\text { Dispute (Stock) } \\
\text { - days }\end{array}$ & $\begin{array}{l}\text { Reactions } \\
\text { (Stock) - days }\end{array}$ \\
\hline $\begin{array}{c}\text { Belarus-Russia } \\
2004\end{array}$ & 1,2 & $3,9,10,11,12$ & 4,5 \\
\hline $\begin{array}{c}\text { Moldova-Russia } \\
2006\end{array}$ & 1,2 & $1,2,23,40$ & $3,4,18$ \\
\hline $\begin{array}{c}\text { Belarus-Russia } \\
2006\end{array}$ & $1,2,4,5$ & $1,3,6,9$ & - \\
\hline $\begin{array}{c}\text { Ukraine-Russia } \\
2006\end{array}$ & 1,2 & $9,2,1,17,21$ & $1,4,8$ \\
\hline $\begin{array}{c}\text { Belarus-Russia } \\
2007\end{array}$ & $1,2,4$ & $6,7,13,14,15$ & $2,4,8$ \\
\hline $\begin{array}{c}\text { Ukraine-Russia } \\
2009\end{array}$ & $1,2,3$ & $24,26,27,66$ & 3,7 \\
\hline
\end{tabular}

In order to maximize the internal validity of the model, several other control variables need to be introduced. More specifically, following other examples in the literature, variables accounting for the exchange rate between the euro and the dollar, exchange rate between the local currency and euro (UK), exchange rate between the dollar and the euro, gas prices ${ }^{115}$, oil prices, domestic demand ${ }^{116}$, inflation ${ }^{117}$, industrial production $^{118}$, exports and imports ${ }^{119}$, unemployment rate ${ }^{120}$, balance of payments ${ }^{121}$, real

\footnotetext{
${ }^{115}$ Natural gas prices in Europe cannot be easily accessed. Some agencies release this kind of information only under the payment of a fee, but for privacy reasons the identity of all traders and the prices charged by them are not disclosed. For this reason, I decided to resort to Nymex Henry Hub Natural Gas prices, futures that are traded on the New York Mercantile Exchange (NYMEX), as a measure of the level of gas prices in Europe. I assume that the prices levels by these quarterly figures of these futures well approximate the same trend of gas prices in Europe.

${ }^{116}$ Data is seasonally adjusted and adjusted data by working days. Percentage of GDP.

${ }^{117}$ Minimum sampling frequency: 1 month. Base year: 2005.

${ }^{118}$ Data is seasonally adjusted and adjusted by working days. Percentage of GDP. Minimum sampling frequency: 1 month.

${ }^{119}$ Data is seasonally adjusted and adjusted by working days. Millions of euro, chain-linked volumes, reference year 2000 (at 2000 exchange rates). Minimum sampling frequency: quarters.

${ }^{120}$ It refers to EU citizens between 15 and 64 years. Minimum sampling frequency: quarters.
} 
consumption $^{122}$, deposit/ lending interest, government consolidated gross debt ${ }^{123}$ are used as controls (Schneider and Troeger 2006, 642-643; Schneider and Troeger 2006; Frey and Kucher 2000; Hamilton 2003).

Table 3.2

\section{Table of sources}

\section{Variable}

Exchange rate between the euro and the dollar, exchange rate between the local currency and euro (UK), exchange rate between the dollar and the euro

Gas prices

Oil prices

Domestic demand

Inflation

Industrial production

Exports and imports

Unemployment rate

Balance of payments

Real consumption

Deposit/ lending interest

Government consolidated gross debt

\section{Data source}

http://quotes.stocknod.com/stocknod/?Month=5\&Pag

e=HISTORICAL\&Ticker $=\$$ NYHUB \&Year $=2010 \&$

Range $=12$

http://quotes.stocknod.com/stocknod/?Month=5\&Pag e=HISTORICAL\&Ticker $=\$$ NYHUB $\&$ Year $=2010 \&$

Range $=12$

http://tonto.eia.doe.gov/dnav/pet/hist/LeafHandler.as $\mathrm{hx} ? \mathrm{n}=\mathrm{PET} \& \mathrm{~s}=\mathrm{RBRTE} \& \mathrm{f}=\mathrm{D}$

Eurostat website

Eurostat website

Eurostat website

Eurostat website

Eurostat website

Eurostat website

Eurostat website

European Central Bank website. See http://www.ecb.int/stats/monetary/rates/html/index.en .html .

Eurostat website

\footnotetext{
${ }^{121}$ Millions of Euro. Current account, Goods and services. Minimum sampling frequency: quarters.

${ }^{122}$ Final consumption expenditure. Data is seasonally adjusted and adjusted by working days. Index, $2000=100$.

${ }^{123}$ Government consolidated gross debt. Percentage of GDP. Minimum sampling frequency: quarters.
} 
The data relative to these variables are publicly available not only through the Eurostat database system and the European Central Bank, but also through several other institutions like the World Bank. In this analysis, however, I preferred to extract as many variables as I could from a single source (Eurostat) so as to reduce to minimum measurements errors, especially across countries. See Table 3.3 for summary statistics of the variables just discussed.

Table 3.3

Summary statistics of dependent, independent variables and control variables (GDP model)

\begin{tabular}{|c|c|c|c|c|}
\hline Dependent Variable & Mean & Std. Dev & Min & Max \\
\hline Real GDP growth & .4345894 & .9670259 & -4.12844 & 2.486839 \\
\hline Independent Variables & Mean & Std. Dev & Min & Max \\
\hline Belarus 2004 (2 Quarters & .1071429 & .2794926 & 0 & 1 \\
\hline Moldova 2006 (2 Quarters) & .0714286 & .2580519 & 0 & 1 \\
\hline Belarus 2006 (2 Quarters) & .0714286 & .2580519 & 0 & 1 \\
\hline Belarus 2007 (4 Quarters) & .1428571 & .3506235 & 0 & 1 \\
\hline Ukraine 2006, 2009 (1\&2 Quarters) & .0396825 & .1956008 & 0 & 1 \\
\hline Control Variable (no PCA) $)^{124}$ & Mean & Std. Dev & Min & Max \\
\hline Gas price & 7.588007 & 1.929084 & 4.528833 & 12.90081 \\
\hline Oil price & 59.69777 & 24.072 & 26.17857 & 121.6884 \\
\hline Exchange rate BRP/Euro & 1.384727 & .1310551 & 1.101 & 1.4994 \\
\hline Exchange rate Euro/US Dollar & 1.301698 & .12023 & 1.0733 & 1.56252 \\
\hline
\end{tabular}

Given that all these data are measured on a quarterly basis, all independent and control variables have been downloaded or transformed into quarterly data. Doing so

\footnotetext{
${ }^{124}$ See below.
} 
not only guarantees a better estimate of the parameters of the true variables (which do not have to be estimated nor averaged), but it won't significantly affect the estimation of the independent variables, which happen to measure phenomena whose effects generally manifest themselves at the beginning of a quarter. The estimation of the effect of the gas crises requires controlling for a wide set of variables, which, however, are measured on a monthly, quarterly or even yearly basis. Controlling for these variables entails making assumptions on the behaviors of these variables before transforming them into daily data, which might render the job of introducing control substantially meaningless, given that the real frequency of these variables cannot be measured nor precisely estimated. Measuring the effects of these crises on other economies can be done by looking at changes on real GDP growth, even if measured quarterly. Despite the loss of several degrees of freedom (which can be compensated with PCA - see below), adopting this kind of measure should not lead to results of lower quality. In fact, the central interest is to test whether there are long terms effects of these crises and such a goal can be achieved by using quarterly data like real GDP growth, especially if the start of these gas disputes coincides with the start of a new quarter (see picture below). 
Table 3.4

\section{Dates corresponding to the start of the disputes analyzed}

$\begin{array}{ccc}\text { Crisis } & \begin{array}{c}\text { Start } \\ \text { Quarter } \\ \text { Q1-04 }\end{array} & \text { Date negotiations failed } \\ \text { Moldova-Russia 2006 } & \text { Q1-06 } & \text { January 1, 2004 } 2006 \\ \text { Belarus-Russia 2006 } & \text { Q2-06 } & \text { End of March 2006 } \\ \text { Ukraine-Russia 2006 } & \text { Q1-06 } & \text { January 1, 2006 } \\ \text { Belarus-Russia 2007 } & \text { Q3-07 } & \text { August 1, 2007 } \\ \text { Ukraine-Russia 2009 } & \text { Q1-09 } & \text { January 1, 2009 }\end{array}$

The analysis is performed on 9 EU countries, which are divided in three groups according to their dependence on Russian gas. In fact, in the EU there are countries with low dependence on Russia like Spain, Sweden, the UK. There are also countries with moderate dependence on Russia's energy like France, Italy and Germany and countries with high to total dependence on Russian energy like the Netherlands, Czech Republic, and Poland. These countries were chosen for their importance as members of the Council of the European Union, an important legislative institution in the EU (Bindi 2010, Young 2009). The total number of votes of the countries considered in this work amounts to $59.42 \%$ of the total available to all EU countries. A pooled design is employed to better deal with country-specific reactions to the gas crises; this design will be then re-applied for every group of countries chosen based on their dependence on Russian energy.

\footnotetext{
${ }^{125}$ In the stock market model, this event has been approximated to have happened on March 20, 2006 given the lack of more precise information. Please note that this crisis refers to the unilateral statement from Gazprom to increase the price of gas supplied to Belarus which was not followed by any significant statement or action from the EU.
} 
Table 3.5

\section{GDP model variables}

\begin{tabular}{|l|l|}
\hline Dependent Variables & $\begin{array}{l}\text { Independent variable } \\
\text { Impact of gas dispute on economies (dummy va- } \\
\text { riables, 0-1) } \\
\text { Control variables }\end{array}$ \\
Real GDP growth: & $\begin{array}{l}\text { Exchange rate between the local currency and Euro } \\
\text { (UK) } \\
\text { 1) Spain (27) }{ }^{126}, \text { Sweden (10), the UK (29) } \\
\text { Exchange rate between the Dollar and the Euro } \\
\text { Gas prices } \\
\text { Oil prices } \\
\text { Domestic Demand } \\
\text { Inflation } \\
\text { Industrial production } \\
\text { Exports and imports } \\
\text { Unemployment rate } \\
\text { Balance of Payments } \\
\text { Deposit/ lending interest } \\
\text { Government consolidated gross debt as percentage } \\
\text { of GDP }\end{array}$ \\
moderate & $\begin{array}{l}\text { France (29), Italy (29), Germany (29) } \\
\text { 3) the Netherlands (13), Czech Republic } \\
\text { (12), and Poland (27) - high }\end{array}$ \\
&
\end{tabular}

By controlling for all these variables, I argue that the effect of the gas dispute can be more precisely identified by the model. Other political variables like research expenditure and country regime (Polity 4 data) ${ }^{127}$ were considered, but dropped given their annual measurement frequency.

The use of daily data (stock market data), however, should produce more precise estimation of the real effects of these crises from the exact day the negotiations failed. Moreover, daily data allows me to test the impact of countries' or the European Commission's reactions to the rise of these crises, by checking the statistical significance of events like public statements of creation of diplomatic institutions dedicated to the resolution of energy disputes on the stock market. However, using financial data entails an

\footnotetext{
${ }^{126}$ Votes assigned to each country in parenthesis.

${ }^{127}$ See http://www.systemicpeace.org/polity/polity4.htm .
} 
increased risk of Type I error, given to the fact that much more is going in a financial time series. In fact, not only traders' expectations matter in stock market data, but also simple speculation and randomness affect the fluctuations of this kind of data. Other political and economic controls were not introduced in this model in order to avoid biases deriving from an incorrect estimation of the daily variation of variables that are measured only monthly, quarterly or yearly. It is important to note that gas disputes had a similar effect (in terms of duration) in both the GDP and the stock market model (Table 3.6). 
Table 3.6

Stock market model: summary statistics of dependent and independent va-

riables

\begin{tabular}{|c|c|c|c|c|}
\hline Dependent Variable & Mean & Std. Dev & Min & Max \\
\hline $\begin{array}{l}\text { Main Stock Market indices ( } 9 \text { coun- } \\
\text { tries) }\end{array}$ & 6634.828 & 9395.41 & 1.95 & 44324 \\
\hline Independent Variables & Mean & Std. Dev & Min & Max \\
\hline Belarus 2004 (4 months) & .0053014 & .0726187 & 0 & 1 \\
\hline Moldova 2006 (1 month) & .0125147 & .1111692 & 0 & 1 \\
\hline Belarus 2006 (2 months) & .0242545 & .1538418 & 0 & 1 \\
\hline Belarus 2007 (1 year) & .1431365 & .3502196 & 0 & 1 \\
\hline Ukraine 2006 (2 weeks) & .0054752 & .0737931 & 0 & 1 \\
\hline Ukraine 2009 (2 months) & .023465 & .1513783 & 0 & 1 \\
\hline \multicolumn{5}{|l|}{ Reaction functions } \\
\hline Belarus 2004 (1 day) & .0003911 & .0197724 & 0 & 1 \\
\hline Moldova 2006 (2 weeks) & .0062573 & .0788571 & 0 & 1 \\
\hline Belarus $2006^{128}$ & NA & NA & - & - \\
\hline Belarus 2007 (2 months) & .0242472 & .1538189 & 0 & 1 \\
\hline Ukraine 2006 (2 weeks) & .0054752 & .0737931 & 0 & 1 \\
\hline Ukraine 2009 (1 year) & .1415722 & .3486184 & 0 & 1 \\
\hline
\end{tabular}

\footnotetext{
${ }^{128}$ In this case, since Gazprom only threatened to increase price only, without doing much else, no intervention of external actor was recorded (see above).
} 
Table 3.7

Stock market model: summary statistics of dependent and independent va-

\section{riables}

\begin{tabular}{|c|c|}
\hline Dependent Variable & Data Source \\
\hline IBEX 35 (Spain) & http://finance.yahoo.com \\
\hline FTSE 100 (UK) & http://finance.yahoo.com \\
\hline OMX 30 (Sweden) & $\begin{array}{l}\text { http://finance.yahoo.com and } \\
\text { http://shb.solutions.six.se }\end{array}$ \\
\hline CAC 40 (France) & http://finance.yahoo.com \\
\hline MIB30 (Italy) & http://uk.finance.yahoo.com \\
\hline DAX (Germany) & http://finance.yahoo.com \\
\hline PX-GLOB (Czech Republic) & http://www.pse.cz \\
\hline WIG20 (Poland) & http://gielda.wp.pl \\
\hline AEX (Netherlands) & http://finance.yahoo.com \\
\hline
\end{tabular}

The reaction functions selected in this work refer to the most important form of reaction, as found in the news, reporting the development of the disputes. More specifically, I selected for the 2006 Ukraine-Russia dispute the statement made by the European Commission President Barroso on February 9, 2006 regarding the need for more cooperation among the EU to reduce dependence on Russian energy and that alternative sources of energy were needed. This was supported the next day by the Polish Prime Minister's statement about the need of creating a "Euro-Atlantic Energy Security Pact". For the 2009 Ukrainian crisis I selected the statement made by the Presidency of the European Union of January 4, 2009, urging the two countries to find an urgent solution to the commercial dispute and to immediately resume full deliveries of gas to the EU member states. 
For the first Belarusian crisis, the reaction functions refer to the Directive of the Council of the European Union 2004/67/EC of April 26, 2004. This directive advocates common EU policies and responsibilities on each EU country and establishes a procedure to be followed in case another dispute arises. For the 2007 crisis the European Commission's statement of August 1, 2007 regarding the deep concern of the whole EU and the activation of the EU's Network of Energy Security Correspondents (NESCO) forum is used ${ }^{129}$. Given the lack of a severe collapse of negotiations (which did not really take place at the end of March 2006 between Belarus and Russia), no reaction function has been added in the statistical model given the lack of relevant statements made by external actors regarding the Russian statement of rising gas price to Belarus European levels.

Finally, the reaction function added in the model regarding the Moldovan dispute refers to the EU's statement made on January 9, 2006 regarding the need to "urgently recommence negotiations and reach an equitable compromise" (Socor 2006).

See below for a summary for the reaction functions adopted in this work. $=$ EN\&guiLanguage=en. See below for more information. 
Table 3.8

Reaction functions

$\begin{array}{ccc}\text { External actors reaction } & \text { Date } & \text { Description } \\ \text { Belarus-Russia 2004 } & \text { April 26, 2004 } & \text { 2004/67/EC Directive } \\ \text { Moldova-Russia 2006 } & \text { January 9, 2006 } & \text { EU statement } \\ \text { Belarus-Russia 2006 } & \text { NA } & \text { NA } \\ \text { Ukraine-Russia 2006 } & \text { February 9, } & \begin{array}{c}\text { European Commission } \\ \text { President's statement }\end{array} \\ \text { Belarus-Russia 2007 } & \text { August 1, 2007 } & \begin{array}{c}\text { EU statement + NESCO } \\ \text { activation }\end{array} \\ \text { Ukraine-Russia 2009 } & \text { January 4, 2009 } & \text { Statement of EU president }\end{array}$

\subsection{Principal Component Analysis (PCA)}

The high multicollinearity stemming especially from the macroeconomic data of the GDP model ${ }^{130}$ requires the generation of statistically independent factors through the use of PCA. Linear algebra allows the dimensional reduction of a complex database not simply by arbitrarily selecting those to be eliminated, but by using a scientific method that supports the generation of a set of statistically independent factors that retains the highest informational content, and dismissing the variables that represent just noise or that are redundant ${ }^{131}$. PCA generates factors with which it is possible to draw bidimensional maps to test the real usefulness of the factors for the final outcome, the ex-

\footnotetext{
${ }^{130}$ Mean VIF=151,934.33.

${ }^{131}$ More specifically, PCA rotates the original matrix so that the main axis is aligned with the most important dimension, the second axis, perpendicular to the first one, is aligned with the second most important axis and so on. The rotated matrix is also centered on the mean of the distribution.
} 
planation of the dependent variable ${ }^{132}$. Factors are generated by a correlation matrix, which is then processed in such a manner to obtain a set of factors (new variables) in equal amount of that of the original variables (Gujarati 2009). As said above, factors have the property of being statistically independent and are the result of a linear transformation of the original variables. The generated factors are then ordered in descending order based on their informative content. Scholars usually choose the number of factors that satisfy at least one of the following criteria (Mortara 2006):

1. auto-values exceed 1 ;

2. new factors contain more than $66 \%$ of the original variance;

3. new factors contain more than $75 \%$ of the original variance;

4. all factors that are on the left of the "elbow" of the curve drawn by INSTAMAP or any other software for the selection of factors to be retained;

5. all factors that can be meaningful from a conceptual/theoretical standpoint;

However, it is important to note that PCA can be successfully employed to better deal with the outliers, limiting their effect on the remainder of the data.

The independent variables and the original control variables selected appear to produce large quantities of collinearity; thanks to the ability of PCA of creating statistically independent factors I hope to reduce this issue to manageable levels. In this work, I retained as few factors as possible, with the additional goal of keeping at least $85 \%$ of the original variance. PCA generated 3 factors using the information from the 12 quarterly macroeconomic data series listed above, retaining, on average, over $90 \%$ of the to-

\footnotetext{
${ }^{132}$ This is true if one considers that using statistically independent variables will reduce the collinearity, while at the same time, retaining almost all the information possessed by the original variables.
} 
tal variance for each country. Control variables like the exchange rate between the Euro and the Dollar, Euro and British Pound, Oil price, Gas price were not processed with PCA in order to be able to test the ability of the model to estimate correct parameters for these control variables. Highly collinear variables (even if not significant) were not removed from the model in order not to bias the estimation of the parameters. By doing so, the average VIF equals 5.67, thus just slightly more than the value of 5 suggested by the literature (Mason and Perreault 1991).

Table 3.9

Control variables processed by PCA and resulting factors (GDP model only)

\begin{tabular}{lcccc|}
\multicolumn{1}{c}{ Control Variable } & Mean & Std. Dev & Min & Max \\
Domestic Demand & 99.34821 & 4.282491 & 91 & 107.3 \\
Industrial Production & 101.0157 & 9.044397 & 81.1 & 130.3 \\
Exports & 89418.29 & 68623.62 & 11600.2 & 295831.6 \\
Imports & 89165.76 & 62947.49 & 12619 & 256117 \\
Unemployment & 8.10935 & 3.635263 & 2.4 & 21 \\
Balance of Payments & 2043.925 & 13520.04 & -22426 & 47923 \\
Inflation & 102.569 & 4.883392 & 92.67 & 113.5 \\
Real Consumption & 114.082 & 9.117031 & 101.01 & 139.86 \\
Deposit Interest & 1.218929 & 0.832248 & 0.25 & 3.22 \\
Lending Interest & 3.2095 & 0.844887 & 1.981 & 5.22 \\
Government Debt & 55.89325 & 21.80309 & 27.4 & 117.1 \\
& & & & \\
Factors & Mean & Std. Dev & Min & Max \\
Factor 1 & .0000317 & .9868027 & -1.9 & 2.338 \\
Factor 2 & $6.28 \mathrm{e}-10$ & .9839433 & -2.093 & 2.333 \\
Factor 3 & .0015873 & .9869499 & -2.6 & 2.2
\end{tabular}


The visual inspection of Figure 3.5 reveals that the stationarity criterion for the GDP model is not respected, that is the series is nonstationary in the homogeneous sense.

Figure 3.5

\section{Raw series of the dependent variable (GDP model)}

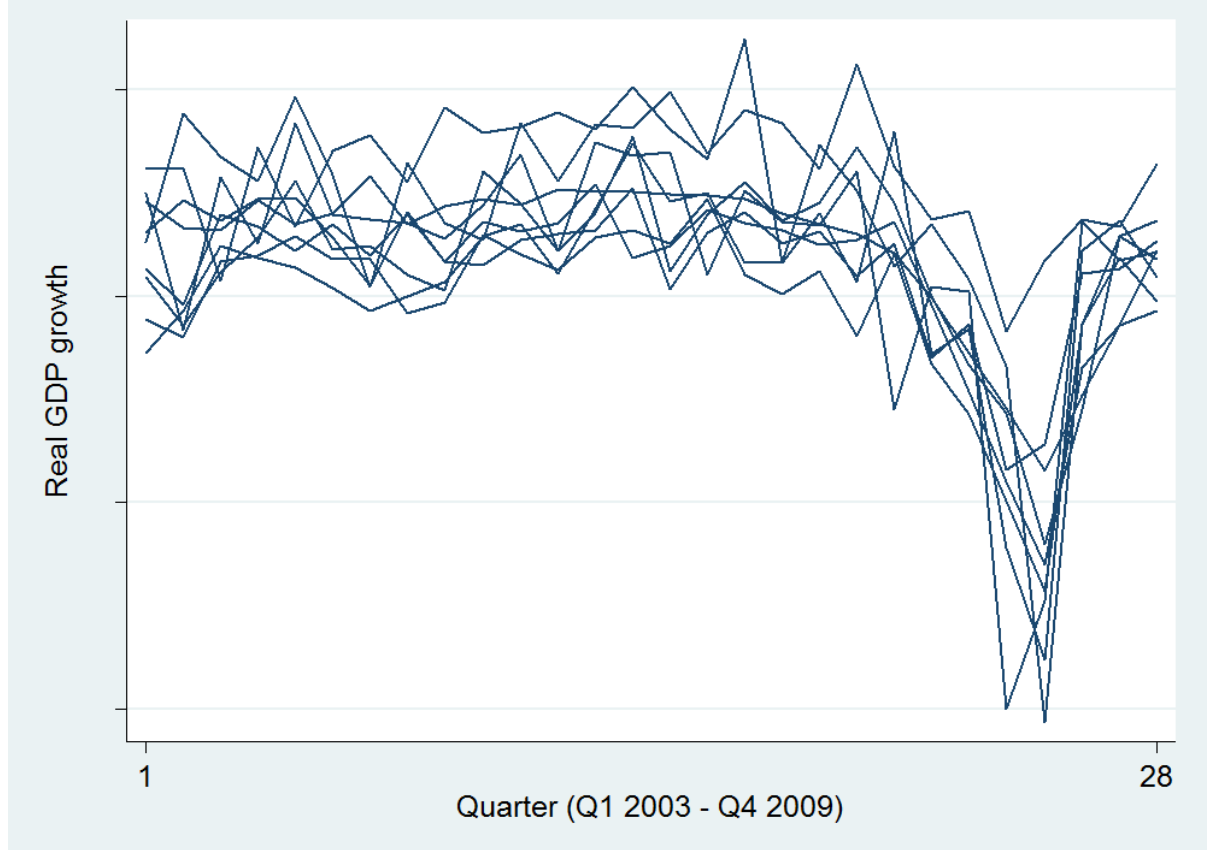

In fact, the observation of the data plotted below clearly reveals that there is an upward trend in the data. It is therefore necessary to differentiate the time series.

The stock market model reveals only a slightly upward trend for all disputes, exception made for the 2009 crisis. Here, the 9 stock markets analyzed were slightly following a downward trend. Thus, differencing is applied also to the stock market model in order to remove these trends. The results for the GDP model are as follow. 
Figure 3.6

First differencing of the dependent variable (GDP model)

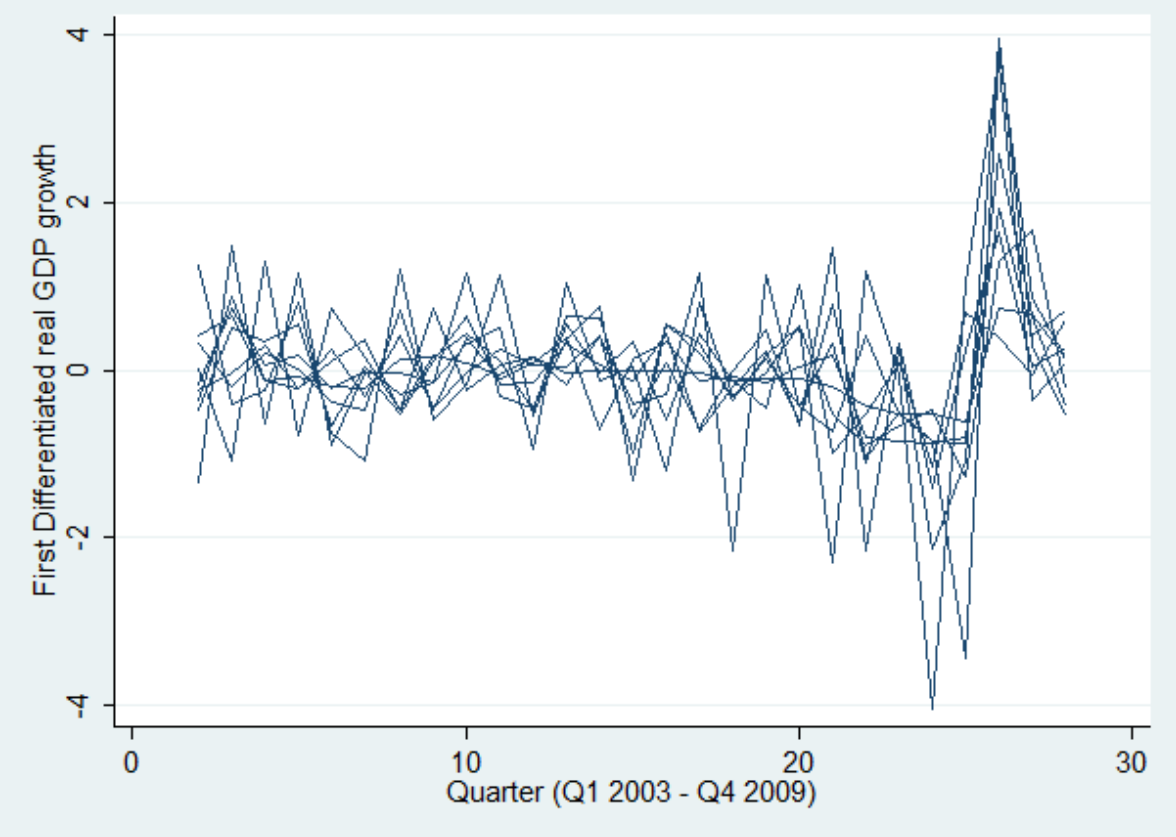

First differentiation is enough for both models to reach stationarity.

Once differentiated, both time series show another problem, non-stationary variance. The variance is lower in the first part of the series, and increases from that point on. The distribution is divided in two parts: the first part is characterized by low variance, while the second part is characterized by a larger variance. It is necessary then to proceed with the logging of the dependent variable. 


\section{Figure 3.7}

\section{First differencing of the logged dependent variable (GDP model)}

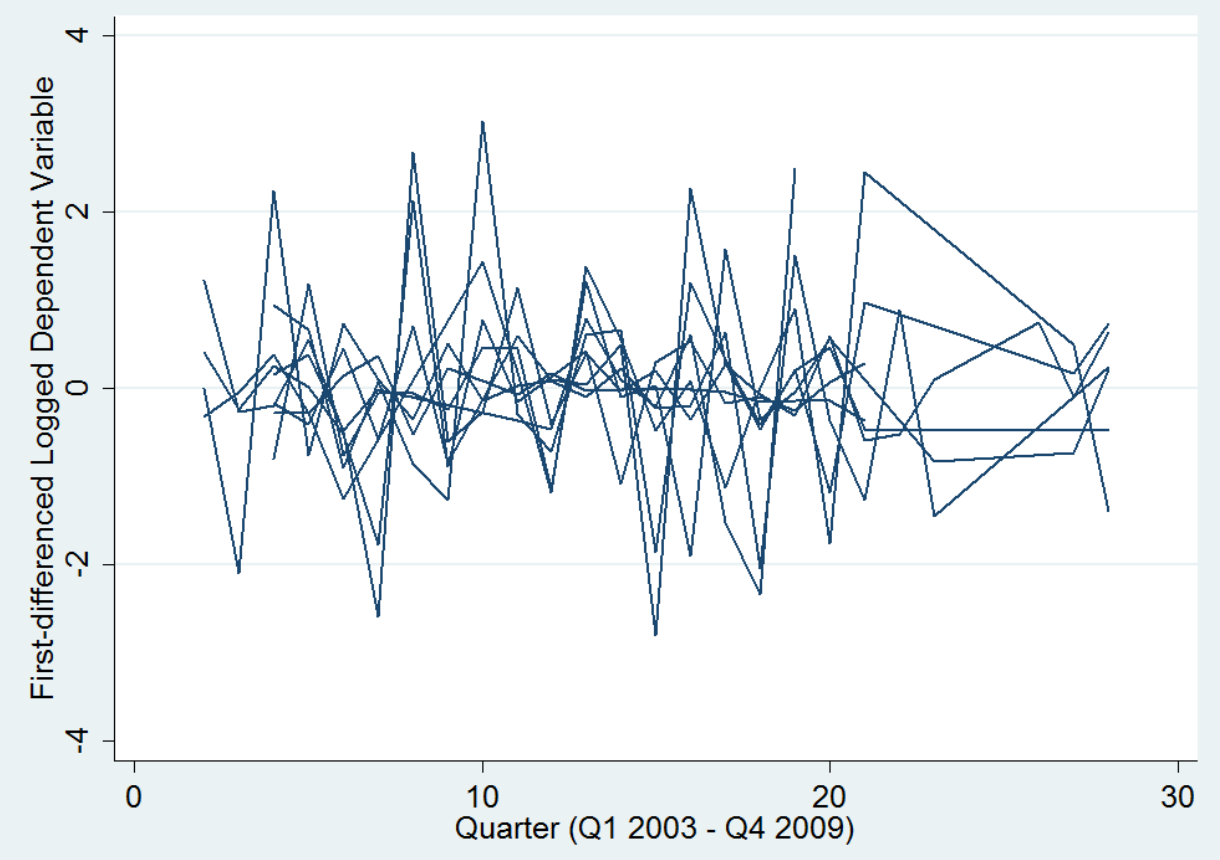

However, even by doing so, the problem is not resolved, and it is for this reason that I chose not to use a simple Box-Jenkins ARIMA model. Additional logs of the dependent variable have not produced significant results, since the distribution continues to show volatility clusters. The implementation of a GARCH is therefore required for the GDP model, as also supported by the significantly better fit of the models ${ }^{133}$ and the visual inspection of residuals showed below.

\footnotetext{
133 AIC and BIC for the pooled cross sectional time series GDP model equal respectively 418.4 and 455.7, compared to the PP-NARCH $(0,0)$ model's values of 361.8 and 408.8. Similarly, AIC and BIC for the pooled cross sectional time series stock market model equal respectively -125889 and -125792.5 , compared to the values of the PP-NARCH $(1,1)$ model with autoregressive and moving average processes of first-order -131765.4 and -131628.7.
} 
Figure 3.8

Residuals of a pooled cross sectional GDP model with first order autoregressive and moving average disturbances

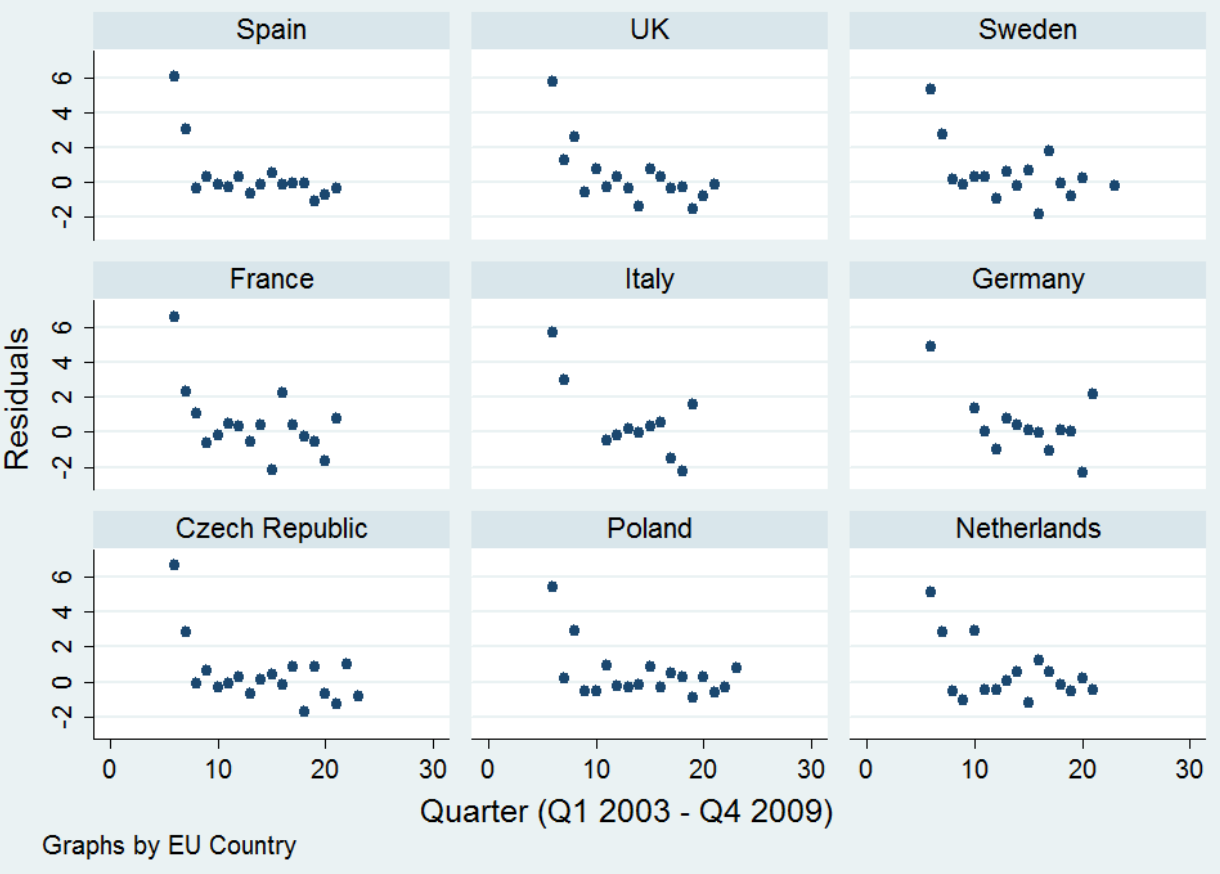

Similar comments apply for the stock market model: especially in the case of the Italian Mib 30 index in the dataset relative to the 2009 dispute, higher volatility characterizes the first part of the time series. Logging, in this case, produces the results as represented by Figure 3.9. 


\section{Figure 3.9}

First differencing of the logged dependent variable (stock market model, 2009

\section{dispute)}

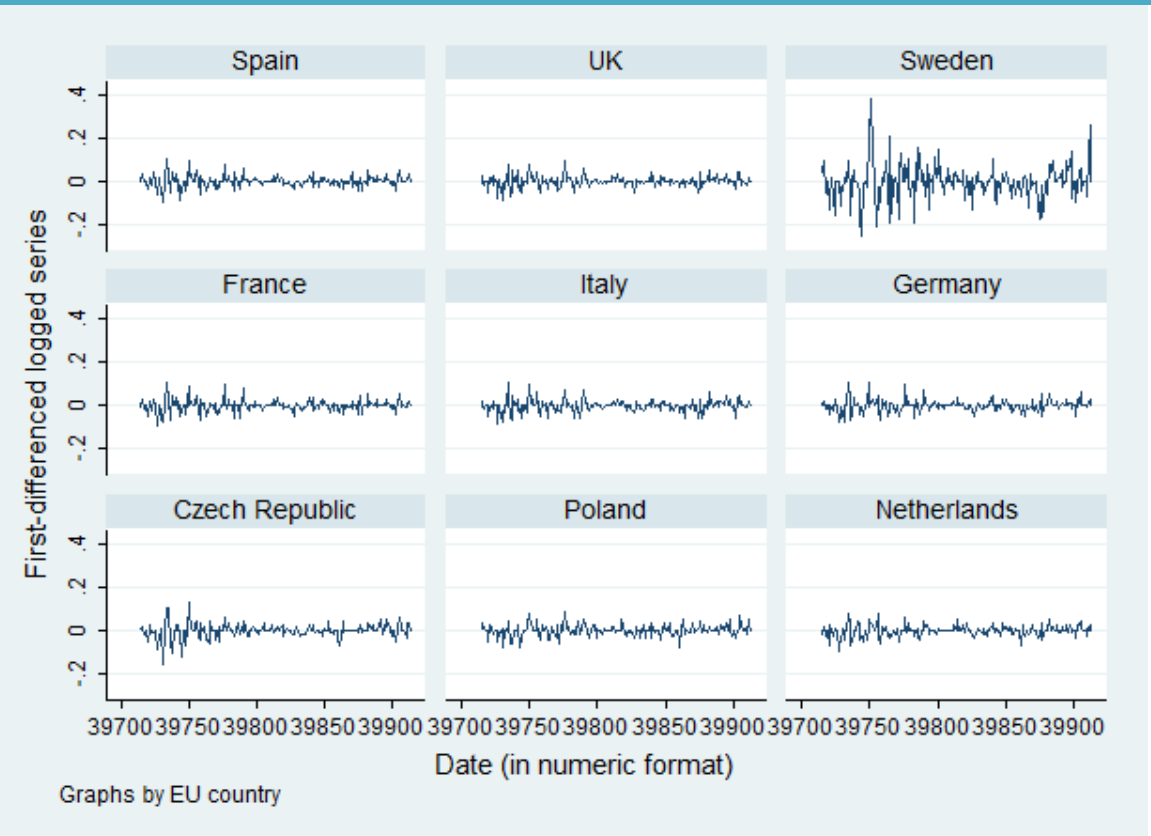

The implementation of a GARCH model, which could be justifiable given the presence of some heteroskedasticity model in the Swedish series, is not required for the stock market model. Since a better fit generally corresponds to the Box-Jenkins ARIMA model (fixed effects) ${ }^{134}$, I adopt this model to perform my analyses. This will also allow me to have better understanding of the impact of the variables on the dependent variables by estimating several models and comparing their results. The datasets relative to all the other disputes show an even lesser degree of heteroskedasticity, which supports the use of a simpler Box-Jenkins ARIMA model (fixed effects) for the analyses of stock markets fluctuations.

\footnotetext{
${ }^{134} \mathrm{AIC}$ and BIC respectively equal to -6828.903 and -6812.431 for the Box-Jenkins ARIMA model and AIC and BIC equal to -7161.561 and -7117.596 for the PP-NARCH model.
} 
Figure 3.10

\section{Residuals of a pooled cross sectional Stock Market model with first order au- toregressive disturbances (2009 dispute)}

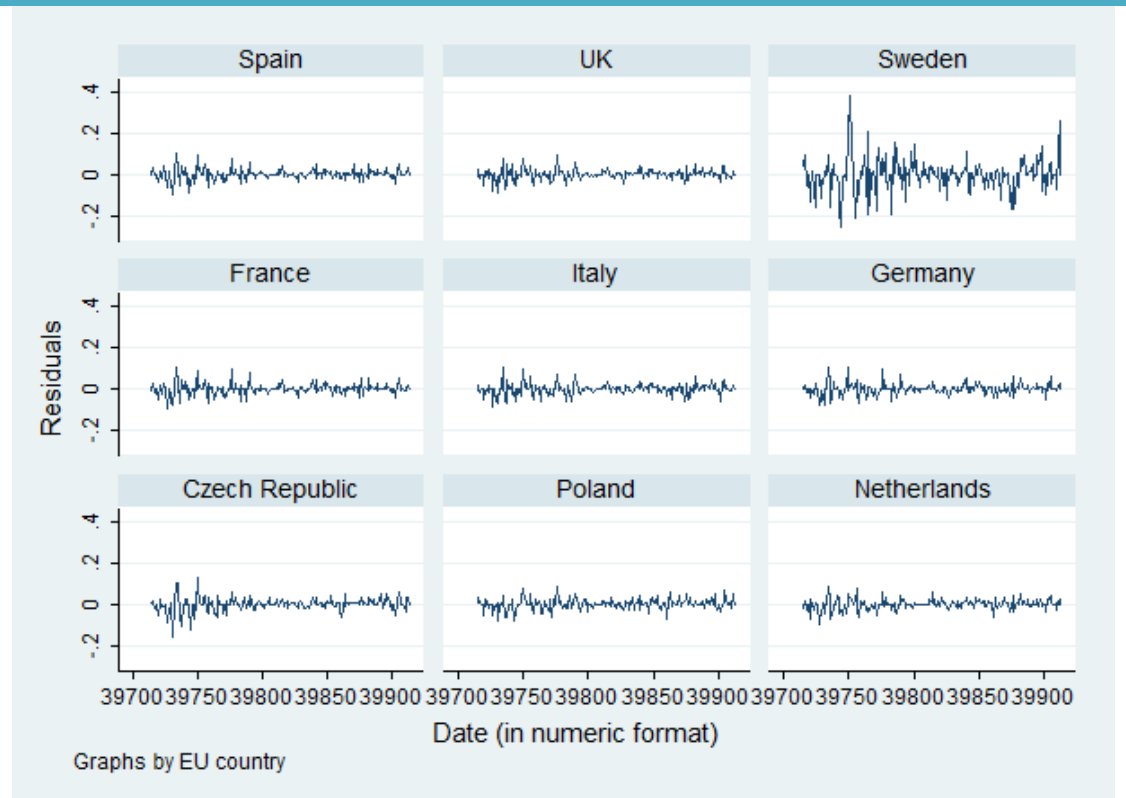

The GARCH model identified as 'best' for the GDP model is not only a pooled panel, but it is also nonlinear, which refers to the nonlinearity of the conditional variance function ${ }^{135}$. The model is further enriched with autoregressive and moving average disturbances of first-order. The correlograms of each panels supports the use of either autoregressive or moving average processes or a combination of both, and firstorder processes (commonly found in real data) are introduced in the model for an overall increase of fitness of the model ${ }^{136}$.

The Shapiro-Silk normality test shows that the residuals of both models do not follow a normal distribution, results which are also confirmed by the Skewe-

\footnotetext{
${ }^{135}$ See Higgins and Bera (1992).

${ }^{136}$ AIC and BIC are now respectively equal to 307.4725 and 360.4221 .
} 
ness/Kurtosis test for normality ${ }^{137}$. For this reason, robust standard errors are employed in the GDP model for a more reliable estimation of the standard errors (Bollerslev \& Wooldridge 1992). This model is the best one found according to the AIC and BIC tests; it reasonably follows the straight line, but, as shown below, it clearly fails to model some variance at the extremes of the distribution, pointing that there are some minor residual patterns in the data.

Figure 3.11

\section{QQ Normal Scores of Standardized Residuals from the fitted PP-NARCH Model} with AR and MA disturbances

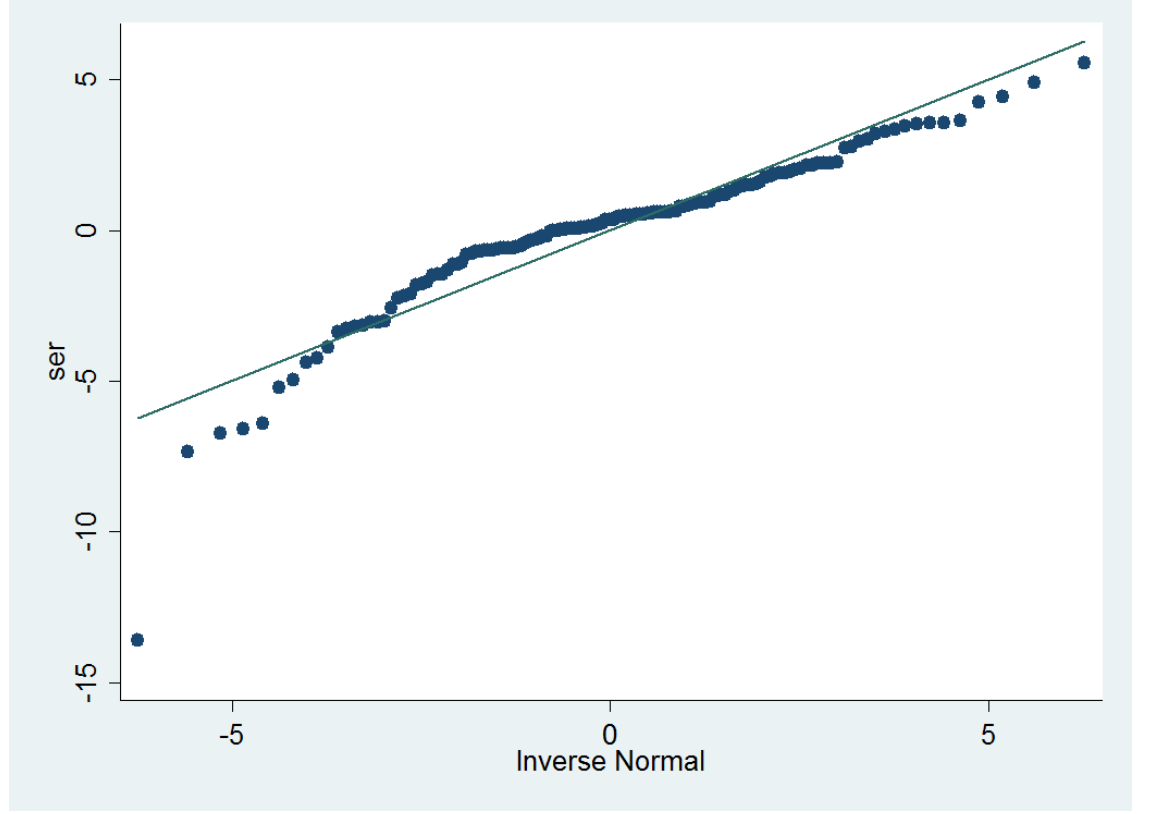

Nonetheless, a search conducted following Cryer and Chan's method (2008) for a fitter model is inconclusive, for all models show (significantly) higher AIC and BIC values (see below).

${ }^{137}$ P-values are less than 0.0001 for both the GDP and Stock Market model. 
Table 3.10

\section{Alternative model specifications}

\begin{tabular}{|c|c|c|}
\hline Model & AIC & BIC \\
\hline 1. PP-NARCH, $\mathrm{ma}(1) \operatorname{ar}(1)$ & 307.4725 & 360.4221 \\
\hline 2. PP-NARCH, $\mathrm{ma}(2) \operatorname{ar}(2)$ & 345.8964 & 398.846 \\
\hline 3. PP-NARCH & 361.7706 & 408.8369 \\
\hline 4. PP-ARCH (1), $m a(1) \operatorname{ar}(1)$ & 313.4452 & 363.4532 \\
\hline 5. PP-GARCH $(1,1)^{138}$ & NA & NA \\
\hline 6. PP-GARCH (1,1), ma(1) $\operatorname{ar}(1)^{139}$ & NA & NA \\
\hline 7. PP-ARCH (1) & 353.5005 & 397.6251 \\
\hline 8. PP-GARCH $(2,1)^{140}$ & NA & NA \\
\hline 9. PP-GARCH $(1,2)$ & 355.4905 & 402.5567 \\
\hline 10. FE (within) regression with $A R(1)$ disturbances & 418.3667 & 455.7443 \\
\hline 11. Fixed-effects (within) regression & 318.1499 & 356.8474 \\
\hline 12. PP-NAGARCH $(1,0)$ & 310.4295 & 363.3791 \\
\hline 13. PP-NAGARCH(1,1) & NA & NA \\
\hline
\end{tabular}

Thus, I accept the current model, a Pooled Panel Nonlinear GARCH model with first-order autoregressive and moving average disturbances.

For the stock market model, a simpler pooled cross sectional model is adopted given the significant increase in fit of the PCTS model. The Breusch-Pagan / CookWeisberg test for heteroskedasticity demonstrates that in both the PCSTS model and NGARCH model some residual heteroskedasticity affects the results, as shown in Figure 3.12 .

\footnotetext{
${ }^{138}$ Error returned by STATA: "flat log pseudo likelihood encountered, cannot find uphill direction”.

${ }^{139}$ Error returned: "flat or discontinuous region encountered, numerical derivatives are approximate", which returns no parameters estimation.

${ }^{140}$ See Cryer and Chan 2008.
} 
Figure 3.12

\section{QQ Normal Scores of Standardized Residuals from the fitted PCSTS Model with}

\section{AR (1) disturbance}

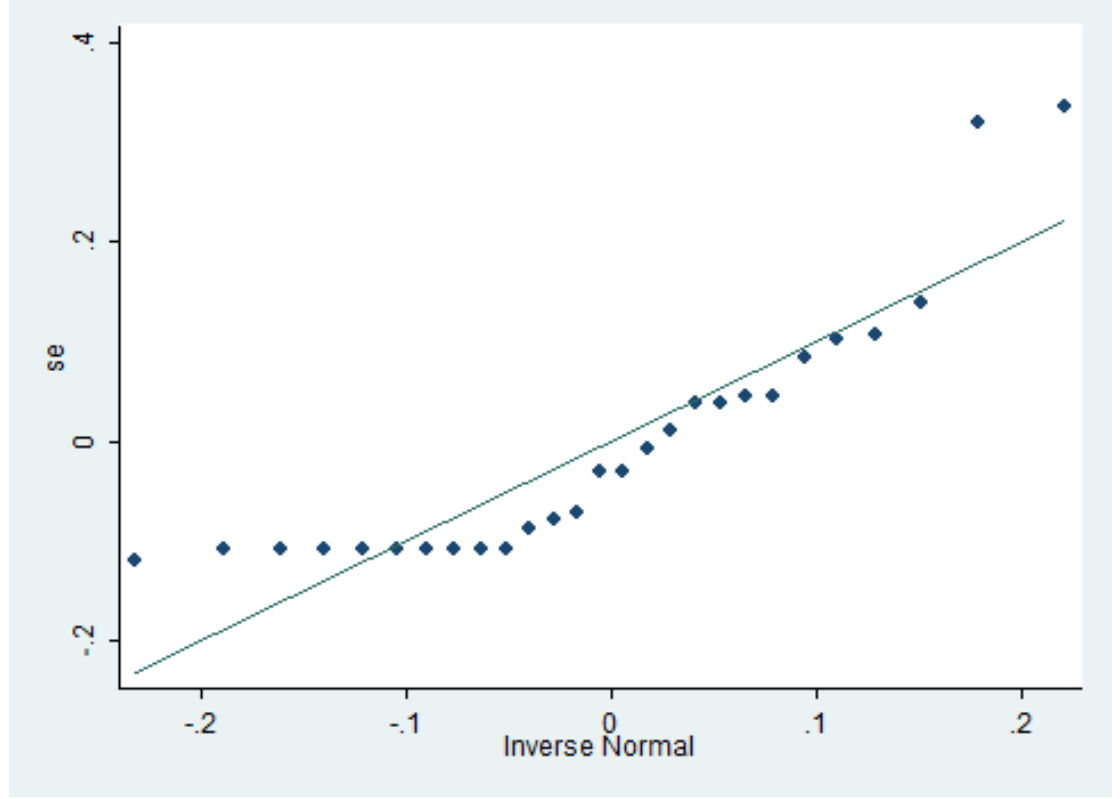

More specifically, the last part of the curve shows a sharp deviation from the line, which describes the inability of the model to deal with the fluctuations of the stock markets of the 9 different countries. The introduction of proper controls is likely to reduce the weakness of this model and reduce the omitted variable bias that is very likely to affect the estimates of this model. However, given the better fit of the PCSTS model, I accept it. Given the lack of options in STATA for using a PCSTS model ${ }^{141}$, I will use only the results offered by the model described above ${ }^{142}$.

\footnotetext{
141 The "xtregar" command allows only the use of autoregressive disturbance processes of first order. Higher-order autoregressive processes or moving average processes of any order can be introduced in STATA 10. However, given the lack of significant differences in terms of AIC and BIC value between the GARCH model with autoregressive and moving average processes, I believe that such lack of option does not significantly affect the validity of the results found in this work.

142 The NGARCH model with first-order autoregressive and moving average processes finds very similar results, where only the $\mathrm{p}$ value take on different values, more strongly rejecting the null hypotheses that
} 


\section{Case Studies}

Among all the cases discussed in the present work, the ones between Russia and Ukraine (especially the 2009 crisis) are of particular relevance. In January 2006, Gazprom reduced gas exports through Ukraine mainly because of the large financial sums owed by Ukraine, which were unsettled in the previous agreements. These were then connected to the price of gas imported to Ukraine and the transit fees of Russian gas (Pirani, Stern and Yafimava 2009; World Gas intelligence 2009). Both countries have benefited from a more favorable agreement since Gazprom gains around two-thirds of its revenues from the European markets and Ukraine's political spheres have earned considerable fortunes from the business (Nichol, Woehrel and Bernard 2006). Ukraine is the biggest importer of Russian gas, but it is also the largest corridor through which over $80 \%$ Russian gas reaches its European customers. In other words, Russia highly depends on the Ukrainian pipeline system to be able to extract from its natural resources, gas in this case, since Belarus is the supplier of less than $20 \%$ of the gas sold to Europe $^{143}$ (Pirani, Stern and Yafimava 2009; Youngs 2009, 88). Russia and Ukraine have been cooperating on energy matters since the 1960s, during which Ukraine was independent in terms of gathering the energy sufficient to support its economy. However, its gas production declined in the 1990s; at that time Ukraine was already heavily dependent on Russian gas, but, as a transit country, it was still an important country in the area. The pipeline system in Ukraine and Belarus was built lacking any kind of ex-

are also rejected by the PCSTS model, while failing to reject the null hypotheses that are found to be so also in the PCSTS model.

${ }^{143}$ With the construction of the Yamal pipeline Belarus was traversed by conduit of Russian gas to Europe (Stern 2005). Before then, only Ukraine and Moldova were the two main countries through which Russian gas was being transported. See above, figure 3. 
pectations of a similar Soviet Union collapse. Cooperation between these countries was ideally supposed to last and therefore a large investment was made in an expensive pipeline system. However, with the collapse of the Soviet Union, Russia lost legal control of large portions of its energy sector ${ }^{144}$. It only lost important production hubs like Turkmenistan, Azerbaijan and Kazakhstan, but it witnessed the nationalization of the important oil pipes and gas pipelines that were used to supply Europe (Bindi 2010, 133). Energy production dropped as a consequence and it was apparent to Russia that a restoration of its control over its energy sector was to be a primary objective, even though several countries were resisting the Russian attempt to exert influence over the newly independent territories (Barylski 1995).

However independent Ukraine was trying to be from Russia after the collapse of the Soviet Union, it was certain that the two economies were already deeply intertwined 145. During its first years, Russia noted in gas and oil sales an emergency financial

${ }^{144}$ Oliker et al (2009, 93-94) report that according to a recent survey, CIS countries are on the top of the list of the Russian foreign policy. Russians, in other words, deem their relationship with CIS countries very important for security and economic reasons. As explained earlier in the book (87), their centrality for Russia economic success and security is based on prestige, historical, economic, security considerations. CIS countries, in fact, have been under Russian control and influence even since before the Soviet Union and it is because of this that many Russians consider these countries as natural partners. Without them, Russia cannot be seen any longer as a great power that deserves as much attention as it used to in the best days of the Soviet Union. It is because of this perception that attempts from any other external state/group to influence CIS countries represent a direct threat to Russian security and prestige. Finally, CIS countries are important trading partners, and represent buffer-zones that can prevent external conflicts from reaching the Russian territory.

${ }^{145}$ More specifically, three other major issues link Russian and Ukrainian politics. The importance of the Ukrainian economy which in the pre-1991 period when it was an essential part of the Soviet economy and military, the Russian desire of maintaining Ukraine within its own influence, so as to use it as a buffer zone (and certainly the Ukrainian access to NATO will not help this happen) and the current situation of Crimea, where a large portion of Russians live and where the Russian Black Sea Fleet is located (Bindi 2010, 138). 
source and could not afford to lose it. On the other side, Ukraine's economy was so heavily dependent on Russian gas that it was nearly impossible for it to switch to alternatives (Pirani, Stern and Yafimava 2009, 5; Bindi 2010, 137). Such a mutual dependence gave birth to several disputes over issues which have continued to present-day and are mainly based on two facts. First, the countries that were now consuming the gas were no longer under direct control of the Russian leadership, and as such, they were comparable to other European countries who paid much higher prices for the gas consumed. Second, these newly independent countries did not have enough financial resources to afford paying ${ }^{146}$ for the gas that was once supplied at prices that barely covered the transit costs (Stern 2005, 66). As a consequence, the relationship between Russia and Ukraine became more complicated and several issues were raised. These issues consist of gas sales to Ukraine that were later estimated to not produce any profit for Russia, Ukrainian debt due to the lack of domestic payments ${ }^{147}$, the siphoning of Russian gas from the pipelines and Russian attempts to convince Ukraine to relinquish a portion of its control of the transit network (Pirani, Stern and Yafimava 2009, 5; Bindi 2010, 137; Shaffer 2009, 116) ${ }^{148}$. Given these problems, Russia has repeatedly attempted to use its 'gas weapon' to force the ex-Soviet Republics to pay the debt they accumulated over years of consumption while at the same time trying to gain access to

\footnotetext{
${ }^{146}$ Thus, for these countries, both affordability and reliability were the main issues for their energy security.

${ }^{147}$ Given the fact that Ukrainian customers could not afford to pay for the gas supply received.

${ }^{148}$ Russia does not allow the sale of its own transit and distribution networks by foreign companies (Shaffer 2009, 116).
} 
the transit system, which represents the only bargaining advantage of Ukraine, Moldova and Belarus ${ }^{149}$.

In particular, the gas imports by Ukraine and Belarus represent over $75 \%$ of all CIS trade, while most gas traded by Russia with Europe transits through Ukraine, Belarus and Moldova, and a remaining portion of Russian gas sales goes to Finland and to Turkey via the Blue Stream pipeline ${ }^{150}$. The economic value of the exchanges among these countries is substantially large enough that dealing with them requires the commitment and involvement of large portions of the executive power of all the countries involved. In particular, the gas flowing through Ukraine, which represents around $80 \%$ of all Russian exports (Stern 2005, 87), has started a vicious circle that initiated with the collapse of the Soviet Union; which is namely the inability of Ukraine to fulfill its financial obligations related to its large consumption of Turkmen and Russian gas. This in turn led to the establishment of a Russian practice of cutting off the gas supply in order to enforce the payment of the large debt contracted and the consequent diversion of gas directed to Europe to compensate for the reduction of gas destined to Ukraine (Stern 2005, 87). The clashes that followed between the two countries are numerous, but in the late 1990s Russia and Ukraine, recognizing the need to find an agreement, settled the dispute by linking the price of gas to be paid by Ukraine and the transit fee to be paid by Russia. Nothing, however, was decided about the large debt Ukraine accrued from 1991

\footnotetext{
${ }^{149}$ See Stern $(2005,67)$. A good example of this example is the gas cut that occurred in the winter 2006 in Georgia. In that case, the gas cut occurred at the same time of electricity cut from Russia, the latter that was attributed by the Russian government to a terroristic attack. Shaffer $(2009,44)$ maintains that if the Moscow's gas cut was purely commercial, then it should have occurred at a later moment, when the electricity line had already been repaired. However, that did not occur, leaving Georgia without electricity and gas in the middle of the winter season, suggesting that Russian intended punishing Georgia for its pro-Western attitudes.

${ }^{150}$ See picture below.
} 
(Stern 2005, 88). Following the financial and economic crisis that started in 1998, tensions between the two countries re-ignited, given the necessity that Gazprom had to maximize its revenues originating from those countries that were hardly struck by the economic crisis and had in turn reduced the global consumption of gas lowering not only its price, but also that of oil. The crisis reached a climax in November 1999, when oil and electricity exports to Ukraine were stopped; however, knowing that that would have not achieved much, and given the Russian lack of control over the Ukrainian pipeline system, Russia decided that it was in its interest to bypass Ukraine and find an alternative way to supply gas to Europe ${ }^{151}$. It was at this time that the idea of building a pipeline to be used to bypass Ukraine was under serious consideration. Even though several diplomatic issues were connected to the building of this expensive infrastructure, Ukraine perceived that the realization of the new pipeline, that was supposed to bypass up to $50 \%$ of the pipes system in the Ukrainian territory, was a serious threat to its centrality and gas delivery to Europe ${ }^{152}$. For this reason, a wave of agreements followed and finally all the problems seemed to be settled, despite its complexity and notable omissions ${ }^{153}$. Following these agreements, Ukraine was to receive gas only from Turkmenistan, while Gazprom would have provided only enough gas to pay for the transit fees, an additional security amount of no more than five billion cubes meters $(\mathrm{Bcm})$ was needed to compensate the eventual lack of gas supplies from Turkmenistan and a bonus supply of gas for two months in winter. In exchange, Ukraine would guarantee Russia the transit of $124 \mathrm{Bcm}$ of gas through its network. Nothing had been decided other than

\footnotetext{
${ }^{151}$ Stern $(2005,89)$ maintains that the new pipeline would have paid itself off very soon, given the large losses due to acts of siphoning of gas.

${ }^{152}$ Its centrality represented its main bargaining advantage in the negotiations with Russia.

${ }^{153}$ See Stern 2005, 90.
} 
the amount and repayment method of the large debts accumulated by Ukraine and it can be the source of additional clashes in the future relationship of Ukraine and Russia. It took several months before the agreement was formalized. In fact, it was in 2002 that the two countries signed a contract in which most of the aforementioned elements were confirmed, which was once again renewed, with slight modifications, in 2005 (Stern $2005,91)$. The tensions among the two countries quickly decreased and a more peaceful environment characterized the formalization of the agreements to be reached. Moreover, less and less attention was given to the project of bypassing Ukraine; actually, this attention was diverted towards expanding or improving the Ukrainian network. This is attributed to the improved diplomatic relations between the two countries.

Foreign policy reasons were alleged to be behind the 2006 gas dispute. Among them was the idea to punish Ukraine for becoming more pro-West (mainly for its desire to join $\mathrm{NATO}^{154}$ ). Also Putin was reported to have hinted that the dispute with Ukraine was different given the poor relationship between the two countries. Moreover, some observers have noted that the crisis occurred sometime before the legislative elections in Ukraine and that the crisis may have been started in order to deliver a significant blow to the incumbent administration. The crisis was then supposed to make apparent that the newly elected members will have to regard Russian influence more closely if Ukraine still wanted to thrive through exports of steel and iron, whose production is based on the supply of cheap gas ${ }^{155}$ (Nichol, Woehrel and Bernard 2006). The allegations that Russia did this with the intent of causing instability in the Ukrainian government are mitigated

\footnotetext{
${ }^{154}$ Bindi 2010. See also Shaffer (2009).

155 Others have argued that if some pointed to the use of gas weapon as a tool for achieving political goals, a similar statement could be made by claiming that in the absence of such raises in price, Russia was buying political support by subsidizing the gas prices (Bindi 2010, 143).
} 
by the evidence that Russia asked a higher price also to Armenia, who is well-known for supporting the Russian government. This suggests that economic reasons played a significant role as well (Nichol, Woehrel and Bernard).

\subsection{Russia and Ukraine}

The 2006 crisis started in early 2005, when Gazprom requested a higher price for gas imported by Ukraine, even though, according to the latter, there was an agreement that was binding Russia to provide gas at the price of $\$ 50$ per thousand cubic meters. Gazprom first asked Ukraine to pay $\$ 160$ and at the end of 2005 they asked them to pay $\$ 230$, thus this price is very close to what the other European markets were paying for the gas (Nichol, Woehrel and Bernard). Ukraine refused to comply with Gazprom's requests and on January 1, 2006 Gazprom reduced the gas flow to Ukraine who then reacted by diverting some gas that was meant for the European market to its own population and industry (Nichol, Woehrel and Bernard). The reduction of gas towards Europe triggered an immediate reaction by the European customers. The following day the two countries restored the gas flow and on January 4, 2006 an agreement was reached, according to which Ukraine was to purchase for $\$ 95$ from an intermediary company, RosUkrEnergo $^{156}$ (owned in equal shares by both Russian and Ukrainian figures) (Yhiah 2008), which in turns buys Central Asian gas for a lower price and from Russia for a higher price. Part of the agreement reached entailed also a higher transit fee to be paid by Russia, but also access to half of the Ukrainian domestic market for the RosU-

\footnotetext{
${ }^{156}$ More precisely, the ownership of RosUkrEnergo is to be attributed to Gazprom and two Ukrainian businessmen, who own respectively $50 \%, 45 \%$ and $5 \%$ of the shares of the company.
} 
krEnergo ${ }^{157}$. The crisis lasted only three days, but two years later, another crisis was to happen. That year in fact, Turkmenistan reduced its exports to Iran who in turn cut its exports to Turkey who then reduced its exports to Greece in order to have enough gas to run its own economy that was later replaced by Russian exports (World Gas Intelligence 2009). Once again, in January 2009, following further disagreements over the same terms of their contracts which are transit fees, gas price and Russia's halt of the gas supply to Ukraine, and this can be defined as one of the worst energy crises in Europe since the 70s (World Gas Intelligence 2009). Unlike the dispute that occurred in 2006, this gas crisis lasted almost seven times longer with a partial gas reduction first and a total stop just six days later. It is still unclear whether it was Russia cutting the supply or rather Ukraine who prevented Russian gas from reaching the European market. It was not clear whether this was intended to damage Russia from a diplomatic point of view or simply to replace the gas that was being transported to Europe with the missing gas that was needed to fuel the Ukrainian economy. Nineteen days after the dispute started, Russia and Ukraine finally found a common ground for their requests and settled their dispute over the gas price and the transportation fee. After, gas started flowing again towards the European countries. With the resumption of gas exports to Europe, soon over 420 million cubic meters flowed into the Ukrainian pipeline system, 75 of which was destined to support the smaller country and the rest exported to Europe (World Gas Intelligence 2009).

${ }^{157}$ See Nichol, Woehrel and Bernard 2006. 


\section{Figure 4.1}

\section{Countries affected by the 2009 gas crisis and gas pipeline system.}

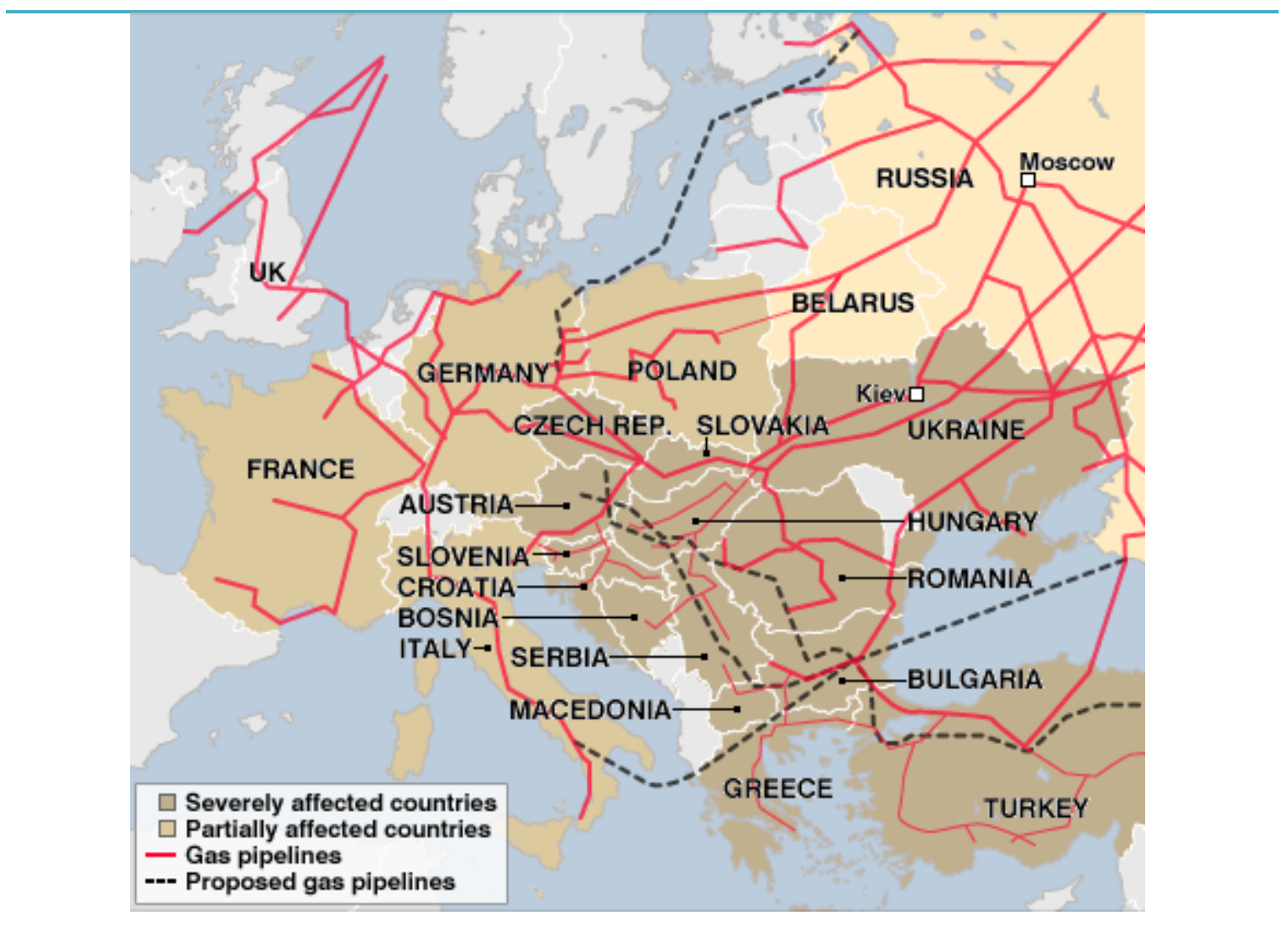

\section{Source: BBC News 2009.}

According to the two decade-long agreements reached on January 20, 2009 between the Russian Gazprom and the Ukrainian Naftogaz Ukrainy ${ }^{158}$, both countries fixed the terms for the Russian gas supply and the Russian usage of the Ukrainian pipeline system to Europe. As emerged in previous discussions, the economic relationship between the two countries would occur without the presence of the RosUkrEnergo (RUE), with the intent of making the transactions much more transparent (World Gas Intelligence 2009; BBC News 2009). The price dispute was settled establishing that

\footnotetext{
158 The agreement reached did not mention any resolution of the dispute regarding the $\$ 650$ million in fines and penalties for 2008 allegedly owed by Ukraine to the Russian Gazprom (World Gas Intelligence 2009).
} 
Ukraine pay the same price applied to the sales of gas to Europe minus twenty percent, thus settling the price to be paid by Ukraine at $\$ 360$ per million cubic meters, which is slightly over double the price paid just one year later. The intent of Gazprom was, in fact, making Ukraine pay an average of $\$ 250$ per million cubic meters for the year 2009 , thus just $\$ 30$ lower than the price paid by European countries, with the intention of applying the same price in the Ukrainian case to all the other European countries starting in 2010 (World Gas Intelligence 2009). Ukraine declared itself ready to pay the full gas price, given that it was time to reduce its gas consumption by minimizing its energy waste. The other portion of the deal involved a transit fee to be paid by Gazprom for 2008 gas exports equal to $\$ 1.70$ for transporting 1,000 cubic meters of gas (Willershausen 2009). Russia depends on Ukraine for its pipeline system as much as Ukraine depends on Russia for the supply of reasonably priced gas (Nichol, Woehrel and Bernard 2006). In fact, the main Ukrainian export sectors, iron and steel production, are heavily dependent on cheap Russian gas to compete in the international arena and a higher price will justify efforts of maximizing the energy efficiency of the country (Nichol, Woehrel and Bernard 2006).

Experts who have studied the 2009 gas crisis have claimed that there was evidence that Ukraine did shut down its pipelines at night between the 6th and the 7th of January 2009, thus further damaging its relations with Russia. Russia also significantly contributed to an escalation of the dispute by asking a $\$ 400-450$ per mcm price, and then reducing the gas flow down to $65 \mathrm{mcm}$, which represented less than $50 \%$ of the gas need of the country (Pirani, Stern, Yafimava 2009, 33). Both these events, combined with Russia's manipulation of the issue of technical gas into that of a 'theft' of gas, led 
to what evolved into the gas disruption of gas exports to Europe (Pirani, Stern, Yafimava, 34).

In conclusion, it is worth noting that at the time of the 2006 gas dispute, there were discussions over the construction of North Stream, a pipeline that was supposed to connect Russia and Germany underwater starting from Vyborg, on the border with Finland. Large financial resources have been mobilized to start the project whose end goal is clearly that of reaching European territories without being involved in political conflicts with transit countries. After almost two decades of conflicts with Ukraine and Moldova, and then also with Belarus, Russia seems to have developed a preference for constructing alternative ways to reach European soil. Such a strategy has power not only to force disputing countries to accept Russia's offers ${ }^{159}$, but also to increase the flow of gas that can be supplied to Europe, making other projects like Nabucco economically unfeasible, due to their saturating of the market with Russian gas.

The 2006 Ukraine-Russia dispute triggered an increased concern about energy security. On February 9, 2006 European Commission President Barroso declared that now more cooperation among EU states was needed to reduce dependence on Russian energy and that alternative sources of energy were needed. This was supported, the next day by the Polish Prime Minister's statement about the need of creating a "EuroAtlantic Energy Security Pact". Given the lack of concrete reply from the EU as a community, Barroso emphasized again the need to build a common policy to improve EU energy security in 2009, stating that: "this crisis has confirmed what we have said when we were proposing this diversification strategy to our member states. It is completely unwise for one country to rely only on one supplier" (Speck 2009).

${ }^{159}$ See also Bindi 2010, 137. 
The diversification can be achieved by supporting and Nabucco, which the European Commission stated to be ready to support with a 250 million Euros ${ }^{160}$ and the construction of the Nord Stream and South Stream pipelines (Speck 2009).

A more intense statement was that from the Presidency of the European Union of January 4, 2009, according to which:

"The European Union calls for an urgent solution to the commercial dispute on gas supplies from the Russian Federation to Ukraine, and for an immediate resumption of full deliveries of gas to the EU member states. Energy relations between the EU and its neighbors should be based on reliability and predictability. Existing commitments to supply and transit have to be honored under all circumstances. The European Union regrets the fact that assurances of the reliability of energy supply have not been met and will continue to monitor the situation closely." (EU2009.cz 2009)

\subsection{Russia and Belarus}

In addition, the relationship between Russia and Belarus exhibited the same trend, in which Russia tried to raise the price of the gas that was previously supplied at a very cheap rate, despite the fact that the amount of gas transported via Belarus is substantially less than that via Ukraine (less than 20\%, compared to around 80\%). The economic and political relationship between Belarus and Russia have always been much more pacific ${ }^{161}$, when compared to Russia-Ukraine; that is to the extent that the two countries have discussed the possibility to merge together and form one state (Stern 2005, 97; Lucas 2008, 134). This suggests that purely economic reasons may have been behind the gas cuts (Oliker et al 2009, 98). The two-decade-long agreements reached in

\footnotetext{
${ }^{160}$ This sums, the author says, covers just 3\% of the total cost of the pipeline (Speck 2009).

${ }^{161}$ See also Bindi 2010, 140. According to the author, the Belarusian President, Alexander Lukashenka has turned his country into an autocratic regime, ruled by him, which has little to share with the democratic regime adopted by Europe, which has even shown unable to prevent and resolve crises like the 2008 war in Georgia and fragmented in its decision (Bindi, 141-142). See also Oliker et al $(2009,98)$.
} 
1993 and 1995 required Russia to provide a large quantity of gas in exchange for transfering the assets of Beltransgaz, the gas transmission company, after 99 years. The relationship between the two countries started degenerating after 1998, when gas debts started reaching very high levels and the two parties failed to agree on the price of the gas deliveries (Oliker et al). In 2002, an agreement was reached in which Belarus would pay for gas supplies at a price that was reserved for Russian territories, therefore much lower than those accorded to higher zones. But since little was being done to commence the joint venture between Beltransgaz and Gazprom and the debt kept increasing, the first threats of halting gas supplies were made. At the time Belarus claimed that the value of Beltransgaz and the value of refurbishments needed was much higher than the believed Russian counterparts. Thus a much higher financial contribution was requested to access half of the assets of the joint venture between the two companies and an additional large fee needed to fix the transportation system (Stern 2005, 98).

In 2003, the crisis degenerated to the point that Gazprom stopped its supplies to Belarus as soon as the contract binding them to do so expired. Lacking any agreement on price, debt and terms to conclude the joint venture, gas supplies were stopped on January 1, 2004. Even though Belarus was being supplied by private companies on short term contracts, Belarus and Russia did not reach an agreement in January of that year and on February 18, 2004 Gazprom cut off all gas supplies for 30 hours, including those that were meant to be delivered to the European market. Evidence of gas diversions were hard to find, although Gazprom claimed that some did occur and it is logical that such an event occurred given the drastic circumstances ${ }^{162}$. Belarus was thus forced to sign short term contracts with other independent firms to be supplied the necessary

\footnotetext{
${ }^{162}$ See Stern 2005.
} 
gas. Over five months after the interruption of gas supplies to Belarus in 2004, the two countries reached an agreement, in which a higher price was set to be paid to Gazprom. This price was still well below the price of the gas sold to European countries. Moreover, Gazprom obtained a lower tariff for the transportation of the gas through the Belarusian pipeline system while Belarus agreed to receive a 175 million dollars loan which would help pay its gas debt to Gazprom (NewEurope.eu. 2006).

The consequences of the cut were significant, especially for the Kaliningrad region and Poland, the former being forced to switch to oil fuel and to hot water and the latter suffering a 35\% diminution on February 18, and 50\% on February 19. Meanwhile, Latvia was able to compensate using its own gas reserves which were sufficient enough to help neighboring Lithuania as well (NewEurope.eu. 2006, 100). In late March 2006 Gazprom requested a raise in price, which was later quantified to become equal to the price of the gas delivered to other European countries. Belarus was confident to still hold bargaining leverage in terms of being an important route towards the European market, and until other pipelines were constructed that bypassed it, it would have been still in a position to avoid entering the Russian sphere of influence (Ria Novosti 2006; Kupchinsky 2006).

Should the gas be cut off, Belarus could have shifted the burden of such a move back to Russia, by redirecting, as Ukraine did, the gas that was supposed to be reaching the European markets, at the expense, evidently, of an increased European concern over their energy security. At stake in the dispute was not just the price of the gas being consumed by the transporting countries, but also the control over the pipeline system, 
which Russia had shown a strong interest in $^{163}$. In fact, there are two major systems in Belarus, one that is the property of Belarus and the other, the Yamal-Europe pipeline is the property of Gazprom, which is required to pay the costs of traversing the Belarusian territory. Belarus already had a significant debt to Russia that stemmed from gas deliveries in the 1990s and a sudden gas price increase was likely to aggravate the financial situation of the country. Therefore this aggravation renders the country vulnerable to Russian pressures to allow access to control the Belarusian pipeline system (Kupchinsky 2006).

As a probable reaction of the European markets to the 2004 crisis, the Directive of the Council of the European Union 2004/67/EC of April 26, 2004, which advocates common EU policies by establishing responsibilities on each EU country, joint operations to safeguard a steady gas flow in the EU, and a procedure to be followed in case another dispute arises ${ }^{164}$.

The situation for Belarus worsened in 2007, when the gas price was increased to $\$ 100$ even though the country was allowed to pay the accumulated debt by July 2007 . However, failing to do so, Belarus was threatened to have its gas supplies reduced by $45 \%$ on August 1, 2007, even after having to forfeit $50 \%$ of the shares in Beltranshaz for 2.5 billion dollars along with a prospecting gas price increase in the years to come that would have made gas prices for Belarus equal to those applied to European countries (Maksymiuk 2007).

\footnotetext{
${ }^{163}$ Russia is alleged to have cut off gas supply when in 2002 Belarus decided not to allow Russia to gain partial control over the Beltranshaz, a company owned by the Belarusian state that runs the local pipeline system (Kupchinsky 2006).

${ }^{164}$ See below for a more detailed description.
} 
The European Commission reacted by making public its concern regarding the development of the crisis, stating on August 1 that:

"We take these developments very seriously and we believe [that] both sides [will be able] to resolve the dispute without any delay and to create conditions for the timely resumption of the deliveries" (Maksymiuk 2006).

Moreover, the following day the European Commission activated the EU's Network of Energy Security Correspondents (NESCO) ${ }^{165}$, a forum created in order to anticipate and prevent disruptions on energy supplies to the EU.

\subsection{Russia and Moldova}

Moldova is a small country which was once occupied by Romania and became part of the Soviet Union after WWII. With the collapse of the Soviet Union, Moldova (now pro-West) declared its independence. The portion of Moldovan territories which covers the land beyond the river Dniest attempted in turn to reach independence under the name Trasnistria (pro-Russia), but it is nowadays still not recognized by the international community. Moldova enjoys the support of the Romanian government not only in its struggle to gain control of Transnistria (currently occupied by Russian troops), but also in its dealing with the Russian increase of gas prices, which Romania declared in 2006 to be willing to counter by supplying the small country with a cheaper alternative (World of Information 2006). $=$ EN\&guiLanguage $=e n$. See below for more information. 
Despite its small gas consumption, Moldova is located in a key position regarding the transportation of gas to Europe: over 22 billion cubic meters of Russian gas need to traverse its territories (Stern 2005, 101). Similarly to the Ukrainian and Belarusian cases, the major issue is the debt contracted for the consumption of Russian gas. In 1998, however, tensions decreased because of the creation of MoldovaGaz, a joint venture owned by Gazprom (50\%), the Moldovan government (35.3\%) and other small parties who are responsible for the distribution of Russian gas in the territory (Stern 2005).

The situation quickly worsened as soon as it was clear that the financial situation of Moldova deteriorated due to the inability to pay for the high prices charged by Gazprom, despite previous agreements stating that the price to be charged was inferior. Moldova compensated for higher prices with higher transit fees; however, due to the large debt, Gazprom repeatedly threatened and implemented complete gas cut offs to Moldova in order to extract more payments or to be guaranteed that the payments were going to be made. The situation did not change until 2004 when Gazprom renewed its threats of halting gas supplies. This failed to be implemented due to the recognized Moldovan role as a transit country (Stern 2005, 102). On January 1, 2006 Moldova was faced with no gas supplies due to its refusal to accept a $100+\%$ increase in price, an increase from the $\$ 80$ the year before. The following day, Ukraine started supplying Moldova with an amount of gas that equaled $50 \%$ of its daily requirements, but, Ukraine being the only (emergency) supplier of energy for Moldova, the latter was left in a weaker bargaining position (Socor 2006). Sixteen days after the gas disruption, Russia resumed the gas supply, having settled with Moldova to pay $\$ 110$ (BBC News 2006). Socor claims that raising the gas price was clearly a Russian attempt at modifying Moldova's 
policy on the resolution of the conflict in Trasnistria and their pro-Western orientation (BBC News 2006).

The Moldovan crisis attracted the EU's attention, and on January 9, 2006 it publicly declared to "urgently recommence negotiations and reach an equitable compromise" (Socor 2006).

Moldova, due to its positioning and connections, was also hardly affected by the 2009 gas dispute between Russia and Ukraine.

\subsection{Results}

The estimation of the PP-NARCH model returns interesting results, which have a high degree of conformity with the characteristics of the case studies I have just described. In fact, not only the 2009 Ukraine-Russia emerges as having had a significant effect on the surrounding economies, but also the 2004 and 2006 Belarusian crisis particularly stand out as relevant explanatory variables of the negative impact on GDP incurred by several countries during and after the gas disputes.

In support of the goodness of fit of the model, there is a significant and negative relationship between real GDP growth and gas prices. Under investigation are in fact all countries that are net energy importers, thus vulnerable to increases in gas prices. The expected relationship is supported by the model, which shows a strong and negative relationship between the two variables. As an additional test of the validity of the model, the direction of the relationship between the exchange rate and the Euro and the Dollar estimated by the model is in the correct direction. As common sense would suggest, I should find a negative relationship between the exchange rate between Euro and Dollar, 
since the higher the value of the Euro compared to that of the Dollar, the more expensive European exports and the less competitive in general the European area becomes relative to the US exports of product and services. The model confirms the negative relationship between the exchange rate Euro-Dollar, further reinforcing the appropriateness of the model.

The parameters for oil price, and the exchange rate between Euro and British pound are not significantly different from zero; even though I left these two variables out of PCA with the precise intent to use them as a test of validity of the model (thus expecting a significant and negative relationship with GDP growth)

The parameter estimation of the crises reveals that there is a significant and negative impact of the Belarus 2004 (2Q), Belarus 2006 (2Q), Ukraine 2006 and 2009 (1Q and 2Q), but no significant relationship is found for the two remaining crises, the one that occurred between Moldova and Russia in 2006, and the one between Russia and Belarus in 2007. 
Table 4.1

Regression results of the PP-NARCH model (GDP model)

\begin{tabular}{|c|c|c|}
\hline Variables & Estimated parameter & p-value \\
\hline Gas price & -0.05051 & 0.187 \\
\hline Oil price & 0.000884 & 0.889 \\
\hline Exchange Euro-Pound & -0.73023 & 0.39 \\
\hline Exchange rate Euro-US Dollar & -2.1385 & 0.12 \\
\hline Factor 1 & -0.02656 & 0.21 \\
\hline Factor 2 & 0.007612 & 0.556 \\
\hline Factor 3 & -0.02982 & 0.217 \\
\hline Belarus 2004 & $-1.49683^{* *}$ & $<0.001$ \\
\hline Belarus 2006 & $-0.41896^{*}$ & 0.021 \\
\hline Moldova 2006 & 0.23299 & 0.169 \\
\hline Belarus 2007 & -0.00304 & 0.981 \\
\hline Ukraine 2006 and 2009 & -0.40146 & 0.057 \\
\hline \multirow[t]{2}{*}{ Constant } & 4.251081 & 0.118 \\
\hline & ARMA disturbances & \\
\hline$A R(1)$ & -0.14113 & 0.252 \\
\hline \multirow[t]{2}{*}{$\mathrm{MA}(1)$} & -0.61447 & 0.000 \\
\hline & NARCH & \\
\hline $\mathrm{NARCH}$ & 1.585872 & 0.026 \\
\hline $\mathrm{NARCH}{ }_{-} \mathrm{K}$ & -0.1531 & 0.242 \\
\hline Constant & 0.060769 & 0.029 \\
\hline
\end{tabular}

Similar results (sometimes weaker, some other times stronger) are offered by some of the alternative specifications reported above. More specifically, the vast majority of these unreported models emphasize the strong significance of the variable measuring especially the dispute between Russia and Belarus in 2004, as found also in the best model indentified. Similar observations can be made for the crisis between the same 
countries in 2006, and, to a less extent also for the two Ukrainian crises in 2006 and 2009.

Several alternative models supported the finding of my best model that the Belarusian crisis in 2006 and the Moldovan dispute did not significantly affect other economies (Table 4.2).

\section{Table 4.2}

\section{Hypotheses supported by alternative model specifications}

\section{Model}

1. PP-NARCH, $\mathrm{ma}(\mathbf{1}) \operatorname{ar}(\mathbf{1})$

2. PP-NARCH, $\mathrm{ma}(2) \operatorname{ar}(2)$

3. PP-NARCH

4. PP-ARCH (1), $m a(1) \operatorname{ar}(1)$

5. PP-GARCH $(1,1)^{166}$

6. PP-GARCH $(1,1), \mathrm{ma}(1) \operatorname{ar}(1)^{167}$

7. PP-ARCH (1)

8. PP-GARCH $(2,1)^{168}$

9. PP-GARCH $(1,2)$

10. FE (within) regression with $A R(1)$

11. Fixed-effects (within) regression

12 PP-NAGARCH(1,0)

13 PP-NAGARCH $(1,1)$

\section{Significant and Negative effect (Crises)}

Belarus 2004, Belarus 2006, Ukraine 2006 and 2009

Belarus 2006

Belarus 2006

Belarus 2004, Belarus 2006, Ukraine 2006 and 2009

NA

NA

Belarus 2004, Belarus 2006

NA

Belarus 2004, Belarus 2006

Belarus 2004

None $^{169}$

Belarus 2004, Belarus 2006, Ukraine 2006 and $2009^{170}$

NA

\footnotetext{
${ }^{166}$ Error returned by STATA: "flat log pseudo likelihood encountered, cannot find uphill direction”.

167 Error returned: "flat or discontinuous region encountered, numerical derivatives are approximate", which returns no parameters estimation.

168 See previous note.

${ }^{169}$ No parameters are significant and negative in this model.

${ }^{170}$ Unlike the best model identified, this configuration finds a positive and significant relationship for the Moldovan crisis. The 2007 Belarusian crisis is not found significant.
} 
As noted in Table 4.2, several models support the hypothesis that the gas dispute between Belarus and Russia in 2004 and 2006 significantly affected real GDP growth of the countries under investigation. Weaker evidence of the significance of the Ukrainian crises is found in other model specifications, while failure to reject the null hypothesis is demonstrated for the 2006 Moldovan crisis and the Belarusian crisis in 2007.

In sum, the models considered above show that a good portion of the cases studied in the present work had a negative effect on the surrounding environment constituted by European countries and other institutions. This negative externality is a strong incentive for the environment to react and become an active player in the negotiation process. A clear example is the 2006 Belarusian crisis, which according to Nichol, Woehrel and Bernard (2006) and Yhiah (2008) quickly reached an end due to a intense reaction of European customers.

The results described above are also supported by the stock market model, with some differences. In fact, in this model the direction of the relationship is at times confused: for some variables measuring the impact of the crises, I find some positive signs, indicating that the disputes brought a growth in the stock markets. Similarly, for some variables measuring the impact of the reaction functions, I find a negative sign, indicating that the stock markets somehow reacted to these statements or creation of new institutions in a negative manner. Looking at the model selected as the best, the 2007 Belarusian dispute, and the 2009 Ukraine dispute are found to have had a strong and negative effect on the stock market indices.

As mentioned above, this second model also reveals that some important political acts like official statements from the EU can significantly affect important economic measures like the stock market. These statements, made by important institutions, have 
indeed affected the transactions made in the stock markets of the EU countries studied here, countering the negative effect of these crises.

More specifically, the stock market model shows that a significant trend occurred in all the cases except for the statement made by the European Commission President Barroso on February 9, 2006 regarding the need for more cooperation among EU to reduce dependence on Russian energy and that alternative sources of energy were needed. I hypothesized that the directions of these relationships was positive, but as can be seen in Table 4.3, only half of the reaction functions (two out of four) that are found to be significant in the direction hypothesized. Similar conclusions are drawn for the effect of the disputes on the markets. This is probably the result of not using control variables and the fact that much weaker evidence of an effect of the disputes and the reactions characterized the Moldovan case and the 2006 Ukrainian cases. 
Table 4.3

Regression results of the stock market model

\begin{tabular}{|l|cc|}
\hline \multicolumn{1}{|c|}{ Independent Variables } & Estimated parameter & p-value \\
Belarus 2004 (3 days) & .0032154 & .065 \\
Moldova 2006 (40 days) & .0024231 & 0.001 \\
Belarus 2006 (6 days) & .0017289 & 0.304 \\
Belarus 2007 (6 days) & -.0171193 & $<0.001$ \\
Ukraine 2006 (9 days) & .0032749 & 0.004 \\
Ukraine 2009 (66 days) & -.0062195 & 0.004 \\
Reaction functions & & $<0.001$ \\
Belarus 2004 (5 days) ${ }^{171}$ & -.0067432 & 0.003 \\
Moldova 2006 (8 days) & -.0031388 & $\mathrm{NA}$ \\
Belarus 2006 & $\mathrm{NA} \mathrm{A}^{172}$ & $<0.001$ \\
Belarus 2007 (8 days) & .0140548 & 0.358 \\
Ukraine 2006 (1 days) & -.0027755 & 0.004 \\
\hline Ukraine 2009 (3 days) & .0180918 & \\
\hline
\end{tabular}

A summary of hypothesis testing is provided in Table 4.4, which follows the hypotheses at the end of chapter 2. Hypotheses that support my claim that disputes and reactions had an effect on GDP and stock markets are highlighted in bold characters.

\footnotetext{
${ }^{171}$ Several other duration models for the 2004 Belarusian dispute were studied, with similar conclusions.

${ }^{172}$ In this case, since Gazprom threatened to increase price only, without doing much else, no intervention of external actor was recorded (see above).

${ }^{173}$ See previous footnote.
} 
Table 4.4

\section{Hypotheses summary}

\section{Hypothesis}

H1a: significant and negative relationship between the GDP growth and the start of the 2006 Ukraine dispute

H1b: significant and negative relationship between the GDP growth and the start of the 2009 dispute

H2a: significant and positive relationship between stock market trend and the start of the dispute between Russia and Ukraine in 2006

H2b: significant and positive relationship between stock market trend and the start of the dispute between Russia and Ukraine in 2009

H3a: significant and positive relationship between stock market trend and the reaction function in the dispute between Russia and Ukraine in 2006

H3b: significant and positive relationship between stock market trend and the reaction function (Russia and Ukraine in 2009)

H4a: significant and negative relationship between the GDP growth and the start of the 2004 Belarusian dispute.

H4b: significant and negative relationship between the GDP growth and the start of the 2006 Belarusian dispute

H4c: significant and negative relationship between the GDP growth and the start of the 2007 Belarusian dispute

H5a: significant and negative relationship between the stock market trend and the reaction function (Russia and Belarus in 2004)

H5b: significant and negative relationship between the stock market trend and the start of the dispute between Russia and Belarus in 2006

H5c: significant and negative relationship between the stock market trend and the start of the dispute (Russia and Belarus in 2007)

H6a: significant and positive relationship between the stock market trend and the reaction function (Russia and Belarus in 2004)

H6b: significant and positive relationship between the stock market trend and the reaction function (Russia and Belarus in 2006)

H6c: significant and positive relationship between the stock market trend and the reaction function (Russia and Belarus in 2007)

H7: significant and negative relationship between the GDP growth and the start of the 2006 Moldovan dispute

H8: significant and negative relationship between stock market trend and the start of the 2006 Moldovan dispute

H9: significant and positive relationship between the stock market trend and the reaction function in the dispute between Russia and Moldova in 2006

\section{Testing result}

Negative; significant at $94.3 \%$ confidence level

Negative; significant at $94.3 \%$ confidence level

Not significant

Significant and positive

Not significant

Significant and positive

Significant and negative

Significant and negative

Not significant

Not significant

Not significant

Negative and significant

Negative and significant

Not significant

Positive and significant

Not significant

Positive and significant

Negative and significant 
166 Changing Games and Evolving Contexts: Political Bargaining in European Energy Disputes

Page intentionally left blank 


\section{Theoretical Issues and Game Theoretic Approaches}

The results presented above emphasize that the environment in which the two actors were bargaining has changed since the collapse of the negotiations and the beginning of the dispute. Whether the direction of the relationships found are in the directionn hypothesized or not, is of little importance. In fact, the models point out that an important political bargaining model like game theory should account for an evolving environment in order to offer a more realistic representation of the facts. The sections that follow offer the reader an understanding of whether, and if so, to what degree, current game theory can model a dynamic environment.

\subsection{Alternative game theoretical models for a changing environment}

Expected utility models have evolved in recent years to the point where several modifications to basic games have been made and new formalizations have been devised so as to make the new models more robust (Schoemaker 1982) or to adjust game theory to a new set of assumptions on the environment of play, in which the concept of utility maximization has been revised and replaced by different driving forces of change, as in evolutionary game theory (Hofbauer and Sigmund 1998; Young 1998; Dixit, Skeath, Reiley 2009; Frey 2010). Also, in which utility the type of probability transformations or the measure of the outcomes are calculated or measured in a different way (Schoemaker 1982). Other recent games have been devised so as to take into account communication among the players in order to monitor its effect on the final outcome of the interaction between the players (Cho and Kreps 1987). 
It is important to note, however, that evolutionary game theory is able to take into account the preferences of actors that were not previously accounted for in earlier games. Danielson (1998) describes evolutionary game theory as the result of game theorists' two main concerns: the large amount of possible equilibriums that one can reach, especially with repeated games, among which only one has to be selected, and the reliability of the unbounded rationality assumption. Evolutionary game theory assumes that players do not behave in a strictly rational way; they rather follow 'rules of thumb' (Danielson 1998, 110) which players update given their past performance in previous games and in the population. In evolutionary games, first-generation populations with $i$ players can select a set of relevant, possible strategies $\mathrm{L}_{\mathrm{i}}$. For every player $i$ (with his strategy set $\sigma_{i}$ in $\mathrm{L}_{\mathrm{i}}$ ), there are also $(i-1)$ animals, which are assumed to immediately play their game according to their strategy set $\sigma_{i}$. From this population, other generations can be created where every $i$-animal plays the part of player $i$ along with a $j$ animal (where $j$ indicates the size of the population of the second generation) that is assumed to react to the new player's strategies. Every $j$ animal can in turn become a player, creating a third-generation population, so on and so forth. Moreover, every animal in generation $\mathrm{k}$ will be able to replicate itself in generation $\mathrm{k}+1$ according to his expected payoff. The contribution of evolutionary game theory is that of reconstructing the evolution of the former generation and understanding which strategies are able to dominate the system in the future, which is generation after generation (Myerson 1991, 117-118; Dixit, Skeath, Reiley 2009).

For randomly matched populations, the equilibrium of a finitely repeated game converges to a situation where defection prevails (Binmore and Samuelson 1992). However, Myerson notes that, despite these results, cooperation can survive for long pe- 
riods. Different results are achieved when players participate in infinitely repeated games; in fact, the learning patterns that characterize these games lead to a cooperative equilibrium (Nachbar 1992).

Although evolutionary games can be very useful in studying the preferences of actors that were not previously accounted for in the original game and their evolution, they are unable to model a changing environment in that it focuses on preferences of actors that do not belong to the current game anymore, but which may have survived the test of time thanks to successful strategies. The focus is on strategies and their degree of successfulness in the system; nothing is here done to model the gradual importance of the preferences of actors that were initially disinterested in the evolution of the dispute, but which were then struck by the negative externalities of the disputes.

Putnam (1988) discusses the relationship between domestic and international politics using the 1978 Bonn summit conference as a case study. Putnam maintains that, although a collection of solutions to the first oil shock was accepted by all states that were present at the meeting, these states would have not accepted this common resolve were international pressures absent. Moreover, according to Putnam, it is due to a small domestic group that the agreement was able to be reached at the international level. In the German case, it was due to officials in the Chancellor's Office and the Economics Ministry, the Social Democratic party and trade unions. In the Japanese case, it was due to the Ministry of Trade and Industry, the Economic Planning Agency and some additional political actors. In the American case, it was a group of key economic officials that supported the package that all accepted and agreed upon.

Putnam views the politics of many international negotiations as a two-level game: governments try to please pressuring domestic groups and individuals strive to 
minimize possible negative repercussions at the international level. It is important to understand that which can please domestic groups can actually harm international negotiations and vice versa. Putnam identifies a precise process in which the bargaining first takes place; once a decision is made at this level (Level 1), an agreement (ratification) is reached at the domestic level (Level 2).

Putnam's two level-games should aid the reader in comprehending the nature of the subject being investigated in this work. He claims that if one wants to understand how bargaining crises end one needs to account for the growing pressure deriving from external actors. Putnam's arguments could seemingly be adapted by replacing the domestic arena with the local confrontation between Russia and one of its neighboring countries. The international arena can be placed within a broader context, which includes European countries that have an interest in an early resolution of the crisis. However, these games fail to take into account the growing diplomatic pressures, assuming, as Putnam does, a static set of preferences that characterize the international arena. The core of these arguments is that even if one considers the Russia-Ukraine or RussiaBelarus dispute a two-level game, where one does account for the influence of other actors, this is done in a non-dynamic way ${ }^{174}$. In fact, these actors have little to no interest in preventing the two countries from escalating their disagreements, for example, to the levels seen in 2009. However, as soon as these crises start damaging the other actors' economies, then these actors have a concrete and valid reason to exert pressure on the other two so that they can reach an agreement in the shortest time possible. The longer the crisis lasts and the greater their effect on the broader environment, the greater the diplomatic pressures stemming from this environment.

\footnotetext{
${ }^{174}$ Dynamicity refers here to the evolution of the context and not to the repetition of a game.
} 
One may argue that all that is needed is to employ a two-level game that represents the bargaining situation which leads to the end of the dispute. In this situation, not only the preferences of the two 'domestic' actors matter but also where other countries belonging to the proximate environment play a role. On the one hand, this representation would symbolize a significant step towards understanding the end of the dispute. However, I argue that this static representation does not fully portray the importance of the cumulated pressures that the international political sphere exerted on the disputing countries. The last interaction of the international players with Russia and Ukraine/Belarus surely adds to general understanding. However, the sequence of the comments, meetings, diplomatic actions made since the start of the dispute can offer a more complete picture than just studying the last moments of the crisis. For this reason, one argues that a more dynamic analysis of the active role of the international arena needs to be added to the current literature of political bargaining.

Similar comments can be made with regards to nested games (Tsebelis 1990; Scholz 1991). In fact, even by increasing the number of games the disputing actors are simultaneously playing does not change the situation. One is not properly studying the accumulated effect of the diplomatic pressures exerted over time on the two main players by the surrounding environment.

Infinitely repeated games (Myerson 1994; Shubik 1991) and multi-agent games (Littman, Kearns, Singh 2001) offer interesting insights in terms of revealing the outcome of the interaction of players. However, the learning process which seems to be guiding players to an equilibrium characterized by cooperation, suffers from the same weakness described above. The players of political crises I discuss in this work are pertaining to participants who play little or no role at the beginning of the crisis, but be- 
come relevant players as time passes and as they perceive that the crisis needs to end in order to avoid further negative consequences. Infinitely repeated games with two or more players study the interaction of those whose preferences are known and/or whose actions teach the other players what the optimal strategy is. But they cannot properly model a situation in which new actors gradually join the game and the game structure evolves in response.

Supergames consist of a series of $2 \times 2$ matrixes. Each payoff contains not only the value relative to that choice, but it may contain also statements that lead to the continuation of the game by replaying it, or that lead to another game included in the supergame. Thus, supergames are like classical games, which, however, may force the player to take into the fact that under some circumstances, the game may not end there, and some features of the game can change as a consequence (Snyder and Diesing 1977, 6163).

Metagames focus on strategies rather than options or moves as in other models. It assumes sequential play, that is one player chooses a strategy after the first player has chosen his own. The combination of sequential moves and strategies as unit of analysis produces an important fact, that the second player usually has more strategic options than the first one. In fact, being the second player entails a larger set of strategies, which are conditional on what the first player has chosen. Conditional strategies are in fact not available to the first player, who cannot have any information about the strategic choices of the other player (63-64). Although supergames and metagames come close to describing evolving behaviors, they fail to achieve the level of complexity that I argue is necessary to account for the preferences of additional actors and, more importantly, the gradual relevance of these actors in shaping the game being played. In fact, supergames, 
as described in Snyder and Diesing (1977), are games that are used to model the cumulative effects of the interaction among a fixed number of players.

Fuzzy game theory has been recently developed in order to better cope with the uncertainty of objectives, constraints, moves and outcomes (Aristidou and Sarangi 2006, 645; Kandel and Zhang 1998). This theory assumes that in reality it is often not possible to attribute, with precision, the degree of membership to a set. In other words, the "fuzziness" of membership introduced in this revised form of game theory is no longer expressed as a binary value, 1 or 0 , but it can take any value between these two numbers. The value of fuzzy game theory is that of being able to exploit to its full extent even minor information about the possible payoffs, strategies and objectives. In fact, in real world situations one cannot always be completely sure that the objective of another player is the one imagined. However, being able to account for example, a 95\% chance that a player wants to achieve what was estimated by another player in terms of goals or moves, removes the inability of classic game theory of dealing with dual (or multiple) membership. This provides the main game theoretic constructs with additional information which can help refine our understanding of real world phenomena. In fact, with fuzzy game theory, one can study more complex and less abstract interactions among players, who, like their actual counterparts, do not or cannot know exactly the strategies, goals and objectives of the game being played. Fuzzy game theory certainly represents a possible construct that a game theorist may use to deal with external actors that gradually intervene in a political crisis. The current state of the literature, however, demonstrates that the number of players is precisely defined and the fuzziness pertains to other aspects of the games like the structure of the payoffs, strategies, objectives, moves, but not the increasing importance of one or more players in a game. 
In conclusion, similar remarks can be made for neutrosophic game theory (Bhattacharya, Smarandache, Khoshnevisan 2006), a generalization of fuzzy game theory which has been applied by the authors of the paper to the study of the conflict between Israel and Palestine. Neutrosophic (Bhattacharya, Smarandache, Khoshnevisan 2006, $59)^{175}$ game theory adds to fuzzy game theory the consideration of the fact that the players of the game do not exactly know what the other player's goal is. This is so, given the two parties' lack of understanding what a 'just' agreement means. Moreover, the theory also argues that not all sets of possible agreements result in favorability of one side or the other one in that there are some sets in the evaluative judgment space of both actors that appear to be favorable to neither actors. This is the case especially if the outcome is heavily affected by the preferences of a mediator actor. This particular branch of game theory progresses closer to considering the preferences of external actors; however, similarly to fuzzy games, it fails to account for a changing environment and its evolving preferences.

\subsection{A critique of bargaining theory: a dynamic, evolving context}

Despite the large number of games that are possible to use ${ }^{176}$, the games described above fail to adequately take into account the dynamic role of the external envi-

\footnotetext{
${ }^{175}$ Neutrosophy studies the role of neutrality as a middle ground between different ideologies.

${ }^{176}$ It is worth at this point briefly describing a slightly different bargaining model, Stahl's (1972) and Rubinstein's (1982) alternating-offer bargaining game. In this game, there can be an infinite number of offers that can be made by the parties involved, but there is a cost in time in keeping the bargaining going. For both players, then, there is an interest in concluding the bargaining process as soon as possible, in that the more time it takes for them to reach an agreement, the more the price to be divided will shrink. The
} 
ronment in the success or the failure in which two or more parties reunite to reach an agreement. No importance is given to the changing nature of the environment, although more modern games can deal with relevant issues affecting the performance of the basic strategic game: among these are the fact that in reality bargainers apply the principle of "equal gains" $" 177$ or that of "greatest good"178, the option of transferring utility (or simply destroying it) or the use of threats (Myerson 1991, 384), incomplete information ${ }^{179}$, or multi-player games (417).

In Shubik (1964) there is recognition of this problem, and the authors of the article maintain that "we repeat most emphatically that our theory is thoroughly static. A dynamic theory would unquestionably be more complete and therefore more preferable. But there is ample evidence from other branches of science that it is futile to try to build one as long as the static side is not thoroughly understood" (p.93). At the time, however, Smith's The Logic of Animal Conflict (1973) and especially Axelrod's The Evolution of Cooperation (1984), the first works discussing evolutionary game theory still had to be published and attract the attention of the academic community.

Evolutionary games do account for an evolving environment but their goals are different from those that are being discussed here. In fact, in order to have a better understanding of why gas disputes were settled in a specific way, one is not interested in

authors conclude that in these kinds of games, the outcome of the bargaining process converges to the Nash equilibrium with a discount factor close to 1 (Myerson 1991, 394).

177 The principle of "equal gains" claims that bargainers make interpersonal comparisons of utility, that is they compare their utility in the bargaining process with the other players. If other players are seen as to be receiving more, then the former player is entitled to ask an higher pay-off in order to equal the gains of the two (or more) sides (Myerson 1991, 381).

178 The principle of "greatest good" maintains that a player is entitled to ask for additional benefits because doing so will allow him to gain more than what the other player would lose (see above).

${ }^{179}$ See Chapter 8 and 10. 
knowing what past strategies were employed by the current actors; one is rather interested in studying why a dyadic context (Russia and Ukraine or Russia and Belarus) is useful for studying the start of the dispute. This situation evolved into a multi-party system where also the preferences of other actors played an important role. The formulation of evolutionary game needs to be deeply revised in order to better explain the developing importance of the preferences of external actors that belong to the same 'generation'. This in turn, determines which player is going to continue in the game. At that point, the insights offered by infinitely repeated games can be applied in order to explain why Russia, Ukraine or Belarus settled a gas dispute in a specific manner. At the moment, however, game theory does not explicitly account for this issue.

Snyder and Diesing (1977) offer the reader a detailed review of several formal models used in the literature to model international crises in the international theory. Despite all the differences, advantage and disadvantages of the models they present, the authors point out that all these models share a conception of both the international system and the domestic system as "relatively static factors that constrain and shape the dynamic processes of interstate bargaining and internal decision making" (31). Snyder and Diesing define the international system as the external parameter and as "the number of major actors in the system and the distribution of power between them" (28) and maintain that they affect decision-making in a crisis by modifying the alignment options available to the disputing countries, and by introducing relevant interest conflicts (29). Domestic factors like public opinion, bureaucracy, political party ideology and the personalities of the major decision-makers have a clear effect on the final outcome of crises, but they do not play a dynamic role in the crisis-resolution process, offering rather the context within which the crisis is dealt with, modifying perceptions and value of the 
actors involved in the process. According to Snyder and Diesing, the number of actors play a comparable role to that of domestic factors, given their effect on the outcome of the bargaining process; however, they do not affect the preferences and strategies of the actors, but they exert their influence on the domestic factors, which in turn shapes the outcome of the decision-making process (31).

To the authors, however, the elements that count the most are domestic elements like bureaucratic roles, strategic preferences of the major actors, power-distribution within the decision-unit and domestic perceptions of another state's internal situation. Adding additional variables is to the authors simply a source of unwanted and unnecessary complexity (32). Allison (1971) briefly talks about the effects of the changed environment on the equilibrium between the two superpowers. According to Allison, the Soviets placed missiles in Cuba because they wanted to attract the American attention away from the European continent, leaving the Soviets free to make a move against Germany (45-46). Offering a chance to the US to attack a small and almost defenseless country like Cuba would have in fact caused internal instability in the US first, but, more importantly, it would have changed the world balance of power with several Latin American countries favorable to the Soviets, rather than the aggressive U.S. Moreover, an American attack on Cuba would have created opposition also within NATO itself, possibly crippling it, and it would have shown other world countries that the U.S. was a real threat to the Communist world. Allison dismisses the hypothesis that the Soviet deployed missiles in Cuba despite clear American warnings not to do so just to divert American attention away from the true target, Germany, because it is hard to believe that the Soviets really intended it. In fact, it would have been easier to provide Cuba with fewer missiles and let the world know that Cuba and the Soviet Union would have 
not retaliated. Such a situation would have more easily prompted an American attack on the missiles, triggering political instability domestically and overseas, and shifting the balance of power more in favor of the Soviet bloc. Moreover, the fact that the Soviet Union withdrew the missiles before an American attack supports his belief that this hypothesis should be disregarded when explaining the Cuban missile crisis.

The point of discussing one of the hypotheses Allison offers the reader is not to discuss its validity; it is to showcase that, once again, a rational interpretation of an international crisis like the Cold War could have gained in explanatory power by taking into account the effects of a changed environment on the resolution of the crisis. In fact, the internal and external situation of the U.S. would have been different in the period pre-attack on the missiles and in the following period, where the latter would have been characterized by more stringent domestic and international constraints on the options that the U.S. had. If an attack did really happen, then in order to have a better understanding of how the Cold War ended, one would have to take into account the degeneration of the American situation and possibly attribute to it a suddenly reached agreement with the Soviets.

Assuming that the Soviets did want the U.S. to attack, the international system structure and therefore also the domestic internal situation would have changed the political environment between the Soviet Union and the U.S. in the following years, possibly leading to a different outcome of the political bargaining. More pressure from the domestic setting, and more anti-Americanism from Latin America could have lead the U.S. to quickly reach an agreement with the Soviet Union that granted it, for example, full influence on some key world areas. In other words, the changed environment could 
have, as Allison also implies, heavily affected the political bargaining environment towards a more successful outcome for the Soviet Union.

Reilly and Sigall $(1976,3)$ are aware of this issue and claim that "every person is affected by the politics of the society in which he lives" and that goes beyond what game theorists do, which is considering the environment as a constraint on choices and perception of the outcome of the bargain. Such a problem is also reported by Reilly and Sigall $(1976,13)$ and Gintis (2010) who claim that economic theory, based on the rational actor assumption, is inherently flawed because social context and norms are usually ignored or assumed to be constant in the game theoretic models developed. It has been demonstrated above that prospect theory is a reaction to some of the weaknesses of the utility-maximizing assumption. But other issues remain open which also may be due to the over-reliance of current economists on outdated literature (Gintis 2010).

According to Gintis, social norms have been a discussion topic for some game theorists, who concluded that social norms represent Nash equilibriums of social games (Lewis 1969; Bicchieri 2006). However, standard game theory lacks acknowledgement of social norms that are not just within a static context in which the interactions occur, but play an active role in defining the players' motivations (Gintis 2010, 35). In many cases, it is logical to assume that the social norms that promote coordination are a constant in a specific case.

However, as the empirical results have shown, gas disputes take place in dynamic environments, characterized by large externalities which can affect the diplomatic relationships among the players belonging to same environment. In such an environment, a researcher that ignores the effects of a dynamic environment in his model risks un- 
dermining the validity of the game-theory used to explain or to predict the outcome of the bargaining process. Gintis (2010) maintains that the preferences of the players do not exclusively stem from personal features of the players, as for the rational actor, but are rather the result of the players and their preferences within the environment of reference. However, scholars have been unable to take into account the influence of the external situation because of the complexity and the lack of literature suggesting the elements that affect the preferences and in what way. The effect of reputation in game theory has been studied by some academics (Kreps and Wilson 1982; Nisan, Rouhgarden, Tardos, Vazirani 2007), but they do not provide an adequate framework with which one can better understand the true preferences and values that guide agreements reached in complex environments, as in the disputes between Russia and ex-Soviet regions $^{180}$.

In fact, there are a lot of exceptions and irregularities that need to be explained which even the models accounting for reputation fail to fully describe. According to Gintis, the typical explanation that the literature provides for unexplained variance is that the players have a cognitive deficit or that there are still unclear values and factors that are difficult to investigate (Gintis 2010, 36). Examples of these principles and val-

\footnotetext{
${ }^{180}$ Nye's (1990) 'soft power' is useful in order to explain why states do perceive and consider the pressures that result from damage to other states' economies. To Nye (1990), soft power is the ability to influence the world to help oneself without using force (or hard power) to influence the other party to act. Since now the world is shifting to multi-dimensional problems, a crisis between two states is very likely to affect others as well. In order for states to solve problems, it is now becoming more and more improper to employ military force but rather problems tend to be solved by cooperating with other states by convincing them that their interests are similar (Axelrod and Keohane 1985). In today's political arena, soft power is a very important tool that allows a state to improve its relative position among its peers: thus, a state should try to maximize this tool in any occasion. Ignoring the pressures deriving from other states may seriously damage the soft power of the state that has been considered responsible for the commencement of the crisis and increased gas and oil prices.
} 
ues are found in the fact that many people are willing to sacrifice personal gain for the goal of approval in his/her community. The authors believes that game players shape their preferences and make decisions that are socially acceptable even if they are directly concerned with reputational issues. In other words, Gintis maintains that the literature covering the importance of building reputation for present and future situations, fails to realize that reputation is just one of the values that individuals account for when playing their games. Selfishness or reputation is too simple an approximation of the actual way players settle disputes. This is due to the belief that a certain course of action is more morally or socially acceptable and may override egoistic preferences. In order to illustrate his point, Gintis claims that there are occasions in which the actors move away from purely egoistic purposes; such as facing higher costs for the sake of punishing cheaters or free-riders, or that the awareness of positive values in the counterpart represent factors that are able to modify the parties' agreement $(2010,36)$.

The problem of the influence of a dynamic context was already known to Smith (1982), who maintained that "an obvious weakness of the game-theoretic approach to evolution is that it places great emphasis on equilibrium states, whereas evolution is a process of continuous, or at least periodic, change" (8). Gas disputes, like evolution, must be understood within a dynamic context which is clear through the introduction of the actions of European leaders leading to the resolution of the 2009 gas dispute ${ }^{181}$. Smith attributes the existence of this weakness to the increased (mathematical) complexity that dealing with continuous change entails. The literature on sequential decision making (Lindblom, 1959; Snyder, Bruck, and Sapin, 1962; Brecher, 1972; Steinbruner, 1974; Anderson 1983; Axelrod, 1984; Sylvan and Ross 1998; Beasley et al. 2001) cor-

\footnotetext{
${ }^{181}$ See below.
} 
responds with this claim and demonstrates that a static process that underpins the decision-making process (goals identification, alternatives search, payoff estimation for each alternative, alternatives evaluation and alternatives selections given the goal), as found in the literature, does not correctly represent reality. Anderson (1983) finds that in the case of the Cuban missile crisis, the Executive Committee, even though it vaguely knew that its goal was to remove the missiles from Cuba, discovered the true nature of its goals while dealing with the crisis itself. For example, while debating the best course of action the US should commit to, Robert Kennedy realized that a surprise airstrike represented a betrayal of the values on which the US image was based upon. In fact, resorting to an attack that resembled the one suffered by the US on December 7, 1941, would have placed the US on the same moral level of the Japanese who killed thousands of soldiers unprepared to even defend themselves. Therefore, preservation of US morality and traditions were at this point integrated in the US strategic plan, de facto making the airstrike an unfeasible option (212).

A similar observation can be made for the Russian-Ukrainian crisis. If the goals at the onset of the crisis were merely those of imposing or resisting the other player's will, with the recognized development of the crisis, as Robert Kennedy did, other factors, namely the growing pressures coming from external actors, needed to be taken into account in order to successfully resolve the crisis. In both situations, the changed environment introduced an additional element of complexity. In the case of the Cuban missile crisis there was also the realization that the morality of the nation had to coincide with its security while in crises like the gas disputes there is a gradual emergence of other relevant actors in the game. 
The lack of game theoretic models in literature that takes into account the environment and its potential effect on the preferences of the actors is even more surprising if one considers Porter's (1985) popular Five Forces model. According to Porter, the success of a company in a competitive environment depends on five factors: the competition within the market the company is operating in, the bargaining power of suppliers (which can extract higher prices for the raw materials they provide), the bargaining power of the buyer (which determines how high the price of the sold goods is), the threat of substitute product or services, and the threat of new entrants (see below).

\section{Figure 5.1}

\section{Porter's Five Forces model.}

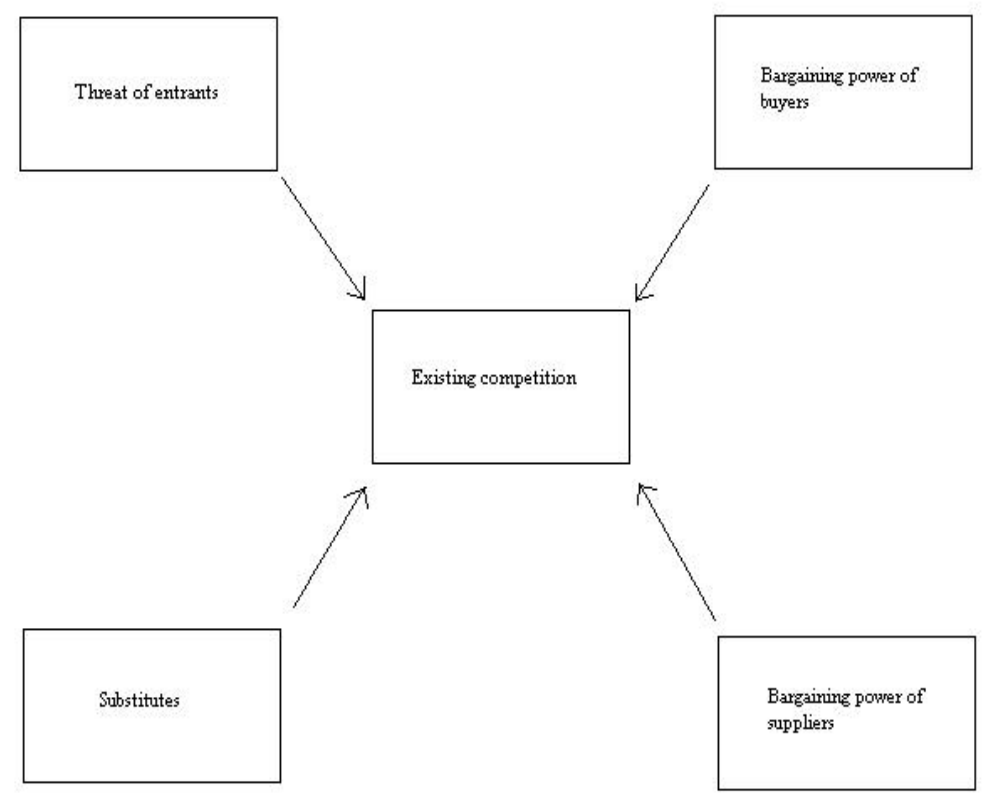

\section{Source: Porter (1985)}

Such a model is able to capture in a more refined way the complexity that is behind the competition among companies that produce the same product and therefore who compete in the same market. It can also be used to compare the performance of different actors across time. In fact, by defining the intensity of the five forces for every 
moment, one can possess information on how the competitive situation evolves over time. Therefore, one can possibly determine a conclusion about the effect of the implementation of a new policy (change of price, or diversification of product). For example, if a company decided to lower its price, with the intention of selling more and consolidating its position in the market, if everything stays the same, the company can reasonably attribute a shift in the competition in the market to the change of price. However, real world competition takes place in a changing environment and that is the main contribution of Porter's model. This is so because position in the market depends also on how disastrous may be the entrance of new competitors in the market, how many people think that the product can be replaced with a similar one, or how strong suppliers or customers are.

One finds it interesting that even though the business strategy literature does indeed deal with the environment as a source of change, the game theory literature lacks any direct consideration of it. Such an issue may be the result of the belief that there is not a well-established knowledge of the influence of specific external factors since game theory can be applied to wide range of situation and crises whose main determinants may or may not be known. Lacking a precise context in which game theory is to be applied, game theorists have not specified which variables must be taken into account, for context varies often, so that it would not make sense to prescribe the study of some specific environmental variables. However, probably as a result of this issue, game theory has remained incapable of dealing with a changing environment. A result of this is the overly large attribution of the outcome of the bargaining process to the preferences of the individuals, unaffected by external factors like social norms (Gintis 2010), or the broader context. 
Porter's model above can be modified to better describe the game theoretic situation that is being studied here and that is the simplified version of a gas price dispute between Russia and Ukraine (see below).

\section{Figure 5.2}

\section{A modified Porter's Five Forces model.}

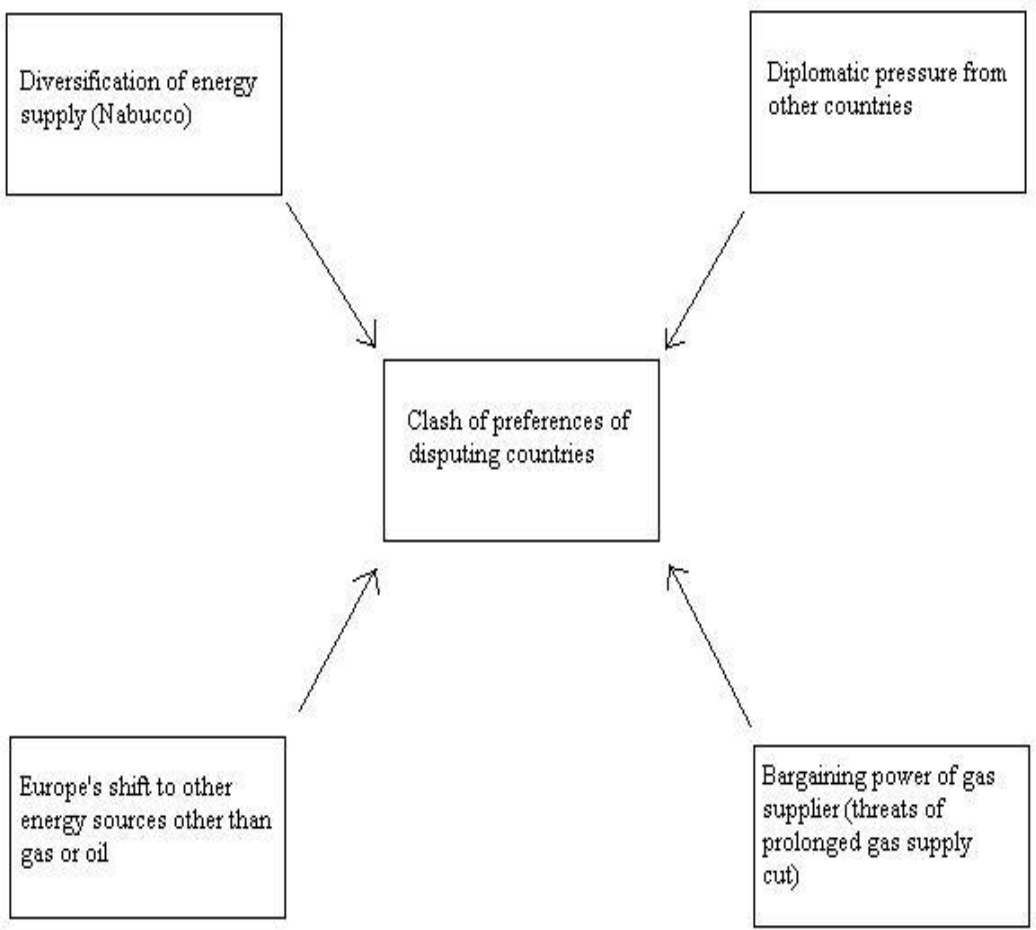

\section{Personal adaptation of Porter's model}

In the revised version of Porter's model, the concept of 'existing competition' is replaced with the conflict of interest that arises between Russia and Ukraine. In this conflict Russia aims at obtaining a higher gas price and control of pipeline system transporting gas to Europe and Ukraine, striving to keep the gas price as low as possible and to keep control over the pipeline system as a bargaining instrument and as a source of income. Given the new situation, one is still discussing the bargaining power of the supplier, which in this case is solely Russia, which is enhanced by strategies like threat- 
ening Ukraine with preventing the gas from being supplied. In the new model the threat of new entrants is a contamination of the market by new players that upsets the price and power relations in the market. They may be represented by systems like Nabucco which is an alternative pipeline system that reduces the dependency of Europe on Russian, and Ukrainian, gas. The existence of alternative paths for Central Asian gas to reach Europe modifies the original preferences of both actors in different ways. Russia will lose markets to which it can sell its own gas while Ukraine will lose, at least temporarily, the revenues stemming from the transport of Russian gas. If new pipelines are constructed, or even if the threat of doing so is communicated by European countries, the preferences of the two players must change towards reaching an agreement sooner. In other words, the entrance of non Russian-Ukrainian gas increases the costs of continuing the dispute. An agreement must be reached to avoid Europe diversifying its energy supply.

'Substitutes' have been replaced in the new model by the European shift, or threat of shifts, to other energy sources like wind energy, geothermal energy, hydroelectricity and so on. If during the dispute Europe sends credible signals that its reliance on Russian energy is to decline because other energy sources become more reliable and cheaper, then the two player's preferences are subject to modification. In fact, as seen above, both Ukraine and Russia, the players of the simplified game, are now placed in a situation where their preferences must consider that a prolonged dispute would deteriorate their economic relationship with the European market. In addition, a minor dependence on Russian energy would result in lost opportunities for Russia to use its economic power to push its political agenda (Lucas 2008). In other words, now the dispute the parties have to consider is the fact that if the dispute lasts too long, the European coun- 
tries will be substantially more likely to suffer from the discontinuous flow of gas. Moreover, they will prefer to invest more resources into developing alternative energy sources that would render them less vulnerable to the disputes deriving from the Russia producers and the ex-Soviet republics. It is not in the Russian or their transporting partners' interests to help diversification occur in that it would make the large investments in pipelines less profitable since less gas would be demanded and transported to Europe. It would slowly reduce the total demand in the main market for Russian gas. Both Russia and Ukraine do not want this to become a realization. Their preferences are now subject to an additional pressure that is similar to whether Europe decided to access Central Asian gas, or other areas, without using the Russian/Ukrainian infrastructure.

Once again, the Russian strategic advantage deriving from using or threatening to keep the gas supply closed, is a powerful strategic tool to force Ukraine to comply with its requests. This tool is of growing power because Ukraine cannot divert the gas for an extended period of time to Europe because of its own survival. The resolution of the dispute would be at that point not only a matter of survival, since having the gas flowing to Europe represents an important source of income, but also a matter of national security for Ukraine. This is so because given the lack of efficiency of the pipeline system, it is likely that the gas internally produced would not suffice to heat houses and permit citizens to continue their normal life. Even though this element represents a strategy, it deserves to be included in the model because it conceptually replaces the 'bargaining power of the supplier'. The supplier in the new model is the same actor that is involved in the dispute. Even though this item should be considered as a detail of the main class 'clash of preferences of the disputing countries', it was included in the model as a separate class in order for its separate connotation and relevance in determining the 
outcome of the bargaining process, and also to stress the increasing relevance that is possessed by Russia.

The diplomatic pressure stemming from the entire European Community has become the key element in the new model. Russia, in fact, supplies a very consistent portion of the entire demand of gas, and sudden cuts in the supply impose damages on the European economies and populations that rely on it for survival and production of goods. Concerns for a long crisis are likely to attract the attention of the European leaders, at least those that are directly affected by the crisis. Their involvement in the resolution of the dispute will be motivated by their desire to re-establish a continuous flow of gas to their countries in order to provide energy to the civilian and industrial infrastructure. Also their involvement is motivated by concerns over the potential shock that the crisis has caused in the gas market and in general, in the world economy. As other major crises have shown, wars and conflicts that have occurred in energy producer regions have been followed by an increase of the price of the main energy sources (see Figure $5.3)$.

Figure 5.3

Real oil price 1989-2005.

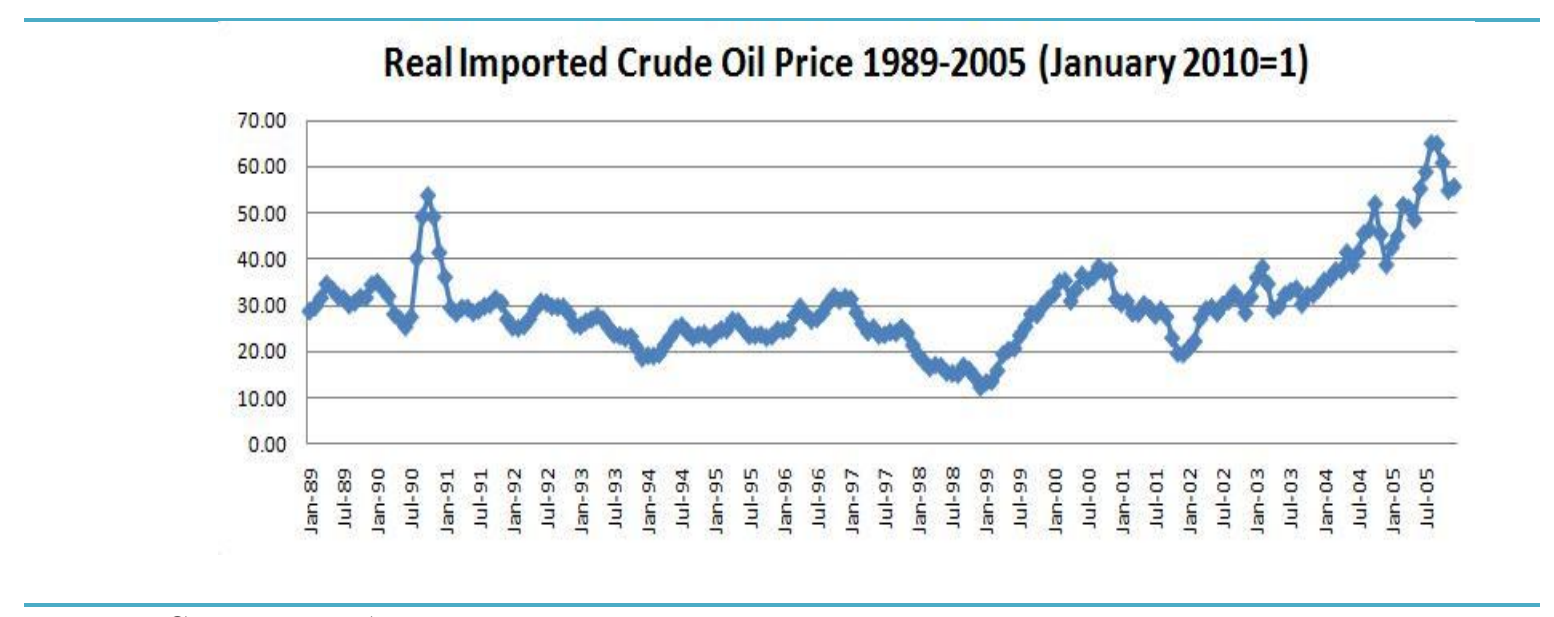


In correspondence to both the invasion of Kuwait and Iraq, respectively in August 1990 and March 2003, one notes an increase in the oil price. This was much more accentuated because of the large destruction that occurred to the Kuwaiti oil industry and the consumers' preoccupation relative to Saddam's rise to a hegemonic power in the Middle East. The high oil prices that characterized the end of 2008 have been shown in the academic literature to have harsh consequences on the economies of those countries that heavily depend on foreign energy (Hamilton 1983, Mork. 1989, Leduc and Sill 2004). However delayed the effects of high oil prices may be on the economy, or how much of it can be attributed to a restrictive monetary policy (Leduc and Sill 2004), it is crucial that states are fully aware of the damaging effect of the oil prices on the economies of those countries that rely on foreign production for their own economic and political survival. As shown above, Europe heavily depends on foreign oil, as also in the Russia Ukraine crisis, and they will not permit threats from these countries regarding their security during the disputes.

Thus, the emergence of a price disagreement directly affects the preferences of the disputing countries in that a timely resolution is in Europe's interest because that will entail a steadier energy supply and more confidence in the supply of gas from the Russian territories. One cannot assume that the outcome of the dispute solely depends on the preferences of the actors because the other countries and the international community will react to the resolution and will enact diplomatic pressures so that a conclusion is quickly found. In other words, the understanding of how the dispute was settled must be placed in a dynamic context initially characterized by a low degree of diplomatic pressure which then grows as the disputes struggles to be resolved. 
It is important to note that the revision of Porter's model, popular among business strategists, reveals that a thorough comprehension of bargaining crises cannot be fully understood just by considering the preferences of the actors involved. In fact, their preferences, that game theory generally assumes to be static (Rumelt, Schendel Teece 1994), may be susceptible to pressures from the environment which are changing due to the rise of the dispute itself. In other words, if one looks at the broader context, thus including the changing influence of the surrounding environment, one can go beyond the static situation that game theory adopts to describe bargaining among the disputing countries and analyze it from a more dynamical standpoint.

Rumelt, Schendel, Teece $(1994,451)$ recognize that the literature covering the competitive advantage of companies suffers from the same problem which is placing the understanding of why some companies finds themselves in a broader and more dynamic context. In response, they offer a model that places the competition of the firm in what they call its proximate environment (Rumelt, Schendel and Teece 1994, 451). According to the authors, the competitive advantage of a firm stems from the local environment in which the firm is operating because it is not just its preferences, its strategies, or its unique way of combining resources that defines whether it is going to dominate or solely operate the market. It is specifically its proximate environment that defines the input, the information, opportunities and hurdles that help or hinder its accumulation of resources and prestige (Rumelt, Schendel and Teece 1994). The authors derive their theory from their observation that some countries represent a more suitable location to establish and develop new businesses, while others, due to a stringent economic policy or other social and financial constraints make it more difficult for similar business development. For example, in Europe many West-European countries have been outsourc- 
ing their main facilities to Eastern Europe where labor is cheaper and is often supported by the local government with the intent of promoting the economy and occupations. The authors claim that the environment inevitably changes and by doing so, it provide firms with a large variety of opportunities which the firms can take advantage of, or that they can ignore and pursue their own strategy. Similarly, these firms can influence the environment as well, responding to these opportunities, innovating, using the resources available, and removing the hurdles present in the territory.

The authors also assume that it is the proximate environment that significantly influences the success of a firm. In this environment, success depends on more than firm strategy, structure, and the level of competition in the market it is operating in. It also depends on other elements like the availability of skilled (or cheaper) workforce, a higher demand that supports the growth of the firm, and other industries, which, with their products, supplies, and more refined technologies offer the firm a competitive advantage over the other firms that reside elsewhere. See Figure 5.4 below. 


\section{Figure 5.4}

\section{The proximate environment of a firm}

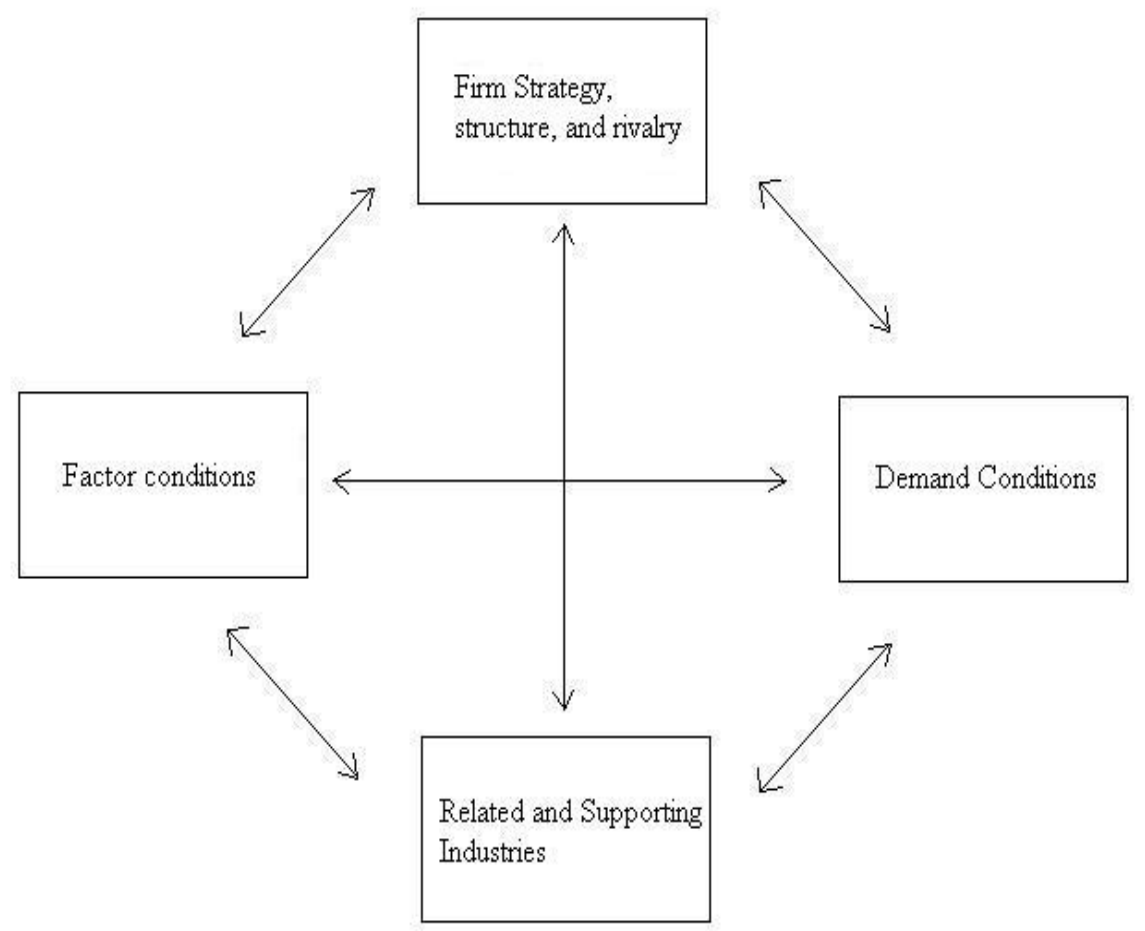

\section{Source: Rumelt, Schendel, Teece $(1994,453)$}

The insights of this model should make the reader ponder the importance of the environment in determining the success of a competing organization. One can easily transplant the ideas of the authors to a better understanding of why the two disputing countries analyzed so far, reach a specific agreement. As argued above, Porter's 'Five forces model' can be modified replacing the competition between firms with the dispute among countries. Even though the issue is competition on the one hand, and bargaining on the other hand, one can still take the ideas from the author and adapt them to the con- 
text of the dispute between the gas-supplier Russia and the gas-transporter Ukraine. The importance of the environment is as important for a competing firm as well as for a disputing country. In both cases there are opportunities and hurdles that can affect the final outcome which is the success of the firm in its market or the success of the country in the ongoing dispute.

Figure 5.5

The proximate environment of a gas importer

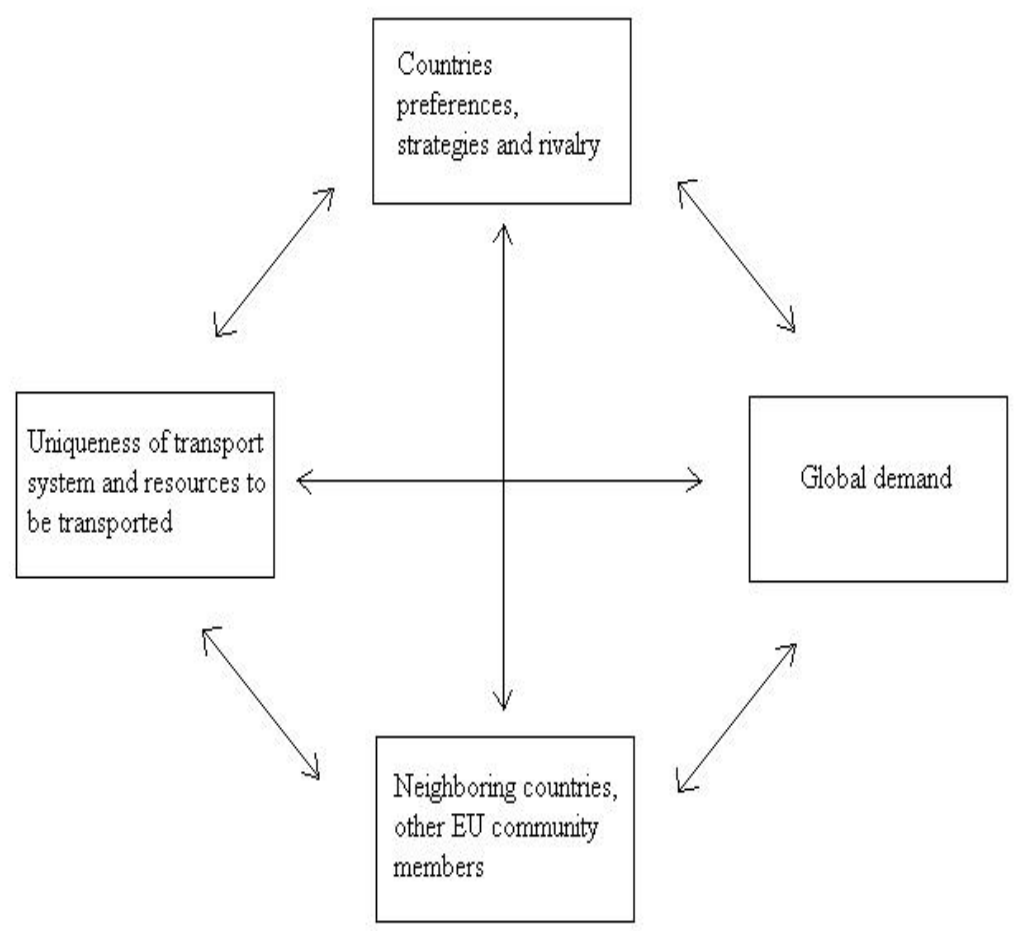

In the adapted model of Rumelt, Schendel and Teece (1994), reworked to efficiently represent the situation of the two disputing countries, factor conditions have 
been replaced by other factors that affect the competition between the two countries. The central economic precondition is the Ukrainian system for the Russian gas to reach the European customers. As also seen in the modified Five Forces model, the exclusivity of the Ukrainian system is what allows the country to maintain a bargaining advantage even though Russia has been trying to reduce it by building Blue Stream, an additional gas line to Turkey in 1997 which is expected to be fully functional in 2010. An alteration of the centrality of the Ukrainian-Russian pipeline system would significantly change the nature of the dispute. The two actors would be put in a situation to collude in order to avoid losing the primacy of their resources which in the case of Ukraine, it is the property of the pipeline system, and in the Russian case, it is the abundance of natural resources and their importance for the European economy. Similarly, global demand is also an important factor that influences bargaining in the example. If the demand increases and no other suppliers exist that can promptly provide gas where needed, the position of both Ukraine and Russia improves. Therefore, both parties are more likely to look for a favorable deal in the dispute. This means that the "pie will grow" in size and the disputers will support further negotiations until the best agreement has been reached. Conversely, if the demand decreases, it is in the best interest of both parties to close a deal as soon as possible and this is done before the economic downturn worsens or before other suppliers or pipelines complete the construction of competing transportation systems/energy alternatives.

Keohane and Nye (1977) indicated in the late seventies that our globe is an interconnected world, which they define as "global village", due to telecommunications and jet travel. This provides an environment in which social and economic transactions are creating a "world without borders". According to the authors, one is engaged in a 
common enterprise and there is not a single nation or group of nations which can gain by pushing beyond the limits that sustain world economic growth. In this "global village" no state or organization benefits from basing progress on demonstrations of strength because the destruction of the rival incurs damages of one's economic, social and political ties with that country and the other surrounding countries. Similarly, and even more clearly in the case of the gas dispute that entail the disruption the gas supply, a dispute over gas transportation and its price has severe consequences on the surrounding countries and the community in general. Drawing from the Rumelt, Schendel, Teece (1994) model of competitive advantage and the idea that it is the proximate context that more significantly affects the situation, one cannot assume that the bargain will not affect the relationship with the members of the proximate community related to the dispute. Especially if the crisis lasts several days and entails a significant disruption of the gas supply to European countries, one must consider the relevance of the other countries in shaping the outcome of the dispute among Russia and Ukraine. If initially the crisis is driven by the preferences of the two countries, the duration of the dispute will entail damages to the community's economy and a severing of ties between Ukraine and Russia within their proximate environment.

With all of these aspects, which interact with each other in the original model, one can delineate the bi-directional relationships associated with them. An example is the global demand and the uniqueness of the transportation systems; if demand is strong and expected to grow, the gas-producing country has an incentive to be the promoter of new additional pipelines in order to avoid other competitors entering the same market which reduces the market share of the existing countries. If the monopolist is not opportunistic enough to seize the occasion to render the construction of rival pipelines eco- 
nomically illogical, other companies and countries may find a favorable situation to build a competing pipeline. This in turn will endanger both Russia's gas and Ukraine's pipeline system.

Similarly, an expansion of the demand also changes the relationship among the community members served by the Russian gas and the Ukrainian infrastructure. The pressure to gain privileged access to these resources may force countries to compete amongst each other and form private agreements directly with the supplier. This in turn may have further effects like the construction of additional pipelines to help the transit of gas directly to the destination with the additional consequence of increasing dependence on Russian gas. Alternatively, the increased demand or future signs of such a trend may foster cooperation among European countries to reunite and find a way to access another sources of gas and/or diversify their energy imports. A mixture of both strategies has characterized the present situation in that some countries, like Italy, have preferred closing a private deal directly with Gazprom rather than joining a community project like Nabucco (BBC News 2009). However, should the demand for gas rise as the economy recovers as expected, new developments in the relationship among the European countries and the gas suppliers resulting in more cooperation or more enthusiasm to close exclusive deals directly with Russia may occur.

The analysis of the business strategic literature has revealed a major limitation of current game theoretic approaches as partly hinted to by Gintis (2010) with his claim that external factors like social norms are responsible for shaping the actors' preferences. However, I have argued that even though game theory tends to not consider other elements that influence the preferences of the actors involved in a dispute, much more is excluded. This is the case especially if the dispute occurs over an extended pe- 
riod of time. One argues that the proximate environment is another source of variation in the actors' preferences because other members of the community in which the two disputing countries belong to may exert pressure to affirm a deal in a timely manner. This is so since they are directly connected to the crisis due to the instability caused by it and the disruption of the gas supply which was originally meant to be employed as a tool of persuasion, but which can be turned into a means of extending the effects of the prolonged crisis to the wider community of reference. The modified models proposed here claim from only a theoretical standpoint that the environment does affect the preferences of the disputing actors. Gintis (2010) focused his critique of game theory on the relevance of the social norms to the general discussion.

I have started from this idea to develop a much larger argument: the proximate environment, that is the environment the dispute can be placed in, is also responsible for the decisions and the agreements reached by the parties, and there is empirical evidence that this environment has a real (economic) interest in doing so. For Gintis (2010) that was the presence of social norms while I argue that the diplomatic network surrounding the dispute can heavily influence the decisions taken by the actors. They have the opportunity to settle not only according to their own preferences but also taking into account the pressures stemming from neighboring countries that may have a personal interest in the conclusion of the dispute in an expeditious way. The evidence that shows that the dispute is associated with damages in other states' economies by directly damaging those economies can be seen as relevant proof that the mere start of a dispute may trigger a mechanism. This mechanism modifies the preferences of the actors, due to the diplomatic interventions of actors that are not directly involved in the dispute (therefore usually not included in a normal bargaining model). However, in order to do 
so, there is a need to find evidence that gas disputes are capable of triggering unfavorable situations for other states. And that actors from the proximate environment become involved at this point.

This then gives outside parties a reason to intervene in the crisis and play an active role in modifying the preferences of the actors by imposing deadlines and urging a resolve to the dispute within pre-determined times. This was especially the case in the 2009 gas dispute when a mission to Russia and to Ukraine was organized to support the claims that were made from both sides. This was done when the President of the European Commission spoke in person to both the Russian and the Ukrainian Prime Ministers, urging them to restore the supply of gas as soon as possible since their reputations as reliable suppliers were in question. A telephone conversation involving the same parties occurred three days later, when the President of the European Commission was granted assurances from the disputants that if a commission was to be deployed, then the crisis would soon reach an end (Pirani, Stern, Yafimava 2009, 46). On January 7th, 2009 the German Chancellor spoke with the Prime Ministers and was able to reach agreement by which a commission of experts would be sent to both countries in order to investigate the actual causes behind the halt of gas to Europe. On January 11th, the Monitoring Agreement was accepted by all parties and European experts were deployed to designated key points of the Russian-Ukrainian pipeline system (Pirani, Stern, Yafimava, 47).

\subsection{Changing games in an evolving environment}


The 2009 crisis represents an extreme case in which the gravity of the situation, determined by the interruption of gas flow to Europe, triggered an immediate and clear response from the highest European political spheres. A similar statement cannot be made with reference to the 2006 gas dispute in which "the European Commission officials were severely criticized for only returning from holiday in time to welcome the end of the crisis" (Pirani, Stern, Yafimava 2009, 46). Despite the lack of intervention at the supra-national level, consumers reacted to the crisis due to the reduction of gas supply, even though the crisis merely lasted three days.

Nonetheless, both crises stress an important fact, which is that the outcome of political bargaining that occurred between Russia and Ukraine, and Russia and Belarus or Moldova was affected in different degrees by the preferences of actors that had an interest in an early resolution of the dispute. In both cases, gas supplies were reduced or cut causing significant damages to the economies and the standards of living of citizens of the countries that were more severely affected by the gas disruptions. Thus, these countries were strongly motivated to impose their preferences on the disputing actors since the consequences of their doing so were evident to all. However, even though crises are not followed by gas disruptions, they may be responsible for more subtle damaging events. These events are a decline in consumption, given the higher perception that the economy will be more unstable and/or like a rise in gas (and oil) price, which the economic literature shows to be the cause of a decline in the real GDP of energy importing countries (Hamilton 1983; Abeysinghe 2001; Leduc and Sill 2004; Ramos and Veiga 2010).

The evidence found that shows that gas crises do influence stock market indexes, energy prices, and GDP supports my claim that when studying and modeling gas dis- 
putes one should consider the pressure deriving from external actors that do not pertain to the commencing causes or clash of preferences of the start of a dispute. In other words, what political bargaining theory fails to account for is a changing environment in which the crisis takes place. More specifically, one argues that the context in which the crisis debuts changes immediately. This occurs as soon as the crisis reaches the point at which its very existence affects the internal situation of other actors. In fact, one ponders two different questions; if one would like to understand how a crisis started, then it is logical to analyze what the preferences of the clashing parties are. However, if one would like to understand why a crisis ends with a specific agreement (that favors one side rather than the other one), then I argue that it is imperative to broaden the reference context and extend it to comprise of all the other actors that may have been affected, along with the pressures they may have exerted on the preferences of the disputing actors.

As seen above, fuzzy games come close to portray a more realistic political bargaining situation. However, in these games the number of players is precisely defined and the fuzziness pertains only to other aspects of the games like the structure of the payoffs, strategies, objectives, moves, but not the increasing importance of one or more additional players in a game. However, one can informally recognize that the fuzziness of these games is 'more' complete by acknowledging the fact that there are actors whose preferences gradually emerge and become active in a game, especially in an environment which has been damaged by the start of the crisis or in an environment that benefitted from an active diplomatic intervention (statement from President of the EU for example). 
In such a game, represented in Figure 5.6, not only the structure of the game changes; from a two-dimensional table its formal representation gradually evolves into a multi-dimensional table, where there are as many dimensions as the total number of players. In what I will call Fully-Fuzzy games the preferences orderings for actions change, aggregating across all "game-dimensions", where the choice/alternatives arise.

Figure 5.6

\section{A Fully-Fuzzy game with three players}

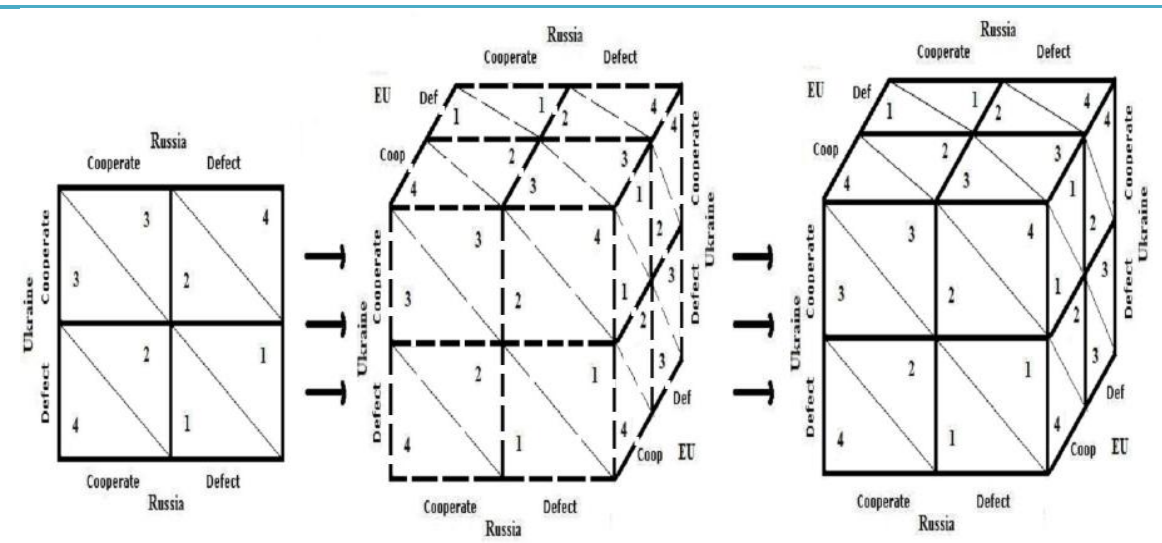

Fully-Fuzzy games possess the ability to consider an environment that gradually evolves to the point of introducing a new player mid-play that in the case of the present work could be identified as Europe, whether with this concept one refers to any combination of European countries and/or European institution which is directly or indirectly involved by the gas dispute in the negotiation process. Figure 5.6 emphasizes the gradual transition (emphasized in the Figure by a dashed line) by which these new actors enter the game. As already said, it is this gradual change, which one can assume to be related to the cumulative damage suffered by these external actors, the central part of my argument and which I claim cannot be directly dealt with by current state-of-the-art of game theoretic models. 
It is important to state here that in this work I am limiting my analysis to the informal definition of Fully-Fuzzy games, leaving to future research the definition of the actual calculation of the pay-offs and equilibriums.

As a final remark, it is important to note that the third party (EU) does not necessarily have to be allied with either of the two former players, Russia and Ukraine. The preferences of this third entity may have some affinity with the preferences of the other actors, but, being a separate entity, they do not necessarily need to be so.

\subsection{Connecting the dots: discussion of results}

The models presented in this work shows that especially the crises between Russia and Belarus in 2007 and Ukraine in 2009 had heavy repercussions on external players, whether investigating is their real GDP growth or their stock markets. Part of the reason surely has to do with the fact that, despite good economic and political relationships between Belarus and Russia (if compared to that Russia-Ukraine), Gazprom stopped supplies to Belarus as soon as the contract binding them expired in January 1, 2004, and in the February of the same year and was repeatedly threatened similar events in later years as well. In 2004, Belarus survived the winter by signing temporary contracts with some private gas companies.

Belarus did not reach any agreement with Russia until February 18, 2004, when Gazprom cut off all gas supplies for 30 hours, including those that were meant to be delivered to the European market. Over five months after the interruption of gas supplies to Belarus in 2004, the two countries reached an agreement, in which a higher price was set and to be paid to Gazprom, while Gazprom obtained a lower tariff for the transporta- 
tion of the gas through the Belarusian pipeline system in exchange of a loan to Belarus which was supposed to help it pay its gas debt back to Gazprom (NewEurope.eu. 2006).

The consequences of the February cut were significant especially for the Kaliningrad region and Poland, the former being forced to switch to fuel oil and to hot water, the latter suffering a 35\% supply decline on February 18, and a 50\% gas diminution on February 19, while Latvia was able to compensate using its own gas reserves, which were even sufficient to help the neighboring Lithuania as well (NewEurope.eu. 2006, 100).

An agreement was found only at the end of year 2005, when Russia was intended to supply gas for a very low price, namely around $\$ 47$ per thousand cubic meter.

In exchange Belarus would commit to (Kupchinsky 2006. 100):

- follow the schedule planned for the completion of the Yamal-Europe pipeline which transports gas to Germany;

- resolve the issues related to the leases of the lands on which the gas compressors were to be built;

- resume the talks about the joint venture Beltrangaz-Gazprom.

As noted above, the 2004 crisis hardly struck Poland, which receives half its supplies via the Belarus pipeline. According to Krushelnycky (2004), the crisis generated widespread fear in the country of being left without gas in the middle of the winter season. The crisis triggered the reaction of the Polish leaders, who requested an "urgent review of their country's energy policies", given their high dependence on Russian energy which transits across countries that can be easily destabilized by crises like the one occurred in 2004. 
The 2004 gas dispute, as shown above, triggered for the first time doubts on the reliability of Gazprom as energy supplier. In 30 years of successful economic and diplomatic relations, this was the first time that Europe cast doubts upon Gazprom's ability to control its gas exports to Europe (Bruce 2005) without having to resort to total stoppage of gas supplies on an important transit country like Belarus. These concerns were strongly supported by Germany, who proposed, along with Russia, the construction of the North-European Gas pipeline, known also as Nord Stream. This pipeline, over half of which is Gazprom's property, is designed with the precise intent to bypass the landbased pipelines that cross the Belarusian and Ukrainian territories, thus reducing Russian dependence on the stability of these two countries for securing a steady flow of gas to Europe. It was in January 2004 that the Russian government made its first official move in support of the construction of this pipeline, which officially started at the end of 2005 (Cohen 2006). Germany has a personal interest in the success of this project, in that it will host the main gas hub for the entire Western section of the European Union and to some countries of Eastern Europe as well. The Nord Stream project will not only secure a more reliable supply of gas to Western Europe, but it will also bring a general reduction of the gas price, since no transit fees would be at that point be due to the transit countries. Transit fees, however, are also the motivation of the opposition of countries like Poland, Czech Republic, Slowakia, and Hungary, which provide an important source of revenues for their economies (Cohen 2006).

Thus, if on the one hand the construction of the Nord Stream pipeline promotes more reliable supplies of gas from Russia, the dependence on Russian energy will be strengthened, making Europe directly vulnerable to the Russian political agenda, and decreasing the European ability to switch to alternative sources of energy. 
However, the damaging effects of the 2004 dispute on the European Community as a whole were probably the reason behind the publication of the Directive of the Council of the European Union 2004/67/EC of April 26, 2004, according to which a minimum of common policy was to be adopted in order to guarantee a certain level of security of gas supplies ${ }^{182}$. Natural gas was, with this directive, recognized as a vital element for economic success of the European Union, and imposed on the Community the requirements of:

- precisely identifying the responsibilities of different market player to secure a pre-defined standard of gas supplies;

- creating gas reserves that are able to counter eventual supply disruptions.

A Gas Coordination Group ${ }^{183}$ created for this specific task will monitor the contracts regulating the supplies to European member States, the efficiency of the gas reserves of the Member States, and the degree of interconnection of gas reserves between Member States. The 2004/67 Directive introduces a 3-step approach to be followed in case of gas disruption: according to this approach, the industry attempts to resolve it first; if not agreement is reached, then the national governments have to intervene. However, if even these measures are not sufficient to resolve the situation, the Community as a whole will mediate and assist the disputing actors.

While this Directive is probably the strongest European reaction to the growing threat of dependence on Russian gas at the time, not much in its language and in its requirements show that the European Union, as a whole, should be forced to create and

\footnotetext{
${ }^{182}$ See http://www.energy.eu/directives/1_12720040429en00920096.pdf and also http://europa.eu/rapid/pressReleasesAction.do?reference=IP/09/1917\&format=HTML\&aged=0\&languag $\mathrm{e}=\mathrm{EN} \&$ guiLanguage $=\mathrm{en}$.

183 This group was formally activated in 2006. See note above.
} 
enforce rules that guarantee the security of supply not just of every single country, but the entire region as well. This suggests that, even though the 2004 crisis did affect several European economies, a recognition of the centrality of Member states' freedom to decide the best approach to guarantee their own gas supply still dominate over the overall concern of growing dependence on foreign energy. Such an issue may be the explanation for why the publication of the 2004/67 Directive did not reach significance in the stock market described above.

The significance of the 2006 dispute not just in the model selected, but also in its variants is likely to reflect the increased relevance of gas security in Europe. In this occasion, the effects of this crisis were probably behind the statements made by Andris Piebalgs, EU energy commissioner, in support of a reaching "as soon as possible a satisfactory agreement that does not put in question gas transits to the EU" (BBC News 2006a) and were also the motivation behind the renewed Polish interest in reducing its dependence on Russian energy, and in making it clear that the disputes between Belarus and Russia had clearly demonstrated how unreliable Russian gas supplies are, implicitly calling for a diversification of supplies.

The 2006 crisis is likely to have further motivated Germany and Russia to construct the Nord Stream pipeline, a project which was opposed for the reasons described above by Poland, which preferred to put additional pressure on the EU as to find a common answer to the Russian moves of consolidating its political and economic influence over the transit countries.

Michael Glos, who was at the time, the chairman of the European Union Energy Ministers' Council, reflecting an experience with the potential negative effects that these kind of disputes can have on the European economies, expressed concern over the 
evolution of the 2006 crisis. This dispute quickly degenerated in January 1, 2007, when Transneft, a Russian company, cut oil supplies on the Druzhba pipeline as a result of the Belarusian siphoning off of oil as a repayment of the unpaid transit fees through its territories (Bloomberg.com 2007). Shortly after, on January 25, 2007, EU Energy Commissioner Andris Piebalgs emphasized the unacceptance of increasing dependence on imports and the importance of building up alternative sources of energy by ${ }^{184}$ :

- confirmation of the goal of reducing energy consumption by $20 \%$ by 2020 ;

- an overall renewable energy target for 2020 of $20 \%$;

- a "minimum target" for biofuels in 2020 of $10 \%$ of the petrol and diesel market.

Although these political reactions may be more easily attributed to the 2006 gas disputes between Ukraine and Russia and Russia and Moldova, it is likely that these are the results of the perceived damage that these crises had on the EU GDP just few months before. The statistical model I described above found not only the dispute in 2004 (Belarus), to be significant to explain the general downturn in the GDP of the 9 countries analyzed; both the 2006 Belarusian and Ukrainian crises contributed to raising a general concern about the European dependence on Russian natural gas. Although the 2006 dispute did not produce significant damages to the GDPs of the 9 countries chosen among the most influential in the Council of European Union, the effects of the crises in 2004 and in 2006 probably carried over the following years and were reinforced by the growing certainty among EU leaders of the political significance of the Russian use of the "gas weapon" (Saunders 2008). uage $=\mathrm{EN}$. 
On the evening of August 1, 2007 the European Commission activated the EU's Network of Energy Security Correspondents (NESCO) ${ }^{185}$, a forum instituted on May 10, 2007 and constituted by representatives of the European Commission, the Council Secretariat and EU Member States with the purpose of anticipating and preventing disruptions on energy supplies to the EU. On this date, NESCO was to officially follow from a close distance the Russia-Belarus crisis and report its potential effect on the EU energy security, de facto advertising the deepness of the EU concern of the potential effects of the 2007 crisis. The stock markets reacted positively to this event, probably reflecting that traders perceived the deep concern and interest of the EU in an early resolution of the dispute.

Saunders (2008) reports that a 2007 survey of the Transatlantic Trends found that $59 \%$ of Europeans had recently changed their opinion regarding the reliability of Russia as an energy supplier; these results, that on the one hand should be reflected by a statistical significance of the Belarusian dispute in 2007, do not necessarily need to be so, given the large negative effects that the Belarusian crises in 2004 and 2006, and the Ukrainian crisis in 2006 had on the economies of the 9 countries studied ${ }^{186}$.

Not surprisingly, the Moldovan dispute did not have any significant effect according to the models presented in this work. The minor attention devoted to this dispute, I believe, might be a reflection that also given its position, the dispute between Russia and Moldova did not cause any relevant effect, or that its effects were so small that the http://europa.eu/rapid/pressReleasesAction.do?reference=IP/07/629\&format=HTML\&aged=0\&language $=$ EN\&guiLanguage $=$ en .

${ }^{186}$ Pirani, Stern and Yafimava (2009) also confirm the strong negative effect of the 2006 Ukrainian dispute with Russia. 
models used in this work could not capture. The model, however, may have attributed the variance that should be attributed to the Moldovan crisis to the other crises that occurred at the same time. The Moldovan crisis, in fact, started (using the gas disruption as the indicator of negotiation failure) in January 1, 2006 at the same time the Ukrainian crisis did, followed few months later by the Belarusian crisis. It is likely, then, that the model struggles attributing variance to the variable that identifies the Moldovan crisis, given that other two crises were playing a role at the same time. However, as said above, it is also possible that the models correctly identify the fact that this crisis did not last long enough and was not followed by disruptions of supplies directed to the European to damage the economies of the 9 countries studied here. Nonetheless, the crisis did attract some attention from the European Commission, which on January 17, 2006 welcomed the temporary agreement found by the two parties. The Commission, however, also sent an energy expert to Moldova in January 18, in order to assess the security of supply for Moldova and the EU (Lobjakas 2006). Thus, political pressure was exerted on the negotiations too late, but the reason behind this act should not be attributed to the insignificant effects of the Moldovan crisis, but rather to the effects of the Belarusian crisis in 2004, which, as discussed above, had attracted the political attention of the European Commission and brought the 2004/67/EC Directive of April 26, 2004. This Directive was the probable factor that led the Commission to send the expert to evaluate the situation in situ.

In conclusion, the model finds a negative and significant effect of the dispute between Ukraine and Russia in 2009. Such a result could have been expected, given the 
large gas disruption that affected several European countries ${ }^{187}$ (World Gas Intelligence 2009).

As shown in Table 4.3 above, the statement from the Presidency of the European Union of January 4, 2009, was negatively seen by EU traders, signifying that traders did not perceive a strong EU commitment that could have been enough to end energy disruptions. Moreover, the European Commission, as a result of the 2009 dispute, reacted also with the establishment of the "early warning mechanism", an agreement drafted by the European Commission EU-Russia Summit on 21-22 May, $2009^{188}$ and accepted by President Medvedev to prevent and more efficiently manage supply disruptions ${ }^{189}$, whether they are of technical, legal or commercial nature. This agreement, reinforced by IP/09/1718, advocates the early notification of any foreseen gas, oil, electricity disruptions which can be followed by consultations and the drafting of common plans to prevent the reduction or the cut-off of gas to occur.

In the occasion of the signing of this agreement in 2009 (which was being discussed already on the EU-Russia Summit in 2007), Commissioner Piebalgs commented that

An energy crisis like the one the EU suffered in January is harmful for supply, transit and consuming countries alike. We need to do everything necessary to make sure that such a situation never happens again. I'm confident that the implementation of this Mechanism will be a powerful tool to prevent, in any event, the transit or export of energy to the European Union being reduced or cut off ${ }^{\prime \prime 190}$.

\footnotetext{
${ }^{187}$ See above.

${ }^{188}$ According to Grant and Barysch (2003), the EU-Russia Energy Dialogues do not to produce significant results for issues like pipelines, gas supply contracts, electricity, sector restructuring and nuclear fuel supplies due to the general tendency of EU countries of dealing with these issues privately and directly with Russia.

${ }^{189}$ The June 2010 gas dispute between Belarus and Russia has shown that this system needs additional efforts to expeditiously prevent damaging effects on Europe.

${ }^{190}$ See http://europa.eu/rapid/pressReleasesAction.do?reference=IP/09/1718\&language=en .
} 
In July of the same year, the Commission proposed a Regulation designed to better cope with potential crises by ${ }^{191}$ :

- giving more independence to the market operators with regards to managing supplies during any disruption;

- promoting market transparency and ensure a deeper knowledge of the balance between demand and supply of gas;

- promoting more collaboration between the disputing Member States and the EU.

Energy security was once again the major topic in November 2009 with the launch of the Eastern Europe Energy Efficiency and Environment Partnership, designed to attract investments in Eastern Europe that maximize efficiency in this area. The project will start in Ukraine, which, according to Benita Ferrero-Waldner, Commissioner for External Relations and European Neighborhood Policy, has

"a fantastic potential to save energy, and energy efficiency represents Ukraine's single best opportunity to improve its energy security by reducing its import dependency. Modest investments can bring big results. I hope that we can demonstrate in Ukraine that energy efficiency is good for the economy, good for the consumer, and good for the planet - so that the projects we undertake here can be copied elsewhere" ${ }^{p 192}$.

This project is just another example of the programmes sponsored by the European Commission to reduce general consumption of energy resources, while, at the same time, reducing dependency and costs. Along this line is the sponsorization of the expan-

\footnotetext{
${ }^{191}$ See http://ec.europa.eu/energy/security/gas/new_proposals_en.htm . 192 $\mathrm{e}=\mathrm{EN} \&$ guiLanguage $=\mathrm{en}$.
} 
sion of a geothermal energy plant in Iceland ${ }^{193}$, the creation of "Marguerite", the 2020 European Fund for Energy, Climate Change and Infrastructure ${ }^{194}$, and an increased attention to other renewable energy sources ${ }^{195}$.

Unlike the dispute that occurred in 2006, the 2009 negotiation process lasted for over 20 days, with a partial gas reduction as soon as they reached a dead end and a total stop just six days later. The 2006 crisis lasted just 3 days, also thanks to the European customers' intervention, which was quickly followed, according to Nichol, Woehrel and Bernard (2006) and Yhiah (2008), by a series of agreements that settled the economic and political relationship between the two countries for a relatively long time especially if compared to the Belarusian case.

The relevance of the external factors was evident not only in the significance of the statements, and institutions studied in the stock market model, but also by Russia decided that it was in its interest to bypass Ukraine with the construction of the Nord Stream. Although several other diplomatic issues were connected to the building of this expensive infrastructure, Ukraine perceived that the realization of the new pipeline, that was supposed to bypass up to $50 \%$ of the Ukrainian pipeline system, was a serious http://europa.eu/rapid/pressReleasesAction.do?reference=BEI/09/226\&format=HTML\&aged=0\&languag e $=$ EN\&guiLanguage $=$ en .

194

http://europa.eu/rapid/pressReleasesAction.do?reference=BEI/09/242\&format=HTML\&aged=0\&languag e $=$ EN\&guiLanguage $=$ en .

195

http://europa.eu/rapid/pressReleasesAction.do?reference=SPEECH/09/539\&format=HTML\&aged=0\&lan guage $=E N \&$ guiLanguage $=$ en . 
threat to its centrality and gas delivery to Europe ${ }^{196}$. It was also for this reason that a wave of agreements followed immediately after European customers reacted to the 2006 dispute, reflected also by the broaden scope and increased amount of projects of INOGATE programme ${ }^{197}$, a EU initiative to foster collaboration with the littoral states of the Black Sea and the Caspian Sea and surrounding countries to enhance energy security, and attract financial resources on important projects dedicated to the achievement of the above mentioned goal.

Similar conclusions, however, could be drawn for the 2009 crisis; in fact, the two parties were aware that a negotiation phase as long as that of the Belarusian crisis in 2004 would have led the EU to seriously invest time and resources in alternative sources of energy, given the statements already made in 2004 about reducing energy consumption, lowering dependence on oil and gas and committing to the construction of the Nabucco pipeline, the White Stream (a pipeline which connects Georgia and Romania through the Black Sea) and the Interconnector between Turkey and Greece and Italy (ITGY). These pipelines, as discussed above, are in direct competition with the North Stream, the pipeline owned in majority by Russia which is planning to use it to bypass transit countries and lower the gas price itself by avoiding paying transit fees. Nabucco and similar projects, however, represents a threat also to Ukraine, which benefits from its being a transit country. This common interest in avoiding the loss of their privileged access to the European market, a loss which can be seen as an externality of a prolonged bargaining, is, I argue, another example that the preferences of external actors need to

\footnotetext{
${ }^{196}$ Its centrality represented its main bargaining advantage in the negotiations with Russia (Saunders 2008).

${ }^{197}$ See http://www.inogate.org/ .
} 
be accounted for to understand the development of important political crises like the ones studied in this work. 


\section{Conclusions}

The 2009 and the 2010 gas dispute have shown the international community that energy is to become a prime issue for European security. In recent years, these conflicts have reached an intensity which was only matched by those of the seventies. In addition to European security, the expansion of Russian political influence in Europe has become a major concern for the highest European leaders, who suspect that Russia may use the energy weapon to advance its political agenda also in Eastern and Western Europe.

Understanding the development and conclusion of these political bargaining events can occur through the use of political bargaining models, and it is discussing the potential of these models where I believe that this work is making its biggest contribution. This work shows that one of the most popular political bargaining models, game theory, has thus far been limited by its inability of dealing with a changing environment. Evolutionary games, infinitively repeated games, multi-agent games, two-level games, nested games, fuzzy games, neutrosophic games, supergames, metagames, despite their value and their emphasisis on specific issues do not account for an environment in which multiple actors gradually become active parts of the game, as shown to be a real occurrance and supported by empirical evidence in political bargaining crises like those between Russia and its former satellites. Figure 5.6 emphasizes that an evolving environment can significantly affect not only the structure of a game (no more just a Chicken game), but it modifies the calculation relative to the aggregation of the preferences, which, in the specific case presented in Figure 5.6, would occur across all thre dimensions.

In conclusion, I believe that a secondary contribution of this work is to bring to light the existence of statistical techniques like ARCH models and Principal Component 
Analysis. These techniques, mostly used in economics or health sciences, would certainly help political scientists produce better research, more robust and of higher quality, to the benefit of the whole scientific community.

It is important to point out that the present work is simply an attempt to stress the limits of modern game theory. As the reader has noticed, there is no attempt to formalize the gradual interaction of multiple players. This work is rather designed to acknoledge this game theoretical limitation and leaves the design of the formal utility calculus to future research, mainly due to the mathematical complexity of the task. I chose the call the game "Fully-Fuzzy" knowing that the computation complexity of this game would probably be at a higher level than Fuzzy games. Nonetheless, it is probable that with the definition of the formal model that the contribution of the present work will be complete. 


\section{Bibliography:}

Abeysinghe, T. 2001. "Estimation of direct and indirect impact of oil price on growth." Economics letters - Elsevier. < http://www.sciencedirect.com/science?_ob=MImg\&_imagekey=B6V84443JYPF-3-

Y\&_cdi=5860\&_user=768492\&_pii=S0165176501004761\&_orig=search\&_coverDate $=11 \% 2 \mathrm{~F} 30 \%$ 2F2001\&_sk=999269997\&view=c\&wchp=dGLzVtb-

zSkWz\&md5=14cad2c016a30204de434152d264c6be\&ie=/sdarticle.pdf >. Accessed: March 2, 2010. Allison, Graham T. 1971. Essence of Decision. Little, Brown \&Company.

Allison, P. David. 2009. Fixed effects regression models. Sage Publications.

Anderson, Paul A. 1983. "Decision Making by Objection and the Cuban Missile Crisis". Administrative Science Quarterly, Vol. 28 (2), 201-222.

Anderton, Charles H., and John R. Carter. 2003. "Does war disrupt trade?" Globalization and armed conflict, edited by Gerald Schneider, Katherine Barbieri, and Nils Petter Gleditsch, 299-310. Lanham, MD: Rowman \& Littlefield.

Anderton, Charles H., John R. Carter. 2001. "The Impact of War on Trade: An Interrupted TimesSeries Study”. Journal of Peace Research, 38(4), 445-457.

Aristidou, Michael and Sudipta Sarangi. 2006. "Games in Fuzzy Environments". Southern Economic Journal, 72 (3), 645-659.

Arrow, Kenneth J. 2008. “Arrow's Theorem”. The New Palgrave Dictionary of Economics, Second Edition, Eds. Steven N. Durlauf and Lawrence E. Blume, Palgrave Macmillan Publishing.

Asimov, Isaac. 1988. Prelude to Foundation. Published: Grafton.

Axelrod, R. \& Keohane, R., 1985. “Achieving Cooperation under Anarchy: Strategies and Institutions". World Politics, 38(1), 226-254.

Axelrod, Robert. 1984. The evolution of cooperation. Basic Books.

Barbieri, Katherine, and Jack S. Levy. 1999. "Sleeping with the enemy: The impact of war on trade." Journal of Peace Research 36 (4): 463-79.

Barylski, Robert V. 1995. "Russia, the West, and the Caspian Energy Hub". Middle East Journal. 48(2). Accessed: February 23, 2010.

BBC News. 2006. Moldova agrees Russian gas deal. < http://news.bbc.co.uk/2/hi/business/4620844.stm >. Accessed: February 24, 2010.

BBC News. 2006a. EU urges end to Belarus gas row.

<http://news.bbc.co.uk/2/hi/business/6215249.stm>. Accessed: June 8, 2010.

BBC News. 2007. Russia oil row hits Europe supply.

<http://news.bbc.co.uk/2/hi/business/6240473.stm>. Accessed: June 8, 2010.

BBC 2009. Putins. scorns EU-Ukraine gas deal.

<http://news.bbc.co.uk/nol/ukfs_news/hi/newsid_7960000/newsid_7961000/7961073.stm>.

Accessed: February 22, 2010.

BBC News. 2010. Ukraine election: Yanukovych urges Tymoshenko to quit. <http://news.bbc.co.uk/2/hi/europe/8508276.stm>. Accessed: February 26, 2010.

Beasley, Ryan K., Juliet Kaarbo, Charles F. Hermann, Margaret G. Hermann. 2001. "People and Processes in Foreign Policymaking: Insights from Comparative Case Studies". International Studies Review, 3 (2), Leaders, Groups, and Coalitions: Understanding the People and Processes in Foreign Policymaking, 217-250.

Becker, Gary S. 1962. "Irrational Behavior and Economic Theory". The Journal of Political Economy, 70(1), 1-13.

Beloposky Helen. 2009. Russia And The Challengers: Russian Alignment With China, Iran , And Iraq In The Unipolar Era. Palgrave Macmillan. 
Bennett, Peter G. 1995. Modeling Decisions in International Relations: Game Theory and Beyond Mershon International Studies Review. pp 19-52.

Bernanke, Ben S., Mark Gertler, and Mark Watson. 1997. "Systematic Monetary Policy and the Effects of Oil price Shocks." Brookings Papers on Economic Activity 1, 91-142.

Bernanke, Ben S., Mark Gertler, and Mark Watson. 2004. "Oil Shocks and Aggregate Macroeconomic Behavior: The Role of Monetary Policy A Reply." Journal of Money Credit, and Banking 36, 287-291.

Bicchieri, C. 2006. "The Grammar of Society: The Nature and Dynamics of Social Norms." Cambridge University Press, Cambridge. Cited in Gintis, Herbert. 2010. "Towards a renaissance of economic theory". Journal of Economic Behavior \& Organization 73, 34-40.

Bindi, Federiga. 2010. The foreign policy of the European Union: assessing Europe's role in the world. Brookings Institution Press: Washington, D.C.

Binmore, K. G., and L. Samuelson. 1992. "Evolutionary stability in repeated games played by finite automata". Journal of Economic Theory, 57:278-305. As cited in Danielson, Peter A. 1998. "Modeling Rationality, Morality and Evolution". Oxford University Press: New York.

Bloomberg.com. 2007. Belarus-Russia Row Cuts Oil Flow to Germany, Poland (Update7).

<http://www.bloomberg.com/apps/news?pid=20601085\&sid=adBGh97FZfCo\&refer=europe >. Accessed: June 8, 2010.

Bollerslev, T. 1986. "Generalized autoregressive conditional heteroskedasticity". Journal of Econometrics, 31, 307-327.

Bollerslev, Tim. 1986. Glossary to ARCH (GARCH). Center for Research in Econometric Analysis of Time Series (CREATES). < ftp://ftp.econ.au.dk/creates/rp/08/rp08_49.pdf>. Accessed: June 28, 2010.

Bonham, Carl, Edwin Fujii, Eric Im, And James Mak. 1992. "The Impact of the Hotel Room Tax: An Interrupted Time Series Approach". National Tax Journal, 45(4), 433-41.

Bornstein, Gary, David Budescu, Shmuel Zamir. 1997. Cooperation in Intergroup, N-Person, and Two-Person Games of Chicken. The Journal of Conflict Resolution, 41 (3), 384-406.

Box, G.E.P. and G.C. Tiao. 1965. "A Change in level of a nonstationary time series." Biometrika, (52), 181-192.

Box, G.E.P. and G.C. Tiao. 1975. "Intervention analysis with applications to economic and environmental problems." Journal of the American Statistical Association, (70), 70-92.

Box, G.E.P. and G.M. Jenkins. 1976. Time series Analysis: Forecasting and Control. San Francisco: Holden-Day.

Brams, Steven J. And D. Marc Kilgour. 1975. Game Theory and Politics. The Free Press.

Brams, Steven J. And D. Marc Kilgour. 1988. Game Theory and National Security. Basil Blackwell Inc.

Braun, R.A., McGrattan, E., 1993. "The Macroeconomics of War and Peace". NBER Macroeconomics Annual, 197-247.

Brecher, Michael. 1972. The Foreign Policy System of Israel. Oxford: Oxford University Press.

Britt, Chester L. Gary Kleck David J. Bordua A. 1996. "Reassessment of the D.C. Gun Law: Some Cautionary Notes on the Use of Interrupted Time Series Designs for Policy Impact Assessment". Law \& Society Review, 30(2), 361-380.

Brockwell, Peter J., Richard A. Davis. 1987. Time Series: Theory and Methods. Springer-Verlag: New York, NY.

Brophy-Baermann, Bryan and John A. C. Conybeare. 1994. "Retaliating against Terrorism: Rational Expectations and the Optimality of Rules versus Discretion". American Journal of Political Science, 38(1), 196-210.

Bruce, Chloë. 2005. Fraternal Friction or Fraternal Fiction? The Gas Factor in Russian-Belarusian Relations. Oxford Institute for Energy Studies. < http://www.oxfordenergy.org/pdfs/NG8.pdf >. Accessed: June 8, 2010. 
Brunner, Martin. 2009. "Does politics matter? The influence of elections and government formation in the Netherlands on the Amsterdam Exchange Index", Acta Politica, 44(2), 150-170.

Caplan, B. 2002. "How does war shock the economy". Journal of International Money and Finance 21 (2): 145-62.

Carlstrom, Charles T. \& Fuerst Timothy. 2005. "Oil Prices, Monetary Policy, and Counterfactual Experiments." Journal of Money, Credit, and Banking, Vol. 38, No. 7 (October). The Ohio State University

Chappel, David, and Robert M. Eldridge. 2000. "Evidence of market inefficiency in a war environment". Applied Financial Economics 10 (5): 489-92.

Charpentier, Ronald R. 2002. "Review: Locating the Summit of the Oil Peak." Science, New Series, Vol. 295, No. 5559 (February), 1470.

Chatfield, Chris. 1984. The Analysis of Time Series: An Introduction. Chapman\&Hall/CRC: London, New York.

Chatfield, Chris. 2001. Time-Series Forecasting. Chapman\&Hall/CRC: Washington, DC.

Cho, In-Koo and David M. Kreps. 1987. "Signaling Games and Stable Equilibria". The Quarterly Journal of Economics, 102(2), 179-221.

Christoffersen, Peter F., 2003. Elements of Financial Risk Management. Academic Press: New York. Cohen, Ariel. 2006. The North European Gas Pipeline Threatens Europe's Energy Security. The

Heritage Foundation. < http://www.heritage.org/Research/Reports/2006/10/The-North-European-

Gas-Pipeline-Threatens-Europes-Energy-Security>. Accessed: June 8, 2010.

Collier, Paul. 1999. "On the economic consequences of war". Oxford Economic Papers 51:168-83.

Cryer, Jonathan D. and Chan Kung-Sik. 2008. Time Series Analysis With Applications in R. Springer: New York, NY.

Danielson, Peter A. 1998. "Modeling Rationality, Morality and Evolution". Oxford University Press: New York.

Dixit, A. \& Nalebuff, B. 1991. Thinking Strategically: The Competitive Edge in Business, Politics, and Everyday Life. New York: W.W. Norton \& Company Ltd.

Dixit, A., Susan Skeath, David H. Reiley, Jr. 2009. Games of strategy. W.W. Norton \& Company, Inc.

Doron, Gideon and Itai Sened. 2001. Political Bargaining: Theory, Practice and Process. SAGE Publications: London.

Doyle, Michael. 1986. "Liberalism and World Politics." American Political Science Review 80 (December): 1151-69.

Douglas, W. Blum. 2008. Russia and globalization: identity, security, and society in an era of change. The Johns Hopkins University Press: Baltimore.

Duval R. 2008. Game Theory. Course slides. West Virginia University, Spring Semester 2008.

Eden, Dov. 1982. "Critical job events, acute stress, and strain: A multiple interrupted time series". Organizational Behavior \& Human Performance. 30(3), 312-329.

Energy Information Administration. 2008. Russia Energy, Data, Statistics, and Analysis - Oil, Gas, Electricity, Coal. <http://www.eia.doe.gov/emeu/cabs/Russia/Full.html>. Accessed: 01/30/2010.

Energy Policy Research Foundation. 2009. Russian Gas to Europe, Part Deux. <http://www.eprinc.org/pdf/gazprom-ukrainedeux.pdf>. Accessed: 02/10/2010.

Engle, Robert F. 1982. "Autoregressive Conditional Heteroskedasticity with Estimates of the Variance of United Kingdom Inflation." Econometrica. 50(4), 987-1007.

Engle, Robert. 2001. "GARCH 101: The Use of ARCH/GARCH Models in Applied Econometrics". The Journal of Economic Perspectives, 15(4), 157-168.

EU2009.cz. 2009. EU calls for urgent resumption of gas supply from Russia through Ukraine to Member States. <http://www.eu2009.cz/en/news-and-documents/news/yx-4651/>. Accessed: June 10, 2010. 
European Commission. 2005. Protecting Europe: Ensuring the security of energy and transport services across the European Union. Brussels: European Commission, Energy and Transport DG. Foster, Lauren, and Julie Earle. 2003. "Threat of war weighs heavy on the markets". Financial Times, February 27, 24.

Fowler, S., A. Webber, B. S. Cooper, A. Phimister, K. Price, Y. Carter, C. C. Kibbler, A. J. H. Simpson and S. P. Stone. 2007. "Successful use of feedback to improve antibiotic prescribing and reduce Clostridium difficile infection: a controlled interrupted time series". Journal of Antimicrobial Chemotherapy, doi:10.1093/jac/dkm014.

Fredholm, Michael. 2006. Gazprom In Crisis: Putin's Quest For State Planning And Russia's Growing National Gas Deficit. Conflict Studies Research Centre: Swindon: UK as cited in Lucas, Edward. 2008. The New Cold War: Putin's Russia and the Threat to the West. Palgrave McMillan.

Frey, Bruno S., and Marcel Kucher. 2000. "History as reflected in capital markets: The case of World War II". Journal of Economic History 60 (2): 468-96.

Frey, Erwin. 2010. Evolutionary Game Theory: Theoretical Concepts and Applications to Microbial Communities. asc.physik.uni-muenchen.de.

Frolov, Vladimir. 2008. 20 Foreign Policy Questions for Medvedev How Does the Successor View Russia's Place in the World? <http://www.cdi.org/russia/johnson/2008-15-15.cfm>. Accessed: March 28, 2008.

Geva, Nehemia and Alex Mintz. 1997. Decision-making on war and peace: the cognitive-rational debate. Lynne Rienner: Boulder, CO.

Gintis, Herbert. 2010. "Towards a renaissance of economic theory". Journal of Economic Behavior \& Organization 73, 34-40.

Glick, Reuven and Andrew K. Rose. 2002. "Does a currency union affect trade? The time-series evidence". European Economic Review, Volume 46(6), June 2002, Pages 1125-1151.

Goeree, Jacob K. and Charles A. Holt. 2001. "Ten Little Treasures of Game Theory and Ten Intuitive Contradictions". The American Economic Review, 91(5), 1402-1422.

Goldman, Marshall I. 2008. Petrostate: Putin, Power and the New Russia. Oxford University Press.

Grant, Charles and Katinka Barysch. 2003. The Eu-Russia Energy Dialogue.

<http://www.cer.org.uk/pdf/briefing_eu_russia.pdf>. Accessed: June 9, 2010.

Grijalva, C., J. Nuorti, P. Arbogast, S. Martin, K. Edwards, M. Griffin. 2007. "Decline in pneumonia admissions after routine childhood immunisation with pneumococcal conjugate vaccine in the USA: a time-series analysis". The Lancet, 369(9568), 1179-1186.

Gujarati, Damodar. 2009. Basic Econometrics. McGraw Hill Higher Education; 5th Revised edition edition.

Hamilton, James D. 1983. "Oil and the Macroeconomy since World War II." The Journal of Political Economy 91: 228-48.

Hamilton, James D. 2003. "What is an oil shock?". Journal of Econometrics 113, 363 - 398.

Harrison, Glenn W. and E. Elisabet Rutström. 2009. "Expected utility theory and prospect theory: one wedding and a decent funeral”. Experimental Economics, 12 (2), 133-158.

Hartmann, Donald P., John M. Gotrman, Richard R. Jones, William Gardner, Alan E. Kazdin, And Russell S. Vaught. 1980. "Interrupted Time-Series Analysis And Its Application To Behavioral Data”. Journal of Applied Behavior Analysis. 133(4), 543-559.

Harvey, David. 2009. Cosmopolitanism and the Geographies of Freedom. Columbia University Press.

Herskowitz, Mickey. 2003. Duty, Honor, Country: The Story and Legacy of Prescott Bush. Nashville: Rutledge Hill Press.

Higgins M.L., A.K. Bera. 1992. "A Class of Nonlinear Arch Models”. International Economic Review 33(1), 137-158.

Hofbauer, Josef and Karl Sigmund. 1998. Evolutionary Games and Population Dynamics. Cambridge University Press: New York. 
Howorth, Jolyon. 2007. Security and defense policy in the European Union. Palgrave MacMillan. International Energy Agency. 2003. Europe in the Global Energy System. < http://www.iea.org/speech/2003/mandil/kolnppt.pdf>. Accessed: 02/10/2010.

Jervis, Robert. 1976. Perception and Misperception in International Politics. Center for International Affairs, Harvard University.

Jervis, Robert. 1989. "Rational Deterrence: Theory and Evidence". World Politics, 41(2): 183-207.

Kahneman, Daniel and Amos Tversky. 1979. "Prospect Theory: An Analysis of Decision under Risk." Econometrica, 47 (2), 263-291.

Kahneman, Daniel, P. Slovic, and Amos Tversky. 1987. Judgement Under Uncertainty: Heuristic and Biases. New York: Cambridge University Press.

Kandel, Abraham, Yan-Qing Zhang. 1998. "Fuzzy Moves". Fuzzy Sets and Systems 99, 159-177.

Keohane, Robert and Nye, Joseph. 2001. Power and Interdependence, 3rd Edition,

Keohane, Robert O. and Joseph S. Nye. 1977. Power and Interdependence: World Politics in Transition. Boston: Little, Brown and Company.

Knut Anton Mork. 1989. "Oil and the Macroeconomy When Prices Go Up and Down: An Extension of Hamilton's Results." The Journal of Political Economy, 97(3), pp. 740-744.

Kreps, David M. and Robert Wilson. 1982. "Reputation and Imperfect Information". Journal of Economic Theory, 27(2), 253-279.

Krupa, Melissa. 1997. ICE Cases: Gulf War Aftermath. < http://www1.american.edu/TED/ice/kuwait.htm >. Accessed: 02/10/2010.

Krushelnycky, Askold. 2004. Rift threatens Belarus ties with Russia after gas supply is cut during $20 C$ winter. The Independent. < http://www.independent.co.uk/news/world/europe/rift-threatensbelarus-ties-with-russia-after-gas-supply-is-cut-during-20c-winter-570600.html >. Accessed: June 8, 2010.

Kupchinsky, Roman. 2006. "Russia/Belarus: Is A Gas War Brewing?" Radio Free Europe/Radio Liberty. < http://www.rferl.org/content/article/1067346.html >. Accessed: February 22, 2010.

Lake, David A. and Robert Powell. 1997. Strategic Choice and International Relations. Princeton University Press: Priceton, New Jersey.

Lebedev, Kirill. 2010. Fears that Russia might lose European gas market ungrounded. Institute for Financial Studies, <http://www.ifs.ru/upload/250110-gas_en.pdf>. Accessed: March 18, 2010.

Lebow, Richard. 1984. Between peace and War: The nature of International Crisis. Johns Hopkins University.

Leduc, Sylvain and Keith Sill. 2004. "A quantitative analysis of oil-price shocks, systematic monetary policy, and economic downturns". Journal of Monetary Economics, 51(4), 781-808.

Leigh, Andrew, Justin Wolfers, and Eric Zitzewitz. 2003. What do financial markets think of war in Iraq?. NBER Working Paper 9587.

Lewis, D. 1969. Conventions: A Philosophical Study. Harvard University Press, Cambridge, MA. As Cited in Gintis, Herbert. 2010. "Towards a renaissance of economic theory". Journal of Economic Behavior \& Organization 73, 34-40.

Li, Quan, and David Sacko. 2002. "The (ir)relevance of militarized interstate disputes for international trade." International Studies Quarterly 46:11-43.

Lindblom, Charles E. 1959. "The Science of Muddling Through". Public Administration Review 19:79-88.

List, John A. 2004. "Neoclassical Theory versus Prospect Theory: Evidence from the Marketplace". Econometrica, 72(2), 615-625.

Littman, Michael L., Michael Kearns, Satinder Singh. 2001. An Efficient Exact Algorithm for Singly Connected Graphical Games. University of Pennsylvania.

Lobjakas, Ahto. 2006. Moldova: EU Lauds Temporary Resolution Of Moldova-Russia Gas Dispute. < http://www.rferl.org/content/article/1064794.html>. Accessed: June 8, 2010. 
Lucas, Edward. 2008. The New Cold War: Putin's Russia and the Threat to the West. Palgrave McMillan.

Maksymiuk, Jan. 2007. "Belarus: Gas War With Russia Reaches New Level”. Radio Free Europe/Radio Liberty. < http://www.rferl.org/content/article/1077943.html>. Accessed: February 22, 2010.

Martin, Lisa. 1999. "The Contributions of Rational Choice: A Defense of Pluralism." International Security, 24(2), 74-83.

Mason, Charlotte, H. and William D. Perreault, Jr. 1991. "Collinearity, Power, and Interpretation of Multiple Regression Analysis”. Journal of Marketing Research, 28(3), 268-280.

McCarty, Nolan and Adam Meirowitz. 2007. Political Game Theory: an Introduction. Cambridge University Press: New York.

McCleary, R. and R.A. Hay. 1980. Applied Time Series Analysis for the Social Sciences. Beverly Hills, Ca: Sage.

McDowall, David, Richard McCleary, Errol E. Meidinger and Richard A. Hay, Jr. 1980. Interrupted Time Series Analysis. Sage Publications: Beverly Hills, London

Ministry Of Energy of The Russian Federation. 2003. The Summary Of The Energy Strategy Of

Russia For The Period Of Up To 2020. Moscow. <http://ec.europa.eu/energy/russia/events/doc/2003_strategy_2020_en.pdf>. Accessed: March 10, 2010 .

Monforti, F., Szikszai, A., 2010. "A MonteCarlo approach for assessing the adequacy of the European gas transmission system under supply crisis conditions". Energy Policy, doi:10.1016/j.enpol.2009.12.043.

Morgan, David R. and John P. Pelissero. 1980. “Urban Policy: Does Political Structure Matter?” The American Political Science Review, 74(4), 999-1006.

Morrow, J.D. 1999. “How Could Trade Affect Conflict?” Journal of Peace Research, 6(4):481-489.

Morrow, James D. 1994. Game Theory for Political Scientists. Princeton University Press: Princeton, New Jersey.

MortaraV.2006. INSTAMAP: un programma per la produzione "istantanea" di mappe fattoriali. Università di Trento.

Myerson, Roger B. 1991. Game Theory: Analysis of Conflict. Harvard University Press: Cambridge, Massachussets.

Nachbar, J. H. 1992. "Evolution in the finitely repeated Prisoner's dilemma”. Journal of Economic Behavior and Organization, 19: 307-326. As cited in Danielson, Peter A. 1998. "Modeling Rationality, Morality and Evolution". Oxford University Press: New York.

Nefte Compass. 2010. South Stream Gets Special Treatment. < http://www.lexisnexis.com/us/lnacademic/search/homesubmitForm.do>. January 14, 2010. Accessed: July 24, 2010.

Nelson, Daniel B. 1991. "Conditional Heteroscedasticity in Asset Returns: A New Approach." Econometrica. 59(2), 347-70.

Neumayer, Eric. 2004. "The impact of political violence on tourism: Dynamic econometric estimation in a cross-national panel." Journal of Conflict Resolution 48 (2): 259-81.

NewEurope.eu. 2006. Putin says Russia-Belarus gas delivery dispute is over. <http://www.neurope.eu/articles/Putin-says-RussiaBelarus-gas-delivery-dispute-is-over/22072.php>. Accessed: February 22, 2010.

Nichol, Jim, Steven Woehrel and Bernard A. Gelb. 2006. Russia's Cutoff of Natural Gas to Ukraine: Context and Implications. CRS Report for Congress. <http://www.italy.usembassy.gov/pdf/other/RS22378.pdf >. Accessed: February 22, 2010.

Nisan, Noam, Tim Rouhgarden, Eva Tardos, Vijay Vazirani. 2007. Algorithmic Game theory. Cambridge University Press: New York.

Nye, Joseph. 1990. “Soft Power”. Foreign Policy, No. 80 (Autumn 1990), pg. 153 - 171. 
Oliker, Olga, Keith Crane, Lowell H. Schwartz, Catherine Yusupov. 2009. Russian Foreign Policy: Sources and Implications. The RAND corporation.

Ordeshook, Peter C. 1986. Game Theory and political theory: an introduction. Cambridge University Press: New York.

Parisi, F and VL Smith. 2005. The law and economics of irrational behavior. Stanford University Press Stanford, California.

Pascual, Carlos and Jonathan Elkind. 2010. Energy Security: Economics, Politics, Strategies, and Implications. Brookings Institution Press. Washington, DC.

Pirani, Simon, Jonathan Stern and Katja Yafimava. 2009. "The Russo-Ukrainian gas dispute of January 2009: a comprehensive assessment". Oxford Institute for Energy Studies (February). < http://oxfordenergy.org/pdfs/NG27.pdf >. Accessed: February 23, 2010.

Porter, M.E. 1985. Competitive Advantage: Creating and Sustaining Superior Performance. New York: Free Press.

Posner, Richard A. 1998. "Rational Choice, Behavioral Economics, and the Law". Stanford Law Review, (50). 5. 1551-1575

Pridemore, William Alex,Chamlin, Mitchell B., Cochran, John K. 2007. “An Interrupted Time-Series Analysis of Durkheim's Social Deregulation Thesis: The Case of the Russian Federation". Justice Quarterly, 24(2), 271-290.

Putnam, Robert. 1988. "Diplomacy and domestic Politics: The Logic of Tow-Level Games." International Organization 42:427-60.

Rabemananjara, R. and J. M. Zakoian. 1993. "Threshold Arch Models and Asymmetries in Volatility." Journal of Applied Econometrics. January/March, 8(1), 31-49.

Ramos, Sofía B., and Helena Veiga. 2010. Asymmetric effects of oil price fluctuations in international stock markets. Universidad Carlos III de Madrid. Departamento de Estadística. <http://earchivo.uc3m.es/dspace/handle/10016/6918>. Accessed: March 2, 2010.

Rapoport, Anatol and Albert M, Chammah. 1966. "The Game of Chicken”. American Behavioral Scientist, 10(3), 10-28.

Rapoport, Anatol and Melvin Guyer "A Taxonomy of 2x2 Games". General Systems: Yearbook of the Society for General Systems Research, 11, 203-214. As cited in Snyder Glenn H. and Paul Diesing. 1977. Conflict Among Nations. Princeton University Press. Princeton, New Jersey.

Reilly, Thomas A. and Sigall Michael W. 1976. Political Bargaining: An introduction to Modern Politics. W.H. Freeman and Company, San Francisco.

Ria Novosti. 2006. Russia warns Belarus of market-level natural gas prices - source. < http://en.rian.ru/world/20060428/47026840.html>. Accessed: June 26, 2010.

Ria Novosti. 2007. Belarus pays Gazprom's bill for Russian natural gas in full -1. <http://en.rian.ru/russia/20070808/70593831.html>. Accessed: June 24, 2010.

Rigobon, Roberto, and Brian Sack. 2003. The effects of war risk on U.S. financial markets. NBER Working Paper 9609.

Rumelt, Richard P. Schenedel, Dan E. Teece, David J. 1994. Fundamental Issues in Strategy. Harvard Business School Press.

Rundquist, Barry S. and David E. Griffith. 1976. "An Interrupted Time-Series Test of the Distributive Theory of Military Policy-Making”. The Western Political Quarterly, 29(4), 620-626.

Sabiruzzaman, Md., Monimul Huq, Rabiul Alam Beg and Sajid Anwar. 2009. "Modeling and forecasting trading volume index: GARCH versus TGARCH approach", The Quarterly Review of Economics and Finance, doi:10.1016/j.qref.2009.11.006.

Saunders, Paul J. 2008. Russian Energy And European Security: A Transatlantic Dialogue. The Nixon Center. < http://www.nixoncenter.org/monographs/saunders08.pdf>. Accessed: June 8, 2010. Schneider, Gerald and Vera E. Troeger. 2006. "War and the World Economy: Stock Market Reactions to International". Journal of Conflict Resolution, (50), 623. 
Schoemaker, P. 1982. "The expected utility model: its variants, purposes, evidence and limitations". Journal of Economic Literature, 20(2), 529-563.

Scholz, John T. 1991. Cooperative Regulatory Enforcement and the Politics of Administrative Effectiveness. The American Political Science Review, 85 (1), 115-136.

Shaffer, Brenda. 2009. Energy Politics. PENN: University of Pennsylvania Press, Philadelphia.

Sheldon, Trevor A, Nicky Cullum, Diane Dawson, Annette Lankshear, Karin Lowson, Ian Watt, Peter West, Dianne Wright, John Wright. 2004. "What's the evidence that NICE guidance has been implemented? Results from a national evaluation using time series analysis, audit of patients' notes, and interviews". BMJ, 329(7473):999 (30 October), doi:10.1136/bmj.329.7473.999.

Shubik, Martin. 1982. Game Theory in the Social Sciences: Concept and Solutions. The MIT Pres: Cambridge, Massachussets.

Simon, H. A. 1947. Administrative Behavior. New York: MacMillan.

Smarandache, Florentin, Sukanto Bhattacharya, Mohammad Khoshnevisan. 2006. The IsraelPalestine Question - A case for Application of Neutrosophic Game Theory., 51-61. Article in Smarandache, Florentin, Sukanto Bhattacharya, Mohammad Khoshnevisan, Housila P. Singh, Rajesh Singh, F. Kaymram, S. Malakar, Jose L. Salmeron. 2006. Computational Modeling in Applied Problems: collected papers on econometrics, operations research, game theory and simulation. ProQuest Information \& Learning.

Smith, J. Maynard and G. R. Price. 1973. "The Logic of Animal Conflict". Nature 246, 15-18.

Smith, Maynard John. 1982. Evolution of the Theory of Games. Cambridge University Press: New York.

Snyder Glenn H. and Paul Diesing. 1977. Conflict Among Nations. Princeton University Press. Princeton, New Jersey.

Snyder, Richard C., H. W. Bruck, And Burt Sapin. 1962. Foreign Policy Decision Making. New York: Free Press.

Socor, Vladimir. 2006. "European Union Responds As Moldova Gas Predicament Deepens". < http://www.jamestown.org/single/?no_cache=1\&tx_ttnews[tt_news]=31266>. Accessed: June 30, 2010. Eurasia Daily Monitor, 3 (7).

Speck, Ulrich. 2009. Another Wake-Up Call? Europe Remains Divided Over Energy Security Policy. Radio Free Europe - Free Liberty. <

http://www.rferl.org/content/Another_WakeUp_Call_Europe_Remains_Divided_Over_Energy_Secu rity_Policy/1381175.html>. Accessed: June 30, 2010.

Steinbruner, John D. 1974. The Cybernetic Theory of Decision. Princeton, NJ: Princeton University Press.

Stern, Jonathan P., 2005. The Future of Russian Gas and Gazprom, Oxford Institute for Energy Studies, Oxford University Press.

Studenmund, A.H. 2005. Using Econometrics: A Practical Guide, Fifth Edition. Addison-Wesley. Surowiecki, James. 2004. The Wisdom of the Crowds. United States of America: Random House, Inc. Sylvan, Donald A and James F. Voss. 1998. Problem Representation in Foreign Policy Decision Making. Cambridnge University Press.

Taylor, S. J. 1986. Modeling Financial Time Series. Chichester: John Wiley \& Sons.

Thaler, R. 1980." Toward a positive theory of consumer choice". Journal of Economic Behavior and Organization, 1, 39-60.

Tryon, W W. 1982. "A simplified time-series analysis for evaluating treatment interventions". Journal of Applied Behavioral Analysis. 15(3): 423-429.

Tsebelis, George. 1990. Nested Games: Rational Choice in Comparative Politics. Berkeley: University of California Press.

United States Congress Senate Committee on Foreign Relations. 2008. Oil, oligarchs, and opportunity energy from Central Asia to Europe : hearing before the Committee on Foreign Relations, United 
States Senate, One Hundred Tenth Congress, second session, June 12, 2008. Washington : U.S. G.P.O. In this work, this document has been mostly cited as USCSCFR (2008).

United States. Congress. Senate. Committee on Foreign Relations. 2009. $\$ 150$ oil instability, terrorism and economic disruption : hearing before the Committee on Foreign Relations, United States Senate, One Hundred Eleventh Congress, first session, July 16, 2009. Washington : U.S. G.P.O., 2009. In this work, this document has been mostly cited as USCSCFR (2009).

Wagner, John A., Rubin, Paul A. Callahan, Thomas J.1988. "Incentive payment and nonmanagerial productivity: An interrupted time series analysis of magnitude and trend". Organizational Behavior and Human Decision Processes. 42(1), 47-74.

Walt, Stephen M. 1999. "Rigor or Rigor Mortis? Rational Choice and Security Studies". International Security, 23(4), 5-48.

Waterfield, Bruno. 2008. EU seeks to end dependency on Russian energy. The Daily Telegraph (London).

Willershausen, Florian. 2009. "A European Energy Crisis Why Ukraine Needs Help in the Gas Row". Spiegel Online International. http://www.spiegel.de/international/europe/0,1518,599796,00.html >. Accessed: February 19, 2009. World Gas Intelligence. 2009. "Crux of Gazprom, Ukraine Deals," World Gas Intelligence, 20(3), p. 3.

World of Information. 2006. Moldova Profile (2006/April). < http://site.ebrary.com/lib/nwvu/docDetail.action?docID=10120908>. Accessed: June 26, 2010. Walden Publishing Ltd Walden Publishing Ltd. Available from the WVU library website.

Yafimava, Katja, Jonathan Stern. 2007. The 2007 Russia-Belarus Gas Agreement. Oxford Institute for Energy Studies. 〈http://www.oxfordenergy.org/pdfs/comment_0107-3.pdf〉. Accessed: June 24, 2010.

Yasmann, Victor. 2006. "Russia: Is Georgian Gas Crisis Evidence Of Moscow's New Energy Strategy?" Radio Free Europe/Radio Liberty. < http://www.rferl.org/content/article/1064978.html>. Accessed: February 22, 2010.

Yhiah. 2008. Nemtsov: Russian part in RosUkrEnergo looks as improper as Ukrainian one. < http://www.unian.net/eng/news/news-241453.html >. Accessed: February 22, 2010.

Young, Peyton H. 1991. Negotiation Analysis. The University of Michigan Press.

Young, Peyton H. 1998. Individual Strategy and Social Structure: An evolutionary Theory of Institutions. Princeton University Press: Princeton, New Jersey.

Youngs, Richard. 2008. Europe's energy policy: economics, ethics, geopolitics. FRIDE, <http://www.fride.org/download/COM_PolEnEU_ENG_ene07.pdf>. Accessed: March 18, 2010.

Youngs, Richard. 2009. Energy Security: Europe's New Foreign Policy Challenge. Routledge, London.

Zhang, Li Energy 2003 "Clearing Price Prediction and Confidence Interval Estimation With Cascaded Neural Networks", IEEE transactions on power systems, 18(1). 